\title{
Inferring past climate from moraine evidence using glacier modelling
}

\author{
by \\ Alice Marie Doughty

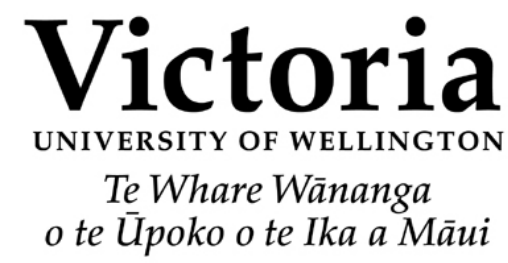

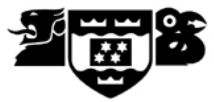

\author{
A thesis \\ submitted to Victoria University of Wellington \\ in fulfilment of the \\ requirements for the degree of \\ Doctor of Philosophy \\ in Physical Geography.
}

Victoria University of Wellington 2013 


\begin{abstract}
Glacier length fluctuations reflect changes in climate, most notably temperature and precipitation. By this reasoning, moraines, which represent former glacier extent, can be used to estimate past climate. However, estimating palaeoclimate from moraines is not a straight-forward process and involves several assumptions. For example, recent studies have suggested that interannual stochastic variability in temperature in a steady-state climate can cause a glacier to experience kilometre-scale fluctuations. Such studies cast doubt on the usefulness of moraines as climate proxy indicators.

Detailed glacial geomorphological maps and moraine chronologies have improved our understanding of the spatial and temporal extent of past glacial events in New Zealand. Palaeoclimate estimates associated with these moraines have thus-far come from simple methods, such as the accumulation area ratio, with unquantifiable uncertainties. I used a numerical modelling approach to approximate the present-day glacier mass balance pattern, which includes the effects of snow avalanching on glacier mass balance. I then used the models to reconstruct palaeoclimate for Lateglacial and Holocene glacial events in New Zealand, and to better understand moraine-glacier-climate relationships. The climate reconstructions come from simulating past glacier expansions to specific terminal moraines, but I also simulated glacier fluctuations in response to a previously derived temperature reconstruction, and to interannual stochastic variability in temperature. The purpose behind each simulation was to identify the drivers of significant glacier fluctuations.
\end{abstract}

The modelling results support the hypothesis that New Zealand moraine records reflect past climate, especially changes in temperature. Lateglacial climate was reconstructed to be $2-3^{\circ} \mathrm{C}$ lower than the present day. This temperature range agrees well with previous estimates from moraines and other climate proxy records in New Zealand. Modelled temperature estimates for the Holocene moraines are slightly colder than those derived from simpler methods, due to a non-linear relationship found between snowline lowering and glacier length. This relationship results from the specific valley shape and glacier geometry, and is likely to occur in other, similarly-shaped glacier valleys. The simulations forced by interannual stochastic variability in temperature do not show significant $(>300 \mathrm{~m}$ ) fluctuations in the glacier terminus. Such fluctuations can not explain the Holocene moraine sequence that I examined, which extends $>2 \mathrm{~km}$ beyond the present-day glacier terminus. Stochastic temperature change could, however, in part, cause fluctuations in glacier extent during an overall glacier recession. Modelling shows that it is also unlikely that glaciers advanced to Holocene and Lateglacial moraine positions as a result of precipitation changes alone. For these reasons, temperature changes are a necessary part of explaining past glacier extents, especially during the Lateglacial, and the moraines examined here likely reflect changes in mean climate in New Zealand.

The glacier modelling studies indicate that simpler methods, such as the accumulation area ratio, can be used to appropriately reconstruct past climate from glacial evidence, as long as the glacier catchment has a straight forward geometry, shallow bed slope and no tributary glaciers. Non-linear relationships between climate change and glacier length develop when valley shape is more complex, and glaciers within these systems are probably better simulated using a modelling approach. Using a numerical modelling approach, it is also possible to gain a greater understanding of glacier response time, length sensitivities, and estimates of ice extent in valleys within the model domain where geomorphic evidence is not available. In this manner, numerical models can be used as a tool for 
understanding past climate and glacier sensitivity, thus improving the confidence in the palaeoclimate interpretations. 


\section{Acknowledgments}

The primary source of funding came from the New Zealand Government under a New Zealand International Research Doctoral Scholarship. Additional funding was provided by Victoria University of Wellington (Antarctic Research Centre, Science Faculty, School of Geography, Environment and Earth Sciences) and the Comer Science and Education Foundation. R. Drews, T. Kerr, L. Kees, A. Mackintosh, and Mt. Hutt Helicopters assisted in field work on Cameron Glacier. Discussions with R. Dadic, H. Horgan, N. Golledge, H. Purdie, L. Carter, A. Lorrey, J. Renwick, R. Mucadam, and A. Tait were particularly helpful.

I am grateful for the support provided by my supervisors, A. Mackintosh and B. Anderson. In addition to teaching me about glacier modelling, they encouraged me to tutor, attend conferences, seek additional funding, and organise fieldwork. Their advice has helped me grow from a student to a collaborator and I look forward to working with them on future research projects. I also appreciate the time I have spent with my supervisors' families, who have helped me feel at home in a foreign country.

Continued support and motivation comes from my colleagues from the University of Maine and Lamont-Doherty Earth Observatory. I want to thank G. Denton for reminding me how exciting the mysteries of the world are, A. Putnam for encouraging additional simulations to answer significant questions, D. Barrell for supplying beautiful maps and detailed comments, T. Chinn for enthusiastic discussions about New Zealand glaciers, and to the late B. Andersen, thank you for teaching me how to map Norwegian style.

Mental sanity support was provided by M. Donaldson and my officemates, in particular M. Patterson, L. Kees, R. Rhodes, R. Gavey, and L. Cohen. My friends and flatmates (especially J. Latchford) as well as the staff at Ferg's Kayaks were particularly helpful in motivating me to finish successfully.

I thank my family for their unconditional support and love. I also appreciate the contributions, including artwork and story telling, from the newest member of my family, my

niece Olivia (born 3 August, 2009). 


\section{Contents}

$\begin{array}{lll}\text { Abstract } & \text { ii }\end{array}$

Acknowledgments $\quad$ v

Table of Contents $\quad$ vi

List of Figures $\quad$ xii

List of Tables $\quad$ xix

1 Introduction 1

1.1 Former glaciers and climate change $\ldots \ldots \ldots \ldots$

1.2 Organisation of the Thesis $\ldots \ldots \ldots \ldots$

1.3 Statement on the contributions made to this thesis by the author, supervisors, and collaborators . . . . . . . . . . . . 7

2 Background $\quad 11$

2.1 Moraines and palaeoclimate . . . . . . . . . . . . . . 11

2.2 New Zealand Lateglacial and Holocene palaeoclimate . . . . . . . . . . . 13

2.3 Lateglacial and Holocene glacial geology of New Zealand . . . . . . . 15

2.3.1 Mapping Lateglacial and Holocene moraines . . . . . . . . . 16

2.3.2 Dating of moraines . . . . . . . . . . . . 17

2.4 Climate of the Southern Alps . . . . . . . . . . . . . . . . . . . . 19

2.4.1 Southern Alps climate variability . . . . . . . . . . . . . . 19

2.4 .2 Alpine meteorology . . . . . . . . . . . . 21

2.5 Glacier monitoring . . . . . . . . . . . . . . . . . 22

2.6 Glacier modelling . . . . . . . . . . . . . . . . . . . . 24

2.7 Research questions . . . . . . . . . . . . . . . . 25 
3.1 Modelling approaches . . . . . . . . . . . . . . . . 28

3.2 Energy-balance model f . . . . . . . . . . . . . . . . . . . 29

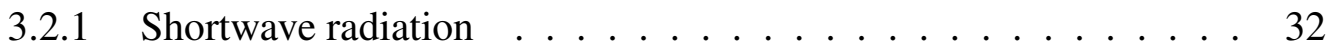

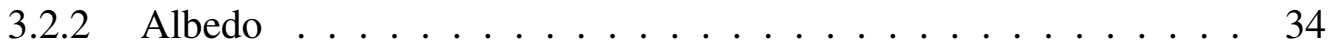

3.2.3 Longwave radiation . . . . . . . . . . . . . . . . . 36

3.2.4 Turbulent heat fluxes . . . . . . . . . . . . . . . 37

3.3 Gravitational snow mass transport and deposition model . . . . . . . . 38

3.4 Models that describe glacier flow . . . . . . . . . . . . . . . . . 43

3.4 .1 Ice-flow model . . . . . . . . . . . . . . . . . . 45

3.5 Model applications . . . . . . . . . . . . . . . . . . 47

3.6 Summary . . . . . . . . . . . . . . . . . . . 48

4 Evaluation of Lateglacial temperatures in the Southern Alps of New Zealand based on glacier modelling at Irishman Stream, Ben Ohau Range 51

4.1 Introduction . . . . . . . . . . . . . . . . 52

4.1.1 Glaciers as a climate proxy . . . . . . . . . . . . 53

4.1 .2 Study area. . . . . . . . . . . . . . . 53

4.2 Modelling glacier extent $\ldots \ldots \ldots$. . . . . . . . . . . 56

$4.2 .1 \quad$ Input data . . . . . . . . . . . . . . 57

4.2.2 The energy-balance model . . . . . . . . . . . . . 58

4.2 .3 The ice-flow model . . . . . . . . . . . . . . . . . . 61

4.2.4 Steady-state simulations . . . . . . . . . . . . . 63

4.2 .5 Transient runs . . . . . . . . . . . . . . . . . 64

4.3 Results . . . . . . . . . . . . . . . . . . . 65

4.3.1 Experiment 1: Steady-state simulations of the ACR Irishman glacier extent ...................... 65

4.3.2 Experiment 2: Transient run driven by chironomid-derived temperature reconstructions . . . . . . . . . . 67 
4.4 Discussion ........................... 71

4.5 Conclusions . . . . . . . . . . . . . . . . . 73

5 Optimising simulated snow depth patterns on an avalanche-fed glacier in New Zealand using GPR and a gravitational mass transport model

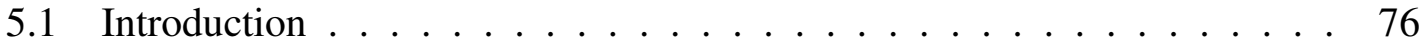

5.1 .1 Geographic Setting . . . . . . . . . . . . . . 78

5.2 Methods .............................. 80

5.2.1 Snow depth measurements . . . . . . . . . . . . 80

5.2.2 Modelling snow distribution . . . . . . . . . . . . 82

5.3 Results and Discussion . . . . . . . . . . . . . . 88

5.3.1 GPR snow depth estimations . . . . . . . . . . . . . . 88

5.3.2 Ability of the model to replicate snow distribution . . . . . . . 92

5.4 Conclusions . . . . . . . . . . . . . . . . . . . . 99

6 What do Holocene moraines at Cameron Glacier, New Zealand tell us about past climate change?

6.1 Introduction . . . . . . . . . . . . . . . . 102

6.1 .1 Site description . . . . . . . . . . . . . 105

6.2 Methods . . . . . . . . . . . . . . . . . . . 106

6.2.1 Bedrock and ice-surface topography . . . . . . . . . . . . 107

6.2 .2 Climatic input data . . . . . . . . . . . . . 107

6.2.3 Mass balance model . . . . . . . . . . . . . . . . 109

6.2 .4 2D ice-flow model . . . . . . . . . . . . . . 111

6.2.5 Experimental set-up . . . . . . . . . . . . . 113

6.3 Results . . . . . . . . . . . . . . . . . . 118

6.3.1 Steady-state experiments . . . . . . . . . . . . . 118

6.3.2 Stochastic temperature forcing . . . . . . . . . . 125

6.4 Discussion . . . . . . . . . . . . . . . . . . . . 128 
6.4.1 Can stochastic variability in temperature cause the length of Cameron Glacier to fluctuate to its Holocene extents? . . . . . . . . . . 128

6.4.2 How do these results differ from previous studies of interannual variability influencing glacier length and why? . . . . . . . 129

6.4.3 How do the modelled palaeoclimate estimates and ELA changes compare to previous estimates? . . . . . . . . . . . 130

6.4.4 What do the Cameron Glacier Holocene moraines tell us about climate changes? . . . . . . . . . . . . . . 132

6.4.5 How do model results fit into the real world? . . . . . . . . . 133

6.5 Conclusions . . . . . . . . . . . . . . . . . . . . 134

\section{Synthesis}

7.1 Introduction . . . . . . . . . . . . . . . . 137

7.2 Contributions made in this thesis toward understanding palaeoclimate and glacier sensitivity . . . . . . . . . . . . . . . . . . 137

7.3 Research questions . . . . . . . . . . . . . . . . . . . 139

7.3.1 What magnitude of past temperature and precipitation change do Lateglacial- and Holocene-aged moraines in New Zealand repre-

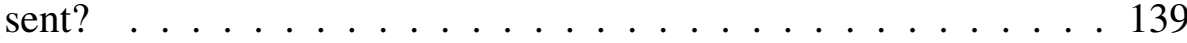

7.3.2 Are these estimates of past temperature and precipitation coherent with other climate proxy records in New Zealand? . . . . . . . . 140

7.3.3 To what extent does the re-mobilisation of snow by avalanches affect the present-day mass balance of New Zealand glaciers? . . 141

7.3.4 Does including a model of snow redistribution in a glacier model change the palaeoclimate reconstructions made? . . . . . . . 142

7.3.5 Could natural, stochastic variability in climate have caused Holocene glacier fluctuations $\quad \ldots \ldots \ldots$. . . . . . . . . 143

7.3.6 What parameters are the modelled glaciers most sensitive to, and how does parameter choice affect the climate reconstructions? . . 143

7.3.7 How do the palaeoclimate estimates derived from modelling glaciers differ from previous estimates using simpler methods? . . . . . . 145

7.3.8 What can we learn from dynamic glacier models that we could not gain from using simpler methods? . . . . . . . . . . . 146

7.4 Proposed future work . . . . . . . . . . . . . . . . . . . 147 
7.4.1 Present-day climate and glaciology . . . . . . . . . . . 148

7.4.2 Model experiments . . . . . . . . . . . . . . . . 149

A Excerpt from: The anatomy of 'long-term' warming since $15 \mathrm{kyr}$ ago in the Southern Alps of New Zealand based on net glacier snowline rise

A.1 Site description . . . . . . . . . . . . . . . . . . 154

A.2 Excerpt from Kaplan et al., submitted . . . . . . . . . . . . . . 155

A.2.1 Methods ...................... 155

A.2.2 Modeling and ELA Results . . . . . . . . . . . . . . 155

A.3 Subsequent simulations . . . . . . . . . . . . . . . . . . . 159

B Ground penetrating radar profiles from the Cameron Glacier neve 161

B.1 GPR survey . . . . . . . . . . . . . . 161

B.1.1 Low-frequency data . . . . . . . . . . . . . . 161

B.1.2 High-frequency data . . . . . . . . . . . . . . 162

$\begin{array}{ll}\text { References } & 181\end{array}$ 


\section{List of Figures}

2.1 Map of shaded topography of central South Island, New Zealand with the last glacial maximum ice extent (pink outline Barrell et al. (2011)) and the Main Divide of the Southern Alps (dashed red line). Numbers mark locations of 1) Franz Josef Glacier, 2) Hokitika, 3) Arthurs Pass, 4) Christchurch, 5) Irishman Stream, 6) Whale Stream, and 7) Cameron valley. 16

2.2 Map of 30-year mean annual precipitation surface (Stuart, 2011), overlain on shaded topography of central South Island, New Zealand and the Main Divide of the Southern Alps (dashed black line). In the central Southern Alps, most of the annual precipitation falls west of the main divide due to a strong orographic effect. . . . . . . . . . . . . .

3.1 Modelled versus measured temperatures at the location of a climate station in Irishman basin. Modelled temperature values (daily interpolated temperature, $T$, smoothed with a thirty-day running mean) were interpolated from climate stations at $<800 \mathrm{~m}$ asl over the 2010-2011 (a) and 2011-2012 (b) intervals. Measured temperature data (black line) are compared to modelled temperatures that were calculated using the 2010-2011 monthly varying lapse rate (red line), using a new variable lapse rate (purple line, panel b only) and a constant lapse rate (blue dashed). Using a constant lapse rate achieves a poor match, especially during winter months $($ Jun-Sep) . . . . . . . . . . . . . . . . . . .

3.2 One-dimensional example of snow redeposition from the MTD parameterisation modified from Gruber (2007). Panels show avalanche profiles resulting from changing parameter values, a) increasing deposition limit $\left(D_{\text {lim }}\right)$ leads to thicker, less-extensive deposits, b) increasing total incoming snow will increase the extent of the avalanche deposit, c) increasing slope limit $\left(\beta_{\text {lim }}\right)$ causes snow to stay close to the valley wall, and d) increasing gamma $(\gamma)$ also results in less-extensive, thicker deposits. For these tests, the total incoming snow is a $100 \mathrm{~m}$ s.w.e. column deposited at the circle labelled 'input', which is an unrealistic process but helps to highlight the shape of the deposit. . . . . . . . . . . . .

3.3 Plots of slope angle versus maximum deposition to show parameter influences on the slope-deposition curve. Parameters evaluated are a) $D_{\text {lim }}$ (yellow circles) set to 0.4 (dotted line), 0.6 (dashed line), and 0.8 (solid line) $\mathrm{m}$ s.w.e., b) $\gamma=0.075$ (dotted line), 0.1 (dashed line), and 0.125 (solid line), and c) $\beta_{\text {lim }}$ (green circles) set to 35 (dotted line), 40 (dashed line), and $45^{\circ}$ (solid line $) \ldots \ldots \ldots \ldots \ldots$

3.4 Cameron Glacier model domain showing a) slope $\left(^{\circ}\right)$ at $25 \mathrm{~m}$ grid resolution, b) slope at $50 \mathrm{~m}$ grid resolution, c) modelled mass balance $\left(\mathrm{m} \mathrm{a}^{-1}\right)$ using the MTD model, and d) modelled mass balance without the MTD model for the 2009-2010 simulation. The black line represents part of the end of summer snowline measured on 19 March, 2010 using a hand-held GPS . . . . . . . . . . . . . . . . . . . . 
4.1 Location of the study area in central South Island, New Zealand. The Ben Ohau Range is outlined in green and Irishman basin is in the white box. Boundary Stream tarn (BST) is represented by the white dot southeast of Irishman basin and the white triangles are the locations of Aoraki/Mt. Cook village (north of the Ben Ohau Range) and Twizel (southeast of Ben Ohau Range). . . . . . . . . . . . . . . . . . . . . . . . 56

4.2 Modelled versus measured temperatures at the location of a climate station in Irishman basin. Modelled temperature values (daily interpolated temperature, $T$, smoothed with a thirty-day running mean) were interpolated from climate stations at $<800 \mathrm{~m}$ asl over the 2010-2011 interval. Measurements (black line) are compared to modelled temperatures that were calculated using a monthly varying lapse rate (red line) and a constant lapse rate (blue dashed). Using a constant lapse rate achieves a poor match, especially during winter months (Jun-Sep). . . . . . . . . . . .

4.3 Modelled extent of Irishman glacier at $13 \mathrm{ka}$ where $\Delta T-2.5^{\circ} \mathrm{C}$ and $\Delta P$ $+11 \%$. We show the (a) mapped geomorphology in the Irishman basin, for details see Kaplan et al. (2010), (b) modelled ice thickness overlaying the moraine map, (c) modelled mass balance with modelled ELA (green dashed line), and (d) previous estimates of Irishman glacier extent (K1 blue, K2 red) and ELA (K1ELA blue dashed, K2ELA red dashed) (Kaplan et al., 2010) based on geometric and AAR reconstructions, compared to this study $($ green $) . \ldots \ldots \ldots \ldots \ldots$

4.4 Experiment 1 results - Inferred $\Delta P-\Delta T$ reconstructions showing the sensitivity of the climate reconstruction to chosen parameter values. Curves identical to the 'Optimal' curve are not shown $\left(I, U_{c}, A\right.$, and $\left.Z_{i c e}=0.002 \mathrm{~m}\right)$. The $x$-intercepts of the different curves are reported in Table 4.3 . . . . .

4.5 Experiment 2 results - BST PLS-smooth temperature reconstructions from Vandergoes et al. (2008) (black) from 15 to $11 \mathrm{ka}$ with modelled glacier length (blue). Orange and yellow diamonds represent the moraine positions dated to $13.0 \pm 0.5$ and $12.1 \pm 0.5$ ka respectively. Glacier length was calculated by identifying the ice with a thickness $>10 \mathrm{~m}$ farthest from the headwall. Plots in the right panel show a) PLS-raw, b) WAPLS-raw where tick marks show the sampling resolution, and c) WAPLS-smooth inferred summer mean $\Delta T$ from 15 to $11 \mathrm{ka}$. Glacier lengths resulting from these three reconstructions extended beyond the $13 \mathrm{ka}$ moraine and are not shown here. . . . . . . . . . . . . . . . . 
5.1 Topographic map of the Cameron Glacier catchment. a) An oblique aerial photograph of the Cameron Glacier showing the steep valley walls, partially debris-covered terminus, and end of summer snowline (red dotted line). The black line delineates the ridgeline of the upper Cameron catchment. Photograph taken 5 March, 2010 by A. Willsman. b) Slope values for a section of the model domain ( $25 \mathrm{~m}$ grid resolution) with labelled GPR profiles on Cameron Glacier. Note the large area on the northern slopes that are $>60^{\circ}$ (black cells). Each profile is $\sim 200 \mathrm{~m}$ long. Profile colours are for differentiating lines only. c) Topographic map with elevation contours, ridgelines (dotted-dashed red line), glacierised area, and mountain peaks (Mt. Arrowsmith $(2781 \mathrm{~m}$ asl) toward the southwest, and Jagged Peak (2705 $\mathrm{m}$ asl) to the northeast). The black star marks the location of the snow pit and the green star marks a location that does not receive avalanche accumulation. d) Shaded relief map of the central Southern Alps showing the location of study area (yellow square) and the location of the Mt. Potts weather station (white dot). Prominent glaciers, lakes, and rivers are also shown. . . . . . . . . . . . . . . .

5.2 Slope angle $(\beta)$ versus maximum snow deposition $\left(D_{\max }\right)$ showing the influence of parameter values on the shape of the $D_{\text {max }}-\beta$ curve. Parameters evaluated are a) $D_{\text {lim }}=0.4,0.6$, and $0.8 \mathrm{~m}$, b) $\gamma=0.075,0.1$, and 0.125 , and c) $\beta_{\text {lim }}=35,40$, and $45^{\circ}$. Yellow circles mark $D_{\text {lim }}$ values, green circles mark $\beta_{\text {lim }}$ values and the solid, dashed, and dotted curves relate to the different values used for each parameter in each plot. . . . . .

5.3 Interpreted snow depth from the December, 2009 Cameron Glacier lowfrequency GPR profiles. Profiles F-G, and Q-Q' show cross sections of the glacier while profile E-L follows the central flowline (see key and Figure 5.1b). Note the strong reflector, interpreted as the end of summer glacier surface for 2009 (red dashed line) and deeper reflectors representing previous summer surfaces (not marked). Reflections in the E-L profile show old accumulated snow deposits below the 2009 summer surface. . .

5.4 Snow depth over the model domain (a-c) and along GPR profiles (d-f). Snow depth (m s.w.e.) from the a) optimal parameter set, b) less appropriate parameter set, c) model run without the MTD model, d) GPR data, e) optimal parameter set, and f) less appropriate parameter set. The snow distribution in the optimal model run reflects the observed accumulation pattern at Cameron Glacier better than the other runs. Panel c) also shows GPR lines for reference, a black star (white outline) to mark the location of the snow pit and a green star to mark a point of interest in the discussion. 90

5.5 Matrices showing relative comparisons (by colour) between modelled data and measured snow depth (a) gradient, (b) mean, and (c) range for each profile for each run. Red-coloured cells show where the model over estimated values, blue represents under-estimated values, and white is within the accepted range where modelled and measured are similar. Black arrows point to the 'best-fit' simulation and the final column (test 28 ) is the simulation without the MTD model. Profile key to the left is for

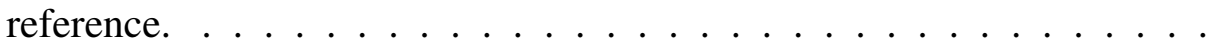


5.6 Graph showing the number of 'acceptable fits' (white cells in Figure 5.5 and Table 5.1) for the gradient (o), mean $(+)$, and range $(*)$ relative comparisons for each model run, with the total sum of the white boxes in bold. Note the overall decrease in the total (bold line) sum of white cells from MR1 - MR28. . . . . . . . . . . . . . . . . . . .

6.1 a) Oblique aerial photograph of the Cameron valley Holocene moraine sequence. This photograph shows the Cameron Glacier snout, the long, sharp-crested lateral moraines, and three of the targeted Holocene terminal moraines (M1 - M3). The most extensive moraine visible in this image (M3), located $3 \mathrm{~km}$ from the terminus, is dated to $8,190 \pm 230$ years before 1950. Scree slopes are abundant in this catchment, as seen on the valley flanks, and the Cameron River has eroded through parts of the terminal moraines. View is towards the northwest, photo by T. Chinn. b) Oblique aerial photograph of Cameron Glacier with a dotted red line marking the end of summer snowline and black line marking the upper Cameron catchment ridgeline. This photograph also shows the upper Cameron catchment with its steep valley walls, which are prone to snow and rock avalanching. Photograph taken 3 March, 2010 by A. Willsman, view is towards the northeast. . . . . . . . . . . . . . . . . 103

6.2 Glacial geomorphological map of the southeast slopes of the Arrowsmith Range, showing the moraine sequences of the Cameron (northeast) and Ashburton (southwest) valleys (Barrell et al., 2011). The black line represents the central flowline from which glacier lengths were measured, and M1 - M5 mark each of the targeted moraine positions. Note the similarities in moraine sequences between the two valleys, although the Cameron sequence contains a larger number of ridges. Location diagram (top left) shows shaded topography (based on a DEM) of the central Southern Alps including the main drainage divide (red dashed line), prominent lakes, rivers, and glacierised area. The Arrowsmith Range is marked by a white box. . . . . . . . . . . . . . . . . . 104

6.3 White noise temperature forcing series with a standard deviation $\left(\sigma_{T}\right)$ of $1{ }^{\circ} \mathrm{C}$ (blue diamonds) and the 30-year running mean temperature (red line). Note the relatively high peak in running mean around model year 1150, showing that the random temperatures can generate a small persistence in climate. . . . . . . . . . . . . . . . . . . . 115

6.4 Glacier ice thickness and mass balance for the five different ice extents with no precipitation change. Note the simulated connection of tributary glaciers to the main trunk glacier at different extents of Cameron Glacier. Yellow arrows point to areas where the modelled ice extent and moraine map differ (see text). . . . . . . . . . . . . . . . . . . . . . . . . 119

6.5 Glacier outline and ELA for each moraine extent. Panel a) glacier area extents overlapped for direct comparisons, and b) glacier outline and corresponding ELA (Table 6.3) . . . . . . . . . . . . . . . . . . . . 120 
6.6 Temperature and precipitation change combinations needed to reach each of the moraines under 12 different parameter combinations (Table 6.2). Note that the palaeoclimate estimates overlap, at least slightly, with those produced for the neighbouring moraine. . . . . . . . . . . . . 122

6.7 Glacier length profile $(\mathrm{m})$ response to $\mathrm{a} \pm 1^{\circ} \mathrm{C}$ temperature change from the steady-state temperature for M1 - M4. Note the greater length change caused by a $-1{ }^{\circ} \mathrm{C}$ temperature change, especially for M3 and M4. This asymmetric behaviour results from glacier geometry and valley shape. . .

6.8 Glacier length from M1 (equivalent to $4.3 \mathrm{~km}$ glacier length) plotted against ELA lowering from modern $2120 \mathrm{~m}$ asl from all tested steadystate model runs. Results from Putnam et al. (2012) based on AAR reconstructions are shown for comparison. Notice that the relationship between glacier length change and ELA change is linear for the late Holocene glacier extents, but differs for early Holocene extents, suggesting a strong topographic influence in this valley. . . . . . . . . . . . . . . . . . 124

6.9 Glacier response to a white-noise forcing in temperature. Panel a) interannual temperature change for each of the transient experiments. Note the different amplitude in temperature change for the different tests (caused by $\sigma_{T}$ ). Panel b) total ice volume in the model domain over time. Panel c) simulated Cameron Glacier length change for each of the stochastic variability experiments. Note the greater amplitude in glacier length fluctuations with increased $\sigma_{T}\left(\mathrm{WNF}-\mathrm{D}, \sigma_{T}=2^{\circ} \mathrm{C}\right) . \ldots \ldots$

A.1 Shaded topography of the Ben Ohau Range (outlined in green) showing the locations of Irishman Stream and Whale Stream (white boxes). . . . . 154

A.2 Modeled ice extent for Whale Stream Glacier. (A) Various glacier outlines and ELAs using the AAR method, (B) modeled glacier extent showing ice surface elevation (20 m contours), accumulation (blue) and ablation (red) areas and ELA overlying the AAR method glacier extent, (C) modeled mass balance gradient ranging from -2 to $+1 \mathrm{~m} \mathrm{a}^{-1}$, and (D) temperature-precipitation change curves with uncertainty for the Whale Stream Late Glacial ice extent.

A.3 Parameter testing curves from the temperature-precipitation change combination needed for a Late Glacial Whale Stream ice extent. . . . . . . . . 158

A.4 Whale glacier simulated at $25 \mathrm{~m}$ resolution. The panels show a) ice thickness $(\mathrm{m}), \mathrm{b})$ mass balance $\left(\mathrm{m} \mathrm{a}^{-1}\right)$, c) slope at $25 \mathrm{~m}$ resolution $\left({ }^{\circ}\right) . \quad \ldots 160$ 
B.1 Map of the Cameron Glacier. a) Topographic map with elevation contours, ridgelines (dotted-dashed red line), glacierised area, and mountain peaks (Mt. Arrowsmith (2781 m asl) toward the southwest, and Jagged Peak (2705 $\mathrm{m}$ asl) to the northeast). b) Shaded topography based on the DEM showing the location of study area (yellow square) in South Island, New Zealand. Prominent glaciers, lakes, and rivers are also shown. c) Slope values for a section of the model domain ( $25 \mathrm{~m}$ grid resolution) with labelled GPR profiles on Cameron Glacier. Profile colours are for differentiating lines only. . . . . . . . . . . . . . . . . . . 162

B.2 Plot of the GPS data for each profile. Each profile is labelled with its associated number, an arrow indicating the direction of travel from start to finish, and a colour to differentiate it from the other profiles. . . . . . . 164

B.3 Profiles 241, 243, and 244. . . . . . . . . . . . . . . . 165

B.4 Profile $245 \ldots \ldots \ldots \ldots \ldots$

B.5 Profiles 246, 247, 248, and 249. . . . . . . . . . . . . . 167

B.6 Profile $250 \ldots \ldots \ldots \ldots$. . . . . . . . . . . . . . . . . . 168

B.7 Profile $251 . \ldots \ldots \ldots \ldots$

B.8 Profile $252 \ldots \ldots \ldots \ldots \ldots$

B.9 Profile $253 . \ldots \ldots \ldots \ldots \ldots$. . . . . . . . . . . . . . . . . . . . . . .

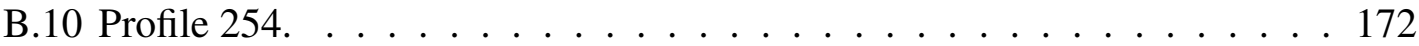

B.11 Profile $255 \ldots \ldots \ldots \ldots$. . . . . . . . . . . . . . . . . . . . . . . .

B.12 Profile $256 . \ldots \ldots \ldots \ldots$. . . . . . . . . . . . . . . . . . . . . . . . . .

B.13 Profile 257. . . . . . . . . . . . . . . . . . . . . . 175

B.14 Profile $258 \ldots \ldots \ldots \ldots \ldots$. . . . . . . . . . . . . . . . . . . . . .

B.15 Profile $259 . \ldots \ldots \ldots$. . . . . . . . . . . . . . . 177

B.16 Profile $260 . \ldots \ldots \ldots$. . . . . . . . . . . . . . . . 178

B.17 Profile 261. . . . . . . . . . . . . . . . . . . . . . . . . . . 179

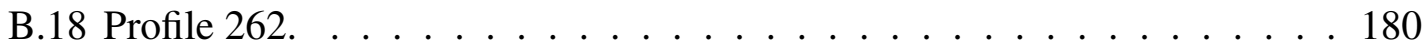




\section{List of Tables}

2.1 Climate information from Hokitika, Arthurs Pass, and Christchurch stations. Statistics from daily mean precipitation and temperature data from 1980 to 2011 (NIWA, Retrieved 2009-2011). Hokitika (west coast) and Christchurch (east coast) data are presented for near sea-level west to east comparisons.

3.1 Energy balance model parameters, values, and references. . . . . . . . . . 38

3.2 Mass transport and deposition model parameter setup. . . . . . . . . . . . 40

3.3 Ice-flow model parameter options and the range of published values for Glen's flow law coefficient. . . . . . . . . . . . . . . . . . . . 46

3.4 Model information summary for comparison between the different studies. 48

4.1 Measured monthly mean temperatures $\left(T_{\text {meas }}\right)$ and calculated temperature lapse rates $\left(\frac{d T}{d z}\right)$ for each month based on Irishman basin climate station data (2010-2011, 4359'30'S, 17002'57'E, $2010 \mathrm{~m}$ asl). Annual mean measured temperature is $\pm 1.2^{\circ} \mathrm{C}$ (assuming a value of $6.2^{\circ} \mathrm{C}$ for February) and the annual mean lapse rate is $-5.4^{\circ} \mathrm{C} \mathrm{km}^{-1}$. . . . . . . .

4.2 Model parameter values. These values define our optimal parameter set, meaning they come from previously published studies optimal for modelling and/or are specific to the site location. Our sensitivity tests use these values, changing one value at a time to understand each parameter's influence on our climate reconstruction. . . . . . . . . . . . . .

4.3 Parameter name, symbol, value, and the $\Delta T$ needed to grow the glacier to the $13 \mathrm{ka}$ moraine without a change in precipitation ( $x$-intercept), with the optimal parameter set yielding a $\Delta T$ of $-2.7^{\circ} \mathrm{C} \ldots \ldots \ldots$

5.1 Model run number with parameter combination and the number of profiles with an acceptable fit (where the relative comparison is between $\frac{2}{3}$ and $\frac{3}{2}$ ). The number of 'acceptable fits' per test for the gradient, mean, and range relative comparisons are listed as well as the total sum of 'acceptable fits' for each model run. MR28 is without the avalanche model. Note that model runs with $\beta_{\text {lim }}=35^{\circ}$ perform relatively well (bold font).

6.1 Cameron Glacier Holocene moraine information modified from Putnam et al. (2012). Information includes cosmogenic exposure ages (M1 - M4), associated age for M5 (Putnam et al., 2010a), $\triangle$ ELA is relative to the AD1995 ELA for Douglas Glacier $(2120 \mathrm{~m}$ asl) . . . . . . . . . . . . . 105 
6.2 Optimal and tested model parameter values. The values with references come from previously published studies, whereas those with ' $\mathrm{S} \#$ ' are values tested in the sensitivity simulations. Names in bold text are the parameters we varied to define our palaeoclimate uncertainty. Our sensitivity tests involve changing one value at a time to quantify the influence each parameter has on our palaeoclimate reconstruction. . . . . . . . 114

6.3 Palaeoclimate estimates for the five targeted moraine positions. Temperature change range reflects $\Delta P$ values. Cameron Glacier length, maximum ablation, maximum accumulation, ELA, area, and AAR are offered for each moraine simulation. AAR values for the Ashburton are also offered, based on the modelled mass balance. . . . . . . . . . . . . . . . . . . 120

6.4 Sensitivity of modelled glacier to interannual temperature variability. Starting from the M1 glacier extent (WNF-A to WNF-D) where baseline/equilibrium glacier length is $4200 \mathrm{~m}$ and from the early Holocene moraine (WNF-E) where baseline glacier length is $5700 \mathrm{~m}$. Below are values of modelled glacier length, including the percentage of time the glacier length spent behind or beyond its equilibrium length and the calculated standard deviation and skewness of the modelled glacier length variations. 126

6.5 Values describing the linear relationship between a change in ELA and its corresponding change in glacier length $(y=a x+b)$. 'Tributary glaciers' refer to the Douglas and Marquee tributary glaciers specifically. . . . . . 130

7.1 Palaeoclimate estimates from different aged moraines for the three targeted locations. Ages are in 1000 years before present $(\mathrm{ka})$ and the range of temperatures represents a precipitation change of $-20 \%, 0 \%$, and $+20 \%$ relative to the present-day value. . . . . . . . . . . . . . 139

A.1 Parameter names, values, and the temperature change needed to grow the glacier without a change in precipitation (x-intercept), with the 'best fit' model parameters yielding $-2.1^{\circ} \mathrm{C} \ldots \ldots \ldots . \ldots . \ldots 156$

A.2 Palaeoclimate estimates using two different modelling approaches. . . . . 159

B.1 Profile information. Direction codes are in reference to the true right or true left sides of the glacier or elevation, left to right (L2R), right to left (R2L), up to down glacier (U2D), down to up glacier (D2U). Profiles used to test the avalanche model are correlated with their alias. . . . . . . . . 163 


\section{Chapter 1}

\section{Introduction}

\subsection{Former glaciers and climate change}

Glacier length fluctuations reflect changes in climate, most notably temperature and precipitation (Oerlemans, 2001, 2005). It follows that moraines, which are deposited by a glacier at its margins, can be used to reconstruct past glacier extent and therefore past climate. Previous studies have shown that palaeo-glacier extents can be simulated using numerical models. Models also afford the possibility of testing different hypotheses regarding past climate and/or glacier behaviour (e.g. Plummer and Phillips, 2003; Kessler et al., 2006; Laabs et al., 2006). Here, I use a modelling approach to help understand what moraines can tell us about palaeoclimate in New Zealand. In the process, I also investigate glacier mass balance processes, response times, and glacier length-valley shape relationships.

Southern Hemisphere moraine sequences offer great potential for helping us to understand the regional and global climate system. The climate in the southern middle-latitudes is ocean-dominated, with only the Andes of South America and Southern Alps of New Zealand extending deeply into the region of the westerly winds. These mountain chains support present-day glaciers and show evidence for past glaciation (Gair, 1967; Porter, 1975a; Suggate, 1990; Hubbard et al., 2005; Ackert et al., 2008; Barrell, 2011; Kaplan et al., 2011; Strelin et al., 2011). The climate of the South Island of New Zealand is influenced by both sub-tropical and sub-polar, atmospheric and oceanic circulation. If a circulation type persists, it can lead to a shift in the climate of the South Island, influencing glacier mass balance (Lamont et al., 1999; Clare et al., 2002; Chinn et al., 2012). Comparing the timing of glacier advances, as determined by moraine ages, between the northern and southern middle latitudes offers clues as to the possible mechanisms of past climate change (Denton and Hendy, 1994; Schaefer et al., 2009; Kaplan et al., 2010; Putnam et al., 2010a). 
The recently published central South Island glacial geomorphology map (Barrell et al., 2011) and emerging cosmogenic exposure age chronologies (Kaplan et al., 2010; Putnam et al., 2010a; Kaplan et al., submitted; Putnam et al., 2012) provide the focus and incentive to further examine moraine-glacier-climate relationships. The chronologies in these publications focus on Lateglacial (15,000 to 11,500 years ago) and Holocene (last 11,500 years) glacier fluctuations in several locations in the Southern Alps. Moraine ages are thought to represent the end point of a period in which a glacier terminus remained stationary (Schaefer et al., 2009). The significance of a moraine sequence, in relation to climate, should be better understood, and this requires a closer look at glaciological processes and glacier responses to climate within individual basins.

In this study, I investigate Holocene and Lateglacial climates by modelling glacier extents in three different valleys. These valleys contain published moraine chronologies and detailed geomorphological maps, which allowed me to target dated moraine positions to estimate past climates. The majority of previous palaeoclimate estimates from glacial records in New Zealand are based on an accumulation-area ratio (AAR) approach (Porter, 1975b; Kaplan et al., 2010; Putnam et al., 2012), which assumes a simple and direct relationship between glacier size and equilibrium-line altitude (ELA). The change in ELA is then used to estimate past temperature, assuming a temperature lapse rate. I compare the published AAR palaeoclimate estimates to my simulated glaciers to test whether this simpler approach is appropriate.

I also address several questions regarding glacier-climate relationships that could not have been answered with an AAR approach. In Chapter 4, the modelled glacier is forced by a temperature reconstruction from a palaeo-ecological proxy. In this type of study, the model is accounting for the response time of the glacier and how it reacts to the magnitude and duration of a temperature change in the climate proxy record. In Chapter 6, I examined the potential of a glacier to advance to its Holocene moraine positions when forced by natural year-to-year stochastic variability in climate rather than a systematic shift in climate. These transient model runs provide insight into glacier length reactions, which could potentially result in moraine deposition. 
A numerical modelling approach, informed by present-day glaciology, can be used to test assumptions that are often made whilst interpreting glacier length changes. The model used here simulates glacier extent by estimating surface energy balance and iceflow within a model domain. Energy balance components are solved for explicitly, and thus topographic influences (e.g. aspect, shading, and elevation) are included. The modelled glacier extent is thus a product of the choice of parameter values as much as the prescribed climate change. Varying parameter values shows the sensitivity of the palaeoclimate reconstruction to each parameter and provides an indication of uncertainty for a reconstruction.

Estimating palaeoclimate from moraines is not a straight-forward process and has several assumptions. The following principles form the basis of this study; (a) in steady-state tests, I assume glaciers deposited moraines while being in equilibrium with the climate, (b) in all model tests, glacier length changes are primarily related to changes in temperature and precipitation, (c) many of the present-day processes and climate variables (e.g. relative humidity, cloudiness, wind speed, and seasonality) are assumed to be the same for palaeo-simulations, and (d) lake calving and extensive debris cover has not influenced the glaciers that I have focused on to any large degree.

In transient simulations, assumption (a) does not apply because we are interested in glacier length fluctuations, for example, in Chapters 4 (where modelled climate and the resulting glaciers are driven by a nearby palaeoclimate proxy) and 6 (where interannual temperature variability within a steady climate is considered). Assumption (b) is examined in the sensitivity tests of Chapters 4 and 6 where changing model parameter values could account for some of the glacier length change. Assumption (c) was not tested here because reliable climate proxy records do not yet exist for past relative humidity, cloudiness, or wind speed (Knudson et al., 2011). We assume that these climate variables are comparable to their present-day values. If these variables changed in the past, as might be expected, their influence on the modelled ice extent is less than temperature and precipitation changes, meaning that they are unlikely to greatly impact our results. The error bars associated with the temperature and precipitation change estimates somewhat account for possible errors introduced by making these assumptions. Lastly, assumption (d) is not examined 
because geomorphic evidence does not suggest there were large lakes or rock avalanches in the valleys chosen. It is possible that simulating past glacier extents would require less of a cooling or precipitation increase if debris cover on the ablation area were included. I do not examine the effects of debris cover on past glacier extents because debris cover is unknown for the past and its effects are beyond the scope of this study.

I aim to understand glacier-climate interactions using the following approach:

1. In the first experiment, I use a coupled energy-balance model (EBM) and ice-flow model to reconstruct past climate in the Irishman basin from a small cirque glacier in the central Southern Alps where a well-dated Lateglacial $(15,000-11,500$ years ago) moraine sequence exists (Kaplan et al., 2010). First, a suite of steady-state model tests provided an envelope of temperature and precipitation change combinations that resulted in ice extending to a 13,000 year old moraine. These results, along with model parameter sensitivity tests, show the relative importance of temperature and precipitation change during the Lateglacial. Second, timedependent simulations forced by a chironomid-derived temperature reconstruction from a nearby tarn are used to compare the resulting glacier length changes to the moraine age and position. This multiple-climate-proxy approach provides an interesting test of the coherence of palaeoclimate estimates in the central Southern Alps.

2. In the second experiment, I use a gravitational snow mass transport and deposition model (Gruber, 2007) to simulate measured snow depth at Cameron Glacier in the central Southern Alps. Different parameter value combinations were then used to optimise a parameter set that provided the best match between measured and modelled snow distribution. This model, which is part of the mass balance model used here, improves predictions of present-day snow deposition patterns on glaciers that receive snow avalanche accumulation (Machguth et al., 2006). Avalanche processes appear to be a significant source for accumulation on the glacier studied in this experiment, as well as many other glaciers in the Southern Alps, and their mass balance processes should be better understood. Modelled mass balance that includes 
the avalanche model results in relatively low AAR values, which makes for an interesting comparison to more typical AAR values. These accumulation processes were likely to have occurred in the past as well. Thus, in an attempt to properly simulate past glacier mass balance, I used the avalanche model in simulations of past glacier extent (Chapter 6).

3. In the third experiment, I use an ice-flow model, coupled to an EBM, which includes an avalanche model, to simulate glacier fluctuations driven by steady-state changes in climate (centennial-scale), as well as stochastic temperature variability (interannual). Steady-state temperature and precipitation change combinations are calculated for four Holocene moraines and one Lateglacial moraine in the Cameron valley in the central Southern Alps. Several modelling studies have shown kilometrescale glacier fluctuations are possible in a steady climate in response to interannual temperature variability alone. This study is designed to better understand glacierclimate links and whether glacier fluctuations caused by stochastic temperature variability in a steady climate could cause the glacier to advance to its Holocene moraine positions.

4. In the final experiment, I reconstruct past climate for Lateglacial moraines in the Whale Stream catchment in the Southern Alps. This particular experiment is part of a larger study including glacial geomorphological maps and cosmogenic nuclidederived exposure-ages from moraines, neither of which formed a part of this thesis. The simulated glacier extent, ice thickness, mass balance, and associated AAR offer insight into the uncertainty associated with using a generic AAR (e.g. 0.65) in a palaeoclimate reconstruction. The simulations also complement the palaeoclimate estimates from the other modelled Lateglacial ice extents in this thesis (Chapters 4 and 6). Additional simulations include a finer horizontal grid spacing, an avalanche model, a higher characteristic sliding velocity, and daily temperature variability to show how differences in model parameter values affect the palaeoclimate interpretations.

Collectively, by carrying out these four studies I have made the following contributions: 
- New estimates of past climate for the Lateglacial and Holocene in New Zealand.

- Comparisons between the glacial geology and modelled glacier fluctuations forced by a chironomid-based climate reconstruction.

- Improved accumulation estimates for an avalanche-fed mountain glacier by including an avalanche parameterisation.

- Comparisons between glacial geology and modelled glacier fluctuations forced by interannual stochastic variability in temperature.

- Evaluation of the relationship between snowline lowering and glacier length change in areas with height-mass balance and hypsometric feedbacks.

In all of these modelling studies, a common finding is that climate change, in particular temperature change, is the primary driver of glacier terminus fluctuations and subsequent moraine records.

\subsection{Organisation of the Thesis}

The main chapters (Chapters 4-6) of this thesis are written as manuscripts that have either been published, or will be submitted to international journals. The background (Chapter 2), methodology (Chapter 3), and synthesis (Chapter 7) chapters, as well as the reference section, are formatted in traditional thesis style. As a consequence of this structure, repetition does occur, particularly in the description of the study sites and models. Chapters 4-6 each address one of the primary research objectives outlined in Section 2.7. Appendix A is unlike the main chapters in that it contains only an excerpt from a manuscript lead by M. Kaplan and others. The manuscript contains glacial geomorphological maps and cosmogenic exposure ages from moraines, neither of which were a result of this thesis and are therefore omitted here. Appendix B contains ground-penetrating radar (GPR) data used in Chapters 5 and 6. These separate chapters together represent a coherent attempt to understand the climatic significance of moraine records in the Southern Alps of New Zealand. 


\subsection{Statement on the contributions made to this thesis by the author, supervisors, and collaborators}

The design of this study, data acquisition, its interpretation and presentation, and writeup represent the efforts of the author. The ice-flow and energy-balance models were originally coded in MATLAB by B. Anderson (Victoria University of Wellington) and the gravitational snow mass transport and distribution model was translated into MATLAB from IDL by myself with help from R. Dadic and H. Horgan. Ground penetrating radar surveys were collected with the help of L. Kees (Victoria University of Wellington), T. Kerr (National Institute of Water and Atmospheric Research (NIWA)), and A. Mackintosh (Victoria University of Wellington).

A. Mackintosh and B. Anderson, my supervisors, appear as co-authors on all the manuscripts. While their contributions to this thesis have been significant, their input to the papers that appear in the thesis was no greater than would be the case for a Ph.D. thesis following traditional protocol. The contributions of B. Anderson and A. Mackintosh were threefold: (i) provision of research funds; (ii) discussion and contribution of scientific ideas and concepts; and (iii) editorial input. Below is a list of manuscripts as they appear in the thesis. The list includes the co-authors, the journal for publication, and a brief account of the contributions of the various co-authors.

\section{Chapter 4:}

Doughty, A.M., Anderson, B.M., Mackintosh, A.N., Kaplan, M.R., Vandergoes, M.J., Barrell, D.J.A., Denton, G.H., Schaefer, J.M., Chinn, T.J.H., Putnam, A.E. (in press) Evaluation of Lateglacial temperature in the Southern Alps of New Zealand based on glacier modelling at Irishman Stream, Ben Ohau Range. Quaternary Science Reviews. DOI: 10.1016/j.quascirev.2012.09.013.

I carried out the modelling simulations. Kaplan, Barrell, Denton, Schaefer, Chinn, Putnam, and I provided published cosmogenic ages and a detailed geomorphology map of Irishman basin. Vandergoes supplied published temperature reconstructions derived from 
chironomid assemblages from Boundary Stream tarn.

\section{Chapter 5:}

Doughty, A.M., Dadic, R., Anderson, B.M., Mackintosh, A.N., Kerr, T., Kees, L., (in prep) Optimising simulated snow depth patterns on an avalanche-fed glacier in New Zealand using GPR and a gravitational mass transport model.

Dadic and Anderson provided source code, support, and aided in experiment development. Kerr, Kees, and Mackintosh assisted in the fieldwork. Kees and H. Horgan (not listed) assisted with initial ground penetrating radar post processing.

\section{Chapter 6:}

Doughty, A.M., Mackintosh, A.N., Anderson, B.M., Putnam, A.E., Barrell, D.J.A., Denton, G.H., Schaefer, J.M. (in prep) What can the Holocene moraines at Cameron Glacier, New Zealand tell us about past climate change?

I carried out the model simulations. Putnam, Barrell, Denton, Schaefer, and I provided cosmogenic ages and a detailed geomorphologic map of Cameron valley.

Appendix A, excerpt from:

Kaplan, M.R., Schaefer, J.M., Denton, G.H., Doughty, A.M., Barrell, D.J.A., Chinn, T.J.H., Putnam, A.E., Andersen, B.G., Mackintosh, A., Finkel, R.C., Schwartz, R. and Anderson, B. (submitted to Geology) The anatomy of 'long-term' warming since $15 \mathrm{kyr}$ ago in the Southern Alps of New Zealand based on net glacier snowline rise.

Here I provide an introduction to the setting described in Kaplan et al. (submitted) and present only the modelling description and results that were included in a publication lead by Kaplan. The publication focuses on the moraine mapping and dating efforts. I added a modelling component to provide estimates of palaeoclimate and mass balance, which allowed me to calculate an AAR and ELA for the targeted glacier extent. The ELA calculated from the model was then compared to the estimated ELAs, which was calculated from the accumulation area ratio method. 
Appendix B

GPR profiles used in Chapters 5 and 6 to calculate snow depth and ice thickness. Kerr, Kees, and Mackintosh assisted in the fieldwork. Kees and Horgan assisted with ground penetrating radar post processing. The raw data from this survey are available on the Victoria University of Wellington 'tuawe' network drive. 


\section{Chapter 2}

\section{Background}

Numerical modelling provides a potentially useful, physically-based method to examine glacier-climate interactions. In recent years, a number of developments have made modelling of past glacier extent in the Southern Alps of New Zealand more feasible. First, recently published glacial geomorphology maps and surface exposure dating (SED) ages of moraines in the central Southern Alps provide the foundation for investigating possible causes of glacier fluctuations in New Zealand. Here, I focus on moraines dating to the Lateglacial (15,000 to 11,500 years ago or 15 - $11.5 \mathrm{ka})$ and Holocene (last $11.5 \mathrm{ka})$. Second, the volume of present-day glacier mass balance and alpine climatological data in the Southern Alps is increasing. These data aid in improving numerical modelling simulations through model evaluation. Third, simple numerical models that take into account the most important mountain glacier processes now exist and improved computing power also makes it possible to carry out a large number of simulations.

\subsection{Moraines and palaeoclimate}

In this thesis, I examine the often-held premise that glaciers are sensitive palaeoclimate indicators and that moraine sequences record past climate events. Moraines are landforms that have been deposited directly by glaciers, and they normally consist of unstratified sediment (Embleton and King, 1975). The form and composition of moraines reflect the local topography, lithology, climate, debris supply, and the efficiency of sediment transport from the glacier to the proglacial environment (Benn et al., 2003). Moraine size is related to glacier debris flux and the amount of time the glacier terminus remained at a single location (Evans, 2003). The term 'moraine' covers a wide range of depositional features, and moraines that formed at the snout of a glacier when it was stationary are ideal for chronologic dating and interpreting past climate (Embleton and King, 1975). 
Interpretations of palaeoclimate from moraines have developed over the last 200 years. In 1837, Louis Agassiz was one of the first to propose that there had been a past ice age, and he observed moraine evidence from the European Alps, Scotland, and North America that supported his theory (Imbrie and Imbrie, 1986). Subsequent theories related summer insolation intensity to the pacing of the ice age cycles (Milankovitch, 1941; Hays et al., 1976), thus relating past climate to past glacier size.

As a means of estimating past climate, glacial geologists have used constraints from glacial geomorphology, such as moraine location and other evidence where present, such as trimlines, to define past glacier extent. This allows equilibrium-line altitudes (ELAs) to be reconstructed using the accumulation-area ratio (AAR) method (e.g. Porter, 1975a; Broecker and Denton, 1990). In this method, the total area of the past glacier extent is divided into the accumulation and ablation areas (using a ratio of 2:3, accumulation:total area). The reconstructed ice surface elevation at the dividing line between the two areas is an estimate of the past ELA. The difference between past and present-day ELA $\left(\Delta z_{E L A}\right)$ can then be converted into an estimate of temperature change $(\Delta T)$ from present-day, using a temperature lapse rate $\left(\frac{d T}{d z}\right.$, typically $\left.-6.5^{\circ} \mathrm{C} \mathrm{km}^{-1}\right)$ :

$$
\Delta T=\Delta z_{E L A} \frac{d T}{d z}
$$

This approach is advantageous because of its simplicity, resource and time efficiency, and ability to provide reasonable ELA and temperature change $(\Delta T)$ estimates. Assumptions implicit in the AAR method, however, translate into considerable uncertainty in the ELA and $\Delta T$ results.

In recent years, as moraine chronologies have improved in precision and coverage, and as present-day glacier-climate interactions are observed, some researchers have questioned the robustness of climate interpretations that can be made from moraines (Balco, 2009; Kirkbride and Winkler, 2012). For example, several modelling studies have shown that significant $(>1 \mathrm{~km})$ changes in glacier length can occur in response to interannual stochastic variability in temperature in an otherwise steady climate (Roe, 2011). This finding has 
caused researchers to question whether or not moraines located close to the glacier terminus require a systematic change in climate in order to be deposited.

To evaluate the robustness of palaeoclimate-moraine interpretations, these alternative ways of explaining changes in glacier length should be explored. The New Zealand landscape contains a variety of glacial deposits, including large, well-preserved moraines. Detailed geomorphic maps and moraine chronologies help to clarify the landscape history and allow for a comparison between moraine records and other palaeoclimate records.

\subsection{New Zealand Lateglacial and Holocene palaeoclimate}

In general, data from terrestrial climate proxy records are more sparse in the Southern Hemisphere than in the Northern Hemisphere due, in part, to there being a smaller land area. New Zealand is one of the few locations in the southern middle latitudes with active mountain glaciers, which can provide a basis for understanding past glaciations. The palaeoclimate of New Zealand since the last glacial maximum (LGM) has been reconstructed from deposits left by glaciers, stable isotopes, flora, and fauna (e.g. McGlone, 1995; Fitzsimons, 1997; Singer et al., 1998; Newnham and Lowe, 2000; Turney et al., 2003; Williams et al., 2005; Anderson and Mackintosh, 2006; Hajdas et al., 2006; Alloway et al., 2007; Vandergoes et al., 2008; Williams et al., 2010). Some moraine sequences show a Lateglacial cooling associated with the Antarctic Cold Reversal (ACR), as well as several Holocene glacial advances. These events differ in timing and magnitude to those which occurred in Europe since the LGM (Gellatly et al., 1988; Ivy-Ochs et al., 1999; Schaefer et al., 2009; Putnam et al., 2012).

The Lateglacial chron includes two abrupt ( $\sim 2 \mathrm{ka})$ cooling events. The Younger Dryas (YD) (12.7 - $11 \mathrm{ka})$ is unambiguously registered in the North Atlantic region in ice cores, pollen records, and moraines (EPICA Community Members, 2006; Broecker et al., 2010; Carlson, 2010). Another event, known as the ACR (15 - $13 \mathrm{ka})$, is primarily found in Antarctic ice cores, Southern Ocean marine sediment cores, and South American and New Zealand moraines and pollen records (Blunier et al., 1997; Newnham and Lowe, 
2000; Fogwill and Kubik, 2005; Hajdas et al., 2006; Barrows et al., 2007a; Carter et al., 2008; Vandergoes et al., 2008; Kaplan et al., 2010; Putnam et al., 2010a). Learning more about the YD and ACR climate signals could help to clarify interhemispheric heat transfer, abrupt climate drivers, and responses of the ocean, atmosphere, and terrestrial systems to climate change.

The timing of a Lateglacial ice advance in the central Southern Alps was originally thought to be synchronous with the YD found in North Atlantic / European records (Denton and Hendy, 1994; Ivy-Ochs et al., 1999) but has now been shown to be asynchronous with this event (Turney et al., 2007; Kaplan et al., 2010; Putnam et al., 2010a). Studies of glaciers and their moraine records, pollen, and chironomids in the Southern Alps suggest that a cooling occurred during the ACR (Newnham and Lowe, 2000, 2003; Vandergoes et al., 2005, 2008). After this cool period, glaciers in New Zealand retreated during the YD, while glaciers in Europe readvanced (Golledge et al., 2009; Kaplan et al., 2010).

A previous attempt to model New Zealand glacier extent during the Lateglacial was carried out for Franz Josef Glacier (Anderson and Mackintosh, 2006). The Waiho Loop moraine, which has been associated with the Lateglacial (Denton and Hendy, 1994; Turney et al., 2003), represents a $10 \mathrm{~km}$ advance of the Franz Josef Glacier from its modern position (Figure 2.1). Anderson and Mackintosh (2006) discovered that a $4.1-4.7^{\circ} \mathrm{C}$ drop in mean-annual temperature, $400 \%$ increase in mean annual precipitation, or some combination of the two would be necessary to explain this advance (Anderson and Mackintosh, 2006). However, the origin (Tovar et al., 2008) and age (Barrows et al., 2007b) of this moraine have been questioned, causing some doubt about the palaeoclimate interpretations that can be drawn at this location (Evans, 2008).

Unlike those in the European Alps, glaciers in New Zealand appear to have retreated steadily during the Holocene, making the Little Ice Age a relatively minor Holocene glacial event (Gellatly, 1984; Gellatly et al., 1988; Ivy-Ochs et al., 1999; Schaefer et al., 2009; Putnam et al., 2012). As a result, New Zealand glaciers did not override and destroy earlier Holocene moraines. This asynchronous behaviour between hemispheres has been attributed to climate processes associated with the bipolar seesaw, insolation, and 
regional climate feedbacks (Broecker, 1998; Schaefer et al., 2009; Kaplan et al., 2010; Putnam et al., 2010a, 2012).

Several modelling studies have shown that stochastic, interannual temperature variability can cause kilometre-scale glacier terminus fluctuations (Oerlemans, 2000; Roe and O'Neal, 2009; Roe, 2011), complicating the traditional view that moraines are deposited as a direct consequence of a change in climate. These simulations shed doubt on the need to explain Holocene glacier fluctuations by invoking a significant shift in climate $(\sim 30$ year mean). In other words, these authors contend that glacier fluctuations of Holocene scale might reflect nothing more than interannual stochastic variability in climate. Consequently, the palaeoclimate significance of recently published New Zealand Holocene moraine chronologies (Schaefer et al., 2009) have been questioned (Balco, 2009).

In summary, the New Zealand landscape contains many moraine sequences that can be mapped, dated, and potentially used to interpret past climate, along with other climate proxy records. There are, however, uncertainties and assumptions made in extracting palaeoclimate data from moraine records, especially when applying simple glacier lengthtemperature change relationships such as the AAR method. The relationships between glacier length and climate change should be further examined using models of glaciers to test these assumptions and to better understand what moraine sequences can tell us about past climate.

\subsection{Lateglacial and Holocene glacial geology of New Zealand}

The extensive nature of many New Zealand moraines is in part due to the high sediment flux delivered to the glacier surface. The central Southern Alps of New Zealand provide an ideal environment for generating and supplying ample debris to glaciers (Shulmeister et al., 2010b). This is due to the combination of steep valley walls, substantial exhumation rates related to the vertical velocity of surface uplift, a highly-fractured and low-grade metamorphic lithology ('greywacke'), large amounts of orographic precipitation, and associated high denudation rates (Little et al., 2005; Houlié and Stern, 2012). The high 
debris supply, along with other conditions mentioned above (Section 2.1), typically result in voluminous moraines (Benn et al., 2003).

Lateglacial and Holocene moraines are located between the LGM and present-day ice extents (LGM marked by a pink line and light blue shows present-day ice extent in Figure 2.1). The best-preserved moraines in New Zealand have been the focus of decades of mapping and dating research, and have been used to evaluate global-scale climate events (Suggate, 1965; Soons and Gullentops, 1973; Burrows, 1975; Mercer, 1984; Gellatly et al., 1988; Fitzsimons, 1997; Ivy-Ochs et al., 1999; Schaefer et al., 2009; Kaplan et al., 2010; Shulmeister et al., 2010a; Putnam et al., 2012).

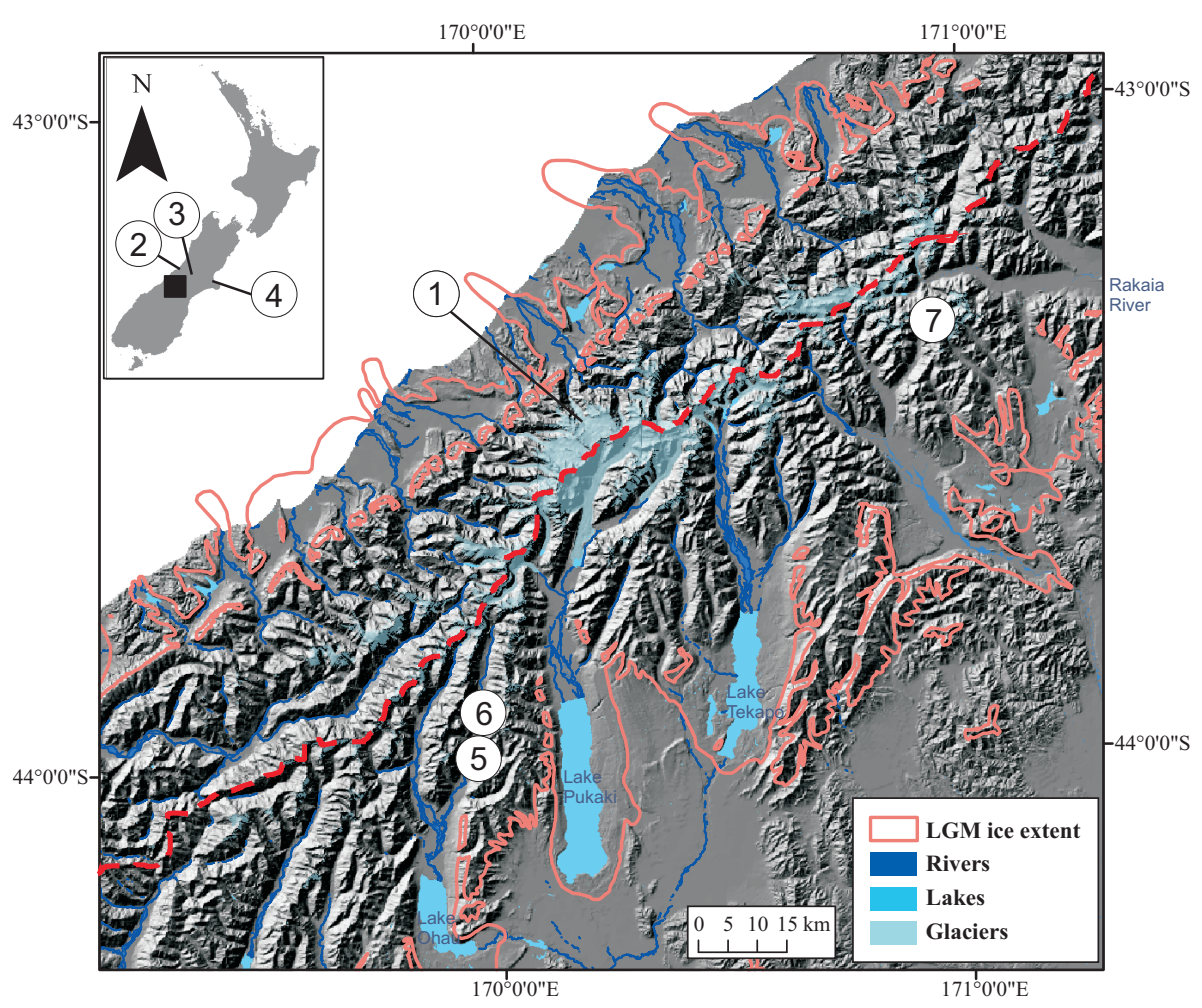

Figure 2.1 Map of shaded topography of central South Island, New Zealand with the last glacial maximum ice extent (pink outline Barrell et al. (2011)) and the Main Divide of the Southern Alps (dashed red line). Numbers mark locations of 1) Franz Josef Glacier, 2) Hokitika, 3) Arthurs Pass, 4) Christchurch, 5) Irishman Stream, 6) Whale Stream, and 7) Cameron valley.

\subsubsection{Mapping Lateglacial and Holocene moraines}

Until recently, glacial deposits in different regions of the South Island (Mackenzie basin, West Coast, Rakaia, etc.) were mapped and described by different geologists and then 
correlated (Gage and Suggate, 1958; Suggate, 1961, 1965; Gair, 1967; Soons and Gullentops, 1973; Porter, 1975a; Shulmeister et al., 2001; Suggate and Almond, 2005; Barrell et al., 2011). Moraines from different areas were matched using the degree of preservation, geographic position, and relative weathering of boulders (e.g. quartz vein heights, weathering rinds, and lichenometry). More recently, the central part of the South Island's glacial geomorphology has been systematically mapped and presented in a monograph by GNS Science (Barrell et al., 2011). Glacial deposits in these maps are categorised by relative age, with colour used to separate Holocene, Lateglacial, LGM, and pre-LGM deposits. The maps are digitised and provide larger-scale context to guide and focus the SED investigations, which in turn, provide absolute age control.

Higher resolution segments of the central South Island glacial geomorphology map have accompanied recent publications, detailing the cosmogenic moraine chronologies by the Denton group (Schaefer et al., 2009; Kaplan et al., 2010; Putnam et al., 2010a, 2012, 2013). The maps provide the context of each moraine within a sequence, showing moraine ridge continuity, size, and complexity. These moraine maps are ideal for modelling studies, where glacier simulations are compared to mapped moraine positions.

\subsubsection{Dating of moraines}

Moraine dating, when applied at a global scale, allows for comparisons of climate events, which may reveal large-scale climate teleconnections (Clark et al., 2009). Determining the age of a moraine is the first step toward the goal of assessing its regional or perhaps, global significance. Initial dating surveys used weathering rind thicknesses (Gellatly, 1984), lichenometry, and Schmidt hammer tests (Winkler, 2005) to compare deposits from valley to valley. However, these techniques provide calibrated ages, rather than absolute dates and their associated uncertainties in age do not allow for broader-scale comparisons.

The first radiometric ages of moraines in New Zealand, and elsewhere, started with radiocarbon dating of buried organic material (Burrows, 1988; Lowell et al., 1995). This method works well in areas with high amounts of organic material (i.e. forested areas). 
For example, radiocarbon ages from tree bark buried under till on a bedrock knoll on the West Coast were interpreted to represent the timing of an advance of Franz Josef Glacier to the Waiho Loop moraine (Denton and Hendy, 1994). More recently, cosmogenic SED has provided the means to accrue a large number of moraine ages in the drier, organicscarce regions east of the Main Divide of the Southern Alps (henceforth referred to as the main divide, red dashed line in Figure 2.1).

Improvements in SED techniques (i.e. refined boulder sampling, low-background carrier, and high accelerator mass spectrometer currents) have allowed for more precise moraine chronologies (Schaefer et al., 2009), extending over a timescale from millions of years right up to the last century. In addition, a local ${ }^{10} \mathrm{Be}$ calibration site in the Macaulay valley (Putnam et al., 2010b) has improved dating accuracy in New Zealand. Sampling campaigns in the central South Island targeted areas with multiple moraine ridges and little post-depositional disturbance. Such areas are readily identified using aerial photographs and detailed glacial geomorphology maps (Barrell et al., 2011). Emerging chronologies of the Lateglacial and Holocene moraines in the Southern Alps help to fill gaps in knowledge of Southern Hemisphere glacier fluctuations (Schaefer et al., 2009; Kaplan et al., 2010; Putnam et al., 2010a; Kaplan et al., submitted; Putnam et al., 2012), dramatically improving our understanding of past glacier behaviour in New Zealand.

Thus far, the published chronologies from the Denton group have highlighted moraine ages, which are interpreted as representing the time when the glacier pulled away from its steady-state position at the moraine, dating from the penultimate glaciation (Putnam et al., 2013) to the late Holocene (Schaefer et al., 2009; Putnam et al., 2012). Moraines dated to the Lateglacial suggest that glaciers advanced coincident with the ACR ( 13 kya) and subsequently retreated during the YD (Kaplan et al., 2010; Putnam et al., 2010a). Holocene moraine sequences show multiple glacial advances (e.g. $\sim 8,200, \sim 6,000$, and 500 years ago) with an overall retreat to the present-day ice extent (Schaefer et al., 2009; Putnam et al., 2012). 


\subsection{Climate of the Southern Alps}

New Zealand is positioned in the southwest Pacific, just north of the present-day location of the Sub-Tropical Front (Carter et al., 2004). The mountains of the South Island trend northeast along the Australia-Pacific plate boundary zone, with many peaks reaching between 2000 and $3000 \mathrm{~m}$ asl in the central Southern Alps (highest peak, Aoraki / Mt. Cook $3754 \mathrm{~m}$ asl). These mountains intersect the southern middle latitude westerly winds, creating a strong orographic effect and precipitation gradient from west to east (Figure 2.2). The pattern of mean annual precipitation is imprecisely known, but is thought to peak at $\sim 10 \mathrm{~m}$ (Griffiths and McSaveney, 1983; Henderson and Thompson, 1999) between the Alpine Fault and main divide and decrease almost exponentially with distance east over to the Canterbury plains (Chinn and Whitehouse, 1980; Henderson and Thompson, 1999; Salinger and Mullan, 1999). The maritime climate is characterised by a low seasonal range in temperatures, which means glaciers with high elevation catchments and low elevation tongues can receive accumulation as well as ablate ice year-round.

\subsubsection{Southern Alps climate variability}

Synoptic-scale atmospheric and oceanic circulation in the South Pacific region ultimately determine the present-day climate variability in New Zealand (Kidson, 1994; Chinn, 1995; Mullan, 1995; Salinger and Mullan, 1999; Clare et al., 2002). The synoptic circulation is responding to larger-scale climate patterns and modes, such as the El NiñoSouthern Oscillation (ENSO), Southern Annular Mode (SAM), and Interdecadal Pacific Oscillation (IPO). These modes or oscillations all affect the precipitation and temperature variability observed in New Zealand to some degree (Jiang et al., 2012). Climate data from Hokitika (West Coast), Arthurs Pass (main divide), and Christchurch (east coast) provide an idea of present-day interannual precipitation and temperature variability (Table 2.1).

Proxy records from New Zealand indicate that synoptic circulation was also important during the Holocene (Ackerley et al., 2011; Lorrey et al., 2012; Fowler et al., 2012), but 


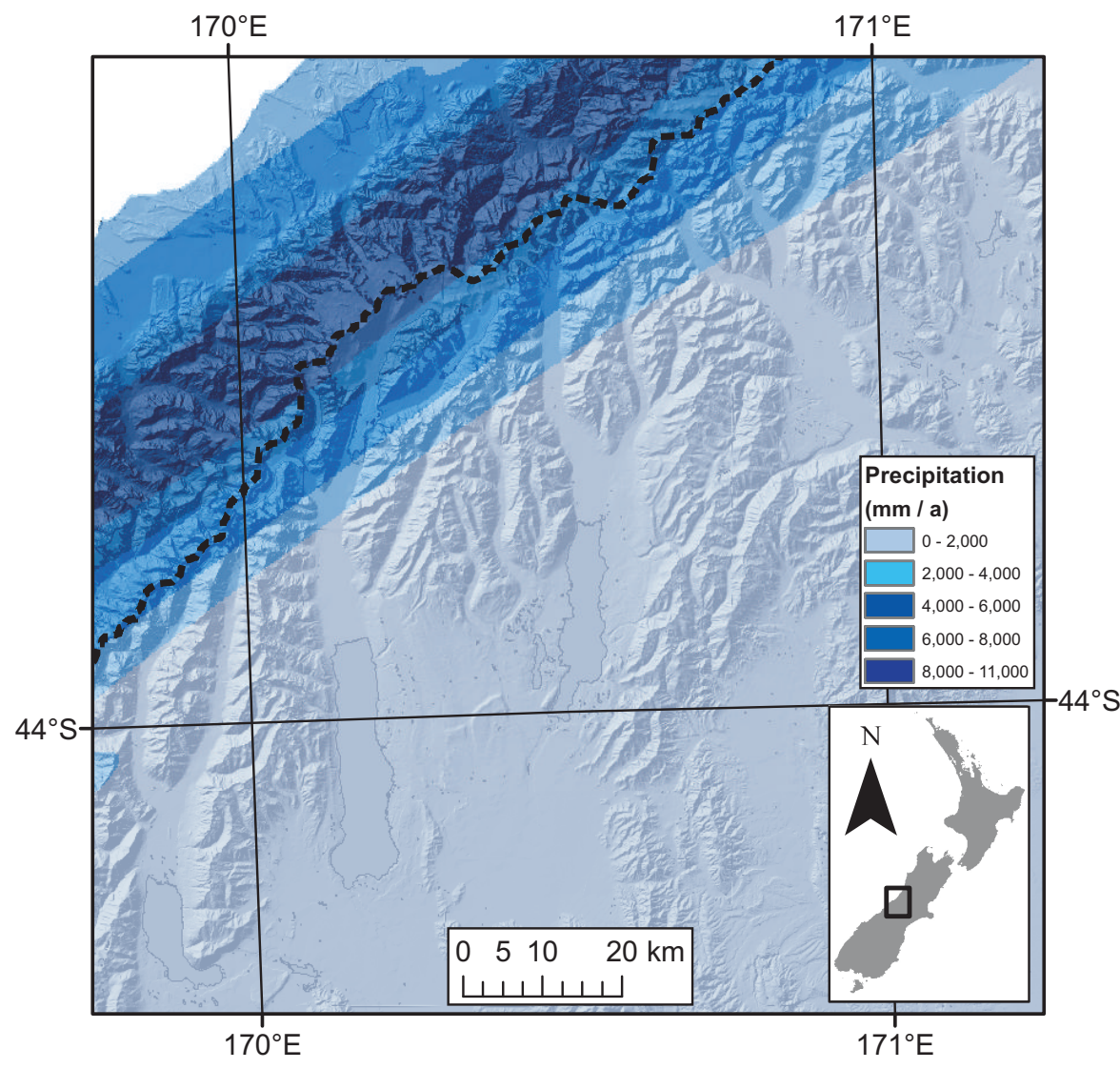

Figure 2.2 Map of 30-year mean annual precipitation surface (Stuart, 2011), overlain on shaded topography of central South Island, New Zealand and the Main Divide of the Southern Alps (dashed black line). In the central Southern Alps, most of the annual precipitation falls west of the main divide due to a strong orographic effect. 
there is still much left to learn. The frequency or intensity of the different climate modes were most likely different from today. For example, the onset of ENSO is thought to have occurred during the mid-Holocene, likely due to a change in orbital configuration. However, the frequency of El Niño / La Niña events was not the same as today (Clement et al., 2000; Liu et al., 2000; Moy et al., 2002).

Table 2.1 Climate information from Hokitika, Arthurs Pass, and Christchurch stations. Statistics from daily mean precipitation and temperature data from 1980 to 2011 (NIWA, Retrieved 2009-2011). Hokitika (west coast) and Christchurch (east coast) data are presented for near sea-level west to east comparisons.

\begin{tabular}{lccc} 
& $\begin{array}{c}\text { Hokitika } \\
\text { Elevation }\end{array}$ & $\begin{array}{c}\text { Arthurs Pass } \\
79 \mathrm{~m} \text { asl }\end{array}$ & $\begin{array}{c}\text { Christchurch } \\
37 \mathrm{~m} \text { asl }\end{array}$ \\
\hline Precipitation & & & \\
Mean (mm) & 2886 & 4661 & 596 \\
Annual std dev. $(\mathrm{mm})$ & 329 & 726 & 113 \\
Annual std dev. $(\%)$ & 11 & 16 & 19 \\
Temperature & & & \\
Mean $\left({ }^{\circ} \mathrm{C}\right)$ & 12 & 7.7 & 11.6 \\
Annual std dev. $\left({ }^{\circ} \mathrm{C}\right)$ & 0.5 & 0.51 & 0.42 \\
Annual std dev. $(\%)$ & 4.1 & 6.6 & 3.6 \\
Daily std dev. $\left({ }^{\circ} \mathrm{C}\right)$ & 1.84 & 2.30 & 2.75 \\
\hline
\end{tabular}

\subsubsection{Alpine meteorology}

While decades of weather station data have helped to describe the spatial and seasonal patterns of temperature and precipitation near sea level in New Zealand, alpine meteorology has received less attention. The relatively few high-altitude automatic weather stations (AWSs) that do exist are monitored by organisations such as universities, Crown Research Institutes (e.g. GNS, NIWA), recreational providers (e.g. ski field), or hydroelectric companies (e.g. Meridian). The stations (at least 11 stations monitored by the National Institute of Water and Atmospheric Research (NIWA) alone) measure air temperature, relative humidity, wind speed and direction, air pressure, solar radiation, reflected radiation, and sometimes precipitation (Gillett and Cullen, 2011). Maintaining an alpine AWS on a glacier surface can be difficult and no permanent glacier AWSs exist: 'Automatic recorders are expensive however, and need to be robust, kea proof (at least in 
New Zealand) and capable of being retrieved from under perhaps 20 m of snow' (Bishop and Forsyth, 1988).

Temperature lapse rates, which describe the change in temperature with increasing elevation, are affected by processes in the atmospheric boundary layer (Barry, 1990, 1992) and vary in time and with location (Blandford et al., 2008). However, due to the scarcity of high altitude climate station data and uncertainty in lapse rate variability, a single value is often used, typically an 'environmental' adiabatic lapse rate $\left(-6.5^{\circ} \mathrm{C} \mathrm{km}^{-1}\right)$, which represents conditions roughly mid-way between the wet and dry adiabatic lapse rates (Sturman and Tapper, 1996). Lapse rates in New Zealand can be estimated using an empirical relationship between the lapse rate and the site latitude, elevation, and distance to the nearest coast (Norton, 1985). However, using a lapse rate from site-specific AWS measurements is more desirable if such data exist.

\subsection{Glacier monitoring}

Glaciological studies, together with studies of alpine meteorology, help to establish links between characteristic weather patterns and glacier mass balance (Oerlemans, 1992; Oerlemans and Knap, 1998; Klok and Oerlemans, 2002; Hock, 2005). Glaciers fluctuate in size to equilibrate with their climate where ice extent is dependent on a combination of factors, including; ice flow rates, topography, total annual accumulation of snow, and total annual melt (Paterson, 1994). Although annual net mass balance (accumulation minus melt) varies from year to year, ice extent adjusts over longer timescales (years to centuries), thus glacier length changes typically mimic a smoothed climate signal.

To interpret past climate from dated moraine positions requires an understanding of how glaciers in New Zealand respond to modern climate. Specifically, observations of glaciers in the Southern Alps provide a basis for tuning and evaluating glacier models. Glacier mass-balance studies in New Zealand have focused on several glaciers chosen for their accessibility, size, and importance. Long-term investigations have focused primarily on the Ivory, Tasman, Franz Josef, Brewster, and Fox glaciers (Anderton and Chinn, 1978; 
Anderson et al., 2008, 2010; Gillett and Cullen, 2011; Purdie et al., 2011b). Brewster Glacier is currently a major part of the mass balance programme, with data reported annually to the World Glacier Monitoring Service (WGMS, 2011). One- and two-year mass-balance studies have been carried out on other South Island glaciers, including the Park Pass, Glenmary (Stumm, 2011), and Dart Glacier (Bishop and Forsyth, 1988). The Rolleston Glacier mass-balance programme started in November 2010 and regular monitoring is planned to continue into the future (personal communication T. Kerr, 2010).

The end of summer snowline (EOSS) survey is the longest record of glacier observations in New Zealand (Chinn, 1995; Chinn et al., 2006, 2012). This survey includes 50 index glaciers from Fiordland to the Kaikoura Ranges and has been on-going since 1977 (Chinn, 1995; Willsman et al., 2010). The record is comprised of oblique aerial photographs, taken from roughly the same elevation and vantage point each year, that show the distribution of snow at the end of the mass balance year. The EOSS in the photograph is then visually compared to a topographic map to estimate the annual ELA. The EOSS at any one time varies geographically due to accumulation and ablation of snow (Chinn, 1995 ) ranging in elevation from $\sim 1600 \mathrm{~m}$ asl in the west to $2200 \mathrm{~m}$ asl in the east. Annual EOSS elevations of individual glaciers are highly correlated to the annual mean EOSS elevation of the Southern Alps, demonstrating that they largely respond to the same climate signal (Chinn et al., 2006, 2012).

Several of the large, low-angle glaciers east of the main divide now show significant debris cover (Reznichenko et al., 2010; Anderson and Mackintosh, 2012), and many are calving into proglacial lakes that have formed as a consequence of recent thinning (Dykes and Brook, 2010; Chinn et al., 2012). Thick debris cover can insulate the ice below, decreasing the melt rates, but does not stop melt from occurring (Anderson and Mackintosh, 2012; Gardelle et al., 2012), whereas iceberg calving into lakes can increase the rate of glacier retreat. Both of these processes are imperfectly understood in the present-day and the impact of these processes is largely unknown for the past. Modelling sites were chosen to avoid glaciers with these features and associated, more complicated, responses to climate.

Overall, New Zealand glaciers can be characterised as temperate mountain glaciers in a 
wet, maritime environment that are highly sensitive to changes in climate due to their high accumulation and high ablations rates (high mass balance gradients). High surface angle glaciers, often but not exclusively found on the West Coast, have faster reaction times to climate changes than the large, low-angle glaciers typically found east of the main divide (Oerlemans, 2000; Chinn et al., 2012).

\subsection{Glacier modelling}

Models are used to represent a complex natural system in a simplified manner. The most important components of a system are included in equations or parameterisations that attempt to describe the physical relationships. Glacier models vary widely in complexity to suit the requirements of the problem being investigated. Glacial geologists typically use the AAR method as a simple model, which can be applied to any catchment with a well-defined terminal moraine using a topographic map. Estimates of past ELA change can be made by outlining past glacier area, as determined by the moraine, and using an assumed AAR (typically of 0.6 to 0.66 ), where the ELA is solved for as the dividing line between the accumulation and ablation zones.

Porter (1975a) used the AAR method to work out the ELA lowering during the Lateglacial period in New Zealand. An ELA lowering of 500 $\pm 50 \mathrm{~m}$ was calculated for the Birch Hill moraine in the Tasman-Pukaki basin. The difference in past and present-day ELAs can then be converted into temperature change by using a temperature lapse rate (typically -6 to $\left.-6.5^{\circ} \mathrm{C} \mathrm{km}^{-1}\right)$. This method is fast and gives an estimate of temperature change for a steady state 'snapshot', but cannot account for mass balance influences such as topographic shading, hypsometry, accumulation concentration, nor distortions resulting from differences in glacier flow. Due to the many assumptions made, the results from this type of model include errors that are difficult to quantify (Plummer and Phillips, 2003; Oerlemans, 2005).

Numerical models may offer more comprehensive palaeoclimate reconstructions than an AAR approach (Hubbard, 1997; Plummer and Phillips, 2003). Past glacier extents have 
been successfully reproduced in a variety of locations, using models of intermediate complexity (Oerlemans, 1988; Mackintosh et al., 2002; Kessler et al., 2006; Golledge et al., 2009). These models typically consist of a mass balance component and an ice-flow component, each containing a suite of tunable parameters. In Chapter 3, I describe several different model types and the benefit and assumptions associated with each.

To date, published palaeoclimate estimates from numerical simulations of past glaciers in New Zealand have come from a range of model types. These types include a degree-day model with a 1-D flowline of Franz Josef Glacier (Anderson and Mackintosh, 2006), a 3-D shallow-ice approximation (SIA)/shallow shelf approximation model for the entire Southern Alps (Golledge et al., 2012), a 2-D SIA simulation of the Rakaia catchment (Rowan et al., in press), and flowline models used to study LGM ice extent in the Pukaki and Ohau catchments (McKinnon et al., 2012; Putnam et al., 2013). Herman and Braun (2008) also produced a simulation of glaciation of the Southern Alps, however, their aim was to simulate landscape evolution.

\subsection{Research questions}

Moraine records have been used as proxy indicators of past climate for more than a century. Models provide a potentially useful means to add value to the mapping and dating of glacial landforms. The following research questions and objectives stem from the desire to understand what moraines and their chronologies represent in terms of palaeoclimate and glacier response. The first two questions are related to past climate, the next three explore some finer details of glacier mass balance variability, and the last three concern the methodology employed.

1. What magnitude of past temperature and precipitation change do Lateglacial- and Holocene-aged moraines in New Zealand represent?

2. Are these estimates of past temperature and precipitation coherent with other climate proxy records in New Zealand? 
3. To what extent does the re-mobilisation of snow by avalanches affect the presentday mass balance of New Zealand glaciers?

4. Does including a model of snow redistribution in a glacier model change the palaeoclimate reconstructions made?

5. Could natural, stochastic variability in climate have caused the Holocene glacier fluctuations?

6. What parameters are the modelled glaciers most sensitive to, and how does parameter choice affect the climate reconstructions?

7. How do the palaeoclimate estimates derived from modelling glaciers differ from previous estimates using simpler methods?

8. What can we learn from dynamic glacier models that we could not gain from using simpler methods?

The overall aim of my work is to improve palaeoclimate estimates from Holocene and Lateglacial moraines in New Zealand. Additionally, I hope to provide an idea of how quickly and by what magnitude these glaciers can respond to changes in climate. Understanding the sensitivity of these glaciers allows for more insightful interpretations of moraine sequences and ultimately, climate. 


\section{Chapter 3}

\section{Methodology}

"Essentially, all models are wrong, but some are useful" Box and Draper (1987).

The study of glaciers and their response to climate change has progressed greatly in the past few decades. Models have been an essential part of developing the understanding of glacier-climate relationships for the present-day, where glaciological and meteorological data are available. Numerical models provide the opportunity to better understand glacier-climate relationships and test different theories about what caused past glacier fluctuations. Models range in complexity, but they all attempt to represent the most important processes within a system, with a series of equations. Simplifying any natural system into a model results in an incomplete representation of the system, and the associated model assumptions and uncertainties must be discussed and explored (Oreskes et al., 1994; van der Veen, 1999).

Numerical models that describe the physics of ice-flow and glacier mass balance can be used to simulate past glacier extents, as delimited by moraines. Such simulations improve our understanding of past climate, glacier-climate feedbacks, glacier response times, and ice thickness estimates, even in areas that lack geomorphic evidence. Simpler models, such as the accumulation-area ratio (AAR), cannot offer these insights, which is why I used numerical models to infer climate-glacier-moraine relationships. Here, I describe a range of available glacier models and explain why I chose the ones used in this study. I also discuss the limitations and advantages of a numerical modelling approach and explore the parameter values used in each model and in different chapters (Tables 3.2, 3.1, and 3.3). 


\subsection{Modelling approaches}

There are several reasons why I chose a numerical modelling approach to evaluate past climate from glacier records. First, input climate data and parameters are adjustable, which allows for testing of different palaeoclimate scenarios, such as precipitation change from present-day, snow avalanche accumulation, or natural stochastic variability in climate. Second, the adjustable parameters allow for sensitivity tests, such as assessing the glacier length fluctuations that result from step changes in temperature, that enhance the understanding of glacier-climate relationships. Third, the models that I used consider locationspecific features, such as aspect, bedrock slope, surface elevation, and topographic shading. Finally, the model can produce transient simulations, thereby allowing the evolving glacier response to a changing climate to be assessed.

The three model components used in this thesis describe (1) surface energy balance, (2) gravitational snow mass transport and deposition (MTD), and (3) ice-flow. The distributed energy-balance model (EBM) accounts for shading, changes in albedo, and aspect, among other factors that affect melt. The gravitational snow MTD model uses the grid cell slope values and total snowfall to simulate small, frequent snow avalanches. The grid of redistributed snow is used to improve mass balance estimates. The ice-flow model calculates the 2-dimensional flow of ice across a landscape, which allows the size of the glacier to evolve as the mass balance changes. These models can be efficiently applied to small areas $\left(<20 \mathrm{~km}^{2}\right)$ with high-resolution digital elevation models (DEMs) (25 to $100 \mathrm{~m}$ ).

The mass balance distribution is ultimately what drives the glacier to advance or retreat. The close coupling between the models allows the responses and feedbacks between mass balance and evolving ice geometry to be explicitly considered. This coupling allows for the EBM to update accumulation and ablation rates for a particular surface topography (bedrock + ice thickness) because mass balance values in a cell are affected by changes in aspect, surface elevation, slope, or total ice cover. The ice thickness is also updated with the calculated horizontal ice flux from cell to cell at each timestep.

Details about model setup, why I chose to use certain parameter values, and how these 
models were applied to answer the research questions (Section 2.7), are explained in the following sections. All models use SI units, however some of the values in the following tables show non-standard units for easier comprehension.

\subsection{Energy-balance model}

A variety of climate-glacier models exist, each with its own level of complexity and parameterisations. Positive degree-day (PDD) models are based on an empirical relationship between ice ablation and air-temperatures (Ohmura, 2001). A PDD model simplifies complex processes that are described in an EBM, and calculates melt by multiplying the sum of PDD with a PDD factor. This attempts to account for the surface energy balance processes that affect melt, including the incoming shortwave and longwave radiation and the turbulent heat fluxes (Braithwaite, 1995; Blard et al., 2011). The EBM explicitly considers the influences of topography on the surface energy balance within the atmospheric boundary layer (Equation 3.1). A surface EBM was chosen over a PDD model for several reasons. First, the EBM allows me to test the sensitivity of glacier extent to climatic inputs other than temperature. One aim of this thesis is to examine the relationship between glaciers and temperature change and test whether past glacier extents in New Zealand can be explained by other climate variables. To do this, I require a model that is not solely dependent on temperature. Second, although the EBM requires more input data (i.e. wind velocity, relative humidity, cloud cover, debris cover), which are poorly known in the past, I assume these data to be the same between past and present. Differences in these values (absolute or spatial gradients) would be interesting to investigate, but is beyond the scope of this study. Third, the EBM used here could be adapted to include the MTD model, which improves the snow distribution and mass balance gradient of an avalanche-fed glacier.

The EBM uses a surface elevation grid (digital elevation model plus an ice thickness grid) and daily climate data. The climate data came from the National Institute of Water and Atmospheric Research (NIWA) CliFlo Database, NCEP reanalysis, and an annual mean precipitation surface (Stuart, 2011), empirically derived from the most comprehensive 
network of precipitation stations available. Precipitation amount depends on the daily or monthly mean interpolated precipitation grids within my model and the annual mean precipitation surface (Stuart, 2011). Snowfall occurs in a grid cell in the model when the atmospheric temperature $\left(T_{a}\right)$ at that grid cell is at or below a snow/rain temperature threshold $\left(T_{\text {snow }}\right) . T_{\text {snow }}$ was set to $1^{\circ} \mathrm{C}(274.15 \mathrm{~K})$ for all simulations (Anderson et al., 2006) (Table 3.1) and varied in the sensitivity tests by $\pm 1^{\circ} \mathrm{C}$. If simulations include the MTD model, modelled snow is transported from steep slopes to lower, gentler slopes (see Section 3.3).

Temperature lapse rates in New Zealand vary spatially and temporally, however, there are limited temperature measurements from alpine sites. An automatic weather station was installed in Irishman basin for a separate study (K. Sattler and others, Victoria University of Wellington) and I calculated monthly mean temperature lapse rates from March 2010 to January 2011 temperature data. There is a noticeable seasonal cycle in the lapse rate values (Figure 3.1a), with lower values in winter (July $-3.5^{\circ} \mathrm{C} \mathrm{km}^{-1}$ ) and higher values in summer (January $-6^{\circ} \mathrm{C} \mathrm{km}^{-1}$ ). After publication of this article, we had access to the 20112012 temperature measurements which showed a similar pattern in temperature lapse rate variability (Figure 3.1b). The monthly lapse rates calculated for 2010 to 2011 seem to work well for the 2011 to 2012 year (Figure 3.1b, red line) however, we offer an improved fit for the final three months using values of $-6.5,-6.5$, and $-7.5^{\circ} \mathrm{C} \mathrm{km}^{-1}$ for October, November and December, respectively.

A DEM (GeographiX (NZ) Ltd) derived from elevational contours by Land Information New Zealand (NZMS260), provided surface elevation for all model simulations. The gridded horizontal resolution of the DEM applied differs between chapters, depending on the research question and domain size (Table 3.4). In Chapter 6, the DEM was altered by removing the present-day ice thickness, which was estimated using the ice surface slope and modelled mass balance. The estimation of Cameron Glacier ice thickness was also guided by ground-penetrating radar (GPR) data which showed the bed topography along the glacier's central flowline (Appendix B). The gridded topography was then smoothed using an average block size of five grid cells $(250 \mathrm{~m})$ (Chapter 6). The ice-removal and topographic smoothing is important for minimising the ice flux correction in the ice-flow 

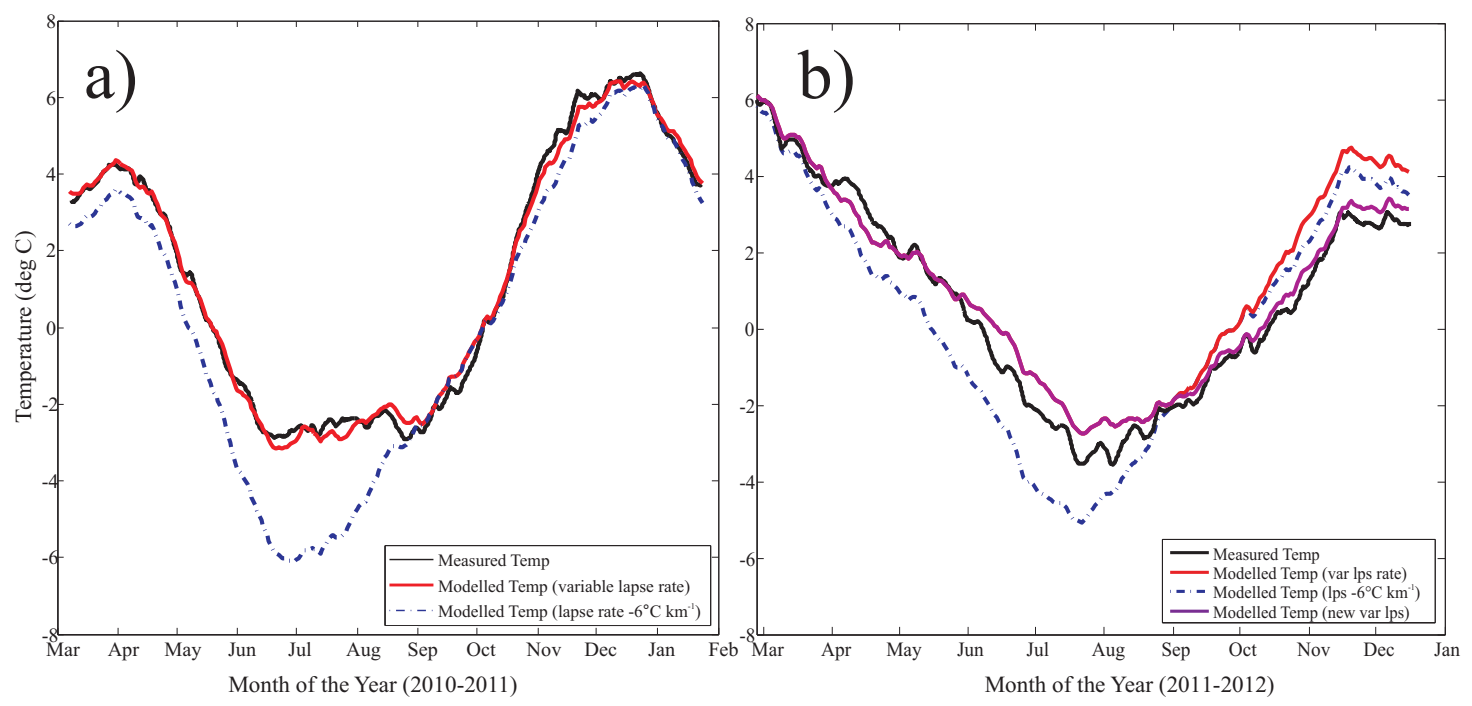

Figure 3.1 Modelled versus measured temperatures at the location of a climate station in Irishman basin. Modelled temperature values (daily interpolated temperature, $T$, smoothed with a thirty-day running mean) were interpolated from climate stations at $<800 \mathrm{~m}$ asl over the 2010-2011 (a) and 2011-2012 (b) intervals. Measured temperature data (black line) are compared to modelled temperatures that were calculated using the 2010-2011 monthly varying lapse rate (red line), using a new variable lapse rate (purple line, panel b only) and a constant lapse rate (blue dashed). Using a constant lapse rate achieves a poor match, especially during winter months (Jun-Sep).

model (Section 3.4.1).

Debris cover was mapped from aerial imagery taken on 30 January, 2006, provided by Terralink International. Modelled melt in cells with prescribed debris cover was reduced by $\sim 90 \%$, based on previous estimates on New Zealand glaciers (Anderson and Mackintosh, 2012). A debris cover grid was only included in the present-day model run because the debris coverage is unknown for the past. It is likely that present-day debris cover is greater than in the recent past, due to glacier thinning (Stokes et al., 2007).

The timestep of the EBM is adjusted depending on the question being addressed. For palaeo-glacier simulations, model runs were carried out for over $>200$ model years to ensure that the glacier reached equilibrium. The climatic input data for these simulations are monthly means based on present-day climate (1981-2010). The EBM uses a monthly timestep for these model runs, which allows the seasonal cycle to be captured. The EBM in Chapter 5 (snow transport simulations) uses daily climatic input data from various meteorologic stations over the 2009-2010 mass balance year that were interpolated across the 
model domain. One goal of the daily simulations in Chapter 5 was to replicate measured snow depths with the model. This investigation required a daily timestep in the EBM to resolve snow deposition and melt during the 2009-2010 mass balance year.

To simulate mass balance gradients seen today on the Cameron Glacier using a monthly timestep, the temperature input data were further adjusted in Chapter 6. The 30-year monthly mean (1981-2010) temperature input data were converted into 'daily' temperatures by adding them to a randomly generated number (normal distribution with a standard deviation of $\left.2.56^{\circ} \mathrm{C}\right)$. The standard deviation of daily temperature variations in a month was extracted from the CliFlo daily temperature statistics (Mt. Potts Station, May 2009September 2012). Inclusion of this 'daily' temperature variability was important for capturing the turbulent heat fluxes with monthly-mean temperatures.

The model calculates the energy available for ablation $\left(Q_{M}\right)$ using the following equation:

$$
Q_{M}=I(1-\alpha)+L \downarrow+L \uparrow+Q_{H}+Q_{E}+Q_{R}+Q_{G}
$$

where $I$ is the incoming shortwave radiation, $\alpha$ is the surface albedo, $L \downarrow$ is the incoming longwave radiation, $L \uparrow$ is the outgoing longwave radiation, $Q_{H}$ and $Q_{E}$ are the sensible and latent heat fluxes, $Q_{R}$ is the heat supplied by rain, and $Q_{G}$ is the ground heat flux. All heat exchanges are in units of $\mathrm{W} \mathrm{m}^{-2}$. Positive values of radiative and turbulent fluxes indicate energy available for melting snow and ice, and negative values indicate a loss of energy. $Q_{R}$ was calculated assuming that precipitation temperature is equal to air temperature (Oerlemans, 1992) and $Q_{G}$ was set at $1 \mathrm{~W} \mathrm{~m}^{-2}$ (Neale and Fitzharris, 1997). I will now discuss each of the main components of the energy balance equation (Equation 3.1).

\subsubsection{Shortwave radiation}

Most of the heat available at the Earth's surface is dependent on the Sun's energy. Solar radiation lies almost entirely between 0.15 and $4 \mu \mathrm{m}$, whereas terrestrial radiation is 
infrared and lies between 4 and $120 \mu \mathrm{m}$, hence separating them into shortwave and longwave radiation. The amount of shortwave radiation that influences a location is primarily dependent on the time of day, time of year, changes in Milankovitch cycles, latitude, topographic shading, and cloudiness.

Incoming shortwave radiation $(I)$ contains direct and diffuse components (Oerlemans, 1992) from calculated radiation at the top of the atmosphere (Eisenman and Huybers, 2006).

$$
I=t_{a} t_{c}\left(I_{d i f}+I_{d i r}\right)
$$

where $t_{a}$ and $t_{c}$ are transmissivity for air and clouds respectively, and $I_{d i f}$ and $I_{d i r}$ are the diffuse and direct components of insolation respectively (Oerlemans, 1992; Anderson et al., 2010). The transmissivity for air was calculated using:

$$
t_{a}=(0.79+0.000024 z)\left[1-\frac{0.08 \frac{\pi}{2}-\varphi_{\text {sun }}}{\frac{\pi}{2}}\right]
$$

where $z$ is the surface elevation ( $\mathrm{m}$ asl), and $\varphi_{\text {sun }}$ is the solar azimuth angle (radians). The transmissivity for clouds was calculated using:

$$
t_{c}=1-(0.41-0.000065 z) n-0.37 n^{2}
$$

where $n$ is cloudiness. The cloudiness parameterisation follows that used in Anderson et al. (2010) where a fitted cubic relationship describes the relationship between cloudiness and the fraction of clear-sky to measured radiation (Hock, 2005). For clear-sky conditions $I_{d i f}$ is typically $\sim 15 \%$ of the total incoming shortwave radiation and for overcast conditions $\sim 85 \%$. Diffuse radiation was calculated using:

$$
I_{d i f}=[0.8-0.65(1-n)] S \sin \left(\frac{\pi}{2}-Z\right)
$$


where $S$ is the solar constant and $Z$ is the solar zenith angle. $S$ is described as:

$$
S=\Psi_{a}\left[1+0.034 \cos \left(\frac{2 \pi N}{365}\right)\right]
$$

where $\Psi_{a}$ is the atmospheric clear-sky transmissivity and $\mathrm{N}$ is the day number (Oerlemans, 1992). For unshaded areas, direct radiation and the cosine of the angle of incidence between the slope normal and the solar beam $(\theta)$ can be calculated using:

$$
I_{d i r}=(0.2+0.65) *(1-n) S \cos \theta
$$

$$
\cos \theta=\cos (\beta) \cos Z+\sin (\beta) \sin Z \cos \left(\varphi_{\text {sun }}-\varphi_{\text {slope }}\right)
$$

where $\beta$ is slope and $\varphi_{\text {slope }}$ is the slope azimuth angle (aspect). The amount of outgoing shortwave radiation depends on the surface albedo. The parameterisations used to estimate albedo are described below.

\subsubsection{Albedo}

Two different albedo parameterisations were used in this thesis because two different timesteps are used. Simulations with a daily timestep (i.e. Chapter 5) used a mode where albedo decays with time (days) since the last snowfall (Oerlemans and Knap, 1998) (Table 3.4). This time-dependent parameterisation has been evaluated using measurements of incoming and reflected radiation data from Brewster Glacier, New Zealand (Anderson et al., 2010). All other simulations used a mode where albedo is dependent on snow thickness and the elevational difference from the modelled equilibrium-line altitude (ELA) (Oerlemans, 1992). This second mode is applied to models with monthly timesteps, where a time-dependent albedo would not be appropriate.

The time-dependent albedo parameterisation depends on the snow cover and different 
albedo values for fresh snow $\left(\alpha_{\text {frsnow }}\right)$, firn $\left(\alpha_{\text {firn }}\right)$, and ice $\left(\alpha_{i c e}\right)$ (Oerlemans and Knap, 1998) (Table 3.1).

$$
\alpha_{\text {snow }}=\alpha_{\text {firn }}+\left(\alpha_{\text {frsnow }}-\alpha_{\text {firn }}\right) e^{-\frac{s}{t *}}
$$

where $s$ is the time since the last snowfall occurred (days) and $t *$ is a timescale (days) determining how fast the snow albedo approaches the firn albedo after snowfall (Oerlemans and Knap, 1998). $\alpha_{\text {snow }}$ is then used to calculate $\alpha$ :

$$
\alpha=\alpha_{\text {snow }}+\left(\alpha_{\text {ice }}-\alpha_{\text {snow }}\right) e^{-\frac{D_{\text {snow }}}{d *}}
$$

where $D_{\text {snow }}$ is snow depth (metres in snow-water equivalent or m s.w.e.) and $d *$ is a characteristic scale for snow depth (m s.w.e.). A difference in albedo of redistributed snow in the avalanche model was not included. These schemes are all empirically derived, and the key parameters (e.g. $\left.\alpha_{\text {snow }}\right)$ are somewhat uncertain and therefore were evaluated in sensitivity tests.

Alternatively, when using the ELA-dependent albedo parameterisation (Oerlemans, 1992), the 'background' albedo, $\alpha_{b}$, was first determined:

$$
\alpha_{b}=0.43+\frac{0.18}{\pi} \arctan \left(\frac{z-z_{E L A}+300}{200}\right)
$$

where $z$ is surface elevation and $z_{E L A}$ is the equilibrium line altitude ( $\mathrm{m}$ asl). The albedo, $\alpha$, is then calculated, where the albedo of snow, $\alpha_{\text {snow }}$, is equal to 0.72 (Table 3.1).

$$
\alpha=\alpha_{\text {snow }}-\left(\alpha_{\text {snow }}-\alpha_{b}\right) e^{-5 D_{\text {snow }}}
$$

For Chapters 4 and 6 and Appendix A areas of the glacier with no snow cover have an albedo set to the ice albedo value ( $\alpha_{i c e}$, set to 0.34$)$. 


\subsubsection{Longwave radiation}

Incoming longwave radiation comes from the surrounding terrain (e.g. heated rocky slopes) as well as the atmosphere (e.g. cloudiness and relative humidity). Unlike shortwave radiation, longwave radiation also depends on the air temperature (Equation 3.13). The viewfield for each cell specifies the amount of surrounding terrain and atmosphere at a particular location. The relative amounts are adjusted in response to ice thickness growth or decay. Incoming longwave radiation $L \downarrow$ is calculated using the Stefan-Boltzmann constant $\sigma\left(\mathrm{J} \mathrm{K}^{-4} \mathrm{~m}^{-1} \mathrm{~s}^{-1}\right)$, effective atmospheric emissivity $\epsilon_{a}$, atmospheric temperature (approximated by $T_{a}$ ), and the terrain viewfield $V_{f}$ in the atmospheric (first) component, and, in addition, terrain emissivity $\epsilon_{t}$ and terrain temperature $T_{t}$ in the terrain (second) component (Corripio, 2003; Plummer and Phillips, 2003; Anderson et al., 2010).

$$
L \downarrow=\left(\sigma \epsilon_{a} T_{a}^{4}\right)\left(V_{f}\right)+\left(\sigma \epsilon_{t} T_{t}^{4}\right)\left(1-V_{f}\right)
$$

Terrain temperature $T_{t}$ is taken as atmospheric temperature for cells that are not snow- or ice-covered and as $273.15 \mathrm{~K}$ for cells with snow or ice. Terrain emissivity $\epsilon_{t}$ is set to 0.4 (Plummer and Phillips, 2003).

Outgoing longwave radiation $L \uparrow$ is calculated using:

$$
L \uparrow=-\epsilon_{\text {snow }} \sigma T_{\text {surf }}^{4}
$$

where $\epsilon_{\text {snow }}$ is snow emissivity (set to 0.99 ) and $T_{\text {surf }}$ is the surface temperature (set to $273.15 \mathrm{~K})$. I assume that the glacier surface is at the melting point, which is appropriate for temperature glaciers (Paterson, 1994; Ohmura, 2001), and this assumption makes the resulting $L \uparrow$ a constant equal to $317 \mathrm{~W} \mathrm{~m}^{-2}$ (Plummer and Phillips, 2003). 


\subsubsection{Turbulent heat fluxes}

Turbulent heat fluxes $\left(Q_{H}\right.$ and $\left.Q_{E}\right)$, which can make up half or more of the energy available for melt in maritime environments (Anderson et al., 2010), were calculated using the bulk method (Oerlemans, 1992; Klok and Oerlemans, 2002; Oerlemans and Grisogono, 2002).

$$
Q_{H}=\rho_{a} c_{p} k_{H} U_{w}\left(T_{a}-T_{\text {surf }}\right)
$$

where $\rho_{a}$ is the density of ambient air, $c_{p}$ is the specific heat capacity of ambient air $(\mathrm{J}$ $\left.\mathrm{kg}^{-1} \mathrm{~K}^{-1}\right), k_{H}$ is the bulk transfer coefficient for heat and $U_{w}$ is wind speed $\left(\mathrm{m} \mathrm{s}^{-1}\right)$.

$$
Q_{E}=0.622 \rho_{a} k_{E} U_{w} \lambda_{v} \frac{\left(q-q_{s}\right)}{p}
$$

where $k_{E}$ is the bulk transfer coefficient for vapour, $\lambda_{v}$ is the latent heat of vaporisation for water $\left(\mathrm{J} \mathrm{kg}^{-1}\right), q$ is the vapour density of ambient air $\left(\mathrm{kg} \mathrm{m}^{-3}\right), q_{s}$ is the vapour pressure on a melting surface $(610.8 \mathrm{~Pa})$, and $p$ is the air pressure $(\mathrm{Pa})$.

$$
k_{H}=\frac{k_{0}^{2}}{\log \left(\frac{z}{z_{0}}\right) \log \left(\frac{z}{z_{0 H}}\right)}\left(1-5.2 R_{b}\right)^{2}
$$

where $k_{0}$ is the von Kármán's constant (set to 0.4), $z_{0}$ is the roughness length for wind (defined by $Z_{\text {snow }}$ and $Z_{i c e}, \mathrm{~m}$ ), $z_{0 H}$ is the roughness length for sensible heat (m), and $R_{b}$ is the Richardson stability criterion (Oerlemans, 1992; Anderson et al., 2010). The bulk transfer coefficient for heat (and similarly for vapour) depends on the roughness length for wind. Roughness lengths are difficult to measure and parameterise and have typically been used as a tuning parameter. Here we use previously published values for the roughness length of snow $Z_{\text {snow }}$ and ice $Z_{\text {ice }}$ (Table 3.1). The bulk transfer coefficients use the Richardson number stability criterion to keep the bulk Richardson number from being unrealistically high (Oke, 1987; Anderson et al., 2010). 
In summary, the EBM used in this thesis was tailored to the specific research question in each chapter. The timestep was prescribed as daily or monthly for present-day or palaeosimulations, respectively. The albedo parameterisation and input climate data that were used in the model depended on the timestep. The ability of the EBM to accommodate different model resolutions, timesteps, and subroutines (such as the MTD model) allowed me to apply the EBM to all of the studies presented in this thesis.

Table 3.1 Energy balance model parameters, values, and references.

\begin{tabular}{llll}
\hline Parameter & Symbol & Values & Source \\
\hline Snow/rain temperature threshold & $T_{\text {snow }}$ & $1{ }^{\circ} \mathrm{C}$ & (Anderson et al., 2006) \\
Temperature lapse rate & $\frac{d T}{d z}$ & variable ${ }^{\circ} \mathrm{C} \mathrm{km}^{-1}$ & refer to individual chapters \\
Albedo ELA & $\alpha_{E L A}$ & $2100 \mathrm{~m}$ asl & (Oerlemans, 1992) \\
Roughness parameter for ice & $Z_{\text {ice }}$ & $0.004 \mathrm{~m}$ & (Anderson and Mackintosh, 2012) \\
Roughness paramter for snow & $Z_{\text {snow }}$ & $0.001 \mathrm{~m}$ & (Brock et al., 2006) \\
Albedo of snow & $\alpha_{\text {snow }}$ & 0.72 & (Oerlemans, 1992) \\
& & 0.75 & Chapter 6 \\
Albedo of fresh snow & $\alpha_{\text {frsnow }}$ & 0.9 & (Oerlemans and Knap, 1998) \\
Albedo of firn & $\alpha_{\text {firn }}$ & 0.53 & (Oerlemans and Knap, 1998) \\
Albedo of ice & $\alpha_{\text {ice }}$ & 0.34 & (Oerlemans and Knap, 1998) \\
Albedo characteristic depth & $d *$ & $11 \mathrm{~mm}$ s.w.e. & (Oerlemans and Knap, 1998) \\
Albedo characteristic time scale & $t *$ & 21.9 days & (Oerlemans and Knap, 1998) \\
Maximum snow depth & $D_{\text {max }}$ & 0.2 or 0.4 m s.w.e. & refer to individual chapters \\
Model time step & $d t$ & variable & see Table 3.4 \\
\hline
\end{tabular}

\subsection{Gravitational snow mass transport and deposition model}

Snow avalanches contribute snow mass directly to glaciers located below areas of steep terrain (Lossev, 1967; Kotlyakov, 1973; Paterson, 1994; Purdie et al., 2011a). Small, frequent avalanches result in relatively thick snow deposits, typically near the base of steep valley walls, and can allow glaciers to persist even when their glacier surface is below the local ELA (Hewitt, 2005, 2011). Without avalanche processes, these low-elevation glaciers would not be sustainable and would retreat. Glaciers that receive avalanche accumulation are typically avoided for studying because of mass balance complexity as well as field hazards and difficult accessibility. However, avalanche-fed glaciers are common in the central Southern Alps where uplift, faulting, landsliding, and glacial and fluvial processes have exposed steep slopes that are prone to small, frequent snow avalanches. Because of this, the influence of avalanche accumulation on glaciers in New Zealand 
needs to be better understood, especially in terms of how these glaciers response to climate change. Simple avalanche models have been used to simulate the effect of avalanche deposits on modelled glacier mass balance in Europe (Machguth et al., 2006; Dadic et al., 2008), and with proper tuning and evaluation, can be applied to studies in the Southern Alps.

To parameterise small snow avalanches, I employ the gravitational MTD model following Gruber (2007). This parameterisation requires minimal input data, little computational time, and has been shown to produce appropriate snow distribution patterns on glaciers such as Vadret da Misaun (Gruber, 2007) and Claridenfirn (Machguth et al., 2006). The gravitational MTD used here was chosen over another snow avalanching model known as SnowSlide (Bernhardt and Schulz, 2010). This is because the Gruber (2007) model provides a larger number of adjustable and testable parameters, allowing for an improved fit between modelled and measured snow deposition.
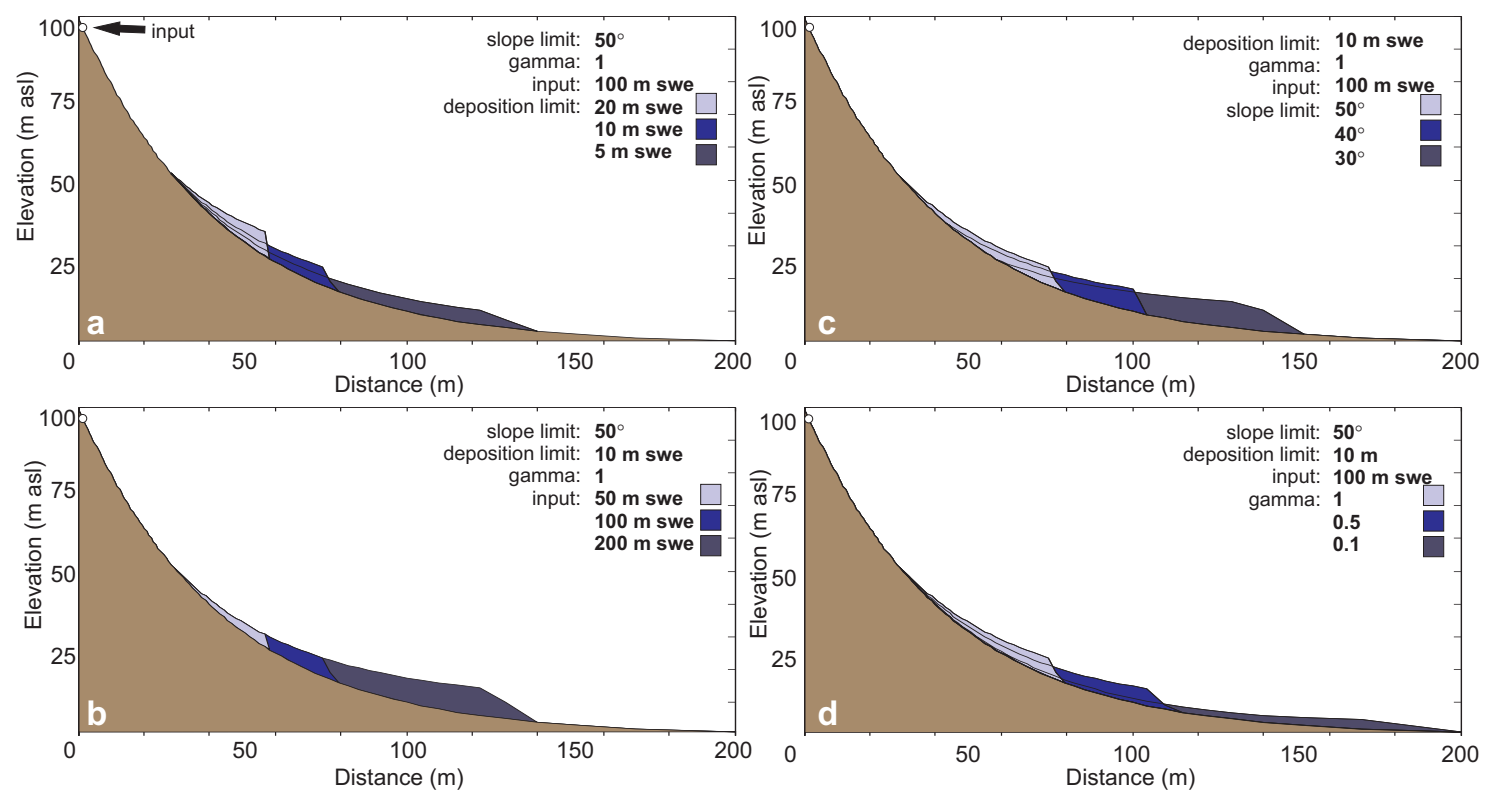

Figure 3.2 One-dimensional example of snow redeposition from the MTD parameterisation modified from Gruber (2007). Panels show avalanche profiles resulting from changing parameter values, a) increasing deposition limit $\left(D_{\text {lim }}\right)$ leads to thicker, less-extensive deposits, b) increasing total incoming snow will increase the extent of the avalanche deposit, c) increasing slope limit $\left(\beta_{\text {lim }}\right)$ causes snow to stay close to the valley wall, and d) increasing gamma $(\gamma)$ also results in less-extensive, thicker deposits. For these tests, the total incoming snow is a $100 \mathrm{~m}$ s.w.e. column deposited at the circle labelled 'input', which is an unrealistic process but helps to highlight the shape of the deposit. 
eter value choice to improve the fit between modelled and measured snow depths from a GPR survey. Chapter 6 and Appendix A use parameter values that were appropriate for the topography and model timestep. It is likely that many other glaciers in the Southern Alps of New Zealand are receiving accumulation through gravitational snow redistribution processes and this model could be used to improve the understanding of glacier mass balance and catchment-scale snow distribution patterns in other areas. I will now describe the MTD model components.

The model begins with a subroutine designed to 'fill' any holes in the DEM to ensure that the topography is 'drainable'. This process is also referred to as 'iterative sink-filling'. There are two main, slope-dependent components in the gravitational MTD model; removal and deposition. The percentage of removed snow (or mobile mass $M_{m}$ (m s.w.e.)) in the model is zero for cells with a slope of less than $40^{\circ}$ and increases linearly to $100 \%$ for cells steeper than $70^{\circ}$. The $M_{m}$ is the excess snow mass available for redeposition, and all remaining snow stays in place.

The deposition mechanism computes the snow depth $\left(D_{\text {snow }}\right)$ including the original snow cover and $M_{m}$ using the specified $D_{\max }$ curve:

$$
D_{\text {snow }}= \begin{cases}M_{m} & \text { if } M_{m}<D_{\max } \\ D_{\max } & \text { if } M_{m} \geq D_{\max }\end{cases}
$$

where $D_{\max }$ is the maximum amount of snow deposition allowed in a cell (m s.w.e.), which is ultimately slope-dependent (Equation 3.19). The simple function below describes the relationship between $D_{\max }$ and the local slope angle $\beta\left(^{\circ}\right)$ :

Table 3.2 Mass transport and deposition model parameter setup.

\begin{tabular}{lll}
\hline Parameter & Symbol & Values \\
\hline Maximum snow depth limit (m s.w.e.) & $D_{\text {lim }}$ & $0.4,0.6,0.8$ \\
Maximum slope for snow deposition $\left(^{\circ}\right)$ & $\beta_{\text {lim }}$ & $35,40,45$ \\
Slope influence & $\gamma$ & $0.075,0.1,0.125$ \\
\hline
\end{tabular}




$$
D_{\text {max }}= \begin{cases}\left(1-\left(\frac{\beta}{\beta_{\text {lim }}}\right)^{\gamma}\right) D_{\text {lim }} & \text { if } \beta<\beta_{\text {lim }} \\ 0 & \text { if } \beta \geq \beta_{\text {lim }}\end{cases}
$$

where $D_{\text {lim }}$ is the maximum deposition limit (where $\beta=0^{\circ}$ ), $\gamma$ alters the shape of the deposition-slope curve and $\beta_{\text {lim }}$ is the maximum slope at which snow begins to deposit. The parameters explored in this model alter the deposition-slope curve (Table 3.2) shown in Figure 3.3, where $D_{\text {lim }}$ sets the y-axis intercept and $\beta_{\text {lim }}$ sets the x-axis intercept. The change in parameter values alters the shape and extent of snow avalanche deposits (Figure 3.2), which influences the goodness of fit between measured and modelled snow depth and distribution (see Chapter 5).
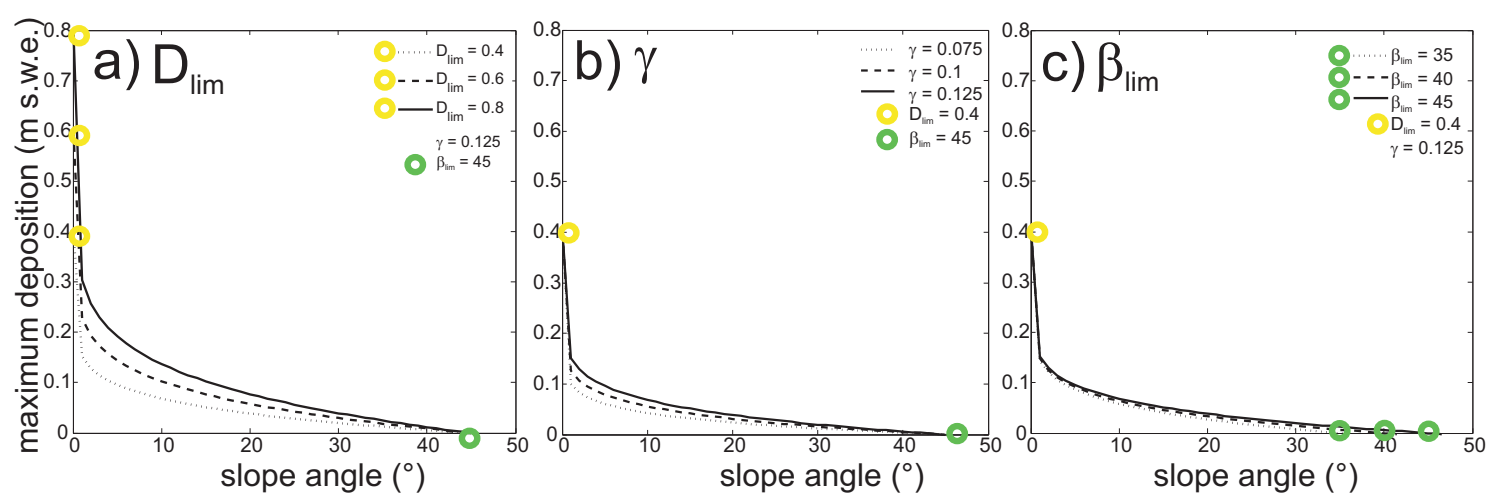

Figure 3.3 Plots of slope angle versus maximum deposition to show parameter influences on the slope-deposition curve. Parameters evaluated are a) $D_{\text {lim }}$ (yellow circles) set to 0.4 (dotted line), 0.6 (dashed line), and 0.8 (solid line) m s.w.e., b) $\gamma=$ 0.075 (dotted line), 0.1 (dashed line), and 0.125 (solid line), and c) $\beta_{\text {lim }}$ (green circles) set to 35 (dotted line), 40 (dashed line), and $45^{\circ}$ (solid line).

Without the MTD model, the snow accumulation in the EBM increases linearly with elevation as a function of the temperature lapse rate. Daily modelled snowfall depends also on precipitation amount, snow temperature threshold, and air temperature at that timestep. My GPR data show that simulated snow distribution on a glacier névé adjacent to steep slopes $\left(>45^{\circ}\right)$ is greatly underestimated without the MTD model. The modelled end of summer mass balance for the Cameron Glacier, in the absence of the MTD model, shows ablation over the majority of the glacier surface (Figure 3.4c-d), which is consistent with inferences that this glacier lies largely below the local estimated ELA (2100 $\mathrm{m}$ asl) (Chinn, 1995; Willsman et al., 2010). In other words, without the avalanche-derived snow input, this glacier would not be able to sustain its current size. Modelling the snow depth 
distribution appropriately is therefore critical for simulating the present-day glacier, as well as its past behaviour.
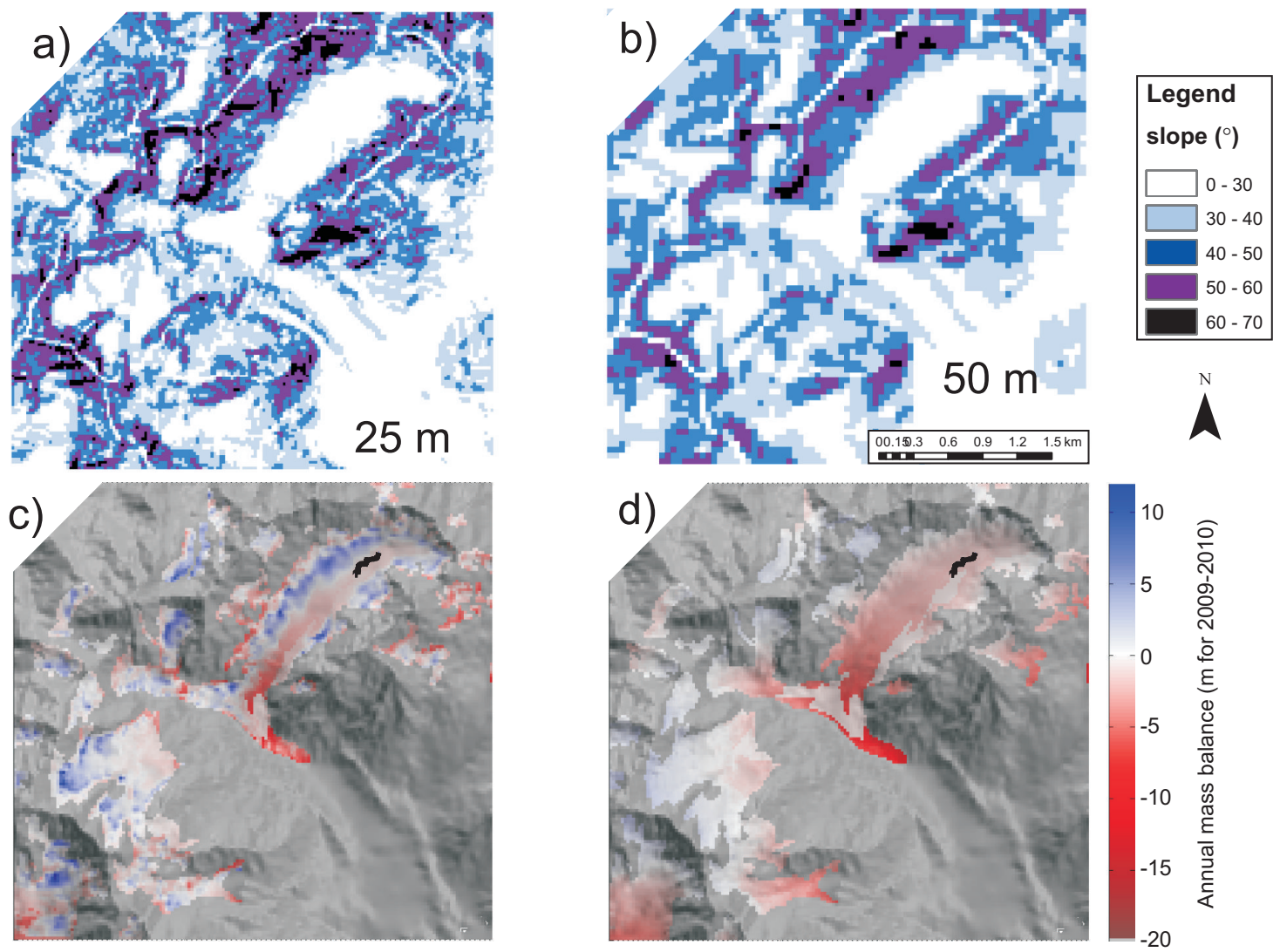

Figure 3.4 Cameron Glacier model domain showing a) slope $\left(^{\circ}\right)$ at $25 \mathrm{~m}$ grid resolution, b) slope at $50 \mathrm{~m}$ grid resolution, c) modelled mass balance $\left(\mathrm{m} \mathrm{a}^{-1}\right)$ using the MTD model, and d) modelled mass balance without the MTD model for the 2009-2010 simulation. The black line represents part of the end of summer snowline measured on 19 March, 2010 using a hand-held GPS.

I adjusted the $D_{\text {lim }}$ and $\beta_{\text {lim }}$ parameter values from those used in Chapter 5 to values that enhance snow dispersion in Chapter 6. This adjustment helped to achieve a similar mass balance distribution between the EBM run at a monthly timestep, with a $50 \mathrm{~m}$ grid resolution, and the EBM run at a daily timestep, with a $25 \mathrm{~m}$ resolution, for the Cameron Glacier. When ice-flow dynamics are included in the monthly EBM, the ice-surface slope decreased through time (Chapter 6). Parameter adjustments also account for slightly lower slope values in the $50 \mathrm{~m}$ than in the $25 \mathrm{~m}$ grid (Figure 3.4a-b). Together these effects meant that the glacier was 'flatter' in a more subdued topography, and consequently, I changed the parameter values from $\beta_{\text {lim }}=35^{\circ}$ and $D_{\text {lim }}=0.4 \mathrm{~m}$ (Chapter 5) to $\beta_{\text {lim }}=45^{\circ}$ and $D_{\text {lim }}=0.2 \mathrm{~m}$ (Chapter 6) so that extensive avalanche deposits were still simulated. 


\subsection{Models that describe glacier flow}

Ice-flow models describe the mechanical movement of ice, based on the Navier-Stokes equation:

$$
\rho_{i c e} \frac{\partial U}{\partial t}+\rho_{i c e}(U \cdot \nabla) U=-\nabla p+\eta \nabla^{2} U+F
$$

where $\rho_{i c e} \frac{\partial U}{\partial t}$ is the rate of change of momentum, $\rho_{i c e}(U \cdot \nabla) U$ is the convective force, $-\nabla p$ is the pressure force, $\eta \nabla^{2} U$ is the viscous force, and $F$ is the external force. By neglecting the inertial terms (because of its slow movement) and assuming incompressability and a constant dynamic viscosity $(\mu)$, the Navier-Stokes equations for fluid flow reduces to the Stokes equations for creeping flow. The left-hand side of Equation 3.20 describes the inertial component and is neglected in the Stokes equations.

$$
0=-\nabla p+\eta \nabla^{2} U+F
$$

The viscous force can be written in terms of the deviatoric stress tensor $\left(\tau_{i j}^{\prime}\right)$. Assuming incompressability $(\nabla \cdot U=0)$ and that the external force, $F$, primarily represents gravity $\left(\rho_{i c e} g\right)$, the Stokes equation can be written as:

$$
0=-\nabla p+\nabla \cdot \tau_{i j}^{\prime}+\rho_{i c e} g
$$

To reduce computational time associated with the full-Stokes solution, many ice-flow models use a series of simplified equations, known as the shallow-ice approximation (SIA). The SIA was originally developed for describing large-scale flow dynamics in ice sheets, where the ice thickness is small compared to the horizontal extent (e.g. aspect ratio of glacier thickness to width is $<0.2$ ) (Leysinger Vieli and Gudmundsson, 2004) and the ice surface slopes and bed slopes are gentle (bed slope $<11^{\circ}$ ) (Le Meur et al., 2004; Egholm et al., 2011). The small aspect ratio is the dimensionless parameter upon which 
the scale analysis is based. The applicability of this scaling depends on the similarity between the ratio of ice thickness to aerial extent and the ratio of vertical to horizontal velocities (Baral et al., 2001; Le Meur et al., 2004). This approximation is therefore less appropriate for ice divides or areas with steep bed slopes.

In the most commonly used zeroth-order SIA, the influences of lateral drag and longitudinal stretching/compression on ice flow are ignored. The longitudinal deviatoric stresses are caused by extensional and compressional flow, which are likely to be important when describing the ice flow of valley glaciers (Egholm et al., 2011). This limitation is acceptable when modelling certain parts of ice sheets (althought it does not work well for ice streams or ice shelves), but can be more problematic for modelling mountain glaciers.

The rugged terrain of mountain ranges presents some challenges for application of the SIA to alpine glaciers (Le Meur et al., 2004; Egholm et al., 2011). For example, this approximation neglects stress terms that are likely to be important for flow of mountain glaciers and ice sheets near their margins. Longitudinal stresses can be significant for glaciers in narrow or steep valleys. In an attempt to make the SIA more appropriate for modelling mountain glaciers, several studies have tried to account for longitudinal stresses. These adjustments either include parameterising the longitudinal deviatoric stresses (Hubbard, 2000) or solving for them directly in second-order SIA models (Baral et al., 2001; Egholm et al., 2011).

Despite the fact that some of the assumptions that underlie the zeroth-order SIA are likely to be incorrect on alpine glaciers, comparisons between the SIA and full-Stokes models have shown similar results (Le Meur et al., 2004). For example, modelled ice extent and thickness are similar between the two approaches when modelling valley glaciers on gentle slopes (Leysinger Vieli and Gudmundsson, 2004). The major differences are in the small-scale velocity estimates generated by the two approaches. It has also been shown that the primary control on glacier evolution is usually the mass balance (Leysinger Vieli and Gudmundsson, 2004). For these reasons, a vertically-integrated 2-D ice-flow model based on the zeroth-order SIA can be used to model past extents of mountain glaciers (Plummer and Phillips, 2003; Kessler et al., 2006; Laabs et al., 2006). 
Ice-flow models can be applied in 1, 2 or 3 dimensions. Flowline models (1-D) capture the basic ice dynamics along a centre flowline of a glacier. Flowline models require predefinition of a central flowline as well as parameterisation of valley geometry, where a valley cross profile is typically described using a trapezium or parabola. This also means that all tributary glaciers must be identified and parameterised as well. These parameterisations can lead to uncertainties in the results because, for example, the glacier width might evolve as ice thickens in a way that is not easy to parameterise. 1-D flowline models would also not be able to account for complex snow distribution caused by avalanching or snow drift, and are intrinsically less useful for comparing against geomorphological evidence, which is best presented in map-plan (2-D) form.

I chose to use the 2-D, zeroth-order, vertically-integrated SIA model for several reasons; First, the valleys chosen in this thesis have relatively low angle slopes $\left(5-15^{\circ}\right)$, for which the longitudinal stresses should be relatively low (Le Meur et al., 2004). Second, the resulting simulated glacier extents are in two dimensions (plan view) and are directly comparable with mapped moraines. Third, the vertically-integrated SIA is computationally fast, allowing for long integrations at relatively high resolutions.

\subsubsection{Ice-flow model}

The modelled ice velocity is comprised of two components; sliding and deformation. Both sliding and deformation velocity in this work follow the equations suggested by Kessler et al. (2006). In this 2-D model, the vertical velocity profile is integrated, which decreases computational time. The ice velocity caused by internal deformation $\left(\vec{U}_{d}\right)$ is calculated using:

$$
\vec{U}_{d}=\frac{2}{5} A H \vec{\tau}_{b}^{n}
$$

where $A$ is the coefficient of Glen's flow law, set to $3.17 \mathrm{e}^{-25} \mathrm{~Pa}^{-3} \mathrm{~s}^{-1}, H$ is ice thickness $(\mathrm{m}), \vec{\tau}_{b}$ is the gravitational driving stress $\left(\vec{\tau}_{b}=\rho_{i c e} g H \nabla z\right)$, and $n$ is Glen's flow law exponent, set to 3. The sliding velocity follows the empirical formulation of Kessler et al. 


$$
\vec{U}_{s}=U_{c} e^{1-\frac{\tau_{c}}{\tau_{b}}}
$$

where $U_{c}$ is a typical sliding velocity ( $\mathrm{m} \mathrm{a}^{-1}$, Table 3.3$)$ and $\vec{\tau}_{c}$ is the characteristic gravitational driving stress $\left(10^{5} \mathrm{~Pa}\right.$, Kessler et al. (2006)). In Chapter 6 where the Cameron Glacier is modelled to its Holocene positions, $U_{c}$ is made to vary with elevation to improve the fit in ice thickness to the height of late-Holocene lateral moraines. The $U_{c}$ is set to $10 \mathrm{~m} \mathrm{a}^{-1}$ for elevations greater than $1700 \mathrm{~m}$ asl in the model, and then increases linearly to $60 \mathrm{~m} \mathrm{a}^{-1}$ for elevations lower than $1500 \mathrm{~m}$ asl. This imposed variability seems sensible because, at elevations below $1500 \mathrm{~m}$ asl, the valley floor flattens out and contains a layer of debris, which likely results in an increase in basal motion. In Chapter 4 where the Irishman glacier 13 ka position is simulated, the characteristic sliding velocity $U_{c}$ is set to $20 \mathrm{~m} \mathrm{a}^{-1}$, following Kessler et al. (2006).

Table 3.3 Ice-flow model parameter options and the range of published values for Glen's flow law coefficient.

\begin{tabular}{llll}
\hline Parameter & Symbol & Value & Source \\
\hline Typical sliding velocity & $U_{c}$ & $20 \mathrm{~m} \mathrm{a}^{-1}$ & (Kessler et al., 2006) \\
& & $10-60 \mathrm{~m} \mathrm{a}^{-1}$ & Chapter 6 \\
Characteristic gravitational driving stress & $\vec{\tau}_{c}$ & $10^{5} \mathrm{~Pa}$ & (Kessler et al., 2006) \\
Ice density & $\rho_{i c e}$ & $917 \mathrm{~kg} \mathrm{~m}^{-3}$ & (Paterson, 1994) \\
Glen's flow law coefficient & $A$ & $1 \mathrm{e}^{-17} \mathrm{~Pa}^{-3} \mathrm{a}^{-1}$ & This thesis (displayed in text) \\
& & $3.17 \mathrm{e}^{-25} \mathrm{~Pa}^{-3} \mathrm{~s}^{-1}$ & This thesis (different units) \\
\hline Other published values for Glen's & $A$ & $2 \mathrm{e}^{-24} \mathrm{~Pa}^{-3} \mathrm{~s}^{-1}$ & (Le Meur and Vincent, 2003) \\
& & $1.3 \mathrm{e}^{-24} \mathrm{~Pa}^{-3} \mathrm{~s}^{-1}$ & (Le Meur et al., 2004) \\
& & $6.8 \mathrm{e}^{-24} \mathrm{~Pa}^{-3} \mathrm{~s}^{-1}$ & (Kessler et al., 2006) \\
& & $4 \mathrm{e}^{-24} \mathrm{~Pa}^{-3} \mathrm{~s}^{-1}$ & (Cuffey and Paterson, 2010) \\
\hline
\end{tabular}

The continuity equation (Equation 4.4) was used to evolve the glacier geometry through time. Using a staggered grid, the ice velocities $\left(\vec{U}_{d}+\vec{U}_{s}\right)$ were calculated at points offset from where the ice thickness change was calculated. The flux gradients were then used to update the ice thickness using a forward explicit time-step. The evolving time-step was calculated using the stability criterion following Hindmarsh and Le Meur (2001).

To minimise the error related to ice thickness at the boundaries, I applied an ice-flux correction. The correction was applied at every timestep to find areas where the ice flux 
exceeded the ice thickness at a cell (Plummer and Phillips, 2003). This can occur at modelled glacier margins where the ice-free ground elevation of a cell is greater than the ice-surface elevation in an adjacent cell. In the correction, the 'phantom ice' mass was identified, removed from the glacier, and moved back to its original cell (Plummer and Phillips, 2003).

\subsection{Model applications}

One overarching goal of this thesis is to understand the behaviour and sensitivity of four glaciers that deposited well studied moraine sequences in New Zealand. The combination of models that I used to simulate palaeo-glacier extents was designed for addressing the research questions (outlined in Section 2.7). The present-day topography, glaciology, and climatology are useful benchmarks for evaluating changes in past climate from today, which is why I used present-day topography and climatology in these simulations. In the steady-state model runs, a glacier length is specified by targetting a terminal moraine position and the model output provides an envelope of temperature and precipitation change combinations. The envelope can be further restricted by limiting the precipitation change to within a particular range (e.g. \pm 20 or $50 \%$ ). Due to differences in glacier response time, the duration of each steady-state run was varied between 240 (Irishman glacier) to 300 years (Cameron Glacier). The steady-state simulations allow me to estimate the magnitude of past temperature and precipitation changes that are consistent with the Lateglacial and Holocene ice advances, thus addressing the first research question (i.e. quantifying past climate Section 2.7).

Two of the studies in this thesis include transient simulations, where climate is varied and glacier extent continually adjusts during the model run. In Chapter 4 where the Irishman glacier was simulated, I forced the model with a previously published chironomid-based temperature reconstruction from Boundary Stream Tarn (Vandergoes et al., 2008), with no change in precipitation, to assess the fit between the modelled ice extent and the glacial geomorphic record. The Antarctic Cold Reversal (ACR) cold peak in the chironomid record caused an advance in the modelled glacier terminus to within $100 \mathrm{~m}$ of the well- 
dated ACR moraine in Irishman Stream. In Chapter 6, I forced the glacier model with present-day interannual natural climate variability using 'white noise' (Oerlemans, 2000; Roe, 2011). This approach allowed me to examine the question of whether the Holocene glacier fluctuations in the Cameron valley were caused by climate shifts, or alternatively, from interannual stochastic variability in an steady climate.

Table 3.4 Model information summary for comparison between the different studies.

\begin{tabular}{lllll}
\hline & Ch. 4 & Ch. 5 & Ch. 6 & App. A \\
\hline Location & Irishman & Cameron & Cameron & Whale \\
Time period & Lateglacial & $2009-2010$ & Holocene & Lateglacial \\
Timestep & monthly & daily & monthly & monthly \\
DEM resolution & $25 \mathrm{~m}$ & $25 \mathrm{~m}$ & $50 \mathrm{~m}$ & $100 \mathrm{~m}$ \\
DEM size & $241 \times 201$ & $161 \times 169$ & $180 \times 184$ & $71 \times 101$ \\
MTD & - & Yes & Yes & - \\
EBM & Yes & Yes & Yes & Yes \\
Albedo mode & ELA & time & ELA & ELA \\
Debris cover & - & included & - & - \\
Ice-flow & Yes & - & Yes & Yes \\
\hline
\end{tabular}

Each model includes various assumptions and uncertainties. Parameter values were varied in order to (1) provide minimal tuning to improve the fit between modelled ice extent and the glacial geomorphic record, (2) explore model sensitivity, and (3) estimate uncertainty in the palaeoclimate reconstructions. Parameter testing was also used in the snow mass transport and deposition model to achieve an optimal fit between measured and modelled snow distribution (Chapter 5) for the present-day. Sensitivity and parameter tests provide means of quantifying uncertainties in model results for palaeo-glacier simulations. In turn, these results allow a first-order assessment of uncertainty to be placed on the palaeoclimate estimates.

\subsection{Summary}

Various models have been employed to study past glacier extents and the associated climate. I used three models in this thesis to simulate past glaciers: a distributed energybalance model, a snow transport and deposition model, and a 2-D ice-flow model. Each model contains a degree of approximation, and sensitivity tests allow the affect of these 
uncertainties to be quantified in terms of the resulting palaeoclimate estimates. The intermediate level of complexity and fast computational execution of the models used here have allowed for hundreds of individual runs, which represent (albeit in a simplified way) relatively complex physical processes and a suite of different conditions. These models were chosen with the aims and research questions of this thesis in mind (Section 2.7). Together, the work within this thesis attempts to address some important questions about glaciers, moraines, and past climate. 


\section{Chapter 4}

\section{Evaluation of Lateglacial temperatures in the Southern Alps of New Zealand based on glacier modelling at}

Irishman Stream, Ben Ohau Range

\section{Abstract}

Climate proxy records from the middle to high latitude Southern Hemisphere indicate that a Lateglacial $(15,000$ - 11,500 years ago) climate reversal, approximately coeval with the Antarctic Cold Reversal (ACR), interrupted a warming trend during deglaciation. In New Zealand, some palaeoclimate proxy records indicate a cool episode during the ACR (ca 14,500 to 12,500 years ago), while others do not express a significant change in climate. Recently published moraine maps and ages present an opportunity to improve the palaeoclimate interpretation through numerical modelling of glaciers. We use a coupled energy-balance and ice-flow model to quantify palaeoclimate from past glacier extent constrained by mapped and dated moraines in the headwaters of Irishman Stream, a highelevation catchment in the Southern Alps. First, a suite of steady-state model runs is used to identify the temperature and precipitation forcing required to fit the modelled glacier to well-dated Lateglacial moraine crests. Second, time-dependent glacier simulations forced by a nearby proxy temperature record derived from chironomids are used to assess the fit with the glacial geomorphic record. Steady-state experiments using an optimal parameter set demonstrate that the conditions under which the 13000 year old moraine formed were $2.3-3.2^{\circ} \mathrm{C}$ colder than present with the range in temperature corresponding to a $\pm 20 \%$ variance in precipitation relative to the present-day. This reconstructed climate change relative to the present-day corresponds to an equilibrium-line altitude of ca $2000 \pm 40 \mathrm{~m}$ above sea level (asl), which is ca $400 \mathrm{~m}$ lower than present. Time-dependent simulations of glacier length produce ice advance to within $100 \mathrm{~m}$ of the 13000 year old terminal moraine, indicating that the chironomid-based temperature forcing and moraine record 
provide consistent information about past climate. Our results, together with other climate proxy reconstructions from pollen records and marine sediment cores, support the notion that temperatures during the ACR in New Zealand were $\sim 2-3^{\circ} \mathrm{C}$ cooler than today.

\subsection{Introduction}

During the Lateglacial interval $(\sim 15,000$ - 11,500 years ago or $15-11.5 \mathrm{ka})$ in the middle to high latitudes of the southern hemisphere, a warming trend was interrupted by the Antarctic Cold Reversal (ACR, 14.5 - 12.5 ka (EPICA Community Members, 2006)). New Zealand is one of the few locations in the southern middle latitudes where Lateglacial moraines exist. Many examples of Lateglacial moraines in the Southern Alps of New Zealand have been identified (Porter, 1975b; Suggate, 1990; Fitzsimons, 1997), mapped (Birkeland, 1982; Barrell et al., 2011), and some have been dated (e.g., Turney et al., 2007; Kaplan et al., 2010; Putnam et al., 2010a). Transformation of glacier fluctuation records to climate changes is not a trivial process due to several non-climatic influences and is not readily achievable for some types of glacier (e.g., debris-covered or calving, (Winkler et al., 2010; Anderson and Mackintosh, 2012; Chinn et al., 2012)). Porter (1975a) estimated that the Lateglacial equilibrium-line altitude (ELA) in the Tasman River catchment was $500 \pm 50 \mathrm{~m}$ lower than modern, based on an accumulation-area ratio (AAR) analysis of reconstructed glaciers inside the Birch Hill moraine limit. Other proxy records rarely afford quantitative climate estimates. Besides glacial deposits, records that show a prominent cooling during the Lateglacial include sea surface temperature reconstructions from around New Zealand (Pahnke et al., 2003; Barrows et al., 2007a; McGlone et al., 2010), pollen records from upland locations in New Zealand (Burrows and Russell, 1990; McGlone, 1995; Newnham and Lowe, 2000; Turney et al., 2003; McGlone et al., 2004; Vandergoes et al., 2008), and chironomid-derived temperature reconstructions (Vandergoes et al., 2008). Less pronounced climate reversals within or overlapping with the ACR period have also been inferred based on other pollen (Newnham et al., 2007, 2012) and speleothem (Williams et al., 2005) records (see also Alloway et al. (2007)). In this paper, 
we aim to improve our understanding of the Lateglacial climate event in New Zealand using glacier modelling techniques.

\subsubsection{Glaciers as a climate proxy}

Glacier extent depends on the balance between accumulation and ablation (Oerlemans, 2001, 2005). Moraine positions in mountainous regions provide evidence of former glacier extents and may be used to infer past climates. Glacial geomorphic mapping of the central South Island of New Zealand (Barrell et al., 2011) has yielded a high-quality constraint on past ice extents, and several surface exposure dating studies provide ages for the culmination of Lateglacial ice advances (Ivy-Ochs et al., 1999; Kaplan et al., 2010; Putnam et al., 2010a).

We present an application of a 2-D ice-flow and energy-balance model (EBM) to reconstruct temperature and precipitation values for the ACR. We apply these models to a glacier whose extent is delineated by moraines mapped by Kaplan et al. (2010) in the headwaters of Irishman Stream in the central Southern Alps of New Zealand and compare our findings to their AAR reconstructions and other climate proxy records. In experiment 1, we explore the different combinations of temperature and precipitation required to produce a steady-state glacier that most closely matches the moraine record, taking account of uncertainties associated with model parameter choices. In experiment 2, we use a chironomid-derived temperature reconstruction (Vandergoes et al., 2008) to drive our glacier model and test if this climate forcing produces ice extents compatible with the moraine record (Kaplan et al., 2010).

\subsubsection{Study area}

The South Island of New Zealand is dominated by the high axial range of the Southern Alps, which impedes the prevailing westerly winds, resulting in a steep west to east precipitation gradient (Griffiths and McSaveney, 1983; Henderson and Thompson, 1999). Glaciers with fast response times to climate perturbations are abundant in the central 
Southern Alps due to high snowfall rates and steep mountain slopes (Chinn, 1996; Fitzharris et al., 1999). We focus on moraines deposited in the headwaters of Irishman Stream (435' $30^{\prime \prime} S$, 170 03’00”E), located in the Ben Ohau Range (Figure 4.1) (McGregor, 1967; Birkeland, 1982; Kaplan et al., 2010). The dated glacial deposits lie at the edge of a cirque, referred to here as Irishman basin, that comprises the upper $2 \mathrm{~km}$ of Irishman Stream valley. The basin floor, for the most part, slopes gently $\left(\sim 15^{\circ}\right)$ towards the southwest.

Aside from the mapped and dated moraine sequence, there are several reasons why Irishman basin is well-suited for this study. First, Irishman basin is located $<30 \mathrm{~km}$ to the southeast of the most glacierised section of the Southern Alps and is affected by the same regional atmospheric circulation, including the prevailing westerly winds (Kaplan et al., 2010; Chinn et al., 2012). Second, Irishman basin lacks complex terrain and has a shallow gradient, making our use of the shallow ice approximation equations an appropriate model choice (Leysinger Vieli and Gudmundsson, 2004). Third, the basin supported a single glacier with no tributaries, making it a very simple glacier system for ice reconstructions. Fourth, the present-day digital elevation model provides an appropriate topographic boundary condition for the numerical model because the basin is presently ice-free, and the visible bedrock knobs and outcrops on the valley floor indicate little sediment accumulation and hence minor topographic change since deglaciation. Moreover, the $15^{\circ}$ down-valley slope of the basin floor precludes the former existence of large proglacial lakes and calving ice termini. Therefore, we assume glacier fluctuations in this valley directly relate to changes in atmospheric conditions and hence climate over this part of the South Island.

There are several reasons why we believe that the Irishman basin glacier at $13 \mathrm{ka}$ did not contain a significant surface debris cover. Although there are rock glaciers at the headwalls of Irishman basin and the basin has a veneer of rock debris, through which bedrock hills are visible, the Lateglacial moraine is not particularly large, especially the left lateral segment (Kaplan et al., 2010). These features suggest that debris cover of past glaciers in this valley was not sufficient to dramatically affect the albedo/energy balance. Also, present-day Glenmary Glacier, $12 \mathrm{~km}$ west of Irishman basin, is an example of 
a small cirque glacier in a similar setting to that of the $13 \mathrm{ka}$ Irishman glacier that is relatively free of debris-cover.

There are no long-term climate data from Irishman basin. We characterised the present climate by interpolating between data from multiple low-elevation stations and measurements from a temporary climate station that we installed in Irishman basin (4359’30’S, $170^{\circ} 2^{\prime} 57^{\prime}$ E, $2010 \mathrm{~m}$ asl). The station operated over an 11 month period, March 2010 - January 2011, so February values are inferred to be the same as January temperature values to calculate an annual mean temperature of $1.2^{\circ} \mathrm{C}$. Hourly temperatures from the temporary station were averaged into monthly mean temperatures (Table 4.1), with the warmest month at $6.2^{\circ} \mathrm{C}$ (January, 2011) and the coolest month at $-6.1^{\circ} \mathrm{C}$ (June, 2010).

Interpolated precipitation data suggest an annual mean of $1240 \mathrm{~mm}$ (Stuart, 2011) for this location. Although the annual total precipitation surface and monthly mean interpolated precipitation data are based on data from many long-term rain gauges located in the central Southern Alps, we use two nearby stations to provide an indication of precipitation variation at Irishman basin. Mean precipitation data from Twizel, $30 \mathrm{~km}$ to the south (Station numbers 4995, 4996, 4997), from 1973 to 1997 is $\sim 610 \mathrm{~mm} \mathrm{a}^{-1}$ with a standard deviation of $\pm 110 \mathrm{~mm} \mathrm{a}^{-1}(18 \%)$ (National Institute for Water and Atmospheric Research (NIWA), Retrieved 2009-2011). Likewise, mean precipitation data from Aoraki/Mt. Cook village, $30 \mathrm{~km}$ to the north (Station numbers 18125, 4591, 4593), from 1930 to 2011 is $\sim 4100 \mathrm{~mm} \mathrm{a}^{-1}$ with a standard deviation of $\pm 900 \mathrm{~mm} \mathrm{a}^{-1}$ (22\%) (NIWA, Retrieved 2009-2011) (Twizel and Aoraki/Mt. Cook village locations are shown in Figure 4.1). We consider the characteristic present-day precipitation variability to be $\sim 20 \%$, based on the standard deviation from these stations. 


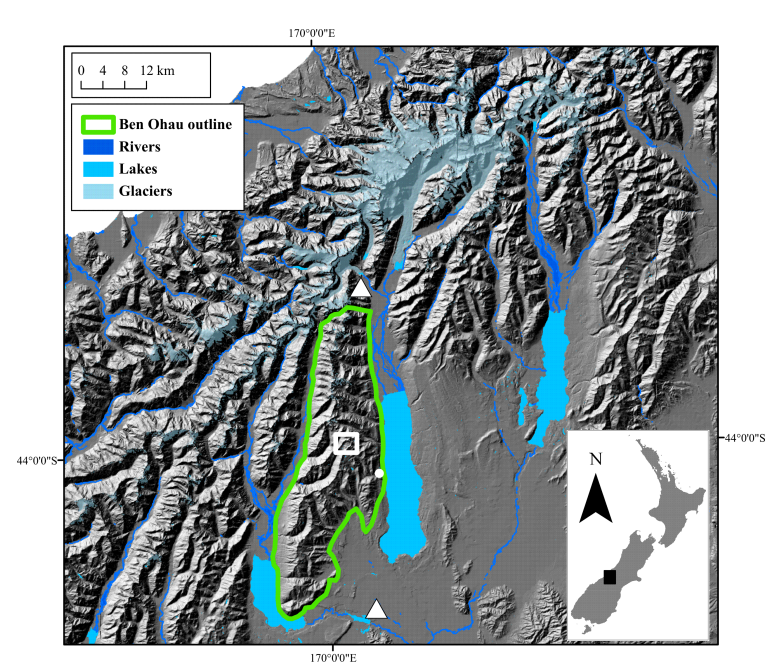

Figure 4.1 Location of the study area in central South Island, New Zealand. The Ben Ohau Range is outlined in green and Irishman basin is in the white box. Boundary Stream tarn (BST) is represented by the white dot southeast of Irishman basin and the white triangles are the locations of Aoraki/Mt. Cook village (north of the Ben Ohau Range) and Twizel (southeast of Ben Ohau Range).

\subsection{Modelling glacier extent}

We used a simple iterative modelling approach to estimate palaeoclimate conditions based on modelled glacier extent. This strategy is similar to those employed in previous studies (Plummer and Phillips, 2003; Hubbard et al., 2005; Kessler et al., 2006; Laabs et al., 2006) except that our 2-D ice-flow model is coupled with a spatially-distributed EBM. Our EBM/2-D ice-flow combination is simple enough to simulate mapped ice extents quickly (steady-state runs take less than an hour on a desktop computer), yet is complex enough to account for shading, aspect, valley slope, and local climate.

A digital elevation model was used to provide surface elevation throughout the model domain. This model was produced from $20 \mathrm{~m}$ interval topographic contours and spot heights on published 1:50,000-scale (NZMS260 series) topographic maps published by Land Information New Zealand. We simulated the $13 \mathrm{ka}$ Irishman glacier at 25 x $25 \mathrm{~m}$ gridded horizontal resolution, with all simulations starting from an ice-free basin. The model domain covers a 5 x $6 \mathrm{~km}$ area centred over Irishman basin. 


\subsubsection{Input data}

Thirty years (1981 to 2010) of daily climate data were converted into monthly means for each grid cell in the model domain. We calculated climate data grids from several different sources depending on availability and reliability. First, daily climate data of relative humidity, solar radiation, temperature, and precipitation came from the NIWA CliFlo Database (NIWA, Retrieved 2009-2011). Relative humidity and solar radiation grids came from the virtual climate station network climate grid interpolations, available directly from the NIWA CliFlo website. The NIWA climate grids were not used for temperature because the data contain some biases in mountainous terrain (Anderson and Mackintosh, 2012). Instead, we created interpolated temperature surfaces using data from multiple, surrounding, low-elevation stations (NIWA, Retrieved 2009-2011). To make the interpolation surface, we took daily temperature data from each station $\left(T_{s t}\right.$ in $\left.{ }^{\circ} \mathrm{C}\right)$, the monthly lapse rate $\left(\frac{d T}{d z}\right.$ in $\left.{ }^{\circ} \mathrm{C} \mathrm{km}^{-1}\right)$, and station elevation $\left(z_{s t}\right.$ in $\left.\mathrm{m}\right)$ to create a 'reference' temperature $\left(T_{r}\right.$ in $\left.{ }^{\circ} \mathrm{C}\right)$ at sea level using:

$$
T_{r}=T_{s t}-\frac{d T}{d z} \frac{z_{s t}}{1000}
$$

Daily reference temperature surfaces were interpolated at sea level in the horizontal plane across the model domain (Tait and Zheng, 2007). Modelled temperature ( $T$ in ${ }^{\circ} \mathrm{C}$ ) in any grid cell was calculated using Equation (4.2), with the grid cell reference temperature, the month's lapse rate, and the elevation value of the grid cell ( $z$ in $\mathrm{m}$ ). Each modelled past temperature change $(\Delta T)$ is an additive change to the temperature $(T)$ in each grid cell and is uniformly applied across the domain:

$$
T=T_{r}+\frac{d T}{d z} \frac{z}{1000}+\Delta T
$$

We calculated and used variable monthly temperature lapse rates (Figure 4.2 and Table 4.1), which were determined by minimising the mismatch between Irishman temporary climate station temperature data and an interpolated temperature grid. This tempo- 
rally varying lapse rate attempts to account for pervasive valley-scale temperature inversions which occur in winter in this region (Figure 4.2). Observed and calculated 'clearsky' solar radiation were used to calculate cloudiness, following Hock (2005) and Anderson et al. (2010).

Second, reanalysis data from the National Centers for Environmental Prediction (NCEP) for present-day wind at the $850 \mathrm{hPa}$ level (1981 - 2010) (Kalnay et al., 1996) were scaled to match observed wind speed and were applied uniformly across the model domain. Wind speeds are not modified for the complex topography and we assume wind speed distribution is uniform over the domain. These data were converted into monthly mean gridded wind speed. Further discussion of these datasets and the rationale for using them is provided in Anderson and Mackintosh (2012).

The third source of input climate data came from an annual mean precipitation surface (Stuart, 2011) based on rain gauge data, from 1971 to 2000, spatially distributed around the Southern Alps to capture the steep precipitation gradient. The interpolated precipitation (Anderson et al., 2010) amount at each grid cell was calculated at monthly mean values from daily measured rainfall at lowland stations (NIWA). The interpolated data were guided by an annual mean precipitation surface (Stuart, 2011).

Modelled past precipitation change $(\Delta P)$ is calculated as a percentage from present day, where present-day precipitation is $\Delta P=0 \%$ change, doubling present-day precipitation is $\Delta P=+100 \%$ change, and halving present-day precipitation is $\Delta P=-50 \%$ change. $\Delta P$ represents the change in precipitation reaching the site, which could be a result of regional changes in annual precipitation and/or changes in the amount of snow settling within Irishman basin as a result of increasing or decreasing snow transport.

\subsubsection{The energy-balance model}

We developed a spatially-distributed EBM that uses the specified topography, monthly interpolated meteorological input, ice thickness at each monthly time-step, and prescribed climate perturbations to calculate annual mass balance at each grid cell. The resulting 
Table 4.1 Measured monthly mean temperatures $\left(T_{\text {meas }}\right)$ and calculated temperature lapse rates $\left(\frac{d T}{d z}\right)$ for each month based on Irishman basin climate station data (2010-2011, $43^{\circ} 59^{\prime} 30^{\prime} \mathrm{S}, 170^{\circ} 02^{\prime} 57^{\prime} \mathrm{E}, 2010 \mathrm{~m}$ asl). Annual mean measured temperature is $\pm 1.2^{\circ} \mathrm{C}$ (assuming a value of $6.2^{\circ} \mathrm{C}$ for February) and the annual mean lapse rate is

$$
-5.4^{\circ} \mathrm{C} \mathrm{km}^{-1} \text {. }
$$

\begin{tabular}{lcccccc}
\hline Month & Jan & Feb & Mar & Apr & May & Jun \\
\hline$T_{\text {meas }}\left[{ }^{\circ} \mathrm{C}\right]$ & 6.2 & - & 4.9 & 3.1 & -1.1 & -6.1 \\
$\frac{d T}{d z}\left[{ }^{\circ} \mathrm{C} \mathrm{km}{ }^{-1}\right]$ & -6 & $-6^{*}$ & -5.5 & -5.5 & -5 & -4 \\
\hline Month & Jul & Aug & Sep & Oct & Nov & Dec \\
\hline$T_{\text {meas }}\left[{ }^{\circ} \mathrm{C}\right]$ & -6 & -3.6 & -1.5 & 0.8 & 4.9 & 6 \\
$\frac{d T}{d z}\left[{ }^{\circ} \mathrm{C} \mathrm{km}^{-1}\right]$ & -3.5 & -5.5 & -6.5 & -5.5 & -5.5 & -6 \\
\hline${ }^{*}$ The February $\frac{d T}{d z}$ was set equal to the January value because of a atata gap.
\end{tabular}

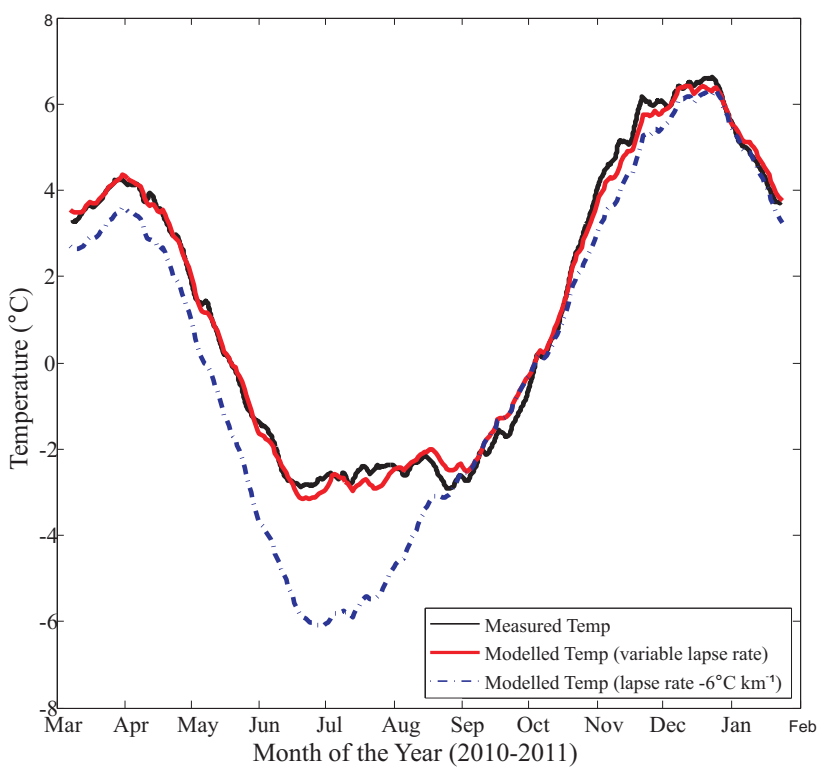

Figure 4.2 Modelled versus measured temperatures at the location of a climate station in Irishman basin. Modelled temperature values (daily interpolated temperature, $T$, smoothed with a thirty-day running mean) were interpolated from climate stations at $<800 \mathrm{~m}$ asl over the 2010-2011 interval. Measurements (black line) are compared to modelled temperatures that were calculated using a monthly varying lapse rate (red line) and a constant lapse rate (blue dashed). Using a constant lapse rate achieves a poor match, especially during winter months (Jun-Sep). 
mass balance grid was then used as a boundary condition in our ice-flow model (Section 4.2.3). Several other workers have employed 1- and 2-D models based on similar sets of equations (e.g., Oerlemans, 1992; Plummer and Phillips, 2003; Hock, 2005). We followed an EBM scheme described in Anderson et al. (2010) and Anderson and Mackintosh (2012), except ours used a monthly timestep and updates mass balance once every 5 or 20 model years (transient and steady-state respectively). The model calculated the energy available for melt $\left(Q_{M}\right)$ using the following equation:

$$
Q_{M}=I(1-\alpha)+L \downarrow+L \uparrow+Q_{H}+Q_{E}+Q_{G}+Q_{R}
$$

where $I$ is the incoming shortwave radiation, $\alpha$ is the surface albedo, $L \downarrow$ is the incoming longwave radiation, $L \uparrow$ is the outgoing longwave radiation, $Q_{H}$ and $Q_{E}$ are the sensible and latent heat fluxes, $Q_{G}$ is the ground heat flux, and $Q_{R}$ is the heat supplied by rain. All heat exchanges are in units of $\mathrm{W} \mathrm{m}^{-2}$. Positive values of radiative and turbulent fluxes indicate a gain of energy for melting of the snowpack, and negative values indicate a loss of energy. $Q_{G}$ was set at $1 \mathrm{~W} \mathrm{~m}^{-2}$ (Neale and Fitzharris, 1997) and $Q_{R}$ was calculated assuming that precipitation is the same temperature as the air (Oerlemans, 1992).

Incoming shortwave radiation $(I)$ was comprised of direct and diffuse components following Oerlemans (1992). Cloudiness (see above) was included in the insolation calculations following Hock (2005) and Anderson et al. (2010). Insolation values for the steady-state simulations were calculated for 13 ka (Berger and Loutre, 1991; Eisenman and Huybers, 2006). The albedo parameterisation $(\alpha)$ was based on a background albedo profile, which shows albedo increasing with altitude and snow thickness, both dependent on the modelled ELA, following Oerlemans (1992). Longwave and shortwave radiation distribution were calculated to include the view field of the surrounding topography from the cell and cloudiness following Plummer and Phillips (2003) and Anderson et al. (2010). Turbulent heat fluxes $\left(Q_{H}\right.$ and $\left.Q_{E}\right)$, which can make up half or more of the energy available for melt in maritime environments (Anderson and Mackintosh, 2012), were calculated using the bulk method (Klok and Oerlemans, 2002; Oerlemans and Grisogono, 2002) following Oerlemans (1992). The turbulent heat calculations used different roughness lengths 
for snow and ice surfaces and the Richardson stability criterion was applied for stable stratification conditions (Oerlemans, 1992; Hock, 2005; Anderson et al., 2010).

Snow accumulation occurred in the model when the temperature at each grid cell was at or below a snow/rain temperature threshold. The snow temperature threshold $\left(T_{\text {snow }}\right)$ was set to $1^{\circ} \mathrm{C}$ (Anderson et al., 2006). We did not take possible surface debris cover effects into account in these palaeo-simulations, although this cover was likely insignificant when Irishman glacier filled much of the basin at the ACR extent as suggested by the present geomorphology and previous glacier reconstructions (Kaplan et al., 2010).

Mass balance of the simulated glacier was calculated by subtracting the mass of possible melt from the mass of snow accumulation at each grid cell. The mass balance was recalculated every 20 model years in steady-state runs (every 5 model years in transient runs) while the ice-flow model ran. Coupling the models allowed the parameters sensitive to topography or the presence of ice (i.e., albedo, turbulent heat fluxes, shading, longwave radiation) to readjust as the ice thickness and extent evolved.

\subsubsection{The ice-flow model}

The ice-flow model employed in this study is a 2-D shallow ice approximation model, with an explicit time-step, similar to Plummer and Phillips (2003) and Kessler et al. (2006). The model used the basic mass continuity equation:

$$
\frac{d H}{d t}=M-\nabla \cdot \vec{q}
$$

where $H$ is the ice thickness, $t$ is time, $\vec{q}$ is ice flux, and $M$ is the mass balance, which was calculated using the EBM described in Section 5.2.2. The flux divergence was calculated using a 2-D finite-difference scheme. The vertically-averaged ice velocity from internal deformation was calculated using the shallow ice approximation (Paterson, 1994): 


$$
\vec{U}_{d}=\frac{2}{5} A H \vec{\tau}_{b}^{n}
$$

where $A$ is the coefficient of Glen's flow law, set to $1 \mathrm{e}^{-17} \mathrm{~Pa}^{-3} \mathrm{a}^{-1}, \vec{\tau}_{b}$ is the gravitational driving stress $\left(\vec{\tau}_{b}=\rho g H \nabla z\right)$, and $n$ is Glen's flow law exponent, set to 3 . The sliding velocity follows the empirical formulation of Kessler et al. (2006):

$$
\vec{U}_{s}=U_{c} e^{1-\frac{\tau_{c}}{\bar{\tau}_{b}}}
$$

where $U_{c}$ is a typical sliding velocity $\left(20 \mathrm{~m} \mathrm{a}^{-1}\right)$ and $\tau_{c}$ is the gravitational driving stress $\left(10^{5} \mathrm{~Pa}\right)$ that results in $\vec{U}_{s}$.

The continuity equation (Equation 4.4) was used to evolve the glacier geometry through time by calculating the ice velocity $\left(\vec{U}_{d}+\vec{U}_{s}\right)$ on a square grid that is offset from the points at which ice thickness is known. The flux gradients were then used to calculate the updated ice thickness using a forward explicit time-step. The evolving time-step was calculated from the stability condition from Hindmarsh and Le Meur (2001).

One way to quantify the error associated with the ice-flow model is to find the proportion of integrated mass balance for a modelled glacier in equilibrium relative to the total accumulation rate. The integrated mass balance over the glacier surface, for the Irishman glacier while it is in equilibrium (where $\Delta T=-2.5^{\circ} \mathrm{C}$ and $\Delta P=11 \%$ ), is $-17.4 \mathrm{~mm} \mathrm{a}^{-1}$. The integrated total annual accumulation for the glacier is $815 \mathrm{~mm} \mathrm{a}^{-1}$. The mass balance divided by the accumulation total gives an estimate of the proportion of mass generated by the flow model $(2.1 \%)$. The proportion is low, indicating that the ice-flow model is not a significant source of error for the palaeoclimate estimates.

The assumptions that underlie the shallow ice approximation are less valid in parts of the model domain where bed slope and glacier aspect ratio are high (Le Meur et al., 2004), however, Irishman glacier overall has a low aspect ratio and a low ice surface gradient. We consider the primary control on glacier evolution in Irishman basin to be the mass balance (Leysinger Vieli and Gudmundsson, 2004), and thus the shallow ice approximation is 
appropriate for our investigation. A summary of the parameter values used in the climate data interpolation, energy balance, and ice-flow models is given in Table 4.2. Most values were taken from published literature and value ranges in the sensitivity tests are used to calculate their effect on results.

Table 4.2 Model parameter values. These values define our optimal parameter set, meaning they come from previously published studies optimal for modelling and/or are specific to the site location. Our sensitivity tests use these values, changing one value at a time to understand each parameter's influence on our climate reconstruction.

\begin{tabular}{llll}
\hline Parameter Name & Symbol & Value & Source \\
\hline Snow albedo - ELA related & $\alpha_{\text {snow }}$ & 0.72 & Oerlemans (1992) \\
Snow/rain temperature threshold & $T_{\text {snow }}$ & $1^{\circ} \mathrm{C}$ & Anderson et al. (2006) \\
Temperature lapse rates & $\frac{d T}{d z}$ & see Table 4.1 & This study \\
Roughness parameter for ice & $Z_{\text {ice }}$ & $0.004 \mathrm{~m}$ & Anderson and Mackintosh (2012) \\
Roughness parameter for snow & $Z_{\text {snow }}$ & $0.001 \mathrm{~m}$ & Brock et al. (2006) \\
Typical sliding velocity & $U_{c}$ & $20 \mathrm{~m} \mathrm{a}^{-1}$ & Kessler et al. (2006) \\
Glen's flow law coefficient & $A$ & $1 \mathrm{e}^{-17} \mathrm{~Pa}^{-3} \mathrm{a}^{-1}$ & Paterson (1994) \\
Wind & & Reanalysis & Kalnay et al. (1996) \\
Maximum snow thickness & & $5 \mathrm{~m}$ w.e. & \\
\hline
\end{tabular}

\subsubsection{Steady-state simulations}

In experiment 1 , incremental changes in temperature relative to modern day $(\Delta T)$ from -1.5 to $-3.5^{\circ} \mathrm{C}$, and in precipitation relative to modern day $(\Delta P)$ from $-50 \%$ to $+200 \%$ were applied uniformly across the year and domain to force the EBM/2-D ice-flow model from initial ice-free conditions. We assumed that the glacier was in or near equilibrium with the climate when it deposited the continuous moraine, and thus steady-state simulations represent a possible climate for a particular glacier size. The resulting steady-state ice extent was then compared to the moraine position, where a good match shows the distance between them being less than two grid cells $(<50 \mathrm{~m})$. These iterations were used to derive a $\Delta P-\Delta T$ curve, where combinations of $\Delta P-\Delta T$ on that curve produced a glacier extent that fitted the moraine position. Each steady-state simulation ran for 240 model years, which is greater than the maximum time for any $\Delta P-\Delta T$ combination for the $13 \mathrm{ka}$ glacier to adjust to equilibrium starting from ice-free conditions. The EBM ran once every 20 model years to recalculate the glacier mass balance. These simulations used values from our optimal parameter set (Table 4.2). 
In order to assess the impact of parameter choices on our results, the following parameters were systematically explored: $T_{\text {snow }}, \alpha_{\text {snow }}, Z_{\text {ice }}, Z_{\text {snow }}, U_{c}$, and $A$. In each case the model ran using the optimal parameter set with the exception of the parameter we were testing. These tests were done with a similar model setup to experiment 1 , each running for 240 model years, changing $\Delta P-\Delta T$ combinations until the glacier reached within $50 \mathrm{~m}$ of the moraine. In the sensitivity tests, we created a new $\Delta P-\Delta T$ curve for each tested parameter (Figure 4.4).

\subsubsection{Transient runs}

In experiment 2, transient model runs were forced using chironomid-derived mean summer temperature reconstructions from sediments at Boundary Stream tarn (BST, $44^{\circ} 02^{\prime} \mathrm{S}$, $170^{\circ} 07^{\prime} \mathrm{E}, 830 \mathrm{~m}$ asl) located $7 \mathrm{~km}$ southeast of Irishman basin, that span the Lateglacial time (Vandergoes et al., 2008) (Figure 4.1). The age model at the Boundary Stream tarn (BST) site is derived from Bayesian modelling of 17 radiocarbon dates, calibrated using IntCal04 (Vandergoes et al., 2008). The chironomid record shows a period of temperature instability between 14.2 and $13.2 \mathrm{ka}$, including a maximum cool spike between 2 and $3^{\circ} \mathrm{C}$ below present values (Vandergoes et al., 2008). Particular strengths of the BST record are that chironomids are sensitive to mean summer temperatures (Dieffenbacher-Krall et al., 2007), the site lies close to Irishman basin, and the chironomid record is compatible with pollen-based palaeoclimate proxies from the same core. Although the chironomid temperature reconstruction describes mean summer temperature values, we apply it to our model as mean annual temperature changes. The sample specific error on the chironomidderived temperatures is $\pm 1.4^{\circ} \mathrm{C}$. Vandergoes et al. (2008) reconstructed summer temperatures from chironomids using two different modern-day chironomid-temperature calibration models and published both the raw and smoothed data from these models. They drew their conclusions (as much as $\sim 2-3^{\circ} \mathrm{C}$ cooling during the ACR) from the smoothed data of the partial least squares (partial least squares (PLS)-smooth) model. We used all four temperature reconstructions (PLS-raw, PLS-smooth, weighted average partial least squares (weighted average partial least squares (WAPLS))-raw, and WAPLS-smooth) to drive our EBM/2-D ice-flow model $\Delta T$ values. Each simulation was compared to the 
moraine sequence dated by Kaplan et al. (2010) to determine the best fit out of the four temperature reconstructions.

Temperatures were interpolated between the data points in each reconstruction from Vandergoes et al. (2008) using nearest neighbour interpolation. Precipitation was set to 0\% change (present-day) for all transient runs. Each simulation ran for 4000 model years (15 - $11 \mathrm{ka}$ ) and the EBM ran once every 5 model years to recalculate the energy balance on the evolving ice surface including differences in insolation $(I)$ due to changing orbital parameters during the period 15 - $11 \mathrm{ka}$.

\subsection{Results}

\subsubsection{Experiment 1: Steady-state simulations of the ACR Irishman glacier extent}

The first experiment of our investigation involved carrying out a suite of equilibrium runs at set $\Delta P-\Delta T$ combinations to identify those that produced a good match with the Irishman basin 13 ka moraine position (Figure $4.3 \mathrm{a}+\mathrm{b}$ ). Figure $4.3 \mathrm{~b}$ shows the fit between modelled ice thickness and the moraine record during a single simulation where $\Delta T$ is $-2.5^{\circ} \mathrm{C}$ and $\Delta P$ is $+11 \%$. The modelled Irishman glacier at the $13 \mathrm{ka}$ extent has an area of $\sim 1.8 \mathrm{~km}^{2}$, volume of $\sim 0.15 \mathrm{~km}^{3}$ and a maximum thickness of $100 \mathrm{~m}$. The modelled glacier response time to a $1^{\circ} \mathrm{C}$ decrease in $\Delta T$ is $10^{2}$ model years, suggesting that the glacier would respond to centennial scale shifts in climate, rather than decadal. The relatively long response time is consistent with the low slope angle of Irishman basin and a relatively low mass turnover.

Figure $4.3 \mathrm{c}$ shows the mass balance of Irishman glacier when $\Delta T$ is $-2.5^{\circ} \mathrm{C}$ and $\Delta P$ is $+11 \%$. Mass balance ranges from $1 \mathrm{~m}$ w.e. accumulation at highest elevations to $-2 \mathrm{~m}$ w.e. ice melt at the terminus. The modelled ELA (mean elevation where mass balance equals zero) in this simulation is $2000 \pm 40 \mathrm{~m}$ asl. The present-day ELA is above the elevation of Irishman basin and has been extrapolated to $>2300 \mathrm{~m}$ asl from present-day 
glacier snowlines (Porter, 1975b; Chinn, 1995; Lamont et al., 1999; Mathieu et al., 2009). To assess this estimate and to compare our palaeo-ELA with that of today, we applied the same climate data interpolation scheme and energy balance model to an idealised, cone-shaped and ice-covered mountain rising to $2500 \mathrm{~m}$ asl at the same location as Irishman basin. The modelled present-day ELA for Irishman basin derived using this method is $\sim 2400 \pm 40 \mathrm{~m}$ asl, only $\sim 100 \mathrm{~m}$ above the highest parts of the headwall of Irishman basin. Therefore, the ELA lowering that corresponds to the ACR event is $\sim 400 \pm 40 \mathrm{~m}$.

Figure 4.4 displays the $\Delta P-\Delta T$ curves using the optimal parameter set (Table 4.2) and variations in parameters. A similar glacier geometry to that shown in Figure $4.3 \mathrm{~b}$ will form with any $\Delta P-\Delta T$ combination on the black curve in Figure 4.4, although the glaciers resulting from a larger precipitation increase are slightly thicker. With no change in temperature, a precipitation increase of $241 \%$ is necessary to simulate the moraine position (not shown in Figure 4.4).

Varying the $T_{\text {snow }}$ and $\alpha_{\text {snow }}$ individually has the largest impact of all parameters on our climate results. Changes of $\pm 1{ }^{\circ} \mathrm{C}$ in the $T_{\text {snow }}$ alone influences the temperature reconstruction by $\pm 0.3^{\circ} \mathrm{C}$. Likewise, changing the $\alpha_{\text {snow }}$ alone by \pm 0.05 modifies $\Delta T$ by $\pm 0.6^{\circ} \mathrm{C}$. Despite the effects of parameter choice on our climate reconstructions, the overall conclusions do not change. Variations in other parameters have smaller influences on the $\Delta P-\Delta T$ curve. For example, varying the local summer insolation $(I)$ between low (18 ka) and high (10 ka) values makes no direct difference in the modelled glacier extent or climate reconstruction.

Table 4.3 lists the parameters, the values used in the sensitivity tests, and the $\Delta T$ needed to model Irishman glacier without a change in precipitation. The model-derived $\Delta T$ ranges from -3.3 to -2.1 with the optimal parameter set (Table 4.2) curve crossing at $-2.7^{\circ} \mathrm{C}$ when $\Delta P$ is set to zero. We consider the temperature uncertainty $\left(0.6^{\circ} \mathrm{C}\right)$ as half the range of temperature values $\left(-3.3\right.$ to $\left.-2.1^{\circ} \mathrm{C}\right)$ shown in Figure 4.4. A smaller temperature change requires an increase in precipitation. For example, a smaller $\Delta T$ of $-1.5^{\circ} \mathrm{C}$ requires a coincident increase in $\Delta P$ of $80 \%$ to achieve the $13 \mathrm{ka}$ glacier extent.

In summary, the model simulations in experiment 1 suggest a temperature reduction of 
$2.7 \pm 0.6^{\circ} \mathrm{C}$ sustained for a century is needed to produce the mapped extent without a change in precipitation. The optimal parameter set curve shows a $\Delta T$ of $-3.2^{\circ} \mathrm{C}$ when $\Delta P$ is $-20 \%$ and $-2.3{ }^{\circ} \mathrm{C}$ when $\Delta P$ is $+20 \%$. Our palaeoclimate estimates are most affected by changes in the $T_{\text {snow }}$ and $\alpha_{\text {snow }}$ parameters. The modelled glacier geometry and ELA are very similar to previous reconstructions (Figure 4.3d) based on geomorphology and AAR methods (Kaplan et al., 2010).

Table 4.3 Parameter name, symbol, value, and the $\Delta T$ needed to grow the glacier to the $13 \mathrm{ka}$ moraine without a change in precipitation ( $x$-intercept), with the optimal parameter set yielding a $\Delta T$ of $-2.7^{\circ} \mathrm{C}$.

\begin{tabular}{llll}
\hline Parameter & Symbol & Value & $\Delta T\left({ }^{\circ} \mathrm{C}\right)$ \\
\hline Snow albedo & $\alpha_{\text {snow }}$ & 0.67 & -3.3 \\
Snow/rain temperature threshold $\left({ }^{\circ} \mathrm{C}\right)$ & $T_{\text {snow }}$ & 0.77 & -2.1 \\
& & 2 & -3.0 \\
Temperature lapse rate $\left({ }^{\circ} \mathrm{C} \mathrm{km}^{-1}\right)$ & $\frac{d T}{d z}$ & -6 & -3.5 \\
Roughness parameter for ice (m) & $Z_{\text {ice }}$ & 0.002 & -2.7 \\
& & 0.008 & -2.8 \\
Roughness parameter for snow (m) & $Z_{\text {snow }}$ & 0.0005 & -2.7 \\
& & 0.002 & -2.8 \\
Incoming shortwave radiation $(\mathrm{ka})$ & $I$ & 10 & -2.7 \\
& & 18 & -2.7 \\
Typical sliding velocity $\left(\mathrm{m} \mathrm{a}^{-1}\right)$ & \multirow{2}{*}{$U_{c}$} & 10 & -2.7 \\
& & 30 & -2.7 \\
Glen's flow law coefficient $\left(\mathrm{Pa}^{-3} \mathrm{a}^{-1}\right)$ & $A$ & $1 \mathrm{e}^{-16}$ & -2.7 \\
& & $1 \mathrm{e}^{-18}$ & -2.7 \\
\hline
\end{tabular}

\subsubsection{Experiment 2: Transient run driven by chironomid-derived temperature reconstructions}

The second experiment of our study was to run four time-dependent simulations of glacier extent forced by the different BST chironomid-derived temperature reconstructions (Vandergoes et al., 2008). The resulting glacier length changes were then compared with the mapped and dated moraine sequence in Figure 4.3a. Figure 4.5 shows the PLS-smooth BST $\Delta T$ (present-day temperature is $\Delta T=0^{\circ} \mathrm{C}$ ) from 15 to $11 \mathrm{ka}$, and the lower plot shows the corresponding change in glacier length. The 13 ka moraine position (in terms of glacier length) is represented on Figure 4.5 by the orange diamond with the error bars corresponding to the age of the moraine derived independently using surface exposure dating by Kaplan et al. (2010). 
From 15 to $14 \mathrm{ka}$, temperature in the PLS-smooth chironomid model varies between +0.5 and $-2.5^{\circ} \mathrm{C}$ relative to the present. In response to this temperature forcing, the modelled glacier fluctuates between a length of $1640 \mathrm{~m}$ (about $100 \mathrm{~m}$ short of the moraine) and ice-free conditions. Ice persists at the headwall with a $\Delta T=-1^{\circ} \mathrm{C}$, which supports our modern ELA estimate and the regional interpretation that the modern ELA lies just above the highest parts of the Irishman basin headwall (Porter, 1975b; Brazier et al., 1998; Lamont et al., 1999). The modelled glacier almost reaches the position of the 13 ka moraine in response to the short-term $2.8^{\circ} \mathrm{C}$ cooling at $13.8 \mathrm{ka}$ and retreats to within $250 \mathrm{~m}$ of the headwall by $13.3 \mathrm{ka}$ after a change in $\Delta T$ from -2 to $-1^{\circ} \mathrm{C}$. Subsequent ice advances from 13.5 to $11 \mathrm{ka}$ are minor $(<250 \mathrm{~m})$ in the model run. The PLS-smooth forcing does not produce ice extents coinciding with the $12 \mathrm{ka}$ and $11.5 \mathrm{ka}$ moraines of Kaplan et al. (2010) (Figure 4.5, represented by the yellow diamond and error bars).

All other BST temperature reconstructions produced modelled glacier extents (not shown) far beyond the moraine position during the coldest part of the curve, leading to a mismatch with the moraine data. PLS-raw data included a maximum $\Delta T$ of $-4^{\circ} \mathrm{C}$, resulting in a modelled glacier length of $3000 \mathrm{~m}$, almost twice the geomorphically delimited length. WAPLS-raw and WAPLS-smooth included a maximum $\Delta T$ of -5.6 and $-4.4^{\circ} \mathrm{C}$ respectively and both produced valley glaciers that were too extensive $(\sim 5500 \mathrm{~m}$ long). Model simulations with a greater magnitude of cooling, such as WAPLS-raw and WAPLS-smooth, also produced ice on the valley wall sides, which is not supported by the geomorphic evidence. 

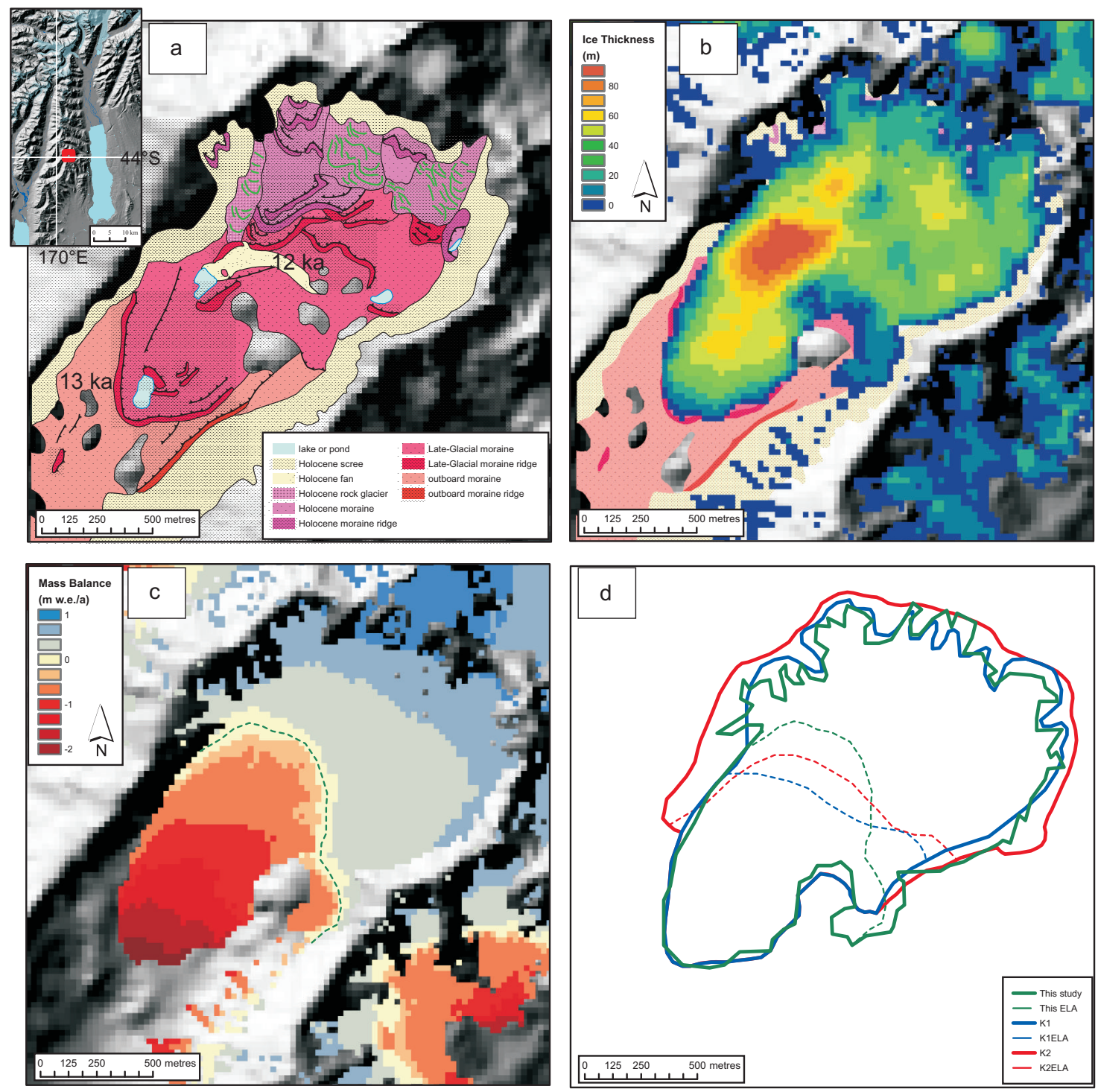

Figure 4.3 Modelled extent of Irishman glacier at 13 ka where $\Delta T-2.5^{\circ} \mathrm{C}$ and $\Delta P$ $+11 \%$. We show the (a) mapped geomorphology in the Irishman basin, for details see Kaplan et al. (2010), (b) modelled ice thickness overlaying the moraine map, (c) modelled mass balance with modelled ELA (green dashed line), and (d) previous estimates of Irishman glacier extent (K1 blue, K2 red) and ELA (K1ELA blue dashed, K2ELA red dashed) (Kaplan et al., 2010) based on geometric and AAR reconstructions, compared to this study (green). 


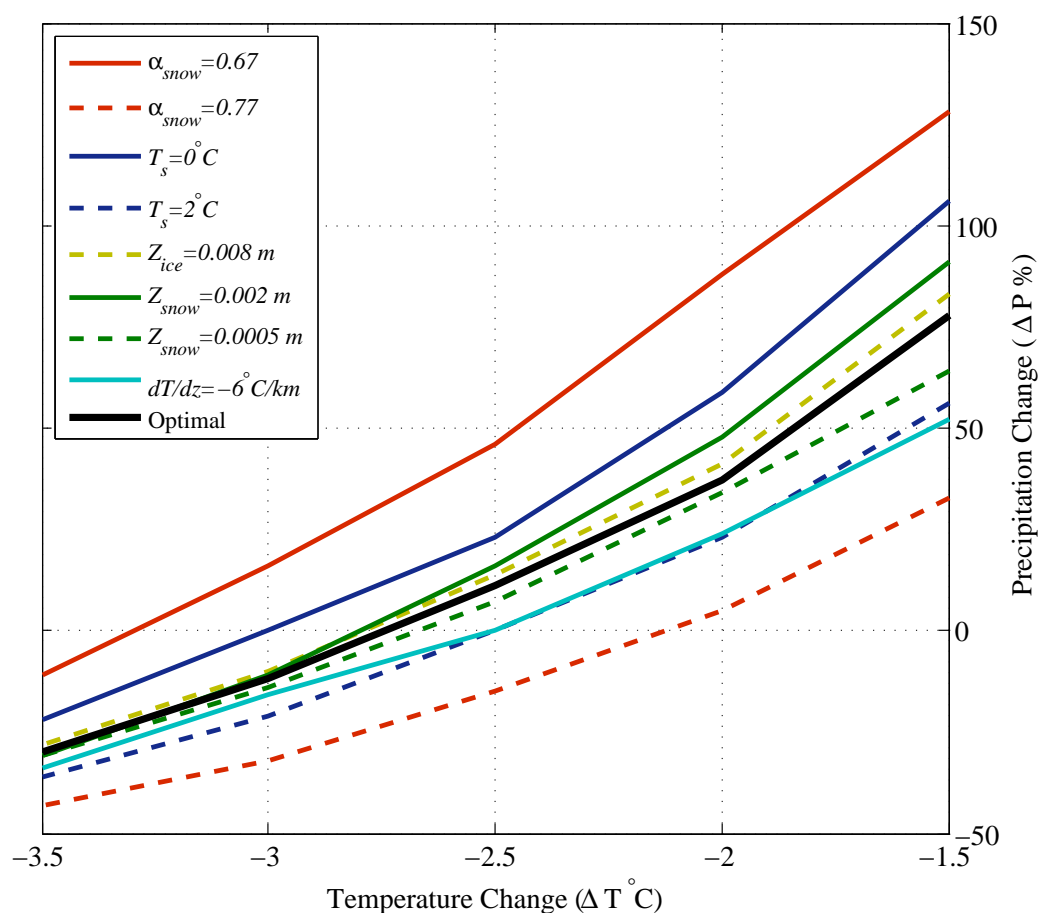

Figure 4.4 Experiment 1 results - Inferred $\Delta P-\Delta T$ reconstructions showing the sensitivity of the climate reconstruction to chosen parameter values. Curves identical to the 'Optimal' curve are not shown $\left(I, U_{c}, A\right.$, and $\left.Z_{i c e}=0.002 \mathrm{~m}\right)$. The $x$-intercepts of the different curves are reported in Table 4.3.
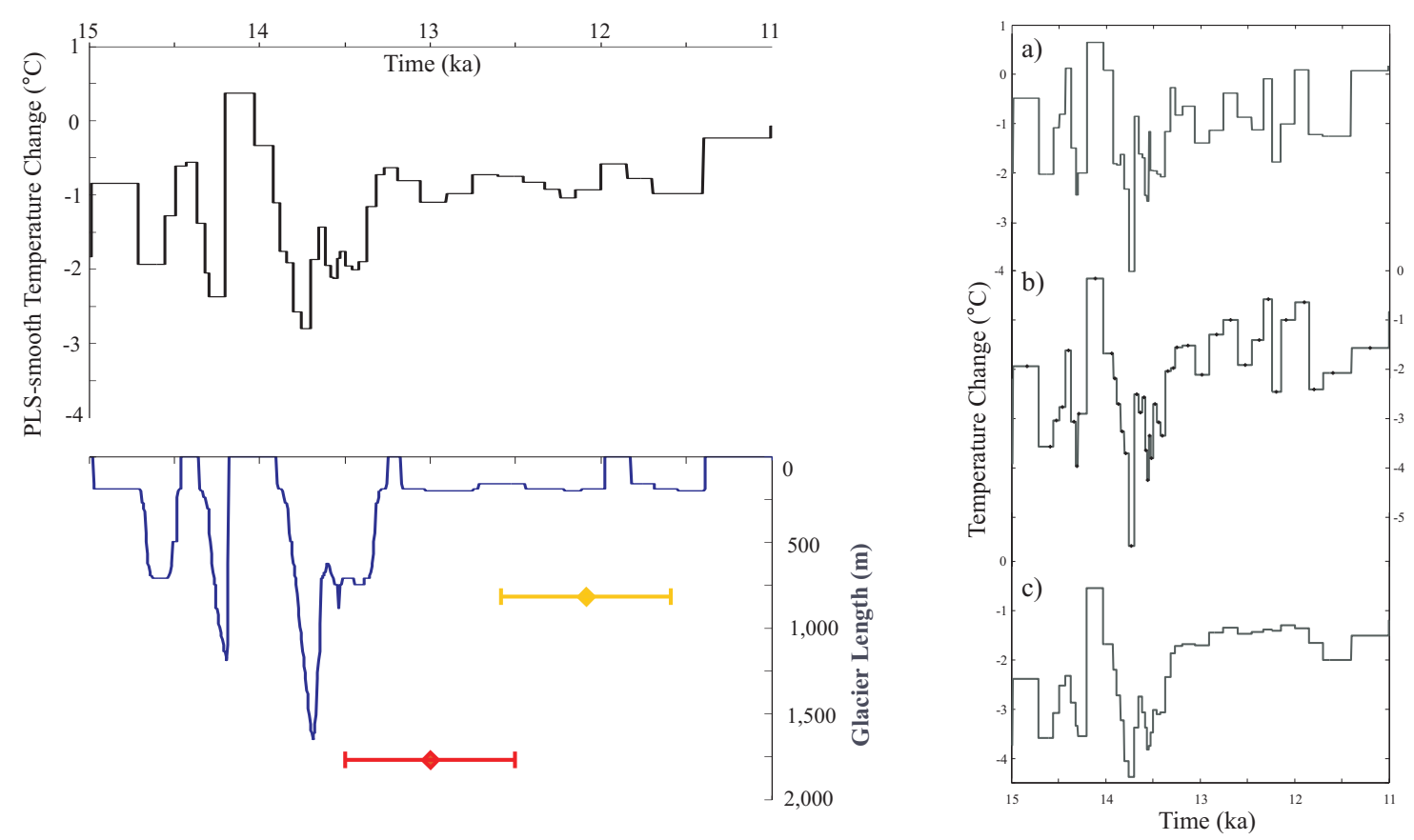

Figure 4.5 Experiment 2 results - BST PLS-smooth temperature reconstructions from Vandergoes et al. (2008) (black) from 15 to $11 \mathrm{ka}$ with modelled glacier length (blue). Orange and yellow diamonds represent the moraine positions dated to $13.0 \pm 0.5$ and $12.1 \pm 0.5$ ka respectively. Glacier length was calculated by identifying the ice with a thickness $>10 \mathrm{~m}$ farthest from the headwall. Plots in the right panel show a) PLS-raw, b)

WAPLS-raw where tick marks show the sampling resolution, and c) WAPLS-smooth inferred summer mean $\Delta T$ from 15 to $11 \mathrm{ka}$. Glacier lengths resulting from these three reconstructions extended beyond the 13 ka moraine and are not shown here. 


\subsection{Discussion}

We sought to improve Lateglacial palaeoclimate estimates derived from glacier reconstructions for central South Island by using a numerical modelling approach. Although this reconstruction is for a single site, ice in the Irishman basin would have responded to the same regional climatic changes as other glaciers in the central Southern Alps (Clare et al., 2002; Kaplan et al., 2010; Chinn et al., 2012). There is no present-day glacier in Irishman basin, and as a result we do not have site specific mass balance measurements with which to compare our results against directly, thereby tuning the model to this site. We do use temperature data from an automatic weather station setup in Irishman basin to determine appropriate seasonal lapse rates. The modelled 'equilibrium-line altitude' is above the ridge elevation, which is similar to previously interpolated ELAs (Chinn, 1995). Moreover, the model has been tuned and tested for other New Zealand glaciers (Anderson et al., 2010; Anderson and Mackintosh, 2012).

At present, Irishman basin has an annual mean temperature of $\sim 1.2^{\circ} \mathrm{C}$, and a cooling of only $1^{\circ} \mathrm{C}$ results in small glaciers developing at the headwall, which suggest that this site is ideal for recording even minor past shifts in climate. Our model successfully reproduced ice extent matching the moraine record with an estimated $\Delta T$ of $-2.7 \pm 0.6^{\circ} \mathrm{C}$, which supports previous evidence of a cold event in New Zealand during the ACR (e.g., Porter, 1975a; Hajdas et al., 2006; Carter et al., 2008; Putnam et al., 2010a). There are a number of model parameter values that are uncertain for palaeoclimate simulations (Table 4.2) and we presented their effect on the modelling results (Figure 4.4).

Ice extent and ELA reconstructions using the AAR method from Kaplan et al. (2010) are compared to our modelled ice extent and ELA in Figure 4.3d. Our modelled area extent $\left(1.8 \mathrm{~km}^{2}\right)$ matches more closely with the smaller ice reconstruction $(\mathrm{K} 1)$, whereas our model-based ELA estimate of $2000 \pm 40 \mathrm{~m}$ asl is closer to the larger reconstruction (K2), which gave an ELA of $1980 \pm 40 \mathrm{~m}$ asl. This is because the AAR (automatically) calculated by the mass balance model was 0.58 , compared to the 0.67 assumed by Kaplan et al. (2010). However, within uncertainties, all three reconstructions yield identical or similar extents, ELAs, and ice thicknesses. The agreement between the methods supports the use 
of the AAR method on glaciers in a simple topographic context with a well expressed geomorphic moraine record. Our estimated ELA lowering from the present day is $\sim 400 \mathrm{~m}$ for Irishman basin, which is similar to the ELA lowering derived for the Birch Hill event $(500 \mathrm{~m})$ in the Tasman valley (Porter, 1975a), which is also dated to $13.1 \mathrm{ka}$ (Putnam et al., 2010a).

The transient simulations, using BST temperatures and moraine age and position as constraints, show an advance/retreat pattern in Irishman glacier from 15 to $11 \mathrm{ka}$. The modelled glacier advances to within $100 \mathrm{~m}$ of the moraine during the BST cold period $(\Delta T=-2$ to $-3^{\circ} \mathrm{C}$ between 13.9 and $13.4 \mathrm{ka}$ ) and retreats to within $240 \mathrm{~m}$ of the headwall when the BST $\Delta T$ increases to $-1^{\circ} \mathrm{C}(\sim 13.3 \mathrm{ka})$. The $2-3^{\circ} \mathrm{C}$ cooling persisting for $\sim 500$ years from the chironomid record is sufficient to grow Irishman glacier out to the 13 ka moraine. The timing of the simulated glacier retreat overlaps within error with the moraine age $(13 \pm 0.5 \mathrm{ka})$ (Figure 4.5). A poorer match, however, is achieved for the 12 and $11.5 \mathrm{ka}$ moraines, where the simulated glacier extent is $\sim 500 \mathrm{~m}$ from the $12 \mathrm{ka}$ moraine. This mismatch occurs because the BST temperature decrease is not of sufficient magnitude to produce the inferred glacier extent. The 12 ka temperature decrease might not be appropriately captured in the BST record due to lower sampling resolution during that time.

Overall, we see a good match between the chironomid-derived temperature reconstruction and the ACR moraine position via our modelling results. The brief cool spike from the PLS-smooth (Figure 4.5) results in a glacier extent near the moraine, but predates the moraine age. Small mismatches in the chironomid and moraine records may reflect model, moraine dating, or BST age-model uncertainties, but could also reflect differences in response of each proxy to climate. We point out that chironomid- and glacier-derived palaeoclimate records are inherently different, because they respond on different time scales and, perhaps, emphasise different characteristics of temperature change (e.g., tarn temperature versus glacier micro-climate). Yet, despite potential differences, these proxies both appear to be predominantly reflecting changes in temperature of approximately the same magnitude during the ACR.

The modelling results presented in this paper supports the idea that the temperature dur- 
ing the ACR was $2-3^{\circ} \mathrm{C}$ cooler than today in New Zealand. This temperature change estimate overlaps, within error, with a temperature change estimate of $3-4^{\circ} \mathrm{C}$ cooler than today, reported by Anderson and Mackintosh (2006) for the Franz Josef Glacier advance to the Waiho Loop during the Lateglacial. Our results are also consistent with published pollen studies (Newnham and Lowe, 2000; Turney et al., 2003; Vandergoes and Fitzsimons, 2003; Hajdas et al., 2006), and regional sea-surface temperature records (Carter and Cortese, 2009; Sikes et al., 2009) that suggest a temporary reversal of the deglaciation warming trend occurred in New Zealand during the Lateglacial.

\subsection{Conclusions}

We simulated a small glacier in the central Southern Alps to infer the local climate change that occurred during the ACR using a coupled energy-balance and ice-flow model. We show that:

1. Our simulated equilibrium-line altitude is $2000 \pm 40 \mathrm{~m}$ asl, which agrees within error with the traditional AAR method of reconstruction (1980 $\pm 40 \mathrm{~m}$ asl (Kaplan et al., 2010)). Our estimated Lateglacial ELA is $400 \mathrm{~m}$ lower than the modelled modern ELA of $2400 \pm 40 \mathrm{~m}$.

2. A $\Delta T$ (temperature change from today) of $-2.7 \pm 0.6^{\circ} \mathrm{C}$ was required to simulate the ACR extent of Irishman glacier assuming no change in precipitation from present day.

3. The optimal parameter set curve shows a $\Delta T$ of $-2.3^{\circ} \mathrm{C}$ when $\Delta P$ (precipitation change from today) is $+20 \%$ and $-3.2^{\circ} \mathrm{C}$ when $\Delta P$ is $-20 \%$.

4. The transient simulation of Irishman glacier length from 15 to $11 \mathrm{ka}$, driven by a chironomid-derived temperature reconstruction (Vandergoes et al., 2008), showed advance to and retreat from the 13 ka moraine.

5. Our model-based temperature reconstructions are compatible with other proxy records from New Zealand that show temperatures during the ACR were cooler than today. 


\section{Acknowledgements}

Funding was provided by the New Zealand Government under a New Zealand International Research Doctoral Scholarship, by the Comer Science and Education Foundation and by Victoria University of Wellington, including the Antarctic Research Centre, the School of Geography, Environment and Earth Sciences, and the Science Faculty Research Committee. M. Vandergoes and D. Barrell were supported by GNS Science's Direct Crown Funded Programme 'Global Change through Time'. We thank S. Stuart for providing his Southern Alps precipitation surface and R. Dadic, N. Golledge, H. Horgan, and K. Sattler for helpful discussions during the preparation of this paper. We also appreciate the helpful comments from M. Plummer and an anonymous reviewer. This publication is LDEO contribution number 7618. 


\section{Chapter 5}

\section{Optimising simulated snow depth patterns on an avalanche-fed glacier in New Zealand using GPR and a gravitational mass transport model}

\section{Abstract}

Gravitational mass movement of snow occurs in steep terrain and directly contributes accumulation to glaciers. Measurements of snow distribution on dominantly avalanche-fed glaciers are scarce owing to safety considerations and are frequently inaccurate owing to the high spatial variability of the deposits. For these reasons, it is desirable to simulate the redistribution of snow using a modelling approach. In this study, we investigate locations on a glacier where a simple gravitational mass transport and deposition (MTD) model can estimate snow depths at the end of winter. Modelled snow depth data were compared to ground penetrating radar (GPR) measurements taken in early December, 2009 at the Cameron Glacier in the South Island of New Zealand. To compare the modelled and measured data, we examined snow depth characteristics, including mean values, ranges (maximum-minimum), and gradients of snow depths along measured cross- and long profiles. We optimised three tunable parameters in the MTD model to fit the GPR data. The model best reproduces the measured snow depth pattern in areas that receive snow from steep slopes $\left(>60^{\circ}\right)$. Areas positioned below moderate slopes $\left(40-60^{\circ}\right)$ are not simulated very well by the model because snow pack evolution and avalanche dynamics are not adequately captured. The simulated snow distribution calculated from this simple model is appropriate for glaciers located adjacent to steep slopes where the MTD parameterisation improves modelled accumulation patterns. Including the MTD model improves the modelled glacier mass balance. 


\subsection{Introduction}

The mass balance of mountain glaciers is influenced by snow redistribution processes, such as wind transport of snow and avalanching. Both of these processes depend on topography (e.g. exposure and slope) to some degree. In addition to influencing the snow thickness distribution, these processes can affect glacier melt by either increasing the glacier albedo in regions of snow deposition, or decreasing the albedo in regions of snow stripping, thus reducing the reflected shortwave radiation from surrounding steep slopes of bare bedrock.

Avalanche-fed glaciers are usually avoided for field mass balance studies. The steep, avalanche-prone terrain is hazardous to work in, and does not provide many safe, stable areas suitable for automatic weather stations (AWSs), campsites, or mass balance equipment. As a result, the sensitivity of snow avalanche-fed glaciers to climate change is poorly understood (Hewitt, 2005, 2011). Correctly simulating small, frequent avalanches is the best option for safely estimating accumulation in these types of glacierised catchments

Snow accumulation in energy balance models is usually calculated as a function of precipitation and temperature, which is linked to elevation via a temperature lapse rate. A straight forward relationship between accumulation and elevation is less likely in areas where avalanches occur or where snow is strongly redistributed by wind. Both processes (gravitational and wind) are rarely accounted for in glacier mass balance models. The Gruber (2007) gravitational mass transport and deposition (MTD) model is simple, computationally fast, and can be used for a number of materials (snow, debris-flow, lava). The model removes excess snow from cells in steep terrain, transports the excess snow through downslope cells along the highest terrain gradient, and then deposits the excess snow where the gradient (or slope) drops below a certain threshold. The deposition component of the model contains several parameters that describe the snow depth as a function of slope.

The influence of gravity on snow movement is slope dependent and can therefore be ap- 
proximated using a digital elevation model (DEM). Parameterisation of gravitational snow transport allows for a representation of avalanches without knowledge of more complex physical processes in the snowpack (Gruber, 2007), which are usually poorly constrained. Gravitational redistribution models can be used to improve predictions of snowpack water storage in hydrological models (Gruber, 2007; Dadic et al., 2008; Bernhardt and Schulz, 2010) or to understand how avalanche-fed glacier mass balance may respond to climate change (Machguth et al., 2006).

We targeted a relatively small $\left(\sim 1.7 \mathrm{~km}^{2}\right)$ glacier (Cameron Glacier) in the Arrowsmith Range of the New Zealand Southern Alps, that displays signs of gravitational snow redistribution. Avalanches occur frequently enough in the Arrowsmith Range during the winter season that avalanche danger forecasting is made available by the Mountain Safety Council of New Zealand (www.avalanche.net.nz). Signs of snow avalanching in this area include snow 'fans' on glacier surfaces, snow deposits beyond the glacier termini, and large areas of bare, steep valley walls above the climatic snowline (Figure 5.1a). These signs suggest that much of the snow distribution pattern on the Cameron Glacier might be explained by gravitational redistribution of snow by small, frequent avalanching, which can be captured by the snow MTD parameterisation (Gruber, 2007). We do not simulate snow redistribution due to wind, but some of the modelled gravitational snow movement (from steep to gentle slopes) could be indirectly accounting for wind-driven processes. Including a gravitational mass balance transport model within our mass balance model allows us to estimate the present-day snow distribution, and to account for this process in palaeo-simulations.

The simulated snow depths were compared against measured snow depths taken December, 2009. We conducted a ground-penetrating radar (GPR) survey on a large flat portion of the Cameron Glacier, that includes both cross- and long GPR profiles to measure the end of winter snow depth distribution. We varied model parameter values in each model run (28 runs total) to identify which parameter combinations resulted in an acceptable fit in snow distribution. This paper aims to determine where on the glacier the MTD model (Gruber, 2007) approximates snow depth well. We discuss the influence of different model parameter values, DEM resolution, timestep, and input climate on the resulting 
snow distribution.

\subsubsection{Geographic Setting}

The Cameron Glacier is a small glacier located east of the main divide of the Southern Alps in the Arrowsmith Range, New Zealand ( $\left.43^{\circ} 21^{\prime} \mathrm{S}, 171^{\circ} 00^{\prime} \mathrm{E}\right)$. Cameron Glacier ranges in elevation from $\sim 1400$ to $2270 \mathrm{~m}$ asl, and receives snow from adjacent steep valley walls, which rise to elevations of $2705 \mathrm{~m}$ asl (Jagged Peak, Figure 5.1c). There are no meteorological data from Cameron Glacier, but the nearby Mt. Potts weather station (2128 $\mathrm{m}$ asl, white dot in Figure 5.1d) shows an annual mean air temperature of $3.5^{\circ} \mathrm{C}$, and a total annual precipitation of $1300 \mathrm{~mm}$ (data from June 2009 - July 2012) (NIWA, Retrieved 2009-2011), although this precipitation measurement is probably affected by undercatch.

The equilibrium-line altitude (ELA) (1977-1993) from nearby Douglas Glacier (Figure 5.1c), has been estimated at $\sim 2120 \mathrm{~m}$ asl (Chinn, 1995), but annual ELA values from 2008 to 2011 range from 2283 to $2380 \mathrm{~m}$ asl (Willsman et al., 2012). The majority (>80\%) of the Cameron Glacier surface elevation lies below $2120 \mathrm{~m}$ asl. However, the thick avalanche-derived snow deposits, that reach these lower elevations, contribute metres of accumulation at elevations where the glacier would otherwise lose mass.

Glacier snowlines observed at the end of the melt season mark the boundary between accumulation and ablation areas for that year. For most glaciers, the snowline roughly follows a single elevational contour. In contrast, the end of summer snowline on the Cameron Glacier traces along the centre of the glacier, perpendicular to elevational contours. This pattern is evident because the snowline marks the lateral extent of avalanche deposits that build out from the true right (northern) valley wall (Figure 5.1a+b). Snow depth measurements provide an opportunity to test the model performance by attempting to find the best-fit set of parameters required to simulate these observations. 

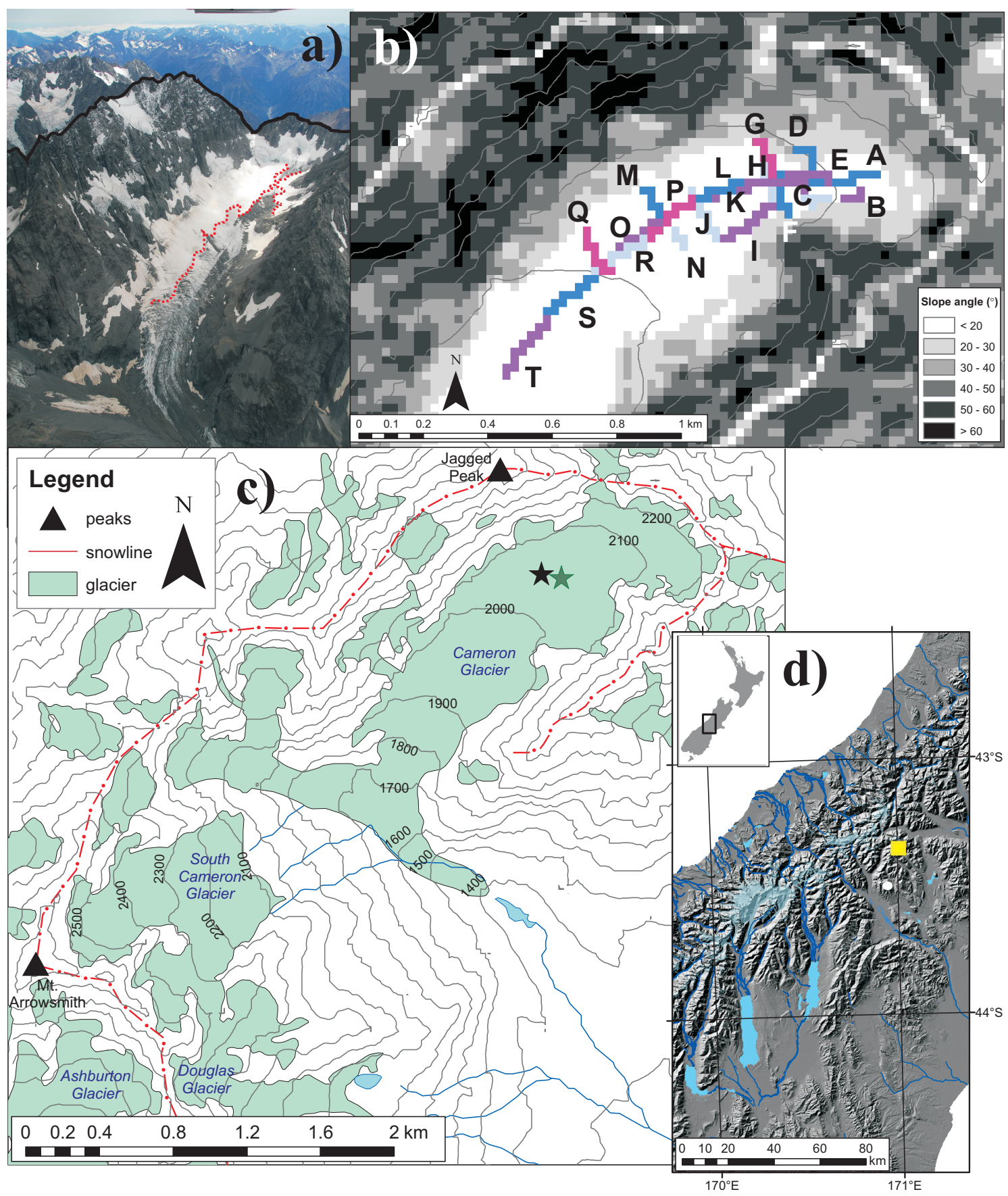

Figure 5.1 Topographic map of the Cameron Glacier catchment. a) An oblique aerial photograph of the Cameron Glacier showing the steep valley walls, partially debris-covered terminus, and end of summer snowline (red dotted line). The black line delineates the ridgeline of the upper Cameron catchment. Photograph taken 5 March, 2010 by A. Willsman. b) Slope values for a section of the model domain ( $25 \mathrm{~m}$ grid resolution) with labelled GPR profiles on Cameron Glacier. Note the large area on the northern slopes that are $>60^{\circ}$ (black cells). Each profile is $\sim 200 \mathrm{~m}$ long. Profile colours are for differentiating lines only. c) Topographic map with elevation contours, ridgelines

(dotted-dashed red line), glacierised area, and mountain peaks (Mt. Arrowsmith (2781 $\mathrm{m}$ asl) toward the southwest, and Jagged Peak (2705 $\mathrm{m}$ asl) to the northeast). The black star marks the location of the snow pit and the green star marks a location that does not receive avalanche accumulation. d) Shaded relief map of the central Southern Alps showing the location of study area (yellow square) and the location of the Mt. Potts weather station (white dot). Prominent glaciers, lakes, and rivers are also shown. 


\subsection{Methods}

\subsubsection{Snow depth measurements}

We conducted a GPR survey on the Cameron Glacier in December 2009 near the end of the winter accumulation season. We used a RAMAC system (MALÅ Geoscience, Malå, Sweden) with shielded $500 \mathrm{MHz}$ and $25 \mathrm{MHz}$ antennae. The measurements were timetriggered. The $25 \mathrm{MHz}$ survey took place on 4 December, 2009 and the $500 \mathrm{MHz}$ GPR survey on 5 December, 2009 (Figure 5.1b). High frequency data were best for detecting shallow snow horizons ( $<3 \mathrm{~m}$ depth) and low frequency data revealed deeper horizons (3 to $30 \mathrm{~m}$ deep). The antennae were dragged over the snow surface by two skiers along cross and long profiles spaced roughly 100 to $200 \mathrm{~m}$ apart. High frequency (500 MHz) data were recorded at a density of 440 16-bit samples per trace using a time window of $232 \mathrm{~ns}$ and low frequency data $(25 \mathrm{MHz})$ at a density of 2024 4-bit samples per trace using a time window of $2168 \mathrm{~ns}$. The trace interval was time-triggered, with readings every other second for both frequencies.

Coordinates along each GPR profile were collected with a GPS at sub-metre accuracies (often $<0.5 \mathrm{~m}$ ). A Trimble GeoXH GPS, which was carried by the skier, recorded coordinates along the GPR tracks. The GPS data were corrected using the Mt. John Observatory base station (MTJO; 4359’08.5”S, 170²7'53.8”E, $1043.66 \mathrm{~m}$ ellipsoidal height, $\sim 80 \mathrm{~km}$ southwest of the field site).

Measured snow pack densities at a single location and three point measurements of snow depth were used to estimate a radio (or electromagnetic) wave velocity, which allows two-way-travel-time to be converted to snow depth. Snow pack densities logged from a pit (2025 m asl, black star in Figure 5.1c) averaged $550 \mathrm{~kg} \mathrm{~m}^{-3}$ in the top $2.3 \mathrm{~m}$ s.w.e. (snow water equivalent) depth. The horizons in the snow pit were dipping southeast, away from the steep northern wall (Figure 5.1b). Probing through the pit floor indicated that the previous summer surface was located $1.5 \mathrm{~m}$ s.w.e. below the bottom of the pit (3.8 m s.w.e. total depth). Two holes, made for ablation stakes, penetrated to 2.4 and $2.6 \mathrm{~m}$ s.w.e. and then encountered a debris layer at the ice surface. These two additional 
measured snow depths help to constrain interpreted snow depths from the GPR profiles.

Processing of radar plots using the software Globe Claritas (Ravens, 1995) allowed for noise-removal in the profiles. The remaining multiple internal reflection horizons were then 'picked' (digitised). This processing included migration to remove diffractions, a debias (akin to a high-pass filter), a Butterworth bandpass filter, and static removal (4300 sec for $25 \mathrm{MHz}$ data and $690 \mathrm{sec}$ for $500 \mathrm{MHz}$ data).

Snow depths (in $\mathrm{m}$ s.w.e.) were calculated using a radar velocity in snow $\left(v_{\text {snow }}\right)$ of $0.2 \mathrm{~m} \mathrm{~ns}^{-1}$ (Arcone, 2002; Heilig et al., 2009), density of $550 \mathrm{~kg} \mathrm{~m}^{-3}$ and the picked two-way-travel times. The following equation describes the relationship between the twoway-travel-time $\left(t_{T W T T}\right)$ and snow depth $\left(D_{\text {snow }}\right)$ in metres:

$$
D_{\text {snow }}=\frac{v_{\text {snow }} t_{T W T T}}{2}
$$

where 2 accounts for the round trip in the radar signal.

The three points of probed snow depth yielded a velocity of $0.254 \mathrm{~m} \mathrm{~ns}^{-1}$, however this value is higher than the typically reported range $\left(0.15-0.2 \mathrm{~m} \mathrm{~ns}^{-1}\right)$. Because there are only three points of snow depth, we decided to use the published velocity value of $0.2 \mathrm{~m} \mathrm{~ns}^{-1}$ (Arcone, 2002; Heilig et al., 2009). A higher velocity value would increase the calculated snow depths systematically, and would not change the overall snow distribution pattern. The resulting snow depths were then converted from units of $\mathrm{m}$ to $\mathrm{m}$ s.w.e. by dividing by the snow density.

All of the GPR picked lines (2009 summer surface) were plotted in 3-D to view the offset between different profiles where they cross. We noted offsets up to $0.5 \mathrm{~m}$ s.w.e. between overlapping profiles, which likely reflects manual picking error. Based on this offset, we consider our snow depth error to be $\pm 0.25 \mathrm{~m}$ s.w.e. The profiles were segmented in lengths of $\sim 200 \mathrm{~m}$ (Figure 5.1b). Snow depth characteristics were calculated for each 200 m section: gradient, mean, and range (maximum - minimum) of snow depth along profile segments. 
To compare modelled and measured snow depth patterns at the same resolution $(25 \mathrm{x} 25 \mathrm{~m}$ grid cells), measured snow depth data were assigned to grid cells corresponding to their geographic location and the maximum snow depth for each cell was used to represent the grid cell. The mean difference between maximum and minimum snow depth within a cell is $<0.5 \mathrm{~m}$, and the overall snow depth patterns remain the same whether we use maximum or minimum snow depths. The measured snow depth data therefore represent the greatest snow depth recorded in the location defined by a $25 \times 25 \mathrm{~m}$ grid cell. Using minimum values (not shown) does not change the results of this study.

\subsubsection{Modelling snow distribution}

The mass balance model used here (Anderson et al., 2010) was modified to include a gravitational snow MTD model (Gruber, 2007) to improve simulated snow depth on the Cameron Glacier. A distributed energy-balance model (EBM) is also part of the mass balance model and calculates the energy available for melt across the glacier. The mass balance model ran at a daily timestep and used daily, interpolated climate input data from 1 April, 2009 to 5 December, 2009 to model snow depth at the date of the GPR survey.

\section{Gravitational mass transport and deposition model}

The purpose of the mass transport and deposition model is to remove snow from steep slopes and move this snow downhill to gentler slopes. This is a simple slope-dependent model and does not capture kinetics nor snowpack evolution, which would be important for modelling larger, less frequent avalanches that occur on $30-45^{\circ}$ slopes. The two components of the MTD model are removal and deposition of snow. The percentage of removed snow (or mobile mass) in the model is set to zero for cells with a slope of less than $40^{\circ}$, increases linearly to $100 \%$ to a slope of $70^{\circ}$, and remains at $100 \%$ for all cells above $70^{\circ}$. These values are similar to those used by Gruber (2007). The mobile mass is moved downslope and distributed according to the equations that govern deposition.

The thickness and extent of modelled snow deposition is determined by the slope, mobile 

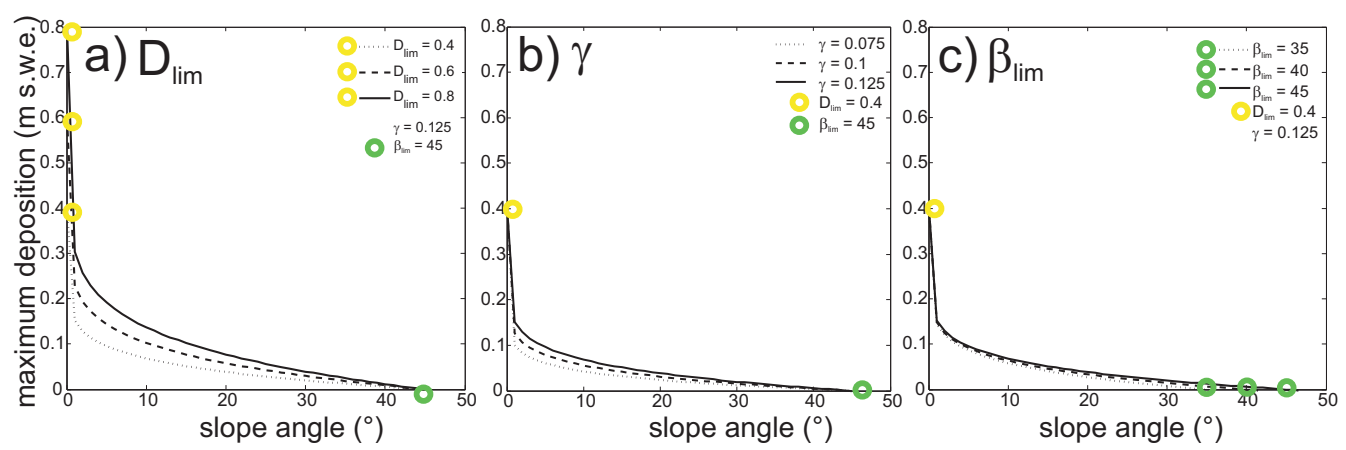

Figure 5.2 Slope angle $(\beta)$ versus maximum snow deposition $\left(D_{\max }\right)$ showing the influence of parameter values on the shape of the $D_{\max }-\beta$ curve. Parameters evaluated are a) $D_{\text {lim }}=0.4,0.6$, and $0.8 \mathrm{~m}$, b) $\gamma=0.075,0.1$, and 0.125 , and c) $\beta_{\text {lim }}=35,40$, and

$45^{\circ}$. Yellow circles mark $D_{\text {lim }}$ values, green circles mark $\beta_{\text {lim }}$ values and the solid, dashed, and dotted curves relate to the different values used for each parameter in each plot.

mass input, and four different parameters. One parameter that was not varied was the dispersion value, set to 0.1 , which accomodates divergent flow in multiple flow directions (Gruber and Peckham, 2009). The three other model parameters $\left(D_{\text {lim }}, \gamma\right.$, and $\left.\beta_{\text {lim }}\right)$, which define snow deposition thickness and extent, were varied for this work to achieve an acceptable fit between the measured and modelled distribution of snow depth. The maximum snow deposition, $D_{\max }$, is calculated as:

$$
D_{\text {max }}= \begin{cases}\left(1-\left(\frac{\beta}{\beta_{\text {lim }}}\right)^{\gamma}\right) D_{\text {lim }} & \text { if } \beta<\beta_{\text {lim }} \\ 0 & \text { if } \beta \geq \beta_{\text {lim }}\end{cases}
$$

where $D_{\text {lim }}$ is the maximum deposition limit (in flat areas $D_{\max }=D_{\text {lim }}$ ), $\beta_{\text {lim }}$ is the maximum slope at which mass begins to deposit, and $\gamma$ is used to control the shape of the curve relating maximum deposition, $D_{\max }$, to slope angle, $\beta$ (Figure 5.2). Snow deposition depth in a cell at each timestep cannot exceed $D_{\max }$ as defined by Equation (5.2). Figure 5.2 shows the effect of parameter value choice on $D_{\max }$ for a specific slope angle, $\beta$.

The shape and position of the $D_{\max }-\beta$ curves appear to be most sensitive to changes in $D_{\text {lim }}$ (Figure 5.2, yellow circles). Lower $D_{\text {lim }}$ values result in thinner and more extensive snow deposits, meaning the maximum reach of a fan is farther from the valley wall than tests with higher values. This parameter is dependent on the snow input and will therefore 
differ depending how much snow is moved in one timestep (Gruber, 2007). Grid resolution has also shown an influence on results and parameter choices (Gruber, 2007). The parameters discussed in this work are used with a daily model timestep on a $25 \mathrm{~m}$ grid resolution.

The parameter $\gamma$ alters the shape of the $D_{\max }-\beta$ curve and thus the relative influence of steep and gentle slopes on the dispersion of snow depth. Lower $\gamma$ values decrease $D_{\max }$ along the $D_{\text {max }}-\beta$ curve resulting in thinner, more extensive, and dispersed snow deposits (Gruber and Peckham, 2009).

$\beta_{\text {lim }}$ sets the maximum slope angle below which deposition can occur. Estimated parameter ranges are $36^{\circ}$ to $41^{\circ}$ with a mean of $39^{\circ}$ slope angle (Gruber, 2007). High $\beta_{\text {lim }}$ values shift the band of snow deposition closer to the valley walls because the snow is permitted to deposit in cells with higher slope angles (Figure 5.2, green circles), consequently, less snow is available to be deposited in the low-slope-angle cells. In other words, spatial extent of the snow deposit does not distribute far toward the centre of the glacier with high $\beta_{\text {lim }}$ values. The opposite is true for low $\beta_{\text {lim }}$ values, when the band of snow deposition is shifted away from the valley walls toward cells with lower slopes. The influence of this parameter on snow thickness and dispersion, in contrast to the previous two parameters, is likely to differ between catchments. In the Cameron Glacier catchment, the influence of $\beta_{\text {lim }}$ on the horizontal extent of snow deposits is the greatest of all three parameters.

\section{Energy-balance model}

To calculate daily ablation over the model domain, we first calculate the energy available for melt $\left(Q_{M}\right)$ following Anderson et al. (2010):

$$
Q_{M}=I(1-\alpha)+L \downarrow+L \uparrow+Q_{H}+Q_{E}+Q_{G}+Q_{R}
$$

where $I$ is the incoming shortwave radiation, $\alpha$ is the surface albedo, $L \downarrow$ is the incoming longwave radiation, $L \uparrow$ is the outgoing longwave radiation, $Q_{H}$ and $Q_{E}$ are the sensible 
and latent heat fluxes, $Q_{G}$ is the ground heat flux ( by rain (assuming that precipitation temperature is equal to air temperature (Oerlemans, 1992)). All energy fluxes are in units of $\mathrm{W} \mathrm{m}^{-2}$.

Incoming shortwave radiation $(I)$ consists of direct and diffuse components following Oerlemans (1992). The time-dependent albedo scheme is calculated using a firn albedo of 0.53, a fresh snow albedo of 0.9, and an ice albedo of 0.34 (Oerlemans and Knap, 1998; Anderson et al., 2010). Longwave and shortwave radiation were calculated to include the effects of the surrounding topography (Plummer and Phillips, 2003). Turbulent heat fluxes $\left(Q_{H}\right.$ and $\left.Q_{E}\right)$, which can make up half or more of the energy available for melt in maritime environments (Gillett and Cullen, 2011), were calculated using the bulk method and including the Richardson stability criterion (Klok and Oerlemans, 2002; Oerlemans and Grisogono, 2002).

There are no meteorological data from Cameron Glacier, and so we interpolated daily climatic input from several sources. First, we used daily interpolated climate surfaces and raw climate station data available from the National Institute of Water and Atmospheric Research (NIWA) CliFlo Database (NIWA, Retrieved 2009-2011). We used the virtual climate station network (VCSN) interpolated surfaces for relative humidity and solar radiation values (Tait and Zheng, 2007). Second, raw temperature data from nearby weather stations were interpolated based on the grid cell elevation and proximity to climate stations. Temperature data from a range of available stations were lapsed to sea level (using a lapse rate of $-5^{\circ} \mathrm{C} \mathrm{km}^{-1}$ ), interpolated to create a 'reference' temperature $T_{r}$ surface across the model domain, and then lapsed to the elevation of each grid point. The lapse rate was determined by minimising the mismatch between interpolated and measured 30day running mean temperatures from May, 2009 to August, 2010 at the nearby Mt. Potts automatic weather station (Station \#37002, 2128 m asl, NIWA (Retrieved 2009-2011)).

Third, a mean-annual (1971 to 2000) precipitation surface (Stuart, 2011) was used to adjust the interpolated daily precipitation amount for each grid cell (Anderson and Mackintosh, 2012). The annual precipitation total is estimated to be $\sim 2570 \mathrm{~mm}$ on the Arrowsmith Range. A precipitation factor of 1.2 (increase in daily precipitation by $20 \%$ ) was 
introduced to account for precipitation undercatch by conventional rain gauges (Trenberth et al., 2007). This increase was also an attempt to account for snow drift caused by preferential concentration and deposition of snowfall in relatively flat areas with lower wind speeds because wind redistribution was not explicitly taken into account in this model (Lehning et al., 2008; Dadic et al., 2010a,b; Mott and Lehning, 2010). The precipitation factor increases precipitation over the entire grid, however, and not only in the areas likely to receive snow drifts (e.g. lee slopes or areas with lower wind speeds).

The fourth source of input climate data came from the National Centers for Environmental Prediction (Kalnay et al., 1996) reanalysis data at the $850 \mathrm{hPa}$ level (from 1977 to 2011) for wind speed, which were scaled to match observed wind speed in the central Southern Alps (Anderson and Mackintosh, 2012) and were applied uniformly to the model domain. This scaling was done because the VCSN windspeed data contain artefacts and are considered to be less reliable. Further discussion on using these datasets for glacier mass balance modelling is given in Anderson and Mackintosh (2012).

A DEM (GeographiX (NZ) Ltd) was derived from the New Zealand map series published by Land Information New Zealand in 1999 (NZMS260). The model domain is a rectangular section, $4 \mathrm{~km}$ by $4.2 \mathrm{~km}$ in size, of Cameron Glacier and the adjacent topography.

Although the model uses a time-dependent scheme to estimate snow albedo (simulating snow ageing processes) not all factors influencing albedo are taken into account. For example, the model simulations did not account for the effects of decreased albedo from dust/ash nor a difference in albedo of fallen versus avalanched snow. We included a debris cover grid to account for reduction in ice ablation (reduced melt by 90\%) (Anderson and Mackintosh, 2012) mapped from orthogonally corrected vertical aerial photographs taken 30 January, 2006 (www.terralink.co.nz).

Modelled snowfall is a function of air temperature, which decreases with elevation according to the input precipitation and temperature lapse rate prescribed $\left(-5^{\circ} \mathrm{C} \mathrm{km}^{-1}\right)$. When the temperature at a grid cell was at or below the snow/rain temperature threshold ( $T_{\text {snow }}$ set to $1^{\circ} \mathrm{C}$ (Anderson et al., 2006)), the precipitation was prescribed as snow. In simulations using the MTD model, avalanching occurs at every timestep (daily) when 
there is solid precipitation in the domain. Mass balance of the glacier was calculated by subtracting the amount of melt from the amount of direct and redistributed snow at each grid cell. For further details about the EBM see Anderson et al. (2010) and Anderson and Mackintosh (2012).

\section{Model experiments}

We explored the effect of $D_{\text {lim }}, \beta_{\text {lim }}$, and $\gamma$ parameters (Table 5.1) on modelled snow depths to find parameter values that best estimate measured snow distribution. We determined the best parameter value combination by comparing modelled and measured snow thickness along profiles of GPR data. Testing the combinations of three parameters, with three different values each, required 27 different model runs (MR1-MR27). Each run started on 1 April, 2009, when snow depth was close to a minimum, and ended 5 December, 2009. The modelled snow thickness distribution was compared to our measured data from 5 December, 2009. A simulation of the glacier snow distribution without the MTD model (MR28) was made for comparison.

For each profile we determined three characteristics that describe the snow depth. First is the gradient of the snow depth along the profile, for example, if the snow depth is relatively uniform along the profile, then the gradient is near zero, whereas gradients of snow depth in profiles intersecting avalanche deposits are noticeably greater. Second is the mean value of the snow depth along each profile and third is the range in snow depths (maximum snow depth - minimum snow depth) along each profile.

To compare these three characteristics between the GPR results and the simulations, relative comparisons (modelled value divided by measured value) were determined for each section for each model run presented for the three characteristics.

$$
F=\frac{\bmod }{\text { meas }}
$$

where $F$ is the relative comparison, mod is the modelled and meas is the measured snow 
depth characteristic. A value of one means the modelled and measured values were the same, whereas less than one means the model was under-predicting and more than one means the model was over-predicting. The number of profile relative comparisons close to unity ( $>\frac{2}{3}$ and $<\frac{3}{2}$ ) were tallied for each model run. We define the 'acceptable fit' range by using a reciprocal, rather than an equally distributed range, because we are examining relative comparisons rather than absolute values.

\subsection{Results and Discussion}

\subsubsection{GPR snow depth estimations}

The GPR profiles show several prominent internal snow horizons (Figure 5.3), and we interpreted the most prominent horizon (marked by a red dashed line, Figure 5.3) as the reflector from the previous end of summer (April, 2009) glacier surface. Deeper horizons (unmarked) are likely to be previous summer surfaces or other significant melt events. The snow depths along profiles, represented by the red line, intersect with our three point measurements within error, with the electromagnetic wave velocity used.

The measured snow distribution from the GPR survey yields an average depth of $3.5 \mathrm{~m}$ s.w.e., with a maximum of $6.2 \mathrm{~m}$ s.w.e. in profile G (Figure 5.4d) located near the steep northern slope (Figure 5.1a+b). Snow depths are greatest near the northern edge of the glacier where high relief and steep slopes supply snow from higher elevations. Because of the steep slopes and avalanching, this area also shows the highest gradients and ranges (maximum-minimum) in snow depth. Two longitudinal profiles (S and T, Figure 5.4d) in the lower part of the glacier show deep snow areas, which are likely where the profiles intersect especially thick avalanche deposits. Profiles A, B, C, E, I, and J (Figures 5.1b and 5.4d) are located in the upper part of the glacier, outside of the influence of prominent avalanche slopes. Snow depths along these profiles range from 1 - 3 m s.w.e. consistent with this observation. In these profiles, the variability in snow depth is likely due to preferential deposition and redistribution by wind (not included in our model). 

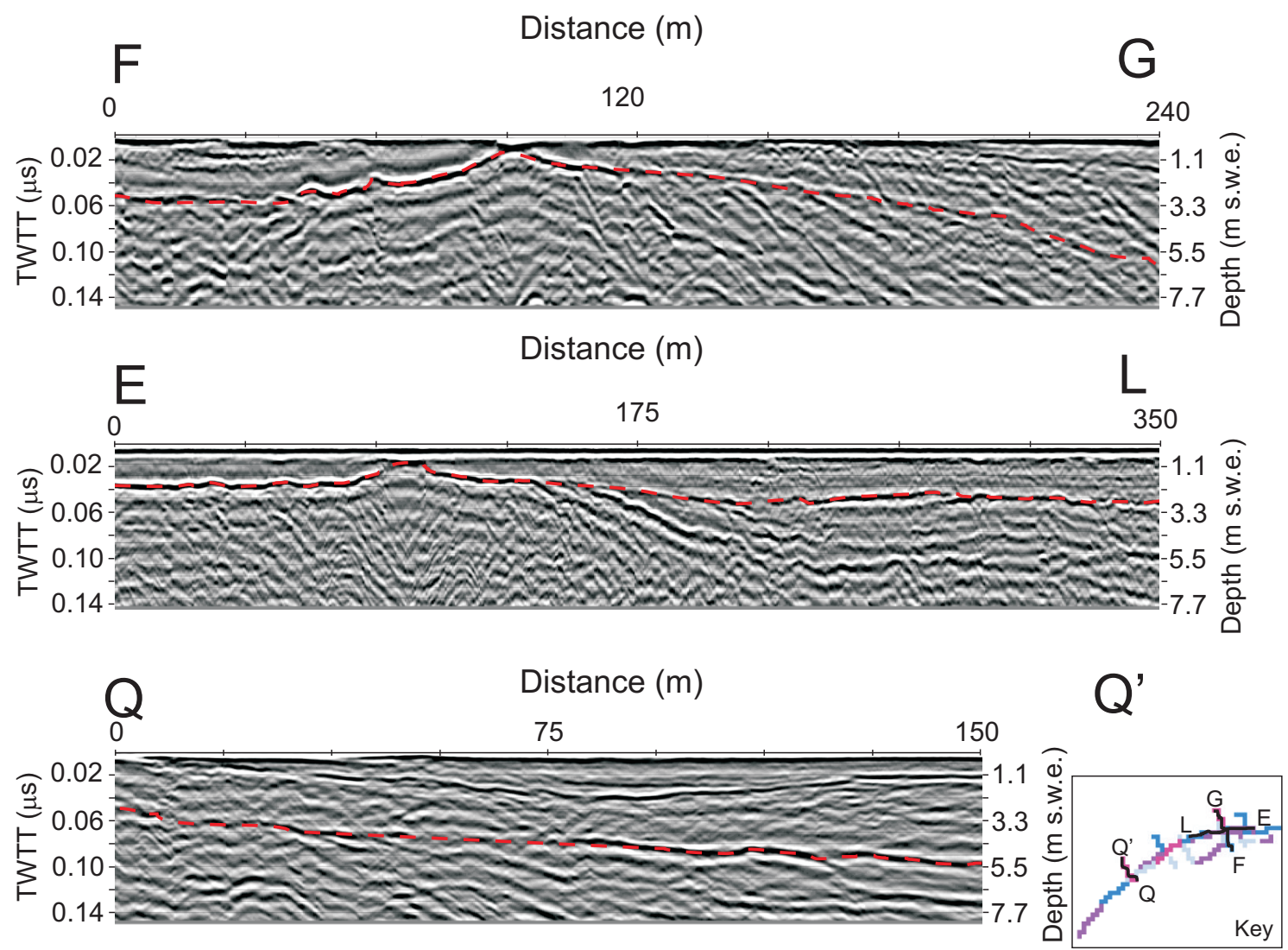

Figure 5.3 Interpreted snow depth from the December, 2009 Cameron Glacier low-frequency GPR profiles. Profiles F-G, and Q-Q' show cross sections of the glacier while profile E-L follows the central flowline (see key and Figure 5.1b). Note the strong reflector, interpreted as the end of summer glacier surface for 2009 (red dashed line) and deeper reflectors representing previous summer surfaces (not marked). Reflections in the E-L profile show old accumulated snow deposits below the 2009 summer surface. 

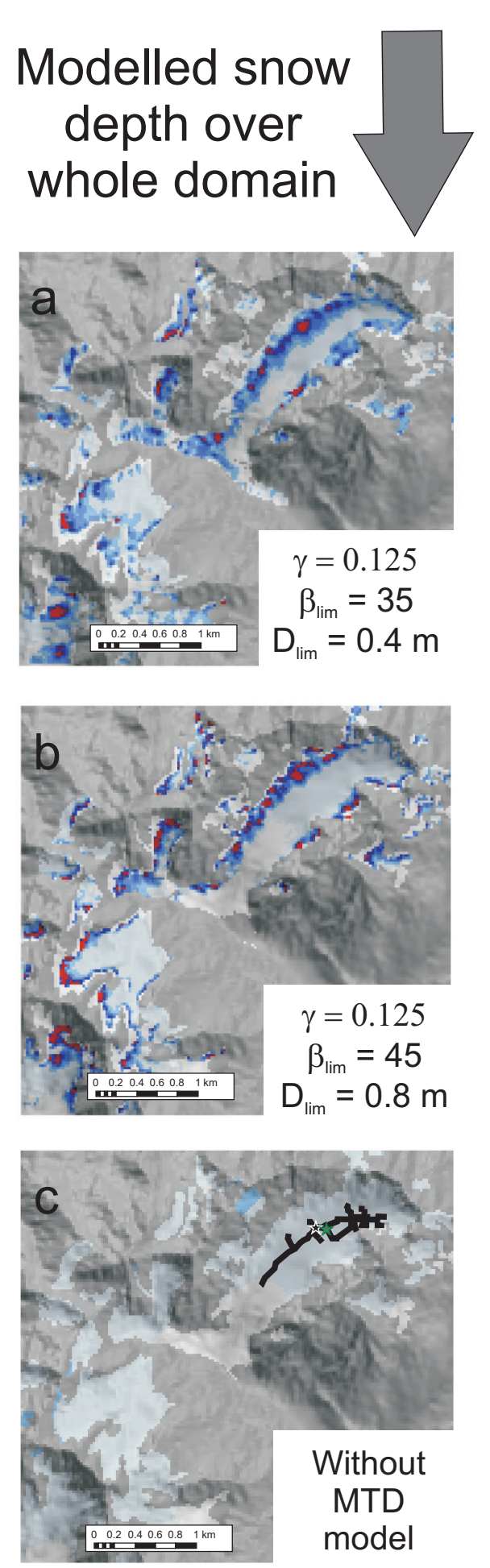
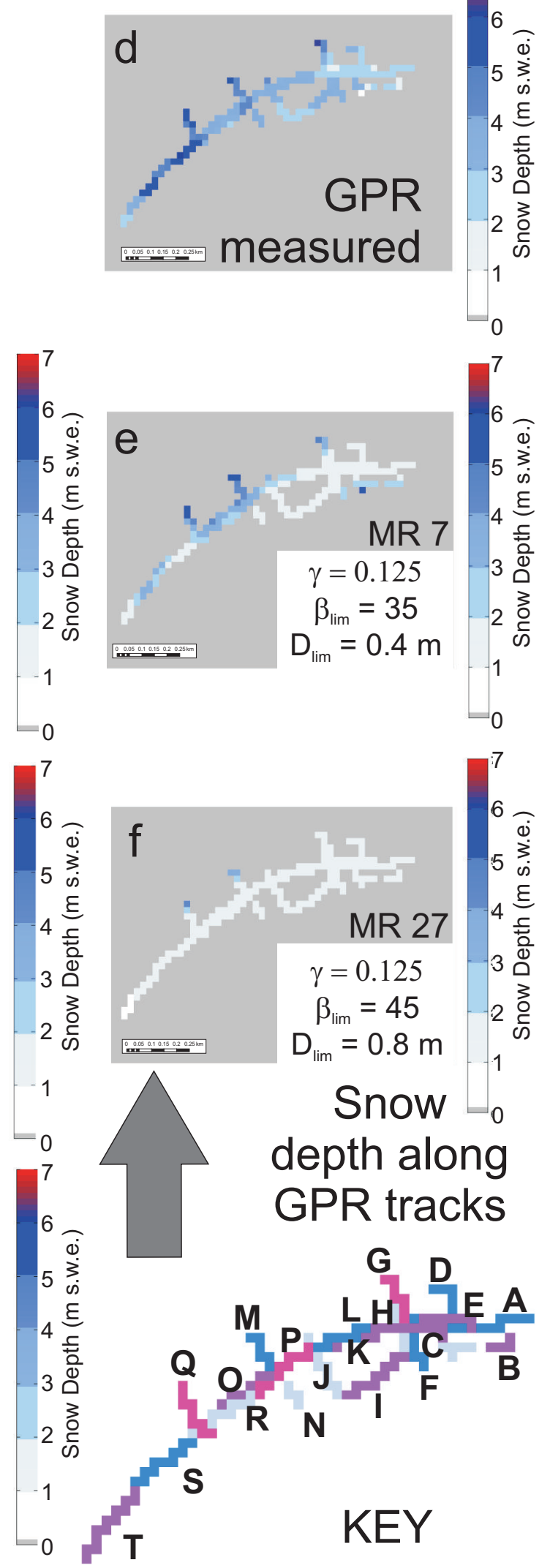

Figure 5.4 Snow depth over the model domain (a-c) and along GPR profiles (d-f). Snow depth (m s.w.e.) from the a) optimal parameter set, b) less appropriate parameter set, c) model run without the MTD model, d) GPR data, e) optimal parameter set, and f) less appropriate parameter set. The snow distribution in the optimal model run reflects the observed accumulation pattern at Cameron Glacier better than the other runs. Panel c) also shows GPR lines for reference, a black star (white outline) to mark the location of the snow pit and a green star to mark a point of interest in the discussion. 
a) Gradient

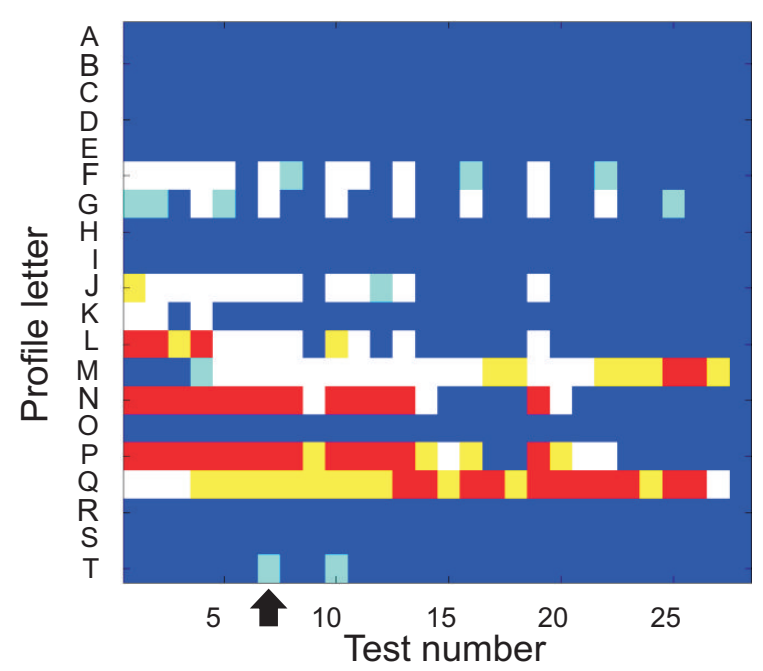

c) Range

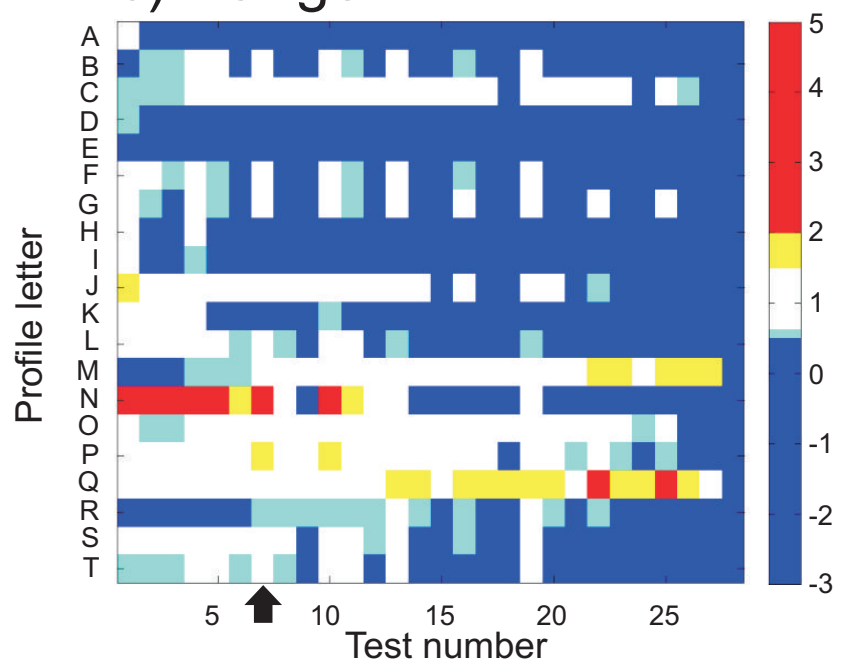

b) Mean
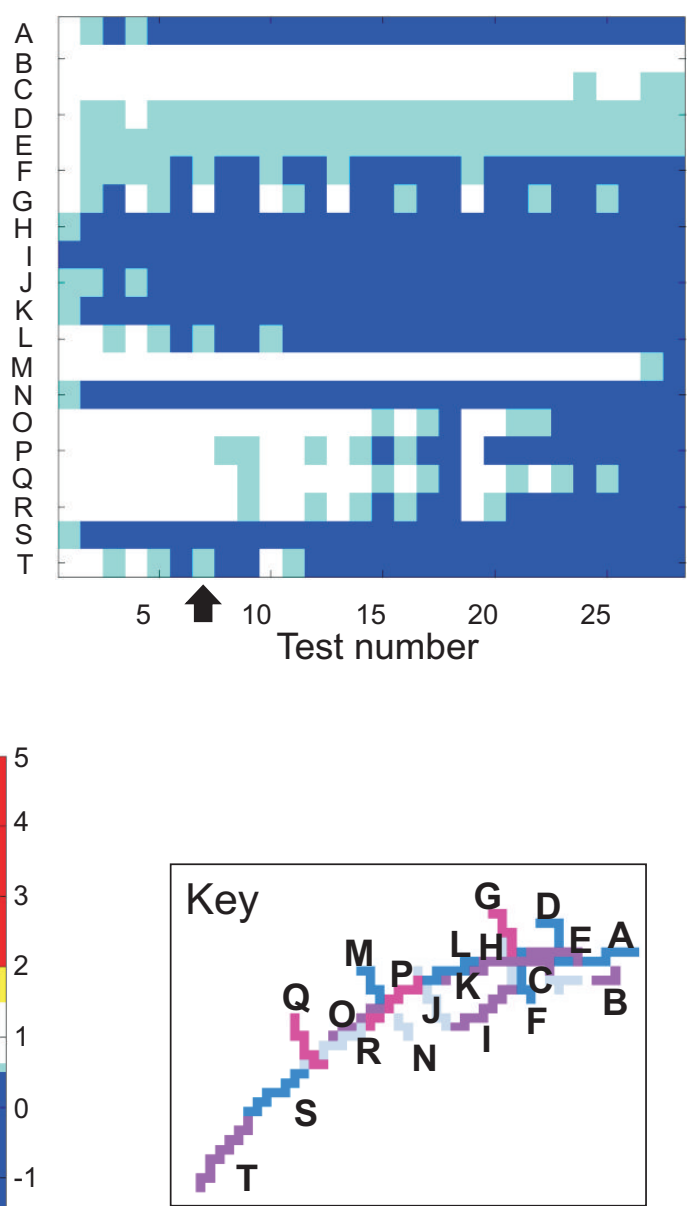

Figure 5.5 Matrices showing relative comparisons (by colour) between modelled data and measured snow depth (a) gradient, (b) mean, and (c) range for each profile for each run. Red-coloured cells show where the model over estimated values, blue represents under-estimated values, and white is within the accepted range where modelled and measured are similar. Black arrows point to the 'best-fit' simulation and the final column (test 28) is the simulation without the MTD model. Profile key to the left is for reference. 


\subsubsection{Ability of the model to replicate snow distribution}

To assess the ability of the MTD model to replicate measured snow depths, we compared the snow depth distribution from GPR measurements to estimates from 27 model runs that used unique combinations of three different values for each of the three parameters $\left(\beta_{\text {lim }}\right.$, $D_{\text {lim }}$, and $\gamma$, Figure 5.2 and Table 5.1). In general, choosing a lower value of $\gamma$, lower limiting slope $\beta_{\text {lim }}$, or lower limiting deposition $D_{\text {lim }}$ results in a simulated snow cover that extends farther than that produced with higher parameter values (Figure 5.4a). High values of $\beta_{\text {lim }}$ and $D_{\text {lim }}$ result in a less extensive deposit and thicker snow closer to the valley walls (Figure 5.4b). In the simulation without the MTD model (MR28), the snow cover is determined by modelled snowfall alone, which increases slightly with elevation as described above (Figure 5.4c). As expected, this simulation severely underestimates snow thickness at the glaciated areas below steep slopes.

The goodness of fit between modelled and measured snow depth varied with each model run (unique combination of the model parameters) and profile location. To visualise the goodness of fit for each model run along each profile, we display the results in three coloured matrices where blue colours represent an underestimation, red is an overestimation, and white represents an appropriate fit between the modelled and measured snow depths (Figure 5.5). Light blue and yellow coloured boxes represent slight underestimates and slight overestimates, respectively. Snow depth characteristics (gradient, mean, and range modelled:measured relative comparisons) are represented in three separate matrices (Figure 5.5a, b, and c respectively). The rows represent different profiles and the columns represent different model runs. We will now explain and interpret each of the characteristic matrices.

'Gradients' describe the uniformity of snow depth, where uniform snow depth along a profile would have a negligible gradient. The gradient relative comparison is difficult to interpret for profiles with small gradients (less than 0.001). This difficulty occurs because (1) we are dealing with small numbers divided by small numbers and (2) the model could be producing appropriately small gradients but sloping in the opposite direction, thus making the gradient (and the resulting relative comparison) negative in sign (Figure 5.5a). 
Table 5.1 Model run number with parameter combination and the number of profiles with an acceptable fit (where the relative comparison is between $\frac{2}{3}$ and $\frac{3}{2}$ ). The number of 'acceptable fits' per test for the gradient, mean, and range relative comparisons are listed as well as the total sum of 'acceptable fits' for each model run. MR28 is without the avalanche model. Note that model runs with $\beta_{l i m}=35^{\circ}$ perform relatively well (bold font).

\begin{tabular}{|c|c|c|c|c|c|c|c|}
\hline \multicolumn{4}{|c|}{ Model } & \multicolumn{4}{|c|}{ Number of 'acceptable fits' (white boxes) } \\
\hline Run & $\beta_{l i m}\left({ }^{\circ}\right)$ & $\gamma$ & $D_{\text {lim }}(\mathrm{m})$ & Grad & Mean & Range & Total \\
\hline 1 & 35 & 0.075 & 0.4 & 3 & 12 & 9 & 24 \\
\hline 2 & 40 & 0.075 & 0.4 & 4 & 9 & 7 & 20 \\
\hline 3 & 45 & 0.075 & 0.4 & 3 & 7 & 5 & 15 \\
\hline 4 & 35 & 0.1 & 0.4 & 3 & 10 & 13 & 26 \\
\hline 5 & 40 & 0.1 & 0.4 & 3 & 7 & 7 & 17 \\
\hline 6 & 45 & 0.1 & 0.4 & 2 & 6 & 5 & 13 \\
\hline 7 & 35 & 0.125 & 0.4 & 5 & 8 & 11 & 24 \\
\hline 8 & 40 & 0.125 & 0.4 & 3 & 5 & 8 & 16 \\
\hline 9 & 45 & 0.125 & 0.4 & 2 & 4 & 5 & 11 \\
\hline 10 & 35 & 0.075 & 0.6 & 4 & 8 & 11 & 23 \\
\hline 11 & 40 & 0.075 & 0.6 & 3 & 7 & 7 & 17 \\
\hline 12 & 45 & 0.075 & 0.6 & 1 & 4 & 7 & 12 \\
\hline 13 & 35 & 0.1 & 0.6 & 5 & 5 & 10 & 20 \\
\hline 14 & 40 & 0.1 & 0.6 & 2 & 4 & 5 & 11 \\
\hline 15 & 45 & 0.1 & 0.6 & 2 & 2 & 3 & 7 \\
\hline 16 & 35 & 0.125 & 0.6 & 2 & 5 & 6 & 13 \\
\hline 17 & 40 & 0.125 & 0.6 & 0 & 2 & 3 & 5 \\
\hline 18 & 45 & 0.125 & 0.6 & 0 & 1 & 2 & 3 \\
\hline 19 & 35 & 0.075 & 0.8 & 5 & 5 & 10 & 20 \\
\hline 20 & 40 & 0.075 & 0.8 & 1 & 4 & 4 & 9 \\
\hline 21 & 45 & 0.075 & 0.8 & 2 & 2 & 3 & 7 \\
\hline 22 & 35 & 0.1 & 0.8 & 2 & 3 & 4 & 9 \\
\hline 23 & 40 & 0.1 & 0.8 & 0 & 2 & 2 & 4 \\
\hline 24 & 45 & 0.1 & 0.8 & 0 & 1 & 1 & 2 \\
\hline 25 & 35 & 0.125 & 0.8 & 0 & 3 & 3 & 6 \\
\hline 26 & 40 & 0.125 & 0.8 & 0 & 1 & 0 & 1 \\
\hline 27 & 45 & 0.125 & 0.8 & 1 & 0 & 1 & 2 \\
\hline 28 & na & na & na & 0 & 0 & 0 & 0 \\
\hline
\end{tabular}


A minor difference between the modelled and measured gradients could produce relative comparisons showing significant underestimations or overestimations. Profiles with small gradients (i.e. along profiles located in the centre of the glacier surface) are thus less likely to show good fits. We therefore do not consider the gradient differences to be a particularly good characteristic for judging the goodness of fit between modelled and measured snow depth.

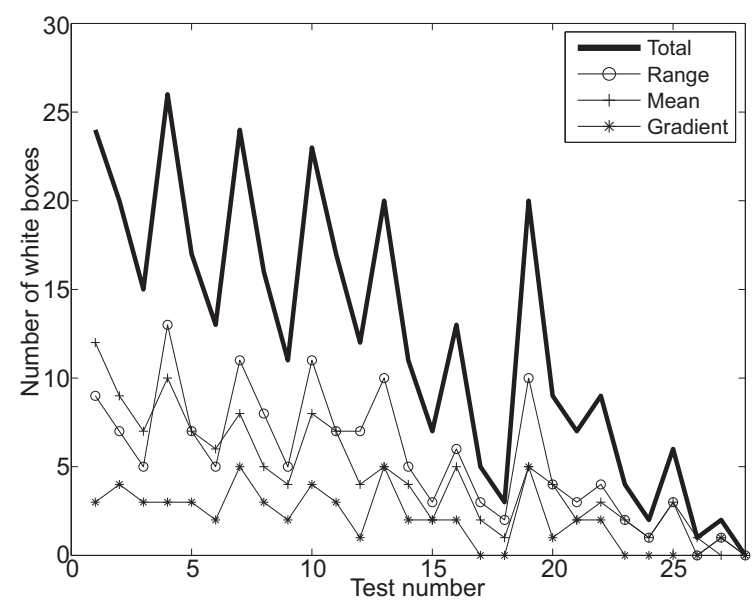

Figure 5.6 Graph showing the number of 'acceptable fits' (white cells in Figure 5.5 and Table 5.1) for the gradient $(\circ)$, mean $(+)$, and range $(*)$ relative comparisons for each model run, with the total sum of the white boxes in bold. Note the overall decrease in the total (bold line) sum of white cells from MR1 - MR28.

For our purposes, it is better to judge the goodness of fit between modelled and measured avalanche snow deposit data based on the relative pattern, rather than the absolute values, of snow depth. The mean snow depth along each profile gives absolute values and the mean snow depth relative comparisons show that the mass balance model consistently underestimates accumulation (Figure 5.5b). This underestimation is an issue for the entire model domain, and is examined by comparing measured and modelled snow depths in areas where snow avalanche deposits do not affect the accumulation (location represented by the green star in Figures 5.1c and 5.4c). At this location, the GPR-measured snow depth is $2.8 \mathrm{~m}$ s.w.e., compared to modelled estimates of $2.0 \mathrm{~m}$ s.w.e. in MR1 and $1.2 \mathrm{~m}$ s.w.e. in MR28. The difference in modelled snow depth estimates is because MR1 simulates unrealistic, thin, extensive avalanche deposits, causing an increase in modelled snow depth for most of the glacier surface, even in areas that should not be receiving avalanched snow. Although the mean snow depth relative comparisons from MR1 are closer to unity (Figures 5.5 and 5.6), the simulation is based on an inappropriate model parameter value 
combination resulting in unrealistic avalanche deposits. The snow depth estimate from MR28 is significantly lower than the measured value (by $1.6 \mathrm{~m}$ s.w.e.), meaning that the modelled background 'snowfall' is greatly underestimated. The underestimation of background snowfall in the model could be explained by the following reasons:

1. The reflective horizon in this GPR profile does not represent the previous summer (Figure 5.3).

2. The mass balance model underestimates total accumulation.

3. The additional snow at this location is caused by preferential deposition or redistribution of snow in lower, more sheltered areas due to wind.

Of these reasons, we consider the latter to be the most likely cause of the offset. The addition of a model that describes wind-driven redistribution would likely improve the simulated snow depth estimates (Liston and Sturm, 1998; Lehning et al., 2008; Dadic et al., 2010a,b). Alternatively without a wind redistribution model, precipitation would need to be more than doubled, which is unrealistic, to achieve similar snow depths in non-avalanche locations. While the mean snow depth provides a good indication of overall model performance (largely underestimating, shown in Figure 5.5b), it does not distinguish the spatial patterns well. For these reasons, we do not use the mean relative comparison to represent the success of the model to produce appropriate snow depth patterns.

We think that the snow depth range (maximum - minimum snow depth within a profile) provides a good representation of the snow depth patterns without needing the absolute values of snow depth to be the same between modelled and measured values. Profiles that intersect deposits caused by avalanches will likely have a greater range value than profiles that are located beyond the reach of the avalanche deposits. This difference is because of the accumulation concentration in the avalanche deposits and generally uniform snow depth elsewhere. Using the range relative comparisons allows us to focus on the ability of the model to simulate similar snow depth patterns. The range relative comparison shows patterns even when the overall magnitude is underestimated. For these reasons, we focus 
the following discussion on the range relative comparison matrix (Figure 5.5c). We will now discuss the profiles in groups, based on their geographic setting and proximity to avalanche deposits.

Cross profiles G, M, and Q (Figure 5.5c) are located close to the steep northern slopes of the catchment and they trend parallel to the axis of avalanches (Figure 5.4). Model runs that simulate extensive, thin snow deposits (e.g. MR1) underestimate the snow depth range in these profiles (by $2.9,0.6$, and $2.0 \mathrm{~m}$ s.w.e. in MR1 respectively). In contrast, model runs with snow depositions that are too deep or too close to the valley walls (e.g. MR27) overestimate the measured snow depth range in profiles $M$ and Q (by 1 and $0.8 \mathrm{~m}$ s.w.e. in MR27 respectively). In the same model run (MR27), the snow depth range in profile $\mathrm{G}$ is underestimated (by $4.4 \mathrm{~m}$ s.w.e.) rather than overestimated. This difference between profiles $\mathrm{G}$ and $\mathrm{M}$, in terms of response to model parameters, is because the snow deposits in MR27 did not reach the location of profile G (Figure 5.4f). Modelled snow depth in profile $\mathrm{G}$ is consistently underestimated for model runs with a $\beta_{\text {lim }}>35^{\circ}$ (Figure 5.5c), because modelled snow deposits in those tests do not reach the position of profile G (Figure 5.4f).

Longitudinal profiles $\mathrm{S}$ and $\mathrm{T}$ are located towards the lower part of the glacier and snow deposits of up to 6.1 and $5.7 \mathrm{~m}$ s.w.e. in depth were measured (Figure 5.4d). We could not replicate these deep, extensive deposits with our model. Modelled snow deposits along these profiles were either not as deep in MR7 (Figure 5.4a and e) or were not extensive enough to reach these profile locations (e.g. MR27, Figure 5.4b and f). The underestimation of snow depth along these profiles could be due to the lack of preferential deposition or redeposition by wind in our model.

Some profiles (A, D, E, H, I, and K) showed little to no variability in range relative comparison with changing parameter values (Figure 5.5c) because they are consistently underestimated. Profiles A, D, and I are located below moderate slopes of valley walls with low to moderate relief where minor avalanching does not appear to affect snow depth across the profile. Profiles E, H, and K are distant from steep slopes and are more likely influenced by direct snowfall and wind distribution effects rather than avalanching. Snow 
depth ranges in profiles $\mathrm{D}$ and $\mathrm{E}$ are underestimated in all model runs, because there is a deep depression visible in both GPR profiles (D and E) where these profiles intersect. We have not investigated the cause of this depression and the model did not resolve the range in snow depths caused by this feature.

Cross profiles located in or near the middle of the glacier (J, N, and P) show an overestimation of snow depth range for some of the model runs with more extensive deposits, meaning that the snow depth ranges are lower than what was modelled. This could be interpreted to mean that the profile locations are beyond the reach of avalanches produced in the earlier model runs (MR1-11). Profiles $\mathrm{J}$ and $\mathrm{N}$ show modelled snow depth means that were lower than what was measured (Figure 5.5b). Profiles $\mathrm{C}$ and $\mathrm{O}$ show an acceptable fit with most of the model tests, suggesting that these locations are not directly affected by avalanche accumulation. Profiles B, F, G, L, and T show a good fit (or slight underestimation) in model runs 4, 5, 7, 10, 11, 13, and 19 (Figure 5.5c).

The southern slopes above the glacier are predominantly between 40 and 60 degrees and reach elevations of $\sim 2400 \mathrm{~m}$ asl, whereas the northern slopes above the glacier exceed 60 degrees and reach elevations of $2700 \mathrm{~m}$ asl (Figure 5.1c). Profiles below steep slopes $\left(>60^{\circ}\right)$ have measured and modelled snow depth ranges that are similar. Steep slopes are far more likely to lose their snow cover due to small and frequent avalanches, as can be approximated by this model, than more moderate slopes $\left(40\right.$ to $\left.60^{\circ}\right)$. The parameters in the MTD model could be adjusted to account for this difference if tuned with more thorough snow distribution data or if parameter values were varied for different regions in the model domain.

Snow depth estimates in the simulation without the MTD model (MR28) are consistently underestimated. All of the snow depth characteristic values (mean snow depth, gradients along the profiles, and ranges in snow depth) are also underestimated (Figure 5.5c) in this model run. As described above, the EBM prescribes snowfall as a function of temperature at each cell and thus modelled snow thickness increases with elevation, according to the temperature lapse rate. This leads to an unrealistic snow cover in steep, high-elevation sites, which do not accumulate snow in reality. At the 5 December 2009 timestep in this 
model run, the area mapped as 'glacier' contains very little snow, with a maximum snow depth of less than $2 \mathrm{~m}$ s.w.e. on the main trunk of the Cameron Glacier (Figure 5.4c).

Figure 5.6 shows the number of profiles with a good fit (white boxes in Figure 5.5c) between modelled and measured snow depth characteristics for each model run number. The lines represent each of the different snow depth characteristics (gradient, mean, and range) and the bold line shows the total number of good fits for each model run. In general, the total number of profiles with a good fit decreases with increased model run number (Figure 5.6). This trend is a result of higher parameter values and thus the development of thicker, less extensive snow deposits in the model. Best agreement between modelled and measured values is when $\beta_{\text {lim }}$ equals $35^{\circ}$ (MR4, 7, 10, 13, and 19, in Table 5.1 and peaks in Figure 5.6). This $\beta_{\text {lim }}$ value works well for this catchment but is low compared to previous studies (typically 36 to $\left.41^{\circ}\right)\left(\right.$ Gruber, 2007). The other two parameters $\left(D_{\text {lim }}\right.$ and $\gamma$ ) appear to compensate for one another. For example, the snow distribution with $D_{\text {lim }}$ set to $0.6 \mathrm{~m}$ and $\gamma$ set to 0.075 (MR10) looks very similar to a snow distribution with $D_{\text {lim }}$ set to $0.4 \mathrm{~m}$ and $\gamma$ set to 0.125 (MR7). However, $\gamma=0.125$ is at the lower end of values that have been tested by Gruber and Peckham (2009) (0.125 to 2).

The number of acceptable fits (where relative comparison is $>\frac{2}{3}$ and $<\frac{3}{2}$, represented by white boxes) in each matrix was summed for each model run in Figure 5.6. MR7 ( $\left.D_{\text {lim }}=0.4, \gamma=0.125, \beta_{\text {lim }}=35\right)$ best represents the measured snow depth ranges. Our lower $\gamma$ and $\beta_{\text {lim }}$ values promote greater deposition on the glacier surface, improving the fit between measured and modelled snow depth. Although these lower parameter values work well for this basin, they could be artificially accounting for effects due to winddriven snow distribution within the catchment (Machguth et al., 2006; Dadic et al., 2010a; Lehning et al., 2011; Dadic et al., in press). Winds could also be bringing additional snow from mountain slopes upwind of the catchment to Cameron Glacier (e.g. slopes of Lawrence Peak or western slopes of Jagged Peak).

Avalanche-derived snow deposits increase the total accumulation over a glacier and delay the seasonal exposure of the ice surface in places. Whether snow or ice is exposed affects the rate of ablation in our mass balance model, because the ice and snow surfaces have 
different albedo values and surface roughness lengths. Simulating the end of summer mass balance, in the absence of the MTD model, would underestimate the accumulation and thus the resulting mass balance would be too negative. Deep snow deposits will take longer to melt than an evenly distributed snow cover (Dadic et al., 2008). The success of the MTD model in simulating snow depth patterns indicates that this parameterisation is a useful addition to mass-balance models.

The $\beta_{\text {lim }}$ and $\gamma$ optimal values in this experiment are likely to be applicable to simulations at different timesteps (e.g. monthly). However, the $D_{\text {lim }}$ value depends on the mobile mass of snow and thus is influenced by the model timestep, DEM grid resolution, and climatic input (Gruber, 2007). We tried running the avalanche model once per model year, month, and day. Running the avalanche model once per year meant that the snow mass input was on the scale of metres. This difference in model setup required the $D_{\text {lim }}$ value to be on the metre-scale as well, $\sim 40 \mathrm{~m}$. Running the avalanche model once per month required a $D_{\text {lim }}$ value of $\sim 4 \mathrm{~m}$ to achieve a similar modelled snow distribution. Essentially, $D_{\text {lim }}$ is linearly correlated to the mobile mass of snow input, and $D_{\text {lim }}$ should be adjusted linearly with the snow input. Running the avalanche model once per day showed that a $D_{\text {lim }}$ set to $\sim 0.4 \mathrm{~m}$ simulates the most appropriate snow distribution. Although running the avalanche model at a daily timestep required more computational time, avalanches should be resolved daily to account for the effects of snow presence or absence in a cell in the energy balance model.

\subsection{Conclusions}

Accumulation concentration by avalanching is an important process to capture in mass balance modelling of glaciers in steep terrain (Machguth et al., 2006). The goal of this study was to test the effect of parameter values on modelled snow deposition in a gravitational snow mass transport and deposition (MTD) algorithm (Gruber, 2007), to evaluate optimal parameter values, and to determine where in the Cameron Glacier catchment this simple MTD model is appropriate. We draw the following conclusions: 
1. $D_{\text {lim }}$ should increase linearly with snow mass input and should be adjusted for a different DEM, climatic setting, and/or timestep. A $D_{\text {lim }}$ value of $0.4 \mathrm{~m}$ s.w.e. worked well for this study at a daily timestep.

2. $\beta_{\text {lim }}=35^{\circ}$ and $\gamma=0.125$ allowed snow deposits to a similar extent as what was observed on the glacier with ground penetrating radar measurements.

3. The algorithm works well in areas with steep slopes $\left(>60^{\circ}\right)$ where small, frequent gravitational snow redistribution events are common. Profiles M and Q are located below moderately steep slopes and their snow depth ranges (maximum - minimum value in s.w.e.) were modelled well.

4. Modelled snow accumulation would be underestimated by up to $6 \mathrm{~m}$ s.w.e. at this site without the use of the MTD model.

The addition of the MTD algorithm to the EBM model greatly improves the comparison between modelled and measured snow distribution on the avalanche-fed Cameron Glacier. The optimal parameter values offered here are likely to be suitable for experiments with a similar DEM grid resolution, timestep, and climatic setting. Simulating avalanche deposit accumulation in a mass balance model should improve estimations of mass balance modelling of avalanche-fed glaciers, snow melt runoff rates in complex terrain, and palaeoclimate estimates derived from avalanche-fed glaciers. 


\section{Chapter 6}

\section{What do Holocene moraines at Cameron Glacier, New}

\section{Zealand tell us about past climate change?}

\section{Abstract}

Even in a steady climate, interannual variability of temperature and precipitation can cause considerable advance or retreat of glaciers. This sensitivity raises questions about whether Holocene glacial moraines, which typically lie close to present-day glaciers, are useful for palaeoclimatic reconstructions. To better understand the relationship between glacier extent and climate at Cameron Glacier, New Zealand, during the Holocene, we use a glacier model that takes climate data as input and returns glacier extent. The model consists of a 2-D ice-flow model coupled to a mass balance model with a gravitational snow transport and deposition component. In a first experiment, a suite of steady-state simulations is used to identify the temperature and precipitation change required to fit the modelled glacier to five dated moraines. The second experiment involves forcing the model with stochastic interannual temperature variability, here described as a 2000 year long sequence of white noise values. We find that temperature changes of $-1.3,-2.1$, $-2.4,-2.7$, and $-3.3 \pm 0.4^{\circ} \mathrm{C}$ are required for the glacier to reach the moraines dated to $180 \pm 48,523 \pm 61,8,190 \pm 230,10,690 \pm 410$ and $\sim 13,000$ years before AD 1950 (years $\mathrm{BP})$, respectively, assuming no change in precipitation occurred. Stochastic variability in annual mean temperature caused the glacier to fluctuate from its baseline moraine position by up to $200 \mathrm{~m}$, which is not enough to produce the Holocene glacier length changes recorded in this catchment. This suggests that the glacier was responding to more persistent (decadal or centennial-scale long) climate changes during the Holocene, and that the moraine record is a reliable indicator of past climate events. 


\subsection{Introduction}

Glacier modelling studies have shown that interannual stochastic variability in mass balance (prescribed as white noise) can result in significant fluctuations $(\sim 1 \mathrm{~km})$ in glacier length (Oerlemans, 2000; Reichert et al., 2002; Huybers and Roe, 2009; Roe and O’Neal, 2009; Roe, 2011). Glaciers act as a filter of annual mass balance changes and fluctuations in glacier length depend on the mass balance changes integrated through time and the specific geometry of the glacier. It is possible for a glacier to filter a random interannual temperature forcing (white noise - no persistence) signal into a decadal-to-century time scale (red noise - some persistence) signal (Oerlemans, 2000). These studies suggest that relatively small events such as the Little Ice Age (LIA), which is often associated with moraines located within the range of 'random' glacier fluctuations $(\sim 1 \mathrm{~km})$, are not necessarily the result of a systematic change in climate (defined as 30 year normal in meteorological data).

Several well-preserved Holocene moraine sequences located in the central Southern Alps of New Zealand have been mapped (Burrows, 1975; Porter, 1975a; Birkeland, 1982; Barrell et al., 2011) and dated (Chinn, 1981; Gellatly, 1984; Schaefer et al., 2009; Putnam et al., 2012). Recent cosmogenic surface exposure dating (SED) results show moraine ages that range from early to late Holocene (Schaefer et al., 2009; Putnam et al., 2012). The late-Holocene moraines, some of which are similar in age to the LIA event registered in the European Alps, are generally close to the present-day glaciers. The LIA was the greatest Holocene glacier advance in many European and North American locations, whereas several moraine records from New Zealand show an overall retreat sequence through the Holocene (Burrows, 1975; Gellatly et al., 1988; Schaefer et al., 2009; Putnam et al., 2012). Schaefer et al. (2009) compared Holocene moraine ages from New Zealand with moraine ages and tree-kill dates from the Northern Hemisphere. This detailed comparison led Balco (2009) to ask "Can the timing and magnitude of observed past glacier changes in a particular region be explained by stochastic variability inherent in a steady climate, or is a change in the mean climate required?"

To test whether Holocene moraines could represent interannual temperature variability 

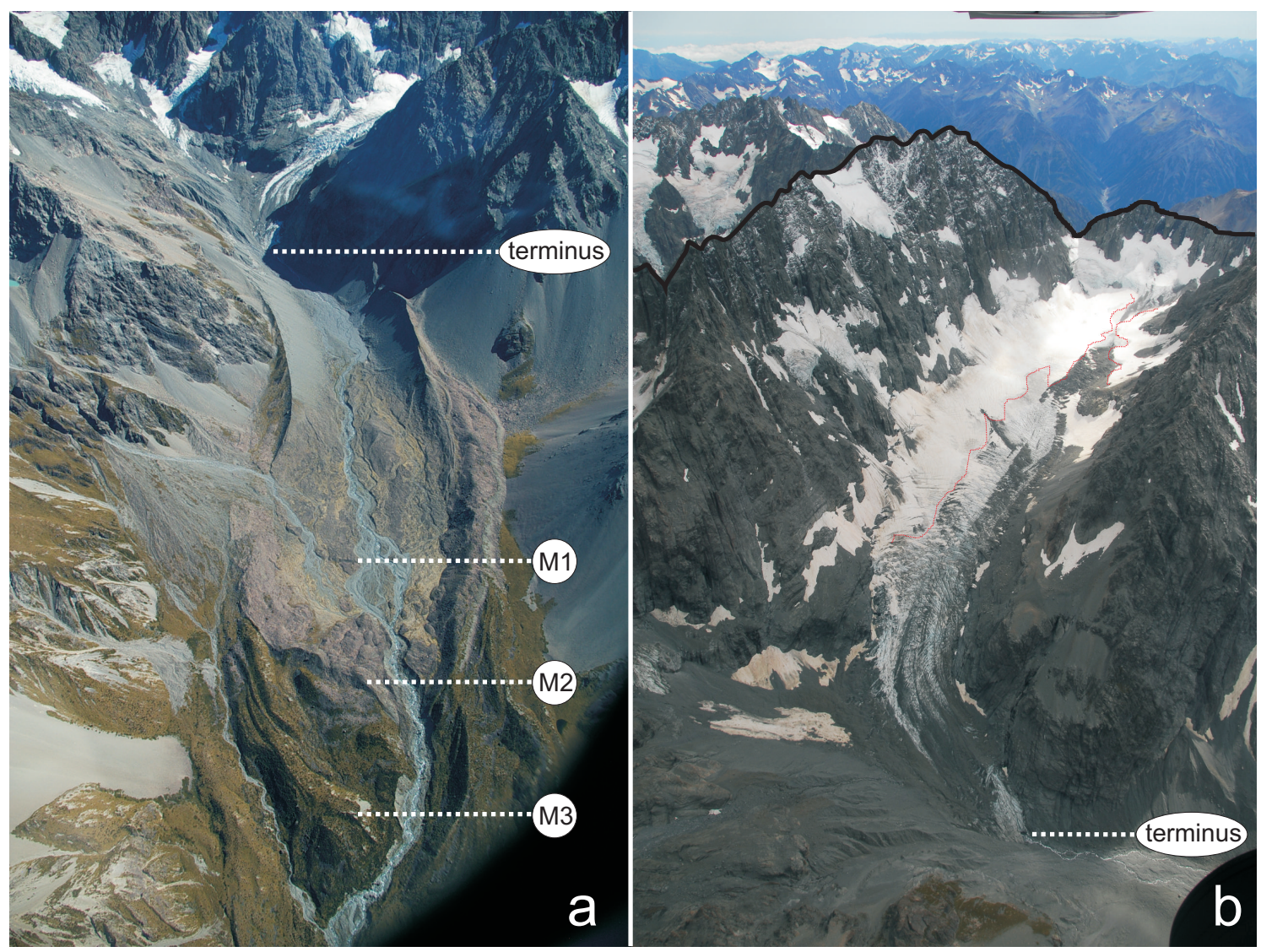

Figure 6.1 a) Oblique aerial photograph of the Cameron valley Holocene moraine sequence. This photograph shows the Cameron Glacier snout, the long, sharp-crested lateral moraines, and three of the targeted Holocene terminal moraines (M1 - M3). The most extensive moraine visible in this image (M3), located $3 \mathrm{~km}$ from the terminus, is dated to $8,190 \pm 230$ years before 1950 . Scree slopes are abundant in this catchment, as seen on the valley flanks, and the Cameron River has eroded through parts of the terminal moraines. View is towards the northwest, photo by T. Chinn. b) Oblique aerial photograph of Cameron Glacier with a dotted red line marking the end of summer snowline and black line marking the upper Cameron catchment ridgeline. This photograph also shows the upper Cameron catchment with its steep valley walls, which are prone to snow and rock avalanching. Photograph taken 3 March, 2010 by A.

Willsman, view is towards the northeast.

within a steady climate, or alternatively, a systematic shift in climate, we chose a glacier with arguably the best Holocene moraine record in New Zealand (Putnam et al., 2012) (Figures 6.2 and 6.1a). The Cameron Glacier occupies a low-angle valley and receives accumulation, at least in part, from snow avalanching from the steep valley walls (Figure 6.1b). Low-angle valleys are thought to promote potentially large changes in glacier length in response to relatively small changes in the equilibrium-line altitude (ELA) (Furbish and Andrews, 1984; Oerlemans, 1989). The small change in climate would theoretically cause large changes in mass balance, resulting in a significant change in glacier length. 
We use a modelling approach to investigate the palaeoclimatic significance of a welldated Holocene moraine sequence. First, we calculate the difference in climate from the present-day required for the modelled glacier to reach equilibrium at the five most prominent moraines (M1 - M5, Figure 6.2). We do this by applying a single temperature and precipitation change combination in a 'steady-state' modelling approach, whereby the glacier is allowed to evolve until it reaches equilibrium with the imposed climate. Second, we evaluate the modelled glacier terminus fluctuations caused by white-noise temperature forcing in order to assess whether stochastic interannual variability in temperature can result in glacier length changes comparable to the Holocene moraine extents.
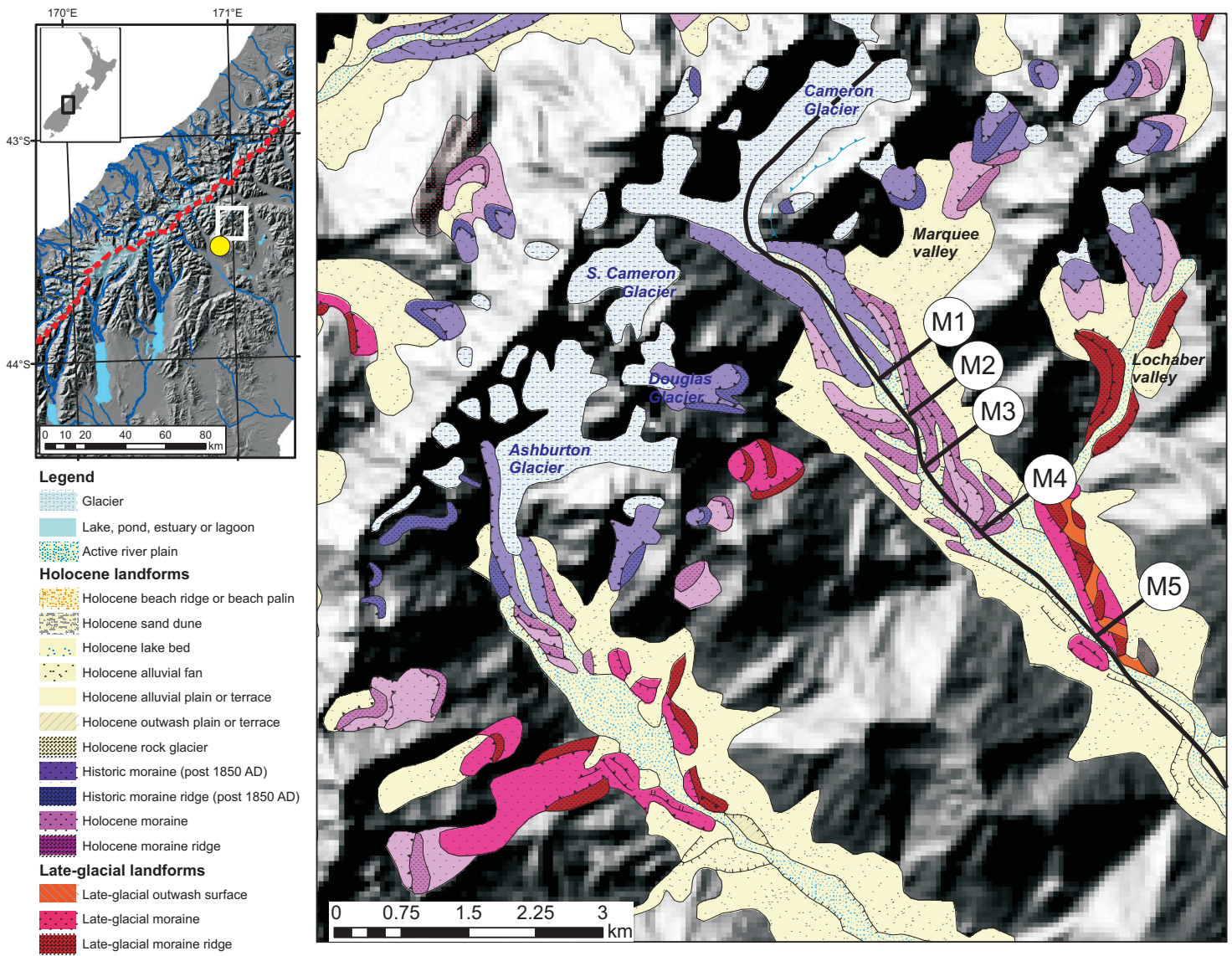

Figure 6.2 Glacial geomorphological map of the southeast slopes of the Arrowsmith Range, showing the moraine sequences of the Cameron (northeast) and Ashburton (southwest) valleys (Barrell et al., 2011). The black line represents the central flowline from which glacier lengths were measured, and M1 - M5 mark each of the targeted moraine positions. Note the similarities in moraine sequences between the two valleys, although the Cameron sequence contains a larger number of ridges. Location diagram (top left) shows shaded topography (based on a DEM) of the central Southern Alps including the main drainage divide (red dashed line), prominent lakes, rivers, and glacierised area. The Arrowsmith Range is marked by a white box. 


\subsubsection{Site description}

The Holocene moraine sequences of the Arrowsmith Range ( $\left.43^{\circ} 21^{\prime} \mathrm{S}, 171^{\circ} 00^{\prime} \mathrm{E}\right)$ in the South Island of New Zealand have been the focus of studies since the 1970s, and have recently been mapped and dated in detail (Barrell et al., 2011; Putnam et al., 2012) (Table 6.1). The Arrowsmith Range, with Mt. Arrowsmith as its highest peak (2775 m asl), is located $130 \mathrm{~km}$ west of Christchurch and $8 \mathrm{~km}$ east of the Main Divide of the Southern Alps (Figure 6.2). The Cameron Glacier and Ashburton Glacier valleys are both low-angle with average bed slopes of $\sim 6^{\circ}$. The valleys are sediment laden and sparsely-vegetated containing active and relict scree slopes (Figure 6.2).

Present-day Cameron Glacier is $2.2 \mathrm{~km}$ long and extends from $\sim 1400$ to $2270 \mathrm{~m}$ asl (mean elevation $\sim 1970 \mathrm{~m}$ asl). The majority $(80 \%)$ of the Cameron Glacier surface is below the regional ELA surface (Douglas Glacier, $2120 \mathrm{~m}$ asl (Chinn, 1995)), but ice persists because of an enhanced accumulation rate due to snow avalanching (Chapter 5). Valley walls adjacent to the glacier reach elevations of $2705 \mathrm{~m}$ asl with slopes often too steep $\left(>60^{\circ}\right)$ and too exposed to winds to accumulate snow. Wind and gravitational processes transport snow from the valley walls down to the glacier surface (Chapter 5). The high mass input and relatively low elevation of the glacier surface lead to a steep mass balance gradient, likely enhancing the glacier's mass balance sensitivity (Anderson and Mackintosh, 2012). This means that a relatively small change in climate will lead to a large change in mass balance.

Meteorological data do not exist for Cameron Glacier valley, but the nearby Mt. Potts weather station $\left(43^{\circ} 30^{\prime} \mathrm{S}, 170^{\circ} 55^{\prime} \mathrm{E}, 2128 \mathrm{~m}\right.$ asl, location marked by the yellow dot in

Table 6.1 Cameron Glacier Holocene moraine information modified from Putnam et al. (2012). Information includes cosmogenic exposure ages (M1 - M4), associated age for M5 (Putnam et al., 2010a), $\Delta$ ELA is relative to the AD1995 ELA for Douglas Glacier (2120 m asl).

\begin{tabular}{lllcc}
\hline & Name & age (yr before 1950) & ELA (m asl) & $\Delta$ ELA (m) \\
\hline M1 & CG X & $180 \pm 48$ & 2010 & -110 \\
M2 & CG IX & $523 \pm 61$ & 1980 & -140 \\
M3 & CG V & $8,190 \pm 230$ & na & -173 \\
M4 & CG I & $10,690 \pm 410$ & 1880 & -240 \\
M5 & CG W & Lateglacial & 1760 & -360 \\
\hline
\end{tabular}


Figure 6.2 inset) provides an estimate of alpine temperature. Temperature data show an annual mean air temperature of $3.5^{\circ} \mathrm{C}$, and a total annual precipitation of $1300 \mathrm{~mm}$ (data from June 2009 - July 2012) (NIWA, Retrieved 2009-2011). Our regional precipitation surface (Stuart, 2011) suggests a higher total annual precipitation of $2573 \mathrm{~mm}$ (average rain gauge data from 1970 - 2000) for the model domain, which is logical because Cameron Glacier is closer to the main divide of the Southern Alps than Mt. Potts station, and the Mt. Potts station probably experiences undercatch. A temperature lapse rate of $-5^{\circ} \mathrm{C} \mathrm{km}^{-1}$ was calculated from the Mt. Potts temperature data by minimising the mismatch between model interpolated daily temperature and measured daily temperature at Mt. Potts station.

The moraines that were targeted in our study range in age from $\sim 13,000$ to $180 \pm 48$ years BP (Table 6.1, Putnam et al. (2012)). A large pair of lateral moraines, located down valley of the Holocene moraine sequence (marked by M5 in Figure 6.2), have been correlated to the Birch Hill moraines in the Pukaki valley (located $100 \mathrm{~km}$ southwest of Cameron valley), based on their geographic position in the valley (Burrows, 1975). The Birch Hill moraines are Lateglacial in age (Putnam et al., 2010a) and thus we also consider M5 to be most likely Lateglacial ( 13,000 years BP) in age (Burrows, 1975; Putnam et al., 2012).

Previous estimates of palaeoclimate from the Cameron valley moraines used simpler methods (Putnam et al., 2012). Past temperature and ELA reconstructions for the Cameron Glacier moraine sequence were derived from glacier outlines, an accumulation-area ratio (AAR) of 0.67 and a temperature lapse rate of $-6.5^{\circ} \mathrm{C} \mathrm{km}^{-1}$ (Table 6.1) (Putnam et al., 2012).

\subsection{Methods}

We used a 2-D ice-flow model (Plummer and Phillips, 2003) coupled with a mass balance model containing a spatially distributed energy-balance model (EBM) (Anderson et al., 2010) and a snow avalanching algorithm (Gruber, 2007). The model was used to simulate past ice extents as delimited by the mapped and dated Holocene moraines (Putnam et al., 
2012). Five past moraine extents were simulated under steady-state conditions to estimate past temperature for a range of past precipitation scenarios (following the methodology employed in Doughty et al. (in press), Chapter 4). Our second experiment included the same models but rather than steady-state climate, we used stochastic interannual temperature variability to represent natural, year-to-year variations within a steady climate.

\subsubsection{Bedrock and ice-surface topography}

A digital elevation model (DEM) (GeographiX (NZ) Ltd) was derived from elevation contours by Land Information New Zealand (NZMS260) and was used as the surface elevation for a lower boundary condition. Present-day ice thicknesses for Ashburton, Douglas, South Cameron and Cameron glaciers were approximated using surface slope and modelled mass balance using a simplification of the Farinotti et al. (2009) scheme, calibrated with ground-penetrating radar (GPR) data which revealed the bed topography along the central flowline. The bedrock topography (at $50 \times 50$ m resolution) was then created by subtracting the ice thickness from the DEM. The gridded topography was smoothed using a window of 5 x 5 grid cells $(250 \times 250 \mathrm{~m})$ to reduce the high bed slopes that occur in a small fraction of the ice-covered cells and to improve model stability.

\subsubsection{Climatic input data}

The mass balance model required monthly-mean climate data to describe present-day temperature, precipitation, wind speed, relative humidity, and insolation at the domain location. Input climate data were calculated from three decades (AD 1981 - 2010) of daily meteorological data available from New Zealand's national climate database (CliFlo) (NIWA, Retrieved 2009-2011) as well as wind speed reanalysis from the National Centers for Environmental Prediction (NCEP). Relative humidity and solar radiation came from the CliFlo Database virtual climate station network climate grid interpolations (NIWA, Retrieved 2009-2011). Wind speed reanalysis data from NCEP at the $850 \mathrm{hPa}$ level were scaled to match observed wind speed data (in the CliFlo Database VCSN Aoraki grid). 
Monthly averages of relative humidity, solar radiation, and wind speed were calculated and applied uniformly across the model domain.

Monthly mean precipitation data were interpolated from daily rain gauge measurements (AD 1981 - 2010, NIWA (Retrieved 2009-2011)), but were scaled to an annual mean precipitation surface (Stuart, 2011) based on rain gauge data from 1971 - 2000 (Doughty et al., in press) (Chapter 4). The thirty-year monthly mean precipitation amount was subsequently divided by the number of days in the month to achieve an average 'daily' precipitation. The daily precipitation is assigned as snow in cells with a daily temperature at or below the snow temperature threshold, $T_{\text {snow }}$, set to $1^{\circ} \mathrm{C}$ (Anderson et al., 2006).

To estimate the monthly mean temperature surface, we used weather station data, the gridded DEM, and a temperature lapse rate. First, the daily temperature data from surrounding, low-elevation weather stations $\left(T_{s t}\right.$ in $\left.{ }^{\circ} \mathrm{C}\right)$, the monthly lapse rate $\left(\frac{d T}{d z},-5^{\circ} \mathrm{C}\right.$ $\mathrm{km}^{-1}$ ), and station elevation $\left(z_{s t}\right.$ in $\left.\mathrm{m}\right)$ were used to create a 'reference' temperature at sea level $\left(T_{r}\right.$ in $\left.{ }^{\circ} \mathrm{C}\right)$.

$$
T_{r}=T_{s t}-\frac{d T}{d z} \frac{z_{s t}}{1000}
$$

Second, the daily reference temperatures were interpolated in the horizontal plane to create a temperature grid at sea level for the model domain (Tait and Zheng, 2007). Reference grids were averaged into monthly mean temperature grids. Third, the monthly mean temperature surface $\left(T\right.$ in $\left.{ }^{\circ} \mathrm{C}\right)$ was calculated using the gridded reference temperature $\left(T_{r}\right)$, the temperature lapse rate, the DEM elevation ( $z$ in $\mathrm{m}$ ), and a prescribed temperature change $(\Delta T)$ (Doughty et al., in press) (Chapter 4). In the experiments presented here, $\Delta T$ represents either a steady-state temperature change or the annual stochastic temperature changes.

$$
T=T_{r}+\frac{d T}{d z} \frac{z}{1000}+\Delta T
$$


(Chapter 4) to ensure that the temperature-dependent energy-balance components were simulated correctly at a monthly timestep. Instead of forcing the model with monthly mean temperatures directly, we reintroduced some 'daily' temperature variability using the present-day standard deviation of daily temperature within a month. 'Daily' temperatures were thus the monthly mean temperature ( $T$ for the specific timestep) added to a randomly generated number (normal distribution, standard deviation $=2.6^{\circ} \mathrm{C}$ ). This 'daily' temperature was then used in the temperature-dependent subroutines, in particular, in calculating turbulent heat fluxes, the melt energy available from rain, and snow accumulation. Refer to Doughty et al. (in press) (Chapter 4) and Chapter 5 for more detail about the input climatology.

\subsubsection{Mass balance model}

We used a gravitational snow mass transport and deposition model (Gruber, 2007) with a spatially distributed EBM (Anderson et al., 2010), to describe accumulation and ablation distribution in the domain. To simulate mass balance for different climates, the input data are changed by an absolute amount (for temperature change, $\Delta T$ ) or a relative amount (for precipitation change, $\Delta P$ ).

\section{Calculating energy available for melt}

To calculate daily ablation over the model domain, we first calculate the energy available for melt $\left(Q_{M}\right)$ following Anderson et al. (2010):

$$
Q_{M}=I(1-\alpha)+L \downarrow+L \uparrow+Q_{H}+Q_{E}+Q_{G}+Q_{R}
$$

where $I$ is the incoming shortwave radiation, $\alpha$ is the surface albedo, $L \downarrow$ is the incoming longwave radiation, $L \uparrow$ is the outgoing longwave radiation, $Q_{H}$ and $Q_{E}$ are the sensible and latent heat fluxes, $Q_{G}$ is the ground heat flux ( by rain (assuming that precipitation temperature is equal to air temperature (Oerlemans, 
1992)). All energy fluxes are in units of $\mathrm{W} \mathrm{m}^{-2}$.

The equations to solve for the energy balance components come from a range of sources described in Anderson et al. (2010) and Doughty et al. (in press) (Chapter 4). Insolation (I) values for the steady-state simulations were calculated for the orbital configurations corresponding to the moraine ages (Table 6.3). For the transient simulations, insolation was calculated for present-day (Berger and Loutre, 1991; Eisenman and Huybers, 2006). The albedo parameterisation follows Oerlemans (1992), where the glacier surface albedo $(\alpha)$ is dependent on the modelled ELA (referred to in the equation as $z_{E L A}$ ). When using this albedo parameterisation, we first determined the 'background' albedo $\left(\alpha_{b}\right)$ :

$$
\alpha_{b}=0.43+\frac{0.18}{\pi} \arctan \left(\frac{z-z_{E L A}+300}{200}\right)
$$

where $z$ is surface elevation and $z_{E L A}$ is the equilibrium line altitude. The albedo, $\alpha$, is then calculated, where the albedo of snow, $\alpha_{\text {snow }}$, is equal to 0.75 and snow depth, $D_{\text {snow }}$, varies daily. We change the input parameter value of snow albedo, $\alpha_{\text {snow }}$, in the sensitivity tests described below.

$$
\alpha=\alpha_{\text {snow }}-\left(\alpha_{\text {snow }}-\alpha_{b}\right) e^{-5 D_{\text {snow }}}
$$

The longwave radiation components ( $L \downarrow$ and $L \uparrow$ ) were calculated using each cell's view field of the surrounding topography, cloudiness, ice coverage, and temperature (Plummer and Phillips, 2003). Turbulent heat fluxes $\left(Q_{H}\right.$ and $\left.Q_{E}\right)$ were calculated using the bulk method (Oerlemans, 1992; Hock, 2005; Anderson et al., 2010).

We did not include debris cover in the simulations because it is unknown for the past. The present-day debris cover on Cameron Glacier is $\sim 17 \%$, which is probably a higher coverage than what occurred during the Holocene, because the glacier has been in a state of retreat for much of the last century, and retreating glaciers tend to concentrate debris on their surfaces (Stokes et al., 2007). Further details regarding the monthly EBM and input climate can be found in Chapters 3 and 4 (Doughty et al., in press). 


\section{Calculating snow distribution}

The snow mass transport and deposition (MTD) model (Gruber, 2007) ran at a daily timestep whenever snowfall occurred in the EBM. Removal of snow from steep slopes (100\% snow removal from slopes $>70^{\circ}$ decreased linearly to $0 \%$ at $40^{\circ}$ ) and deposition of snow on lower, more gentle slopes $\left(<45^{\circ}\right)$ improves the comparison between modelled and measured mass balance patterns on Cameron Glacier (Chapter 5).

Snow deposition depth in a cell at each timestep cannot exceed $D_{\max }$ as defined by Equation (6.6). Three MTD parameters largely control the modelled snow deposition pattern $\left(D_{\max }\right)$. First, the maximum depositing slope, $\beta_{\text {lim }}$, is the highest slope angle at which modelled snow is allowed to be deposited. Second, the maximum deposition limit of snow, $D_{\text {lim }}$, sets the maximum possible snow depth in the avalanche deposit for a single iteration of this model (in flat areas $D_{\max }=D_{\text {lim }}$ ). Third, $\gamma$ is used to control the shape of the curve relating maximum deposition, $D_{\max }$, to slope angle, $\beta$. The $\beta_{\text {lim }}$ and $D_{\text {lim }}$ values $\left(45^{\circ}\right.$ and $\left.0.2 \mathrm{~m}\right)$ are adjusted from those used in Chapter $5\left(35^{\circ}\right.$ and $0.4 \mathrm{~m}$, respectively) to produce a similar snow avalanche deposit extent despite changes in grid size and ice surface topography caused by the ice-flow model (details in Chapter 3).

$$
D_{\text {max }}= \begin{cases}\left(1-\left(\frac{\beta}{\beta_{l i m}}\right)^{\gamma}\right) D_{\text {lim }} & \text { if } \beta<\beta_{\text {lim }} \\ 0 & \text { if } \beta \geq \beta_{\text {lim }}\end{cases}
$$

\subsubsection{D ice-flow model}

A vertically-integrated 2-D ice-flow model based on the shallow-ice approximation (SIA) (Plummer and Phillips, 2003; Kessler et al., 2006) was chosen because of its efficiency and ability to produce generally appropriate ice volume results for alpine glaciers (Le Meur and Vincent, 2003). One main drawback of the SIA is that it neglects longitudinal deviatoric stresses, and thus caution is needed when applying the model to glaciers with complex bed roughness (Le Meur and Vincent, 2003). We smoothed the DEM to improve the applicability of the scaling parameter, and the main trunk valleys have low bed slopes. 
Thus, we suspect the influence of longitudinal deviatoric stresses would be small for the large trunk glaciers. In addition, previous studies have shown that the dominant driver of ice volume in this type of model is climate on timescales greater than the response time of the glacier (Greuell, 1992; Leysinger Vieli and Gudmundsson, 2004).

The vertically-integrated ice velocity from the internal deformation velocity, $\vec{U}_{d}$ was calculated following Paterson (1994):

$$
\vec{U}_{d}=\frac{2}{5} A H \vec{\tau}_{b}^{n}
$$

where $A$ is the coefficient of Glen's flow law, set to $3.17 \mathrm{e}^{-25} \mathrm{~Pa}^{-3} \mathrm{~s}^{-1}, \vec{\tau}_{b}$ is the gravitational driving stress $\left(\overrightarrow{\tau_{b}}=\rho g H \nabla h\right)$, and $n$ is Glen's flow law exponent, set to 3. The sliding velocity follows the empirical formulation of Kessler et al. (2006):

$$
\vec{U}_{s}=U_{c} e^{1-\frac{\tau_{c}}{\bar{\tau}_{b}}}
$$

where $U_{c}$ is the characteristic sliding velocity and $\vec{\tau}_{c}$ is the gravitational driving stress $\left(10^{5} \mathrm{~Pa}\right)$ that results in $\vec{U}_{s}$.

We varied $U_{c}$ with elevation, which helped to achieve an ice thickness profile similar to the lateral moraine heights. The $U_{c}$ parameter ranged from $10 \mathrm{~m} \mathrm{a}^{-1}$ for elevations above $1700 \mathrm{~m}$ asl, to $60 \mathrm{~m} \mathrm{a}^{-1}$ below $1500 \mathrm{~m}$ asl. By adjusting this flow parameter, we could be compensating for the tendency of the SIA to produce thinner, longer glaciers on steep slopes and thicker, shorter glacier snouts on lower bed slopes (Le Meur et al., 2004; Egholm et al., 2011). Alternatively, changing this parameter could be compensating for deformation of sediments (moraines, till, outwash) on the valley floor, which could increase the basal velocity of these glaciers.

Although the adjustment of these flow parameters can alter glacier shape, the dominant drivers of glacier extent changes are temperature change $(\Delta T)$, and precipitation change $(\Delta P)$ (Leysinger Vieli and Gudmundsson, 2004). We conduct sensitivity tests for each 
moraine with different $A$ and $U_{c}$ to show the influence of these parameter values on our climate estimates.

The modelled mass balance and ice thickness are co-dependent, hence the EBM is called either every year (transient, white-noise temperature forcing runs) or every 10 years (steady-state run), depending on the experiment, to update the mass balance distribution. When the mass balance is calculated, it uses the ice thickness at that timestep to calculate a surface topography. The modelled ice thickness then continues to evolve using the updated mass balance.

\subsubsection{Experimental set-up}

\section{Initial conditions}

We used the Cameron Glacier ca. 1864 moraine (Burrows, 1975, 2005; Putnam et al., 2012) and its corresponding simulated ice mass to represent the 'pre-industrial' climatic baseline. In New Zealand, several historic glacier positions from the mid- to late 1800s have been documented (primarily by J. Haast) and these paintings have been used to link past glacier extents to well-preserved moraines (Burrows, 1975, 2005; Schaefer et al., 2009). One such example is the ca. 1864 moraine, positioned $\sim 1.5 \mathrm{~km}$ southeast and down valley of the modern (2012) Cameron Glacier terminus. A $-1.3^{\circ} \mathrm{C} \Delta T$ relative to today (1981-2010) is required for the modelled glacier to reach this moraine. A cooling of this magnitude is slightly greater than a temperature change estimated from station data of $0.91^{\circ} \mathrm{C} /$ century between 1909 and 2009 in New Zealand (Mullan et al., 2010). The ca. 1864 moraine position (M1) corresponds to a Cameron Glacier length of $4200 \mathrm{~m}$ and we discuss moraine distances and glacier lengths relative to this baseline (Figure 6.2).

\section{Steady-state experiments}

All steady-state simulations started from the M1 position, and a single $\Delta T, \Delta P$ combination was used to run the modelled glacier to equilibrium (between 250 and 300 model 
Table 6.2 Optimal and tested model parameter values. The values with references come from previously published studies, whereas those with ' $\mathrm{S} \#$ ' are values tested in the sensitivity simulations. Names in bold text are the parameters we varied to define our palaeoclimate uncertainty. Our sensitivity tests involve changing one value at a time to quantify the influence each parameter has on our palaeoclimate reconstruction.

\begin{tabular}{|c|c|c|c|}
\hline Parameter name & Symbol & Value & Source or test number \\
\hline \multicolumn{4}{|l|}{ Energy balance model } \\
\hline \multirow[t]{3}{*}{ Snow albedo } & $\alpha_{\text {snow }}$ & 0.75 & Oerlemans (1992) \\
\hline & & 0.72 & $\mathrm{~S} 1$ \\
\hline & & 0.77 & $\mathrm{~S} 2$ \\
\hline \multirow[t]{3}{*}{ Snow/rain temperature threshold } & $T_{\text {snow }}$ & $1^{\circ} \mathrm{C}$ & Anderson et al. (2006) \\
\hline & & $0^{\circ} \mathrm{C}$ & S3 \\
\hline & & $2^{\circ} \mathrm{C}$ & $\mathrm{S} 4$ \\
\hline Temperature lapse rates & $\frac{d T}{d z}$ & $-5^{\circ} \mathrm{C} \mathrm{km}^{-1}$ & \\
\hline Roughness parameter for ice & $Z_{i c e}$ & $0.004 \mathrm{~m}$ & Anderson and Mackintosh (2012) \\
\hline Roughness parameter for snow & $Z_{\text {snow }}$ & $0.001 \mathrm{~m}$ & Brock et al. (2006) \\
\hline \multicolumn{4}{|l|}{$2 D$ ice-flow model } \\
\hline \multirow[t]{3}{*}{ Typical sliding velocity } & $U_{c}$ & variable $\mathrm{m} \mathrm{a}^{-1}$ & This study \\
\hline & & $20 \mathrm{~m} \mathrm{a}^{-1}$ & S5, Kessler et al. (2006) \\
\hline & & $100 \mathrm{~m} \mathrm{a}^{-1}$ & S6 \\
\hline \multirow[t]{3}{*}{ Glen's flow law coefficient } & $A$ & $3.17 \mathrm{e}^{-25} \mathrm{~Pa}^{-3} \mathrm{~s}^{-1}$ & Paterson (1994) \\
\hline & & $3.17 \mathrm{e}^{-24} \mathrm{~Pa}^{-3} \mathrm{~s}^{-1}$ & S7 \\
\hline & & $3.17 \mathrm{e}^{-26} \mathrm{~Pa}^{-3} \mathrm{~s}^{-1}$ & $\mathrm{~S} 8$ \\
\hline \multicolumn{4}{|l|}{ Mass transport and deposition model } \\
\hline \multirow[t]{3}{*}{ Maximum slope for deposition } & $\beta_{\text {lim }}$ & $45^{\circ}$ & \\
\hline & & $35^{\circ}$ & S9 \\
\hline & & $55^{\circ}$ & S10 \\
\hline \multirow[t]{3}{*}{ Maximum deposition limit } & $D_{\text {lim }}$ & $0.2 \mathrm{~m}$ w.e. & \\
\hline & & $0.1 \mathrm{~m}$ w.e. & S11 \\
\hline & & $0.3 \mathrm{~m}$ w.e. & $\mathrm{S} 12$ \\
\hline Gamma & $\gamma$ & 0.125 & (Gruber, 2007) \\
\hline
\end{tabular}


years). This was done for four additional moraine positions beyond M1. The $\Delta T$ was recorded for $\Delta P$ set to $+20,0$, and $-20 \%$ in runs where the modelled equilibrium glacier extent was within $\pm 100 \mathrm{~m}$ of the targeted moraine. We do not currently understand how precipitation varied during the Holocene, thus we varied precipitation change by this range to account for reasonable changes in precipitation over the domain. Each time the mass balance function was called (once every 10 model years) the annual mass balance grids from five independent iterations were averaged and applied to the flow model as a surface boundary condition. The average mass balance of five iterations was used to ensure that the daily random temperature values were not affecting the results. The randomly generated daily temperatures do not cause variation in the resulting palaeoclimate interpretation in repeat model runs.

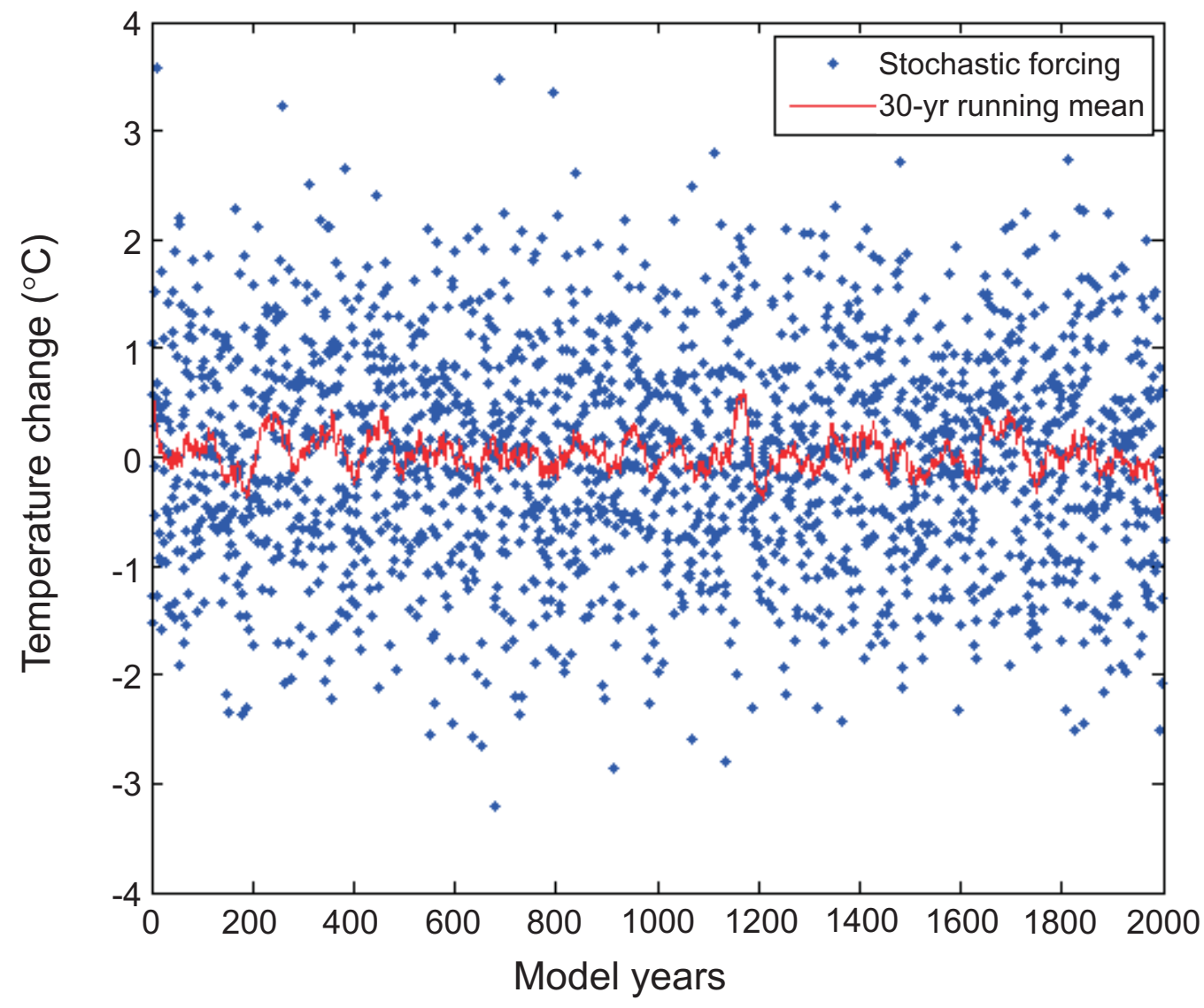

Figure 6.3 White noise temperature forcing series with a standard deviation $\left(\sigma_{T}\right)$ of $1{ }^{\circ} \mathrm{C}$ (blue diamonds) and the 30-year running mean temperature (red line). Note the relatively high peak in running mean around model year 1150, showing that the random temperatures can generate a small persistence in climate.

We varied two important parameters from each model component (ice-flow, EBM, MTD) 
to evaluate the sensitivity of our palaeoclimate estimates to the choice in parameter values

(Table 6.2). The following parameters were systematically explored: $\alpha_{\text {snow }}, T_{\text {snow }}, U_{c}, A$, $\beta_{\text {lim }}$ and $D_{\text {lim }}$. We chose these parameters because they have been shown to change the palaeo-temperature estimates by up to $0.6^{\circ} \mathrm{C}$ in previous modelling studies (e.g. $\alpha_{\text {snow }}$ and $T_{\text {snow }}$ in Doughty et al. (in press), Chapter 4) or because the parameter values used here are different from those previously reported. We also simulated mass balance for M1 and M4 without the avalanche model to discuss the differences in resulting modelled palaeoclimate, ELA, and AAR estimates. In each case, all parameters were kept at their 'optimal' values, with the exception of the parameter we were varying. These tests were done with a similar model setup to experiment 1, each running for 250 model years for $\Delta P=-20,0$, and $+20 \%$, iteratively, altering $\Delta T$ until the equilibrium glacier terminus was within $100 \mathrm{~m}$ of each moraine.

We also tested the glacier length sensitivity relative to an initial modelled ice mass starting at each of the five moraines. We did this to see if the change in glacier length to a change in temperature by $1{ }^{\circ} \mathrm{C}$ depended on glacier size, because it is likely that the sensitivity of a glacier to climate change depends on its specific geometry (Oerlemans, 1989). For these tests, we started each model run with ice thickness results obtained from the steadystate simulation at each of the five moraine positions. We then altered $\Delta T$ by $\pm 1^{\circ} \mathrm{C}$ and recorded the length changes over 250 model years.

\section{Stochastic temperature forcing}

Previous studies of glacier length change driven by stochastic variability in climate offer several different modelling approaches. Oerlemans (2000) used a flowline model and an estimate of mass balance sensitivity, known as a 'seasonal sensitivity characteristic', to describe three glaciers. The model was forced with randomly generated annual mass balance values (standard deviations of 0.75 and $1.05 \mathrm{~m}$ w.e.) based on changes in mass balance caused by $\mathrm{a}+1{ }^{\circ} \mathrm{C}$ temperature or $10 \%$ precipitation perturbation. Roe and O'Neal (2009) used a linear glacier length-climate model after obtaining similar results for both a flowline and linear glacier model. The linear model allowed glacier length to 
respond immediately to changes in precipitation and temperature. Snow accumulation in this model was based on annual mean precipitation, with snow prescribed to occur at high elevations. Roe and O’Neal (2009) used standard deviations of temperature $\left(0.78^{\circ} \mathrm{C}\right)$ and precipitation $\left(0.36 \mathrm{~m} \mathrm{a}^{-1}\right)$ variability from a 75-year meteorologic record, whereas Oerlemans (2000) imposed the white noise variability directly via the modelled mass balance. Both studies (Oerlemans, 2000; Roe and O'Neal, 2009) used white noise with a Gaussian distribution with a prescribed standard deviation.

We generated 2000 normally distributed random numbers using a standard deviation of annual mean temperature, $\sigma_{T}$ (Figure 6.3). We applied different values of $\sigma_{T}(0.25,0.5,1$, and $2^{\circ} \mathrm{C}$ ) to simulate the sensitivity of Cameron Glacier to changes in the magnitude of interannual temperature variability (model tests WNF-A, -B, -C, and -D respectively). The present-day (1854-1996) standard deviation in interannual temperature, from the 'seven station series' in New Zealand (long term meteorological data), ranges from 0.2 to $0.4^{\circ} \mathrm{C}$ (Dean and Stott, 2009). We investigated the effect of this range of variability in our study by using values of $\sigma_{T}$ set to 0.25 and $0.5^{\circ} \mathrm{C}$. We also ran simulations with $\sigma_{T}$ set to 1 and $2{ }^{\circ} \mathrm{C}$ to represent significantly greater $\sigma_{T}$ values from today. These higher $\sigma_{T}$ values are two- and four-fold the present-day maximum interannual temperature variability and should be treated as a extremes.

To make all four runs (WNF-A to WNF-D) comparable, we used the same random numbers in the same sequential order for each transient model run. The normalised white noise sequence was multiplied by the respective $\sigma_{T}$ value for each model run and then added to $\Delta T-1.2^{\circ} \mathrm{C}$, which was the $\Delta T$ required to achieve the steady-state glacier close to M1 (100 m short of the moraine, which is within error of the grid resolution). Adding this temperature change sets the equilibrium baseline climate and glacier configuration to the 'pre-industrial' condition.

Simulations WNF-A through WNF-D begin with ice extent near M1, which is located $\sim 2 \mathrm{~km}$ down valley of the 2012 Cameron Glacier terminus and $\sim 0.5 \mathrm{~km}$ up valley of the innermost late Holocene moraine (Figure 6.2). An additional simulation was run to explore the differences between glacier geometry and length sensitivity to stochastic 
temperature forcing (WNF-E). In this simulation, the ice extent began between the M3 and M4 positions (5700 m length, equilibrium temperature change of $-2.6^{\circ} \mathrm{C}$ ) and we used a $\sigma_{T}=1^{\circ} \mathrm{C}$. This position was chosen to capture the glacier length changes caused by the connection/disconnection of the tributary glaciers. Precipitation is not changed during these transient simulations and present-day insolation values are used. The mass balance model is called from the flow model every year to ensure we are capturing the interannual temperature change and likewise, the model results are saved every year to record any changes in glacier length, volume, and mass balance.

\subsection{Results}

\subsubsection{Steady-state experiments}

Glacier extents, ice thicknesses, and mass balance distributions from the steady-state simulations are shown for the five different moraine positions in Figure 6.4. Temperature estimates for precipitation changes of $+20,0$, and $-20 \%$ are displayed in Table 6.3 , along with details about the modelled Cameron Glacier (length, maximum ablation, maximum accumulation, ELA, area, and AAR, Figure 6.5). ELA values were calculated by averaging the modelled ice surface elevation where mass balance equal to $0 \pm 0.2 \mathrm{~m} \mathrm{a}-1$ on the central part of the South Cameron Glacier, where simulated avalanche deposits do not occur. In the absence of precipitation change, the modelled glacier reaches each of the five moraines by applying temperature changes of $-1.3,-2.1,-2.4,-2.7$, and $-3.3^{\circ} \mathrm{C}$ for $\mathrm{M} 1$ - M5, respectively.

The overall match between the mapped glacial geomorphology and the modelled ice extents is good in both the Cameron and Ashburton valleys, as well as unnamed tributary valleys (Figure 6.4). This is an encouraging result because the only fitting we prescribed was the length of the Cameron Glacier (Figure 6.2). The model simulated glaciers in tributary valleys that merged with the main trunk glacier (Cameron or Ashburton, depending on the valley) in each of the model runs. The modelled South Cameron Glacier fed ice mass into the Cameron Glacier in all model runs, even though these glaciers are presently 


\section{Ice Thickness}

(m)
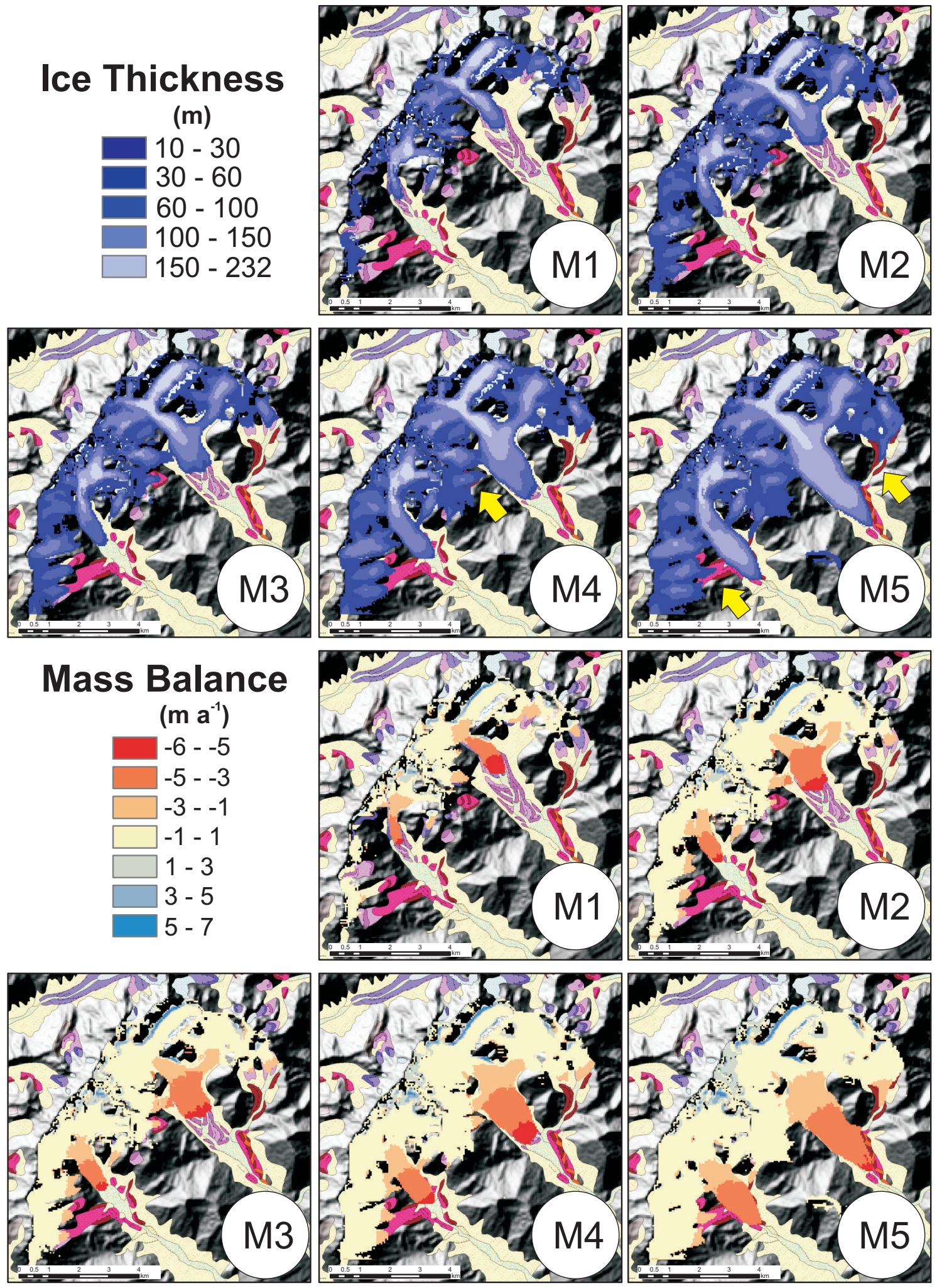

Figure 6.4 Glacier ice thickness and mass balance for the five different ice extents with no precipitation change. Note the simulated connection of tributary glaciers to the main trunk glacier at different extents of Cameron Glacier. Yellow arrows point to areas where the modelled ice extent and moraine map differ (see text). 

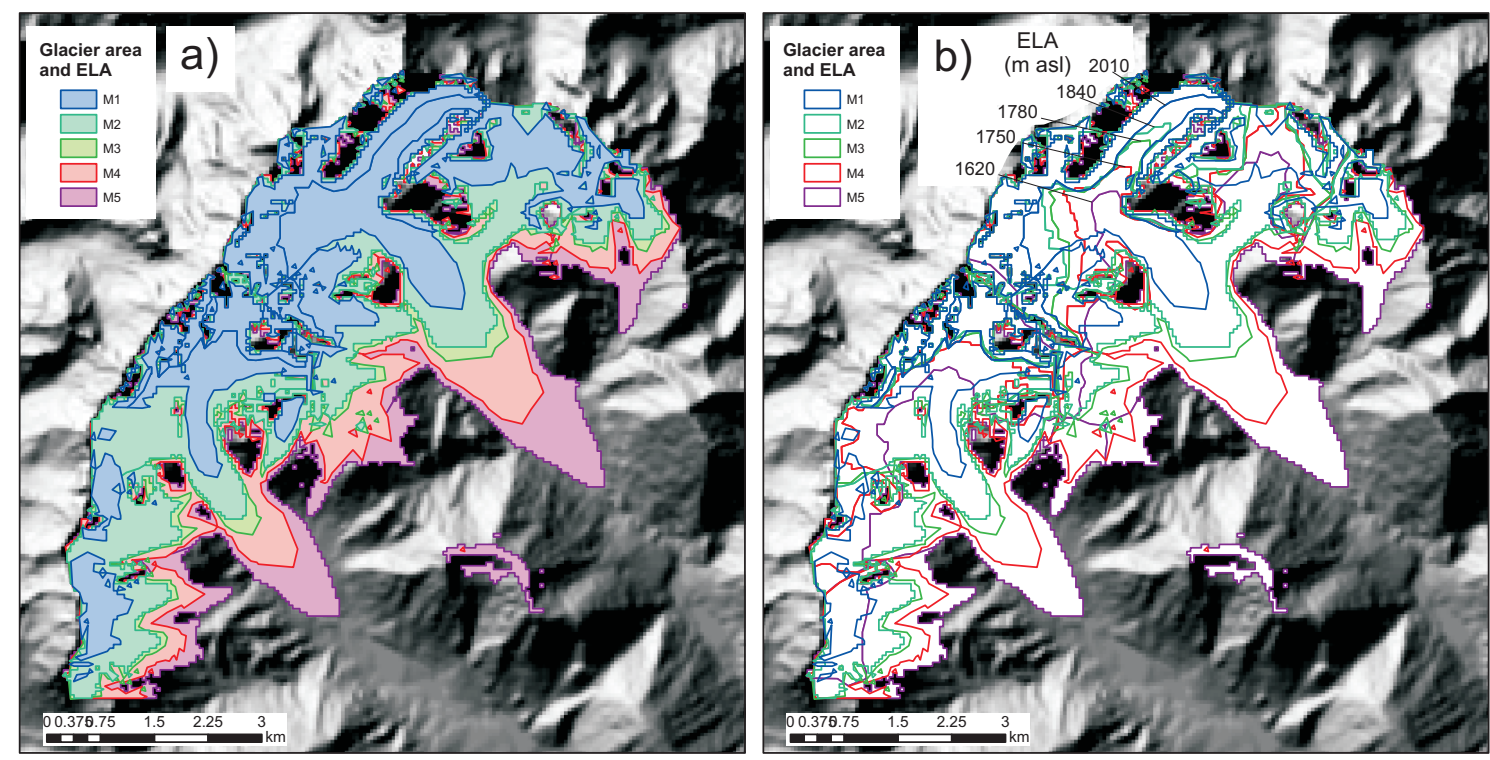

Figure 6.5 Glacier outline and ELA for each moraine extent. Panel a) glacier area extents overlapped for direct comparisons, and b) glacier outline and corresponding ELA

(Table 6.3).

independent in the current climate. Ice contributions from the Marquee valley (located northeast of Cameron Holocene moraines) occur in M2 - M5, whereas the modelled Douglas Glacier (located west of the Cameron Holocene moraines) flows into the Cameron Glacier only in M4 - M5, when temperature change is $-2.7^{\circ} \mathrm{C}$ or lower and modelled glaciers are at or beyond their greatest Holocene extent.

The modelled glacier extent in some of the tributary valleys differs slightly from the mapped moraines. We found three locations within the model domain that show a mismatch between the modelled Lateglacial ice extent and mapped Lateglacial moraines

Table 6.3 Palaeoclimate estimates for the five targeted moraine positions. Temperature change range reflects $\Delta P$ values. Cameron Glacier length, maximum ablation, maximum accumulation, ELA, area, and AAR are offered for each moraine simulation. AAR values for the Ashburton are also offered, based on the modelled mass balance.

\begin{tabular}{|c|c|c|c|c|c|c|c|c|c|c|}
\hline & \multicolumn{3}{|c|}{$\Delta T$ values $\left({ }^{\circ} \mathrm{C}\right)$ for $\Delta P$} & \multirow{2}{*}{$\begin{array}{l}\text { length } \\
(\mathrm{m})\end{array}$} & \multirow{2}{*}{$\begin{array}{c}\max \text { abl. } \\
\left(\mathrm{m} \mathrm{a}^{-1}\right)\end{array}$} & \multirow{2}{*}{$\begin{array}{c}\max \text { acc. } \\
\left(\mathrm{m} \mathrm{a}^{-1}\right)\end{array}$} & \multirow{2}{*}{$\begin{array}{c}\text { ELA } \\
\text { (m asl) }\end{array}$} & \multicolumn{2}{|c|}{ Cameron } & \multirow{2}{*}{$\begin{array}{c}\text { Ashburton } \\
\text { AAR }\end{array}$} \\
\hline & $+20 \%$ & $0 \%$ & $-20 \%$ & & & & & $\operatorname{area}\left(\mathrm{km}^{2}\right)$ & AAR & \\
\hline M1 & -0.8 & -1.3 & -1.8 & 4300 & -7.9 & 9.0 & 2010 & 4.4 & 0.42 & 0.31 \\
\hline M2 & -1.5 & -2.1 & -2.6 & 4950 & -7.1 & 9.8 & 1840 & 9.0 & 0.42 & 0.27 \\
\hline M3 & -1.8 & -2.4 & -2.9 & 5150 & -6.7 & 10.9 & 1780 & 10.8 & 0.43 & 0.26 \\
\hline M4 & -2.3 & -2.7 & -3.4 & 6050 & -6.3 & 11.2 & 1750 & 12.5 & 0.48 & 0.34 \\
\hline M5 & -2.8 & -3.3 & -4.0 & 7500 & -5.7 & 12.6 & 1620 & 15.9 & 0.50 & 0.48 \\
\hline \multicolumn{11}{|c|}{ Simulations without the avalanche model } \\
\hline M1 & -0.8 & -1.3 & -1.8 & 4300 & -7.9 & 2.0 & 1920 & 5.5 & 0.76 & 0.76 \\
\hline M4 & -2.1 & -2.6 & -3.2 & 6200 & -6.3 & 2.0 & 1660 & 15.8 & 0.75 & 0.77 \\
\hline
\end{tabular}


(marked by the yellow arrows in Figure 6.4 M4 - M5). The first mismatch (marked in Figure 6.4 M4) is located in the valley south of Douglas Glacier, where the glacial geomorphological map (Barrell et al., 2011) shows there are moraines correlating to the 'Lateglacial' or the M5 moraine in the Cameron valley. In this panel (Figure 6.4 M4), the modelled ice in a small tributary valley advanced to moraines correlated to the 'Lateglacial' (M5) advance. The second mismatch (marked by a yellow arrow in Figure 6.4 M5) is where glacier extent in an Ashburton tributary valley does not reach the mapped 'Lateglacial' lateral moraines at this location. And third, ice extent in the Lochaber tributary valley (north of Cameron 'Lateglacial' moraines, marked by a yellow arrow) is also smaller than expected in the M5 simulation. These differences, however, are relatively minor and within the uncertainty of model parameter choice.

There are several possible reasons why mismatches might occur between the mapped and modelled ice extent in the tributary valleys. The first possibility is that the estimated moraine age (e.g. Holocene, Lateglacial, Last Glacial Maximum) is incorrect, as no absolute age control exists for these sequences. This suggestion, however, is unlikely given the attention paid to moraine position, size, and relative weathering of surface boulders in the mapping. A second possibility is that the modelled glacier extents are incorrect because of a modelling uncertainty, such as the detailed mass balance forcing, model choice, or parameters used, especially $U_{c}$ and $A$.

\section{Model sensitivity analysis}

Parameter tests were carried out for each of the five glacier extents. We tested the change in palaeoclimate reconstruction with a change in parameter value for $T_{\text {snow }}, \alpha_{\text {snow }}, U_{c}$, $A, D_{\text {lim }}$, and $\beta_{\text {lim }}$ (Table 6.2 and Figure 6.6). As expected, the palaeoclimate estimates overlap for moraines that are close to one another, when accounting for the uncertainty $\left( \pm 0.4^{\circ} \mathrm{C}\right)$ caused by uncertainties in the parameters. We consider this range of possible temperature change for each moraine to represent the uncertainty in our palaeoclimate estimates $\left( \pm 0.4^{\circ} \mathrm{C}\right)$. Possible past precipitation change can also influence the palaeotemperature estimates by up to $\pm 0.7^{\circ} \mathrm{C}$ (Table 6.3). Given that past changes in precip- 
itation are difficult to quantify, we chose to focus on the temperature change estimates associated with no change in past precipitation. Our palaeo-temperature reconstruction uncertainty is thus reported as $\pm 0.4^{\circ} \mathrm{C}$.

The simulations of M1 and M4 without the avalanche model were somewhat surprising. Interestingly, the palaeoclimate estimates for M1 and M4 in these runs were identical, within error $\left( \pm 0.4^{\circ} \mathrm{C}\right)$, to those from the steady-state models runs made using the avalanche model (Table 6.3). There were, however, significant differences in the AAR and ELA values estimated from the modelled mass balances. The model runs without the MTD model produced greater ice distribution in the upper catchments (e.g. on steep valley walls $>60^{\circ}$ ) where ice is not present today and where the avalanche model would not allow snow to accumulate. This greater distribution of ice in the upper parts of both the Cameron and Ashburton glaciers lead to larger AAR values calculated from the modelled mass balance ( 0.78 for M1 and 0.75 for M4 for Cameron Glacier). The estimated ELA values, from the modelled mass balance without the MTD model, were $\sim 100 \mathrm{~m}$ lower in elevation than those in simulations with the avalanche model.

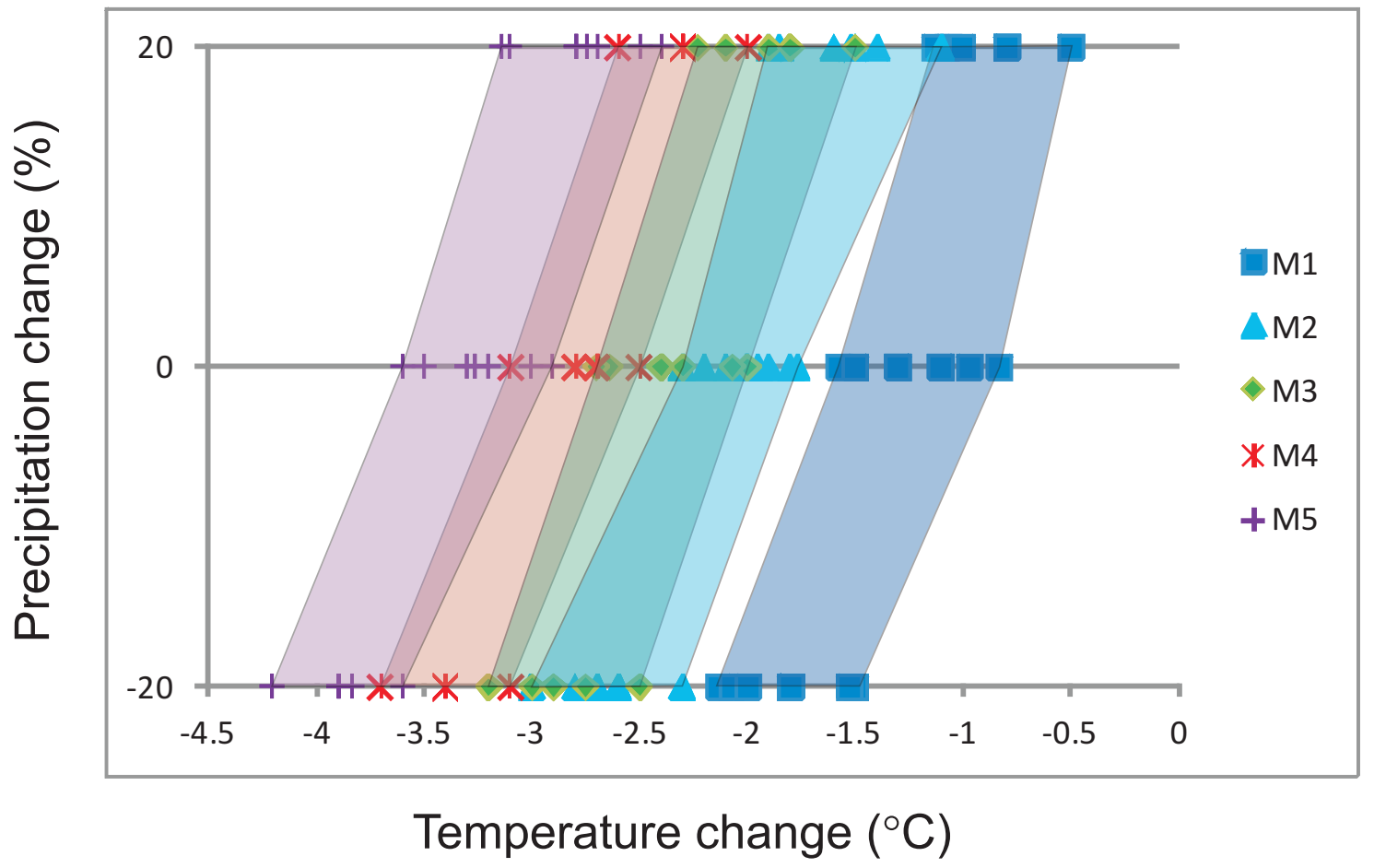

Figure 6.6 Temperature and precipitation change combinations needed to reach each of the moraines under 12 different parameter combinations (Table 6.2). Note that the palaeoclimate estimates overlap, at least slightly, with those produced for the neighbouring moraine. 


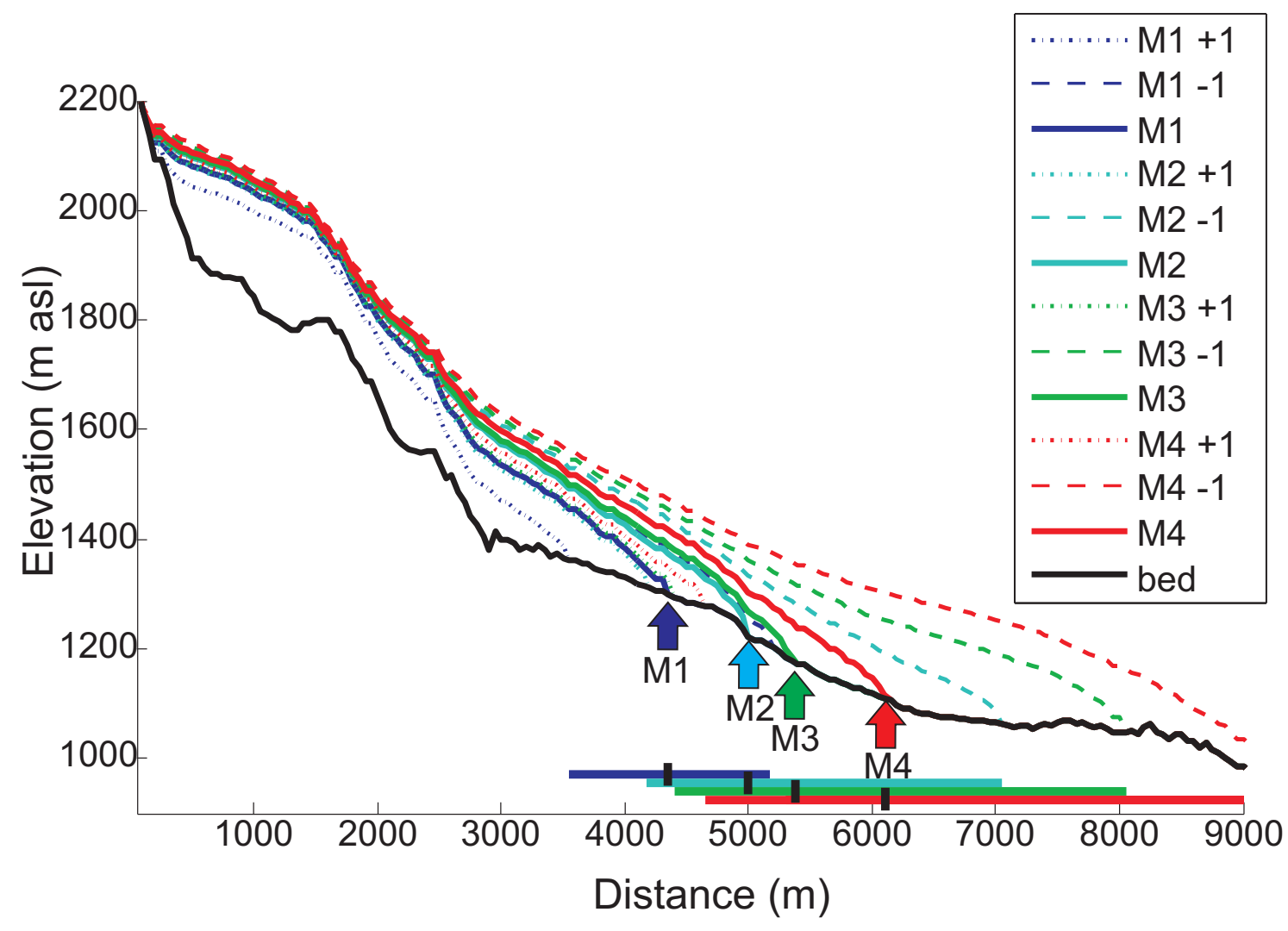

Figure 6.7 Glacier length profile $(\mathrm{m})$ response to $\mathrm{a} \pm 1^{\circ} \mathrm{C}$ temperature change from the steady-state temperature for M1 - M4. Note the greater length change caused by a $-1{ }^{\circ} \mathrm{C}$ temperature change, especially for M3 and M4. This asymmetric behaviour results from glacier geometry and valley shape.

\section{Sensitivity of the glacier terminus position to temperature change}

We tested the change in terminus position for a $\pm 1^{\circ} \mathrm{C}$ temperature change, $\Delta T$, from the steady-state temperature and corresponding glacier terminus position (Figure 6.7). Cameron Glacier flows into a low angle $\left(\sim 6^{\circ}\right)$ valley, which may cause a large change in terminus position for a small change in steady-state temperature (Furbish and Andrews, 1984). Non-linear topographic feedbacks in models of past glaciers in New Zealand have been discussed previously (Golledge et al., 2012) for the Last Glacial Maximum, and we see similar, but smaller-scale effects during the early Holocene and Lateglacial.

Changes in glacier length resulting from a change in mass balance are largely dependent on valley shape, especially topographic confinement, valley slope, and catchment hypsometry (Figures 6.4, 6.7, and 6.8). These effects are evident in our simulations. For example, at every glacier extent, the imposed $1{ }^{\circ} \mathrm{C}$ cooling to the equilibrium $\Delta T$ caused 


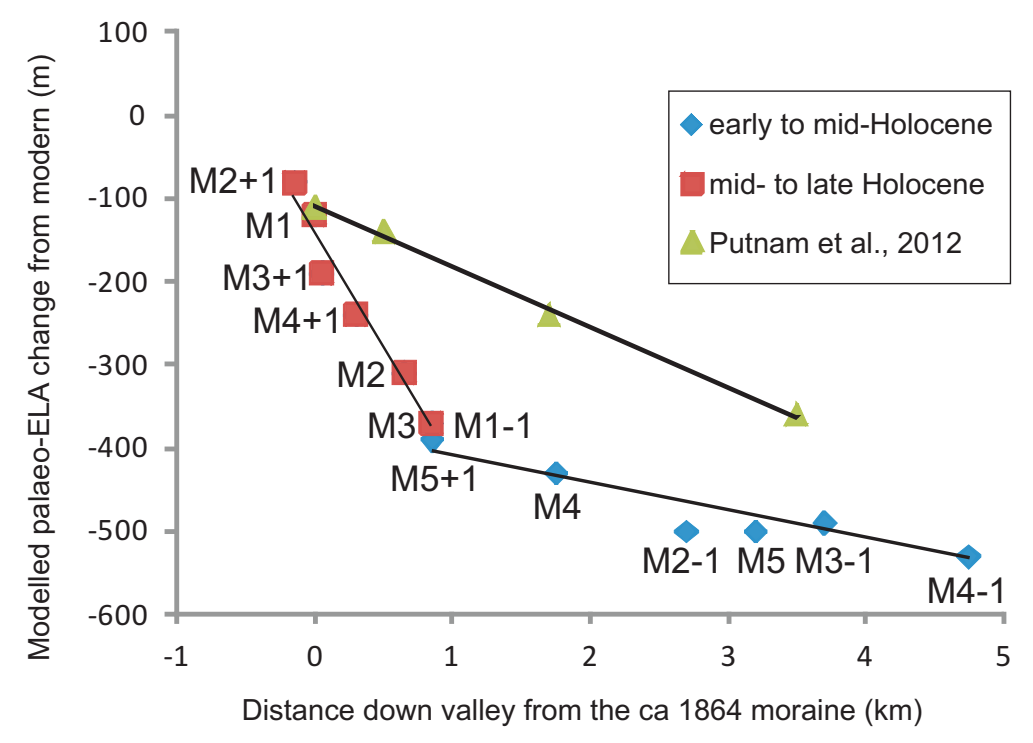

Figure 6.8 Glacier length from M1 (equivalent to $4.3 \mathrm{~km}$ glacier length) plotted against ELA lowering from modern $2120 \mathrm{~m}$ asl from all tested steady-state model runs. Results from Putnam et al. (2012) based on AAR reconstructions are shown for comparison. Notice that the relationship between glacier length change and ELA change is linear for the late Holocene glacier extents, but differs for early Holocene extents, suggesting a strong topographic influence in this valley.

a greater length change than a warming of the same magnitude. Also, the simulations initialised from greater ice extent (M3 and M4) resulted in advances of $2-3 \mathrm{~km}$, whereas the simulations initialised from lesser ice extent (M1 and M2) resulted in advances of $\sim 1 \mathrm{~km}$ (Figure 6.7 and Table 6.2).

The increased length sensitivity evident with increased glacier size is likely facilitated by valley topography. For example, the simulated tributary glaciers (Marquee and Douglas, Figure 6.2) contributed mass to the Cameron Glacier while the glacier terminus was at or beyond the M3 position. As a result, the modelled Cameron Glacier accumulation area changed from $3.8 \mathrm{~km}^{2}$ in M2 to $6 \mathrm{~km}^{2}$ in M4 and $7.9 \mathrm{~km}^{2}$ in M5 (Figure 6.5) and the total glacier size increased (Table 6.3). The M3 glacier extent represents a threshold, whereby the relationship between the change in glacier length and change in temperature (or ELA) changes (Figure 6.8). This response is because the modelled trunk glacier remains in a confined, low-angle valley, and these additional sources of ice mass cause a greater length change than what would have occurred without them. 


\subsubsection{Stochastic temperature forcing}

Random changes in annual mean temperature, simulated in model runs WNF-A - WNF-E, caused corresponding variability in the total mass balance, total volume, and length of the modelled glaciers (Figure 6.9). Glacier length fluctuations, with a baseline length equivalent to $\mathrm{M} 1$, did not exceed $550 \mathrm{~m}$, even with a $\sigma_{T}$ value set to $2^{\circ} \mathrm{C}$, which is quadruple the present-day standard deviation in interannual temperature variability $\left(\sigma_{T}=0.2-0.4^{\circ} \mathrm{C}\right)$. These simulations show that although the Cameron Glacier length could fluctuate in response to stochastic variability in temperature, the fluctuations in glacier length are minor and not capable of reaching most of the Holocene moraines.

Larger values of $\sigma_{T}$, comparing WNF-A $\left(\sigma_{T}=0.25^{\circ} \mathrm{C}\right)$ and WNF-D $\left(\sigma_{T}=2^{\circ} \mathrm{C}\right)$, resulted in a greater range of variability in Cameron Glacier length from its baseline length (Figure 6.9, Table 6.4). Interestingly, the ice volume and Cameron Glacier length changes produced in WNF-D were predominantly (76\% of the time) less than the baseline values (Figure 6.9 and Table 6.4). WNF-A $\left(\sigma_{T}=0.25^{\circ} \mathrm{C}\right)$ - WNF-C $\left(\sigma_{T}=1^{\circ} \mathrm{C}\right)$ produced fewer departures from the baseline than WNF-D $\left(\sigma_{T}=2^{\circ} \mathrm{C}\right)$. The model run with the smallest $\sigma_{T}\left(\mathrm{WNF}-\mathrm{A}, \sigma_{T}=0.25^{\circ} \mathrm{C}\right)$ resulted in glacier length changes of $100 \mathrm{~m}$ (two grid cells), which is within error. In other words, interannual stochastic temperature variability with a standard deviation similar to that of present-day $\left(\sigma_{T}=0.25^{\circ} \mathrm{C}\right)$, does not result in any significant fluctuations in the modelled length of Cameron Glacier.

The departures from the baseline values are skewed toward lower values (i.e. smaller volume, shorter ice extent). For example, the simulated Cameron Glacier retreated up to $550 \mathrm{~m}$ and advanced up to $250 \mathrm{~m}$ relative to its baseline in WNF-D $\left(\sigma_{T}=2^{\circ} \mathrm{C}\right.$, Figure 6.9). This skewness could occur because a single year with anomalously warm temperatures can obliterate multiple years of mass gain (Bradley and England, 1978). The greatest retreat event occurs around model year 1150 and coincides with a noticeable increase in the 30-year running mean in annual temperature (red line, Figure 6.3) towards more positive temperatures, that persist for a few decades.

Model run WNF-E $\left(\sigma_{T}=1^{\circ} \mathrm{C}\right)$ was initialised near the early Holocene moraines (total glacier length is $5700 \mathrm{~m}$, between M3 and M4), using a baseline temperature change 
of $-2.6^{\circ} \mathrm{C}$. The simulated glacier advanced in WNF-E $\left(\sigma_{T}=1^{\circ} \mathrm{C}\right)$ up to $250 \mathrm{~m}$ beyond this moraine, and retreated up to $700 \mathrm{~m}$ relative to its baseline. This simulation resulted in a skewed length, meaning that for the majority of the simulation $(>70 \%)$ the glacier length was shorter than the baseline length (skewness=-0.09). When compared to the simulation initialised at a shorter glacier length with the same $\sigma_{T}$ applied (WNF-C), the WNF-E showed a greater magnitude of glacier length fluctuations (Table 6.4). The higher length sensitivity of the glacier is a result of tributary glaciers adding ice flux to the main flow, as explained in the previous section.

Table 6.4 Sensitivity of modelled glacier to interannual temperature variability. Starting from the M1 glacier extent (WNF-A to WNF-D) where baseline/equilibrium glacier length is $4200 \mathrm{~m}$ and from the early Holocene moraine (WNF-E) where baseline glacier length is $5700 \mathrm{~m}$. Below are values of modelled glacier length, including the percentage of time the glacier length spent behind or beyond its equilibrium length and the calculated standard deviation and skewness of the modelled glacier length variations.

\begin{tabular}{lcc|ccc|cccc}
\hline Model & $\sigma_{T}\left({ }^{\circ} \mathrm{C}\right)$ & baseline & \multicolumn{3}{|c}{ Glacier length $(\mathrm{m})$} & \multicolumn{4}{c}{ Comparison to baseline length } \\
test & & length $(\mathrm{m})$ & $\max$ & $\min$ & mean & $\%$ less & $\%$ beyond & std. dev. & skewness \\
\hline WNF-A & 0.25 & 4200 & 4300 & 4200 & 4250 & 0 & 48 & 50 & 0.10 \\
WNF-B & 0.5 & 4200 & 4350 & 4100 & 4250 & 3 & 52 & 54 & -0.10 \\
WNF-C & 1 & 4200 & 4400 & 3950 & 4210 & 32 & 33 & 84 & -0.01 \\
WNF-D & 2 & 4200 & 4450 & 3650 & 4080 & 76 & 13 & 146 & -0.38 \\
WNF-E & 1 & 5700 & 5950 & 5000 & 5510 & 96 & 2 & 186 & -0.09 \\
\hline
\end{tabular}



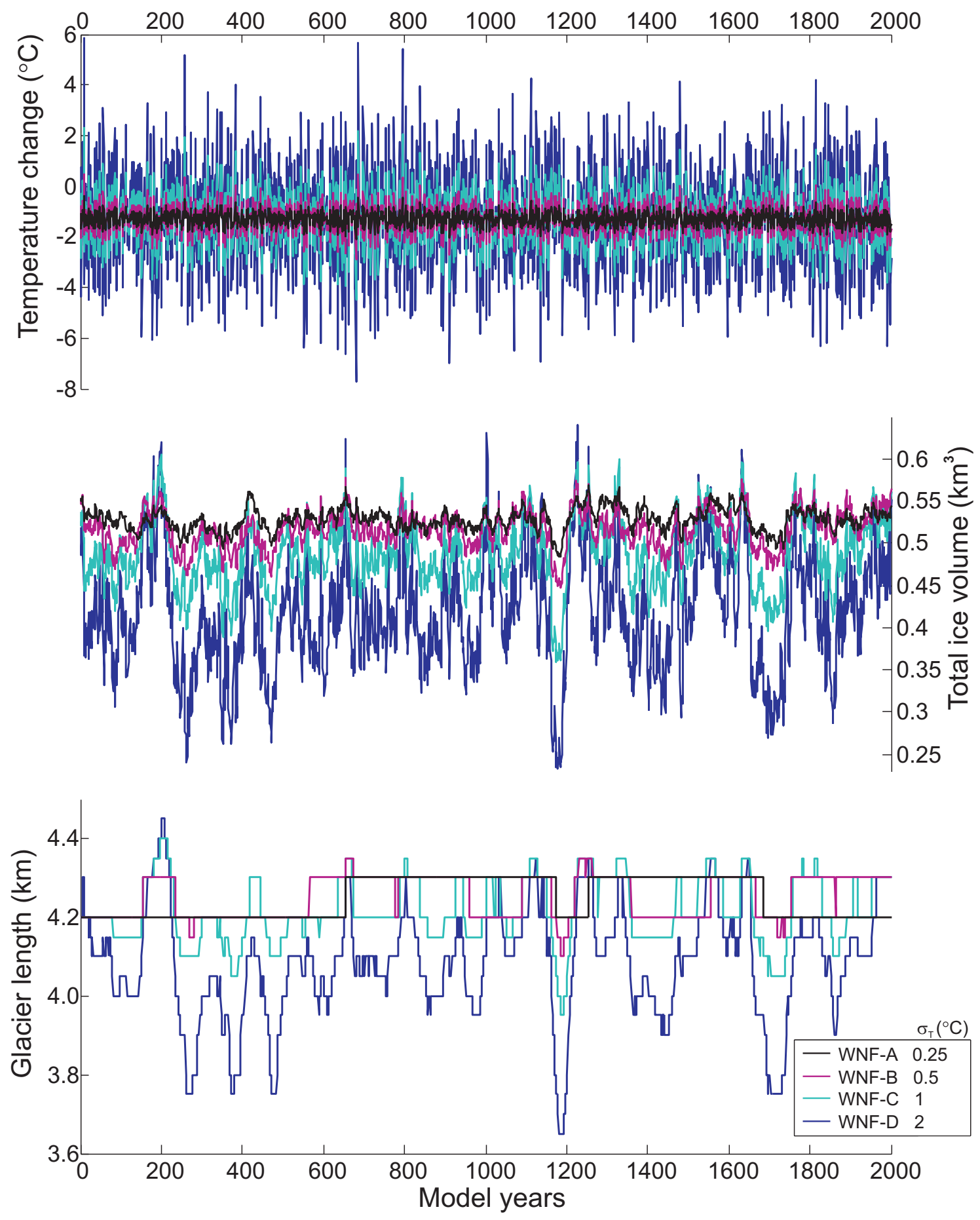

Figure 6.9 Glacier response to a white-noise forcing in temperature. Panel a) interannual temperature change for each of the transient experiments. Note the different amplitude in temperature change for the different tests (caused by $\sigma_{T}$ ). Panel b) total ice volume in the model domain over time. Panel c) simulated Cameron Glacier length change for each of the stochastic variability experiments. Note the greater amplitude in glacier length fluctuations with increased $\sigma_{T}\left(\mathrm{WNF}-\mathrm{D}, \sigma_{T}=2^{\circ} \mathrm{C}\right)$. 


\subsection{Discussion}

We used a numerical modelling approach to address questions about the palaeoclimate significance of Holocene moraine sequences. In addition to estimating past temperature and precipitation changes from today, we examined the glacier length sensitivity and found topographic feedbacks. A second suite of model runs showed the response of the Cameron Glacier to interannual stochastic variability in temperature. These results have allowed us to examine several questions relating glacier length to temperature variability.

\subsubsection{Can stochastic variability in temperature cause the length of Cameron Glacier to fluctuate to its Holocene extents?}

In our transient simulations, we found that the modelled glacier does not fluctuate significantly $(>200 \mathrm{~m})$ when forced by interannual stochastic variability in temperature similar to today. Increasing temperature variability to quadruple the present-day standard deviation (i.e. $\sigma_{T}$ set to $2^{\circ} \mathrm{C}$ ) caused larger-scale terminus fluctuations (up to $550 \mathrm{~m}$ ), with a tendency for the glacier length to be less than the typical baseline length (76\% of the model years). Higher $\sigma_{T}$ values result in reduced ice volume and glacier length (Table 6.4 and Figure 6.9) compared to a lower $\sigma_{T}$. These glacier responses to interannual stochastic temperature variability in a steady climate suggests that:

1. It is not possible to cause the Cameron Glacier to advance significantly ( $>200 \mathrm{~m}$ ) from its M1 extent with present-day stochastic variability in temperature.

2. Increased standard deviation of interannual temperature variability, within a steady climate, causes a reduced glacier length and ice volume in this valley.

3. The shortest glacier length $\left(3650 \mathrm{~m}\right.$ for $\left.\sigma_{T}=2^{\circ} \mathrm{C}\right)$ from the transient tests occurs during a time when the 30-year mean in stochastic values show a $\sim 50$-year persistence of warmer annual mean temperatures (mean temperature change $0.5^{\circ} \mathrm{C}$ ), showing that multi-decadal persistence in forcing is required for large length changes. 
In simulations starting from the M1 extent, stochastic variability alone cannot cause the magnitude of glacier advances similar to those related to the Holocene. Simulations starting from the early Holocene position, however, indicate that stochastic variability cannot fully explain, but could contribute, to retreat of the Cameron Glacier documented by Putnam et al. (2012). These simulations support the interpretation that Holocene moraine records contain important information about long-term climate changes (Schaefer et al., 2009; Putnam et al., 2012).

\subsubsection{How do these results differ from previous studies of interannual variability influencing glacier length and why?}

Previous modelling studies on the effect of stochastic variability in mass balance or climate on glaciers, showed that kilometre-scale fluctuations in glacier length could occur (Oerlemans, 2000; Reichert et al., 2002; Roe and O’Neal, 2009). The greater fluctuations in these modelling studies could be a product of either glacier response time or glacier sensitivity. Glaciers such as the Franz Josef, with very short response times and high mass turnover, are more likely to exhibit many, small terminus fluctuations in response to stochastic variability in climate. Oerlemans (2000) showed that glaciers with slower response times (Nigardsbreen, $\sim 68$ years) can produce fluctuations of greater magnitude than glaciers with a fast response time (Franz Josef Glacier, $\sim 24$ years). The Cameron Glacier, however, does not show such large departures from the baseline length and volume in response to stochastic variability in temperature, despite having a similarly long response time (70 years) to Nigardsbreen.

It seems surprising that the Cameron Glacier is not capable of experiencing significant random walks in response to stochastic temperature forcing, given that it has been shown in this study to be sensitive to temperature change, and has a relatively long response time. There have been few studies of this kind, and it is possible that the glacier behaviour shown here is actually more characteristic of glaciers than that of Oerlemans (2000) and Roe (2011), who used simpler models and mass balance forcings than those applied here. Further work is required in order to test this hypothesis. 


\subsubsection{How do the modelled palaeoclimate estimates and ELA changes compare to previous estimates?}

Putnam et al. (2012) used a temperature lapse rate of $-6.5^{\circ} \mathrm{C} \mathrm{km}^{-1}$ and an AAR of 0.67 , to reconstruct past climate from moraine evidence at Cameron Glacier. In their study, the glacier outline included the headwall right up to the ridge line in the accumulation area. Although much of the valley walls leading up to the ridgeline are presently ice-free, these slopes are contributing snowfall to the glacier accumulation area. By including this area in the AAR calculation, Putnam et al. (2012) were indirectly accounting for avalanche accumulation.

Our study used a temperature lapse rate of $-5^{\circ} \mathrm{C} \mathrm{km}^{-1}$ and our modelled mass balance suggests lower AAR values (0.42-0.5) than those used in Putnam et al. (2012). The low AAR values in our study result from including the modelled avalanche accumulation. With avalanching, the mass gain of the glacier is concentrated into a smaller area than if it is left distributed more evenly on steep slopes. Without the avalanche model, our modelled mass balance suggests a higher AAR of $\sim 0.75$ and a slightly lower (by $\sim 100 \mathrm{~m}$ ) ELA (Table 6.3). The difference in ELA estimates between that in Putnam et al. (2012) and those in our study is predominantly caused by the piecewise relationship between $\Delta T$ and glacier length (Figure 6.8 and Table 6.5). We follow Putnam et al. (2012) and use the following equation to relate distance from the ca. 1864 (M1) moraine (x variable) to a palaeo-snowline change (y) (values in Table 6.5). However, we use two linear equations and the values differ depending on the glacier length (Figure 6.8).

$$
y=a x+b
$$

Table 6.5 Values describing the linear relationship between a change in ELA and its corresponding change in glacier length $(y=a x+b)$. 'Tributary glaciers' refer to the Douglas and Marquee tributary glaciers specifically.

\begin{tabular}{lll}
\hline $\mathrm{a}$ & $\mathrm{b}$ & Notes \\
\hline-72.73 & -108.68 & Putnam et al. (2012) \\
-275 & -140 & without tributary glaciers \\
-35 & -370 & with tributary glaciers \\
\hline
\end{tabular}


Our model results suggest that the relationship between snowline change and glacier length change would be best described by a piecewise function with two different linear equations (Table 6.5). The threshold that separates the two equations occurs near the M3 glacier length (Figure 6.8), and can be explained by the Marquee and Douglas tributary glaciers starting to contribute a significant amount of mass to the trunk glacier (Figure 6.4). An AAR reconstruction would be capable of accounting for this change if the tributary catchments were included at the appropriate glacier lengths, which is difficult to distinguish without geomorphic evidence.

The Cameron Glacier length response can be explained by the valley topography and height-mass balance feedbacks. Essentially, when the snowline becomes lower in elevation, more surface area resides above the snowline and can begin to form tributary glaciers. In response, the tributary glaciers may coalesce and contribute mass to a trunk glacier, thereby increasing the total accumulation area (Porter, 1975b). This expansion in total accumulation area leads to a large change in glacier length, because this extra mass is funnelled down a long, narrow valley. The height-mass balance feedback occurs as glaciers thicken and more of the glacier surface is above the snowline, which could also increase the total accumulation received by the glacier (Furbish and Andrews, 1984; Oerlemans, 1989). The large changes in modelled glacier length within the Cameron valley help explain the relatively detailed, well-preserved Holocene moraine sequence.

Our modelled mass balance distribution produced lower AAR values and higher ELA values (Table 6.3) than those used in Putnam et al. (2012) (Table 6.1). This is particularly evident for an AAR when Cameron Glacier is relatively small, and the terminus is at or behind M1, because the accumulation area is confined to the base of the steep valley walls (Figure 6.5). In these locations, thick avalanche deposits are able, at least in part, to persist through the ablation season and contribute snow mass to the glacier. As the ELA lowers, the accumulation area increases in size and the avalanche accumulation pattern becomes relatively less important. 


\subsubsection{What do the Cameron Glacier Holocene moraines tell us about climate changes?}

The stochastic temperature forcing experiments resulted in very minor changes in the modelled length of Cameron Glacier. Real climate variability, however, contains nonpersistent (white-noise) and persistent components, which are observed as lower-frequency oscillations (Solomon et al., 2007; Trenberth et al., 2007; Dean and Stott, 2009). Presentday temperature and precipitation variability in New Zealand is influenced by atmospheric and oceanic circulation and leads to changes in New Zealand glacier mass balance (Fitzharris et al., 2007; Salinger et al., 2001; Purdie et al., 2011b; Chinn et al., 2012). If we had forced the glacier model with random temperature changes that persisted for five years instead of one, the results would have been different. For example, the El Niño-Southern Oscillation (ENSO) (periodicity of 3-7 years) and the Interdecadal Pacific Oscillation (IPO) (decadal-scale climate oscillation related to ENSO) have affected New Zealand climate, and in turn, glacier mass balance and ice volume during the twentieth century (Woo and Fitzharris, 1992; Hooker and Fitzharris, 1999; Gillett and Cullen, 2011; Purdie et al., 2011b,c). The influence of these kinds of climate phenomena on glaciers in New Zealand during the Holocene is likely significant, but still poorly known. It is likely that such fluctuations in climate might be responsible for some of the relatively minor oscillations in the terminus of glaciers observed in the moraine record at Cameron Glacier.

Another important observation that requires explaining is the overall recessional nature of the Holocene moraine sequence in Cameron valley. This length reduction could be due to (1) the direct effect of orbital insolation changes on glacier mass balance, (2) the combined effect of stochastic variability in temperature, as shown in our experiments, with a gradual warming, (3) the effect of the southward shift of the intertropical convergence zone (ITCZ), as described by Putnam et al. (2012), or (4) another, as yet undocumented reason. Glacier modelling results have shown little to no influence in glacier mass balance by direct insolation changes in New Zealand, and over this time period (Doughty et al. (in press), Chapter 4). The stochastic variability experiments present here show changes in glacier length, but they are minor and cannot explain the recessional nature of the 
Cameron valley moraine sequence alone. This leaves the most likely cause of Holocene glacier fluctuations to be systematic shifts in climate, where minor fluctuations in glacier length might reflect stochastic variability in temperature (and/or precipitation).

\subsubsection{How do model results fit into the real world?}

Kirkbride and Winkler (2012) suggest that when interpreting palaeoclimate from glacier chronologies, one should consider the complex processes involved with climate variability, glacier response, and moraine formation. They maintain that a lack of basic conceptual understanding is the weakest link in interpretations of climate-moraine relationships, now that absolute dating and palaeoclimate modelling techniques have improved. We have followed this suggestion by investigating how a series of climatic triggers could result in a moraine sequence. We have shown that interannual stochastic variability cannot explain the moraine sequence alone. It is possible, however, that even significant glacier fluctuations $(\sim 1 \mathrm{~km})$ might not explain moraine occurrence because of the time needed to form a large moraine. In other words, the brief glacier terminus fluctuations simulated in our model might not be stable at a single location for a long enough time to make a moraine sequence.

Several of the Holocene moraines in Cameron valley are relatively large ( $>30 \mathrm{~m}$ in relief, $>1 \mathrm{~km}$ in length (Putnam et al., 2012)). Moraine size is thought to depend on the rate of sediment supply and the amount of time the glacier spends at a single extent (Evans, 2003). The steep upper headwalls of the Cameron valley likely produce a steady supply of rock debris to the glacier surface. Despite this debris supply, it is unlikely that the simulated, short-lived ( $<5$-year) stabilisations in the glacier terminus would result in formation of large moraines, such as those observed in the Cameron valley (Putnam et al., 2012). It is more likely that these moraines are a product of the Cameron Glacier stabilising for several decades or longer. In other words, both the scale of glacier terminus variability observed in our stochastic temperature forcing experiments, as well as the nature of the moraines, point to these landforms as representations of past glacier stabilisations caused by systematic changes in climate. 
Our modelling experiments also reveal that the moraines in Cameron valley are ideal for reconstructing palaeoclimate because of the characteristics of the glacier, and the valley that it once occupied. First, the low surface elevation of the glacier and avalanche accumulation result in a high annual mass balance sensitivity to annual climate conditions. Second, the glacier geometry and valley topography are such that the main trunk glacier has a high length sensitivity. Together, this sensitivity means that relatively larger changes in glacier length occur in response to small changes in climate. This glacier-climate response must, in part, explain why Cameron valley contains such a fine moraine sequence.

\subsection{Conclusions}

A glacier modelling approach has helped us to better understand the climatic significance of Lateglacial and Holocene moraines in the Cameron valley, New Zealand. Our glacier modelling simulations have lead us to the following conclusions:

1. The outermost moraine, correlated to other Lateglacial moraines, yielded a temperature change of $-3.3 \pm 0.7^{\circ} \mathrm{C}$ below present, which is similar to previous glacier modelling estimates of Lateglacial climate (Anderson and Mackintosh, 2006; Doughty et al., in press; Kaplan et al., submitted) (Chapter 4 and Appendix A). This provides further support for a regional-scale cooling in New Zealand during the Lateglacial.

2. Model-derived past temperature estimates are lower than those estimated by Putnam et al. (2012) for the Cameron valley Holocene moraine sequence. Interestingly, a linear relationship between snowline and glacier length, as suggested by Putnam et al. (2012), is supported by our modelling experiments for the Holocene moraines. However, we recommend using a piecewise linear equation to describe different glacier length sensitivities when considering both the early and late Holocene moraines. The two linear equations we present are meant to account for the changes in glacier length response due to topographic feedbacks. In addition, the Cameron Glacier is more sensitive to cooling than warming. This asymmetry in glacier length response results from the valley topography and height-mass balance feedback. This 
effect is likely to exist in many glacier catchments and should be considered when reconstructing snowline changes from moraine positions.

3. Stochastic variability in temperature causes small length and volume fluctuations in the modelled glacier. These fluctuations are insufficient to explain large advances seen during the Holocene. They could, however, in part explain the recessional nature of the moraine record, although a warming trend is still necessary to explain the 2-km long sequence of recessional Holocene moraines in the Cameron valley. This supports published views that the Cameron Glacier Holocene moraines were deposited at times when the glacier was larger than today because of a change in mean climate (Burrows, 1975, 2005; Putnam et al., 2012). 


\section{Chapter 7}

\section{Synthesis}

\subsection{Introduction}

The primary aim of this thesis was to explore possible climatic implications of wellpreserved Lateglacial and Holocene moraine sequences in New Zealand by using a numerical modelling approach. The model results and interpretation contribute to the scientific understanding of moraine-glacier-climate relationships. Two specific goals were to (1) estimate palaeoclimate by modelling past glacier extents as delimited by terminal moraines and (2) examine the influence of interannual stochastic variability in climate on glacier fluctuations.

\subsection{Contributions made in this thesis toward understand- ing palaeoclimate and glacier sensitivity}

Palaeoclimate modelling studies on individual past glaciers have not been carried out previously on any New Zealand glaciers besides Franz Josef Glacier (Anderson and Mackintosh, 2006). In this thesis, new palaeoclimate estimates have been generated for several Lateglacial and Holocene moraines in the Southern Alps using this modelling approach. The results are internally consistent from three different catchments for the Lateglacial (Chapters 4 and 6 and Appendix A). I compared the modelled mass balance results to previous estimates of equilibrium-line altitude (ELA) values in these valleys (Kaplan et al., 2010; Putnam et al., 2012). I found that the simple accumulation-area ratio (AAR) method works well in catchments with simple geometry (Chapter 4) and is less appropriate for complex valleys where the contribution of ice from tributary valleys is not well constrained by geomorphic evidence (Chapter 6). 
Transient simulations offered insight into glacier response to an evolving climate. In Chapter 4, the glacier model was forced by a faunal-based temperature reconstruction and produced a glacier extent similar to the mapped and dated Lateglacial moraine. This result suggests that the moraine record and nearby climate proxy record provide consistent information about past climate, primarily that both proxy records reflect similar changes in temperature (Chapter 4). Although Plummer and Porinchu (2003) attempted a similar experiment for a Sierra Nevada glacier, this was the first attempt at forcing a glacier model with a chironomid-derived temperature reconstruction in New Zealand. In Chapter 6, glacier terminus fluctuations caused by interannual stochastic variability in climate were found to be insufficient to explain the significant advances $(>500 \mathrm{~m})$ that occurred during the Holocene, but could explain minor characteristics of the Holocene moraine record. This finding supports the interpretation that these moraines represent systematic changes in past climate.

Avalanche deposits result in rapidly-varying snow thicknesses, and the most efficient way of measuring this snow distribution is with ground-penetrating radar (GPR). The combination of continuous profiles of snow thickness from GPR and a mass transport and deposition (MTD) model is a powerful tool for analysing the impact of avalanche processes on glacier mass balance. However only one other study has used GPR-derived snow depths and an avalanche model as part of a mass balance modelling study on an avalanche-fed glacier (Machguth et al., 2006). The improvement in modelled mass balance assists in the understanding of glacier behaviour and response to climate forcing.

In summary, my findings support the hypothesis that moraine sequences can offer insight into past glacier behaviour. Glaciers respond mainly to temperature and/or precipitation perturbations and moraines provide a record of past glacier extents and therefore, past climate (Leclercq and Oerlemans, 2011). Care should be taken when choosing a moraine sequence for palaeoclimate reconstructions because glacier sensitivity to climate can be dependent on site-specific characteristics, such as topography, lake-calving, and avalanche accumulation. Models can help to identify and/or take into account some of these processes. 


\subsection{Research questions}

In Section 2.7, I posed several scientific questions. Below I summarise the results from the experiments in this thesis as they pertain to each research question.

\subsubsection{What magnitude of past temperature and precipitation change do Lateglacial- and Holocene-aged moraines in New Zealand represent?}

Table 7.1 Palaeoclimate estimates from different aged moraines for the three targeted locations. Ages are in 1000 years before present $(\mathrm{ka})$ and the range of temperatures represents a precipitation change of $-20 \%, 0 \%$, and $+20 \%$ relative to the present-day value.

\begin{tabular}{|c|c|c|c|c|c|c|c|c|c|}
\hline Location & $\begin{array}{l}\text { age } \\
\text { (ka) }\end{array}$ & $\begin{array}{l}\Delta T\left({ }^{\circ} \mathrm{C}\right. \\
(-20 \%)\end{array}$ & $\begin{array}{l}\text { when } \\
(0 \%)\end{array}$ & $\begin{array}{c}P \text { equals: } \\
(+20 \%)\end{array}$ & EBM & MTD & $\begin{array}{c}\text { daily T } \\
\left({ }^{\circ} \mathrm{C}\right)\end{array}$ & ice-flow & $\begin{array}{l}\text { resolution } \\
\text { (m) }\end{array}$ \\
\hline Irishman & 13 & -3.2 & -2.7 & -2.3 & $\checkmark$ & & & $\checkmark$ & 25 \\
\hline \multirow[t]{2}{*}{ Whale } & 15 & -2.6 & -2.1 & -1.8 & $\checkmark$ & & & $\checkmark$ & 100 \\
\hline & & -2.9 & -2.4 & -2.0 & $\checkmark$ & $\checkmark$ & $\checkmark$ & $\checkmark$ & 25 \\
\hline \multirow{7}{*}{ Cameron } & 13 & -4.0 & -3.3 & -2.8 & $\checkmark$ & $\checkmark$ & $\checkmark$ & $\checkmark$ & 50 \\
\hline & 10.7 & -3.4 & -2.7 & -2.3 & $\checkmark$ & $\checkmark$ & $\checkmark$ & $\checkmark$ & 50 \\
\hline & 10.7 & -3.2 & -2.6 & -2.1 & $\checkmark$ & & $\checkmark$ & $\checkmark$ & 50 \\
\hline & 8.2 & -2.9 & -2.4 & -1.8 & $\checkmark$ & $\checkmark$ & $\checkmark$ & $\checkmark$ & 50 \\
\hline & 0.5 & -2.6 & -2.1 & -1.5 & $\checkmark$ & $\checkmark$ & $\checkmark$ & $\checkmark$ & 50 \\
\hline & 0.2 & -1.8 & -1.3 & -0.8 & $\checkmark$ & $\checkmark$ & $\checkmark$ & $\checkmark$ & 50 \\
\hline & 0.2 & -1.8 & -1.3 & -0.8 & $\checkmark$ & & $\checkmark$ & $\checkmark$ & 50 \\
\hline
\end{tabular}

Table 7.1 shows palaeoclimate estimates from various past glacier extent simulations, and comparing these results allows me to draw several conclusions. First, the palaeoclimate estimates for the Lateglacial moraines from Irishman, Whale (Appendix A), and Cameron valleys show that, within error, temperatures were $\sim 2-3^{\circ} \mathrm{C}$ colder than today during this time (Table 7.1). The similarities in these three palaeoclimate estimates suggest that the glaciers were responding to a similar, and likely regional, cooling during the Lateglacial. Second, the Cameron Glacier simulations with and without the avalanche model yield similar palaeoclimate estimates, suggesting that the avalanche model does not necessarily need to be included when reconstructing past climate. The avalanche model does, however, offer useful insights into changes in ELA and mass balance patterns. Third, comparisons between the palaeoclimate estimates on the Whale glacier show that using 
the avalanche model, increasing the horizontal grid resolution, and including daily temperature variability do not significantly change the results for this past glacier. Although avalanche processes and daily temperature variability will influence the modelled glacier mass balance, they do not appear to greatly affect the resulting palaeoclimate estimates.

I modelled the Whale glacier extent, dated to $15 \mathrm{ka}$, using two different model setups. The 'newer' model for Whale glacier included randomly generated 'daily' temperatures, the MTD model, and a higher grid resolution. This 'daily' temperature variability helped to improve modelled mass balance in the Cameron valley between simulations at a daily and monthly timestep (Chapter 3). I thought that palaeoclimate results from other areas would be improved if I included the 'daily' temperatures with models run at a monthly timestep. The difference in past temperature estimates between the old and new model versions is likely a consequence of the simulated 'daily' temperature variability, rather than the resolution or MTD model. Simulations on the Irishman glacier in Chapter 4 used the 'older' monthly timestep model, where 'daily' temperatures were not generated. It is likely that the palaeoclimate estimates from this study would be slightly lower (by $\sim 0.2^{\circ} \mathrm{C}$, i.e. $2.5-3.4^{\circ} \mathrm{C}$ cooler than today) if I had used the 'newer' model.

\subsubsection{Are these estimates of past temperature and precipitation co- herent with other climate proxy records in New Zealand?}

Palaeoclimate estimates from my steady-state Lateglacial simulations are similar to those from previous palaeoclimate studies from mapped moraines in New Zealand (Anderson and Mackintosh, 2006; Kaplan et al., 2010; Putnam et al., 2012). One reason that palaeoclimate estimates from Anderson and Mackintosh (2006) for the Franz Josef Glacier during the Lateglacial might be slightly colder $\left(3-4^{\circ} \mathrm{C}\right)$ is that their model did not include possible ice flow from the Callery valley, which may have formed a tributary glacier during the Lateglacial. Modelling of palaeo-glaciers in the Cameron valley shows that tributary glaciers can play a critical role in the overall extent, and hence, the climate forcing required for a glacier to advance. 
The influence of debris cover on glacier ablation can affect the sensitivity of a glacier to climate change (Stokes et al., 2007; Reznichenko et al., 2010; Anderson and Mackintosh, 2012; Kirkbride and Winkler, 2012). I did not attempt to account for debris cover in the palaeoclimate simulations because it is unknown for the past and it was not likely to be a significant influence on these glaciers, given the lack of present-day debris cover on glaciers such as these (e.g. Glenmary in the Lake Ohau catchment) and the nature of the moraines and till deposits in the valleys. In addition, I do not consider the possibility that the moraines, described in this thesis, formed as a result of a rock avalanche-induced glacier advance (e.g., Tovar et al., 2008). Including debris cover (e.g. an increase of $20 \%$ ) could reduce the magnitude of cooling necessary to match a glacier extent to a past moraine, but is likely within the range of palaeoclimate uncertainty. The coherence of timing and climate forcing required to form these moraines in different valleys demonstrated in this thesis makes a 'one-off rock avalanche cause' unlikely.

Other climate proxy records from New Zealand also suggest a similar-scale cooling during the Lateglacial, or more specifically, the Antarctic Cold Reversal (ACR) (15 - $13 \mathrm{ka}$ ). The chironomid-derived temperature reconstruction from Boundary Stream tarn (BST) (Vandergoes et al., 2008) in the Ben Ohau Range shows a cold spike at $\sim 13 \mathrm{ka}$. The glacier simulated by this reconstruction advanced to within $100 \mathrm{~m}$ of the moraine dated to the ACR (Kaplan et al., submitted). Sea surface temperatures also show a cooling during the ACR (Carter and Cortese, 2009), as do several pollen records from around New Zealand (Newnham and Lowe, 2000; Hajdas et al., 2006).

\subsubsection{To what extent does the re-mobilisation of snow by avalanches affect the present-day mass balance of New Zealand glaciers?}

The Southern Alps are an actively uplifting mountain range, and many glaciers are surrounded by steep topography, which is potentially a source of accumulation to the glacier via gravitational and/or wind transport of snow. The accumulation pattern of Cameron Glacier in the Southern Alps was observed during one winter using GPR (Chapter 5). These data suggest that snow avalanching from the steep headwall bounding this glacier 
results in thick accumulations of snow on the glacier surface, directly adjacent to the steep rock walls. Including this process in my simulations via a snow avalanche model significantly improves the match between modelled and observed snow accumulation patterns. If the gravitational snow mass transport and deposition model (Gruber, 2007) is not used, the glacier surface shows a thin, even distribution of winter snow, which melts away completely over the summer (Figure 3.4). Without this preferential snow accumulation, Cameron Glacier would lie beneath the regional snowline (Chinn et al., 2005), and would not exist in today's climate. It is highly likely that similar processes affect many glaciers in the Southern Alps and elsewhere. These gravitational snow redistribution processes clearly need to be taken into account in simulations of present-day glacier mass balance.

\subsubsection{Does including a model of snow redistribution in a glacier model change the palaeoclimate reconstructions made?}

Given the apparent importance of snow redistribution processes on present-day glaciers in the Southern Alps, I assumed that including this process in the Cameron Glacier simulations would result in an improvement in palaeoclimate estimates. Inclusion of the snow redistribution model was found to influence the spatial pattern of reconstructed ELAs and AARs. In simulations that include the avalanche model, the total glacier area decreases because the snow is removed from the adjacent steep valley walls and is deposited onto the glacier surface. This transfer of mass also causes a decrease in the AAR because the accumulation is concentrated on the flanks of the glacier at the base of the steep valley walls. These results reinforce the notion that including the avalanche model is important for simulations of the present-day glacier mass balance. However, palaeoclimate estimates made using the glacier model at Cameron Glacier with and without the avalanche routine, were found to be indistinguishable within error. This surprising result occurs because in the absence of an avalanche model, snow accumulates on the high-elevation, steep slopes above the glacier, and then the ice-flow model moves the ice downslope to contribute this mass to the main trunk glacier. Thus, the change in accumulated snow mass between the Holocene ice extents and the present day is almost the same with or 
without the avalanche model. This means that including an avalanche model might not be essential when inferring past climates.

\subsubsection{Could natural, stochastic variability in climate have caused Holocene glacier fluctuations?}

Simulations in Chapter 6 suggest that stochastic variability in temperature cannot cause significant changes in glacier length $(>500 \mathrm{~m})$, at least at Cameron Glacier. The size of the interannual temperature variability prescribed affects the results, in that a greater standard deviation causes greater glacier fluctuations. However, using a standard deviation in interannual temperature similar to that of today ( $\sim 0.2$ to 0.4 , Dean and Stott (2009)), the simulated glacier does not change more than $150 \mathrm{~m}$ from an initial glacier length at the ca 1864 moraine. This suggests that the Cameron valley Holocene moraines could not have been deposited by glacier length changes due to stochastic variability alone, and therefore, the moraine record more likely reflects systematic changes in past climate.

Stochastic variability in interannual temperature could, in part, explain some of the overall retreat of the Cameron Glacier during the Holocene. The simulations in Chapter 6 show decreased ice volume with increased interannual temperature variability, suggesting that the Cameron Glacier could retreat a few hundred metres without a change or trend in multi-decadal climate. Changes in this variability during the Holocene are largely uncertain. It is probable that glaciers experience both the 'random' fluctuations due to stochastic temperature variability and greater fluctuations due to longer-term climate trends.

\subsubsection{What parameters are the modelled glaciers most sensitive to, and how does parameter choice affect the climate reconstruc- tions?}

Aside from the primary variables, temperature and precipitation, the modelled glacier showed smaller, but noticeable responses to changes in albedo, temperature lapse rate, and 
the snow temperature threshold. Albedo has long been known to influence glacier mass balance. There are very few albedo measurements from New Zealand glacier surfaces (Anderson et al., 2010; Gillett and Cullen, 2011) and most of the model parameterisations for albedo come from European glaciers (Oerlemans, 1992; Oerlemans and Knap, 1998). The lack of albedo data leads to a considerable uncertainty in the parameter values used. Sensitivity tests in the previous chapters use a range of \pm 0.05 in albedo to account for this uncertainty, and in some locations, this changes the palaeoclimate estimate by up to $\pm 0.6^{\circ} \mathrm{C}$ (Chapters 4 and 6).

The present-day temperature lapse rate is another potential source of error. The temperature lapse rate used in the model can change the palaeoclimate interpretations by $\sim 1^{\circ} \mathrm{C}$ and is therefore a weakness in estimating past temperatures by modelling glaciers. Because temperature lapse rates can vary temporally and spatially by several degrees per kilometre, it is important to better understand how to parameterise these values for glacier modelling studies. The monthly temperature lapse rate values in Chapter 4 were calculated using data from a temporary automatic weather station (AWS) in the upper basin of Irishman Stream. Local meteorological data are not yet available for Cameron Glacier, thus I used temperature data from a nearby alpine weather station to estimate a presentday temperature lapse rate. A greater focus on studying alpine climate and atmospheric boundary layer processes in New Zealand would help in assessing the ability of models to capture these important, secondary climate characteristics.

Modelled snow accumulation in high precipitation areas is sensitive to the prescribed temperature at which precipitation is designated as snow (snow temperature threshold). The value used for the snow temperature threshold (typically $1^{\circ} \mathrm{C}$ ) is somewhat uncertain, and can lead to a significant change in the amount of modelled precipitation partitioned as snow. I varied the snow temperature threshold between 0 and $2^{\circ} \mathrm{C}$, which resulted in changes in the palaeoclimate estimate of up to $\pm 0.3^{\circ} \mathrm{C}$ (Chapters 4 and 6). This is a minor change in the palaeoclimate estimate relative to the changes caused by varying the albedo.

Other parameters tested did not affect the palaeoclimate estimates as much as these three parameters. The albdeo parameterisations used here have been adjusted to account for 
observations of snow albedo made on a New Zealand glacier (Anderson et al., 2010), however, it would be useful to know if snow in other locations New Zealand show similar values. The nature of albedo, and the temperature lapse rate, is such that there will always be a range of uncertainty associated with the parameterisation, thus the sensitivity analyses presented in this thesis are an appropriate way to estimate the error in the palaeoclimate reconstructions.

The MTD model showed great improvements in simulated present-day snow distribution (Chapter 5) and modelled mass balance (Chapter 3). These simulations suggested the importance of including an avalanche model in past and present-day glacier simulations. The interpreted ELA and AAR values from the modelled mass balance of Cameron Glacier (Chapter 6) were significantly different (ELA differed by $100 \mathrm{~m}$ and AAR differed by 0.36) with and without the MTD model (Section 6.3.1). However, simulations of the Holocene glacier extents in the Cameron valley showed no difference in palaeoclimate estimates with or without the MTD model (Table 6.3). Similarly, the slight differences in palaeoclimate estimates for Whale Stream from the two model versions (Table 7.1) are probably attributable to the reintroduction of daily temperature variability, instead of the MTD model (Appendix A). The MTD makes little impact on the temperature results because without simulating avalanches, the modelled ice, unrealistically, clings to the steep valley walls and eventually contributes mass to the glacier. The inclusion of the avalanche model is important for mass balance estimates, but its inclusion seems less necessary to estimate palaeoclimate when an ice-flow model is used.

\subsubsection{How do the palaeoclimate estimates derived from modelling glaciers differ from previous estimates using simpler methods?}

The comparisons between palaeoclimate reconstructions made using the AAR method and those made using numerical models show that the AAR approach works well in most cases, especially where the past glacier outline is easily determined and where glacier geometry is simple (Kaplan et al., 2010; Doughty et al., in press) (Chapter 4). The palaeoclimate reconstructions made with the two approaches often agree within uncertainty. 
However, caution is needed when applying the AAR method in valleys with tributary glaciers (Chapter 6).

Past temperature estimates from the Holocene moraine simulations (Chapter 6) are almost twice as cold as those suggested by Putnam et al. (2012). Noticeable differences in palaeoclimate estimates between the AAR method and the modelling approach could be attributed to estimating past glacier geometry. The modelled Holocene glacier extents included ice flowing from tributary valleys, shown in Chapter 6. Putnam et al. (2012), on the other hand, did not account for these tributaries. It is difficult to predict which tributaries contributed ice into the main trunk glacier without geomorphic evidence in the tributary valleys, or a 2-D numerical model to determine ice extent. Prescribing a past glacier geometry where evidence is not available can lead to uncertainty in the palaeoclimate estimates, especially in valleys with potential tributary glaciers. This is potentially an issue in the application of both the AAR and 1-D flowline methods.

Unfortunately, there is no appropriate way to quantify the uncertainty in the palaeoclimate estimates made using the AAR method. The numerical modelling approach used in this thesis has allowed me to explore some of these uncertainties, and the results are reassuring, supporting the idea that the AAR method provides a reliable, first-order reconstruction of past climate in most cases.

\subsubsection{What can we learn from dynamic glacier models that we could not gain from using simpler methods?}

There are many things we can learn using dynamic models, here I focus on three:

1. The response time of a glacier describes how quickly a change in mass balance is translated into a terminus change. In the Chapter 4 transient simulations, Irishman glacier fluctuated greatly over century-timescales, suggesting that significant terminus changes are possible between episodes of moraine deposition. In the Chapter 6 stochastic temperature variability simulations, Cameron Glacier had a relatively 
long response time, but did not exhibit a 'long-walk' response as suggested by Oerlemans (2000). These results suggest that response time, as well as glacier geometry and valley topography, will determine the response of the glacier to stochastic variability in climate.

2. Ice extent is difficult to estimate in areas where geomorphic evidence is not available. The ice extents predicted in Putnam et al. (2012) were sometimes smaller than those in Chapter 6 because of neglected tributary glaciers. Our 2-D numerical models do not require the location of contributing ice masses to be prescribed, as the AAR method does. Properly accounting for input from tributary glaciers is important because they can cause non-linearities in the relationship between the trunk glacier terminus length and snowline change.

3. Glacier length sensitivities to climate perturbations, topography, and parameter choice can be examined with a numerical modelling approach. The correlation between long term temperature change and glacier length change has been observed and discussed since the mid-1800s. In this thesis I examined alternatives to the traditional interpretation of temperature-driven glacier length changes, such as the influence of precipitation change and stochastic variability in climate. The link between glacier extent and past temperature is strongly evident in the work presented in this thesis, and these alternatives can only explain relatively minor changes in glacier length.

\subsection{Proposed future work}

Throughout the course of conducting the research presented in this thesis, I have developed new interests and questions about climate-glacier-moraine relationships. Here I suggest some potential research topics for future work. 


\subsubsection{Present-day climate and glaciology}

\section{Climate parameterisations}

Model parameterisations could be improved by tuning the model with more AWS climate data. Glacio-meterological experiments could involve multiple AWSs on a single glacier over a year, and/or multiple AWSs located on different glaciers in the Southern Alps (e.g. Oerlemans and Knap, 1998; Oerlemans and Grisogono, 2002). Measurements of wind speed, shortwave radiation, longwave radiation, and air temperature should be used to test the parameterisations and decrease uncertainty in the present-day modelled climate in both ice-free and glacierised settings. Attention to air temperature and wind speed could help to improve the turbulent heat flux calculations.

Reanalysis datasets (e.g. wind speed) should be scrutinised. In the simulations presented in this thesis, wind speed is applied uniformly across the model domain, although wind speed affects the turbulent heat fluxes and varies greatly in complex topography. The effects of wind on snow deposition and redistribution have been studied in several mountain ranges and similar studies in New Zealand could improve modelled mass balance in areas of steep, complex terrain (Lehning et al., 2008, 2011; Dadic et al., 2010a) (Chaper 5).

Shortwave radiation data from high elevations could help to refine the albedo and cloudiness parameterisations. Albedo measurements from Brewster Glacier were higher than the Oerlemans and Knap (1998) parameterisation allowed. Thus, the parameterised snow albedo was adjusted to improve the fit between measured and modelled albedo (Anderson et al., 2010) and it would be useful to measure albedo, and its spatial and temporal evolution, on other New Zealand glaciers, especially in ablation zones where few measurements have been made.

Measured temperature data from alpine AWS should also be used to better parameterise the modelled temperature lapse rate. The monthly mean present-day temperature lapse rates could then be compared to estimates suggested by an empirical relationship derived from lowland stations (Norton, 1985). However, the nature of temperature lapse rate variability could be such that any parameterisation will still include uncertainties. Ideally, 
the temperature lapse rate would be derived from AWS temperature data measured at the site of interest (Chapter 4).

\section{Flow of New Zealand glaciers}

Investigating New Zealand glacier mechanics could reduce uncertainty in model parameter choice. More information on surface ice-flow velocities, internal ice deformation, glacier basal sliding (Kehrl, 2011), and ice thickness would be useful for assessing the parameter values used in the ice-flow model. These measurements are difficult to quantify, especially on New Zealand temperate mountain glaciers that could experience significant basal sliding either due to water or deformable sediment at the bed. There are many unknowns in this particular field of research, thus parameter choices can span a range of values (e.g. characteristic sliding velocity in Chapter 6).

\subsubsection{Model experiments}

There are many possibilities when it comes to potential modelling experiments, so here I stress a few relatively important topics.

\section{Couple energy balance model with a general circulation model}

Palaeoclimate simulations could be more informative if the glacier model was coupled to a general circulation model. This would enable atmospheric and oceanic circulation, which is influenced by insolation on a hemispheric scale, to affect the modelled New Zealand climate and its glaciers. For example, it would be interesting to attempt simulations of New Zealand glaciers forced by the results of the Paleoclimate Modelling Intercomparison Project (PMIP2/3, Rojas and Moreno (2010); Bosmans et al. (2011)). However, such simulations would require appropriate methods for downscaling climate fields from a general circulation model to mountain scale. 


\section{Southern Alps simulations}

Modelling simulations applied to the whole Southern Alps, such as those carried out by Golledge et al. (2012), could be run for the Lateglacial moraines. Comparing such model results to the mapped moraine deposits could highlight areas that require an alternative climate. Alternatives may include changes in the east to west precipitation gradient on the South Island or north to south temperature gradients (Newnham et al., 2012; McKinnon et al., 2012). A simulation of the Southern Alps ice cover during the Lateglacial might also provide a useful test of the rock avalanche hypothesis at Franz Josef Glacier. If all of these moraine limits could be simulated with a single climate change, there would be no need to invoke rockfall as a driver. Comparing high-resolution studies, such as those presented in this thesis, with simulations of ice extent for the whole Southern Alps during the Lateglacial could also improve the understanding of glacier response to local climate conditions.

\section{Model intercomparison}

Differences in palaeoclimate estimates can result from model type and the assumptions that accompany a particular model. In this thesis, I focused on differences between the model used here and the AAR approach. I would be interested to know if model results, such as those from forcing the mass balance model with interannual stochastic variability in temperature (Chapter 6), are more dependent on model choice rather than site-specific differences (Oerlemans, 2000; Roe, 2011). For example, Roe (2011) compared results from a flowline model and a linear model to justify using the simpler linear model for describing changes in glacier length due to melt-season temperature and annual accumulation. The linear model showed a faster (almost immediate) and larger-scale (by 10\%) glacier response to climate perturbations than the flowline model did. Perhaps this linear model should be applied to the Cameron Glacier to better understand how much the model results depend on model type. It might be that the linear model used by Roe (2011) is too sensitive, and shows unrealistic fluctuations. It would be useful to repeat some of my experiments using a more complex ice flow model (e.g. full Stokes), to check that my 
shallow ice approximation model performs well in all catchments studied.

\section{Present-day glacier sensitivity to climate change}

Future studies should investigate the affects of snow avalanche accumulation on glacier sensitivity. It is likely that avalanche-fed glaciers are common in New Zealand because of the steep alpine slopes and high annual precipitation. Retreat of these glacier could influence the ski industry, irrigation management, and hydroelectric planning. It would be useful to know if these types of glaciers are more resistant or more vulnerable to a warming climate.

Although most glaciers respond on decadal to centennial time-scales, the influence of sub-decadal climate variability, such as the El Niño-Southern Oscillation (ENSO), should be tested on Holocene glacier fluctuations. The synoptic patterns that are typical of an El Niño, for example, could help us understand how temperature and precipitation anomalies could influence glacier mass balance over several years, possibly resulting in terminus fluctuations. Temperature and/or precipitation changes from high-resolution (annual) proxies, such as tree-rings, could resolve ENSO events and could be used as input data for the glacier model. The influence of interannual-decadal scale climate variability is likely to cause more significant fluctuations in glaciers than interannual variability and should be compared against Holocene moraines.

Future model experiments could account for the effects of lake calving and changing debris cover on glaciers. I chose locations where lake calving and debris cover were unlikely to significantly affect the glacier terminus. However, many of the New Zealand Holocene moraines (e.g. Mueller, Hooker, Tasman, Classen, Grey, and Godley) border pro-glacial lakes (Warren and Kirkbride, 2003), and modelling lake calving could contribute toward estimating glacier change in the future. Debris transport models may also help us quantify the debris flux or time necessary for a glacier terminus to remain at a location for a moraine to deposit. Vacco et al. (2010) have modelled the deposition that results from a glacier advance caused by a rock avalanche, and suggests that the resulting landform would be hummocky, rather than the single moraine ridges that are typically targeted for 
dating. Modelling of this type may help to better understand the potential influence of rock avalanches on glaciers, and also to provide criteria for the identification of features resulting from this process in the field. 


\section{Appendix A}

\section{Excerpt from: The anatomy of 'long-term' warming since 15 kyr ago in the Southern Alps of New Zealand based on net glacier snowline rise}

The modelling simulations explained in this chapter were part of a larger study, which included detailed mapping and dating of the moraine sequence in Whale Stream valley in the Ben Ohau Range. Because the glacier modelling was only one component of the study, and because the mapping and dating of moraine deposits were done separately from this thesis, only the modelling contributions are presented in this chapter. The methodological approach used to model Lateglacial ice extent in Whale Stream is nearly identical to that of Chapter 4, with differences explained in Chapter 3 and in the excerpt below.

This appendix contains a brief site description followed by an excerpt from the Whale Stream manuscript that includes the palaeoclimate estimates from simulated ice extents. The manuscript uses language that is preferred by the scientific journal Geology, thus words such as 'Late Glacial', 'paleoclimate', and 'modeling' differ from the rest of this thesis. 


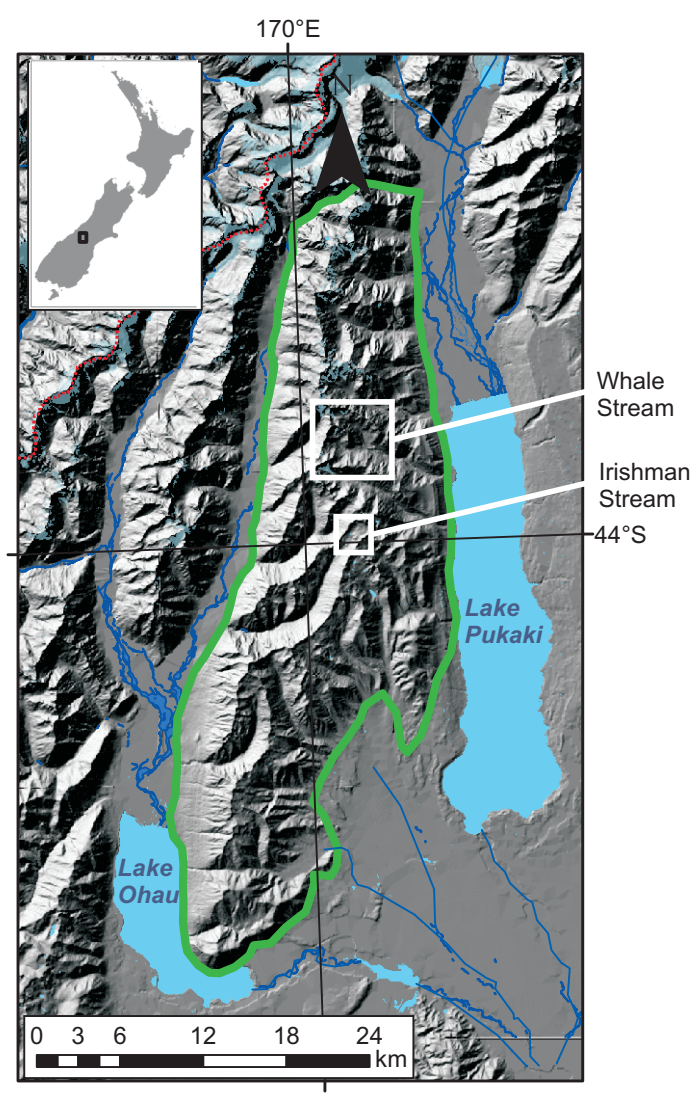

Figure A.1 Shaded topography of the Ben Ohau Range (outlined in green) showing the locations of Irishman Stream and Whale Stream (white boxes).

\section{A.1 Site description}

Whale Stream occupies a southeastward-draining valley in the Ben Ohau Range, South Island, New Zealand (Figure A.1). The Lateglacial moraines are large, composite features located at a separation of the valley into the north and south branches $\left(43^{\circ} 56^{\prime} \mathrm{S}\right.$, $\left.170^{\circ} 03^{\prime} \mathrm{E}\right)$. Relatively small ice patches and rock glaciers persist below the headwalls in both branches today, and scree slopes are prevalent along the valley walls. Because this valley is relatively close to the upper part of Irishman Stream valley, we use many of the same model parameters, such as the variable monthly lapse rate. 


\section{A.2 Excerpt from Kaplan et al., submitted}

\section{A.2.1 Methods}

We quantified possible temperature $(\Delta T)$ and precipitation change $(\Delta P)$ combinations during Late Glacial time by using a coupled 2-D ice-flow approximation model with an explicit time step, and an energy-balance model (Figs. A.2; DR6). The latter is driven by present-day climate input data in the form of 30-year monthly means (1981-2010; Doughty et al., in press). Our model methods are described in detail and are similar to those in Doughty et al. (in press), except that in this study, the model is applied at $100 \mathrm{~m}$ horizontal grid resolution and the simulations are run for 300 model years. This is long enough for the Whale Stream glaciers to reach equilibrium. Additional model sensitivity tests with slightly different parameter values, and determination of uncertainties specific to this study, are shown in Figure DR7.

A $2.1 \pm 0.4^{\circ} \mathrm{C}$ change is required to simulate a glacier to the $15-14 \mathrm{kyr}$ limits, assuming no change in present-day precipitation (Fig. A.2). A $20 \%$ increase and decrease in precipitation corresponds to a temperature change -1.8 and $-2.6^{\circ} \mathrm{C}$ respectively (Fig. A.2). We consider the temperature uncertainty to be $\pm 0.4^{\circ} \mathrm{C}$, which is half the range of temperature values $\left(-2.6\right.$ to $\left.-1.8^{\circ} \mathrm{C}\right)$ for a single precipitation value in the sensitivity tests. The model-derived glacier areas and snowlines are similar to those obtained in the minimum glacier geometric reconstruction (Fig. A.2B), especially considering uncertainties in both approaches. In particular, the model does not predict ice cover on the steep slopes at the head of the catchments.

\section{A.2.2 Modeling and ELA Results}

A $-2.1 \pm 0.4^{\circ} \mathrm{C}$ temperature change is required to simulate a glacier at the $15-14$ ka glacier limits, assuming no change in present-day precipitation. A $20 \%$ increase or decrease in precipitation from present-day corresponds to a temperature change of -1.8 and $-2.6{ }^{\circ} \mathrm{C}$, respectively (Figures A.2D and A.3). Sensitivity tests showed that changing the snow 
albedo (set to 0.72 ) by \pm 0.05 has a small but notable effect on our climate reconstruction. This difference in snow albedo causes the temperature change estimates to shift $\pm 0.4^{\circ} \mathrm{C}$ (Figure A.3). We consider the temperature uncertainty to be $\pm 0.4^{\circ} \mathrm{C}$, which is half the range of temperature values $\left(-1.8\right.$ to $\left.-2.6^{\circ} \mathrm{C}\right)$ for a single precipitation value for the sensitivity tests.

Late Glacial simulations show ranges in annual mass balance from 1 to $-3 \mathrm{~m}$ w.e. (Figure A.2). The equilibrium-line altitude (ELA) calculated from the modeled mass balance shows slightly different values for glaciers in the north and south branches. The south branch glacier, with an area of $3.1 \mathrm{~km}^{2}$, has an ELA of $\sim 1540 \mathrm{~m}$ asl, whereas the north branch glacier, with an area of $3.6 \mathrm{~km}^{2}$, has an ELA of $\sim 1660 \mathrm{~m}$ asl. These differences likely result from the unique topography and climate of each catchment, which are explicitly considered in the model.

Table A.1 Parameter names, values, and the temperature change needed to grow the glacier without a change in precipitation ( $\mathrm{x}$-intercept), with the 'best fit' model parameters yielding $-2.1^{\circ} \mathrm{C}$.

\begin{tabular}{|c|c|c|c|c|c|}
\hline $\begin{array}{l}\text { LEGEND } \\
\text { Parameter name }\end{array}$ & symbol & optimal value & source & sensitivity value & temp change $\left({ }^{\circ} \mathrm{C}\right)$ \\
\hline Snow Temperature Threshold & $T_{\text {snow }}$ & $1^{\circ} \mathrm{C}$ & Anderson et al. (2006) & $\begin{array}{l}0^{\circ} \mathrm{C} \\
2^{\circ} \mathrm{C}\end{array}$ & $\begin{array}{l}-2.4 \\
-1.9\end{array}$ \\
\hline Characteristic sliding velocity & $U_{c}$ & $20 \mathrm{~m} / \mathrm{a}$ & Kessler et al. (2006) & $\begin{array}{l}10 \mathrm{~m} / \mathrm{a} \\
30 \mathrm{~m} / \mathrm{a}\end{array}$ & $\begin{array}{l}-2.3 \\
-2.0\end{array}$ \\
\hline Ice roughness & $Z_{i c e}$ & $0.004 \mathrm{~m}$ & Anderson and Mackintosh (2012) & $\begin{array}{l}0.002 \mathrm{~m} \\
0.008 \mathrm{~m}\end{array}$ & $\begin{array}{l}-2.0 \\
-2.3\end{array}$ \\
\hline Snow roughness & $Z_{\text {snow }}$ & $0.001 \mathrm{~m}$ & Brock et al. (2006) & $\begin{array}{c}0.002 \mathrm{~m} \\
0.0005 \mathrm{~m}\end{array}$ & $\begin{array}{l}-2.3 \\
-2.0\end{array}$ \\
\hline Snow Albedo & $\alpha_{\text {snow }}$ & 0.72 & Oerlemans (1992) & $\begin{array}{l}0.67 \\
0.77\end{array}$ & $\begin{array}{l}-2.5 \\
-1.8\end{array}$ \\
\hline
\end{tabular}



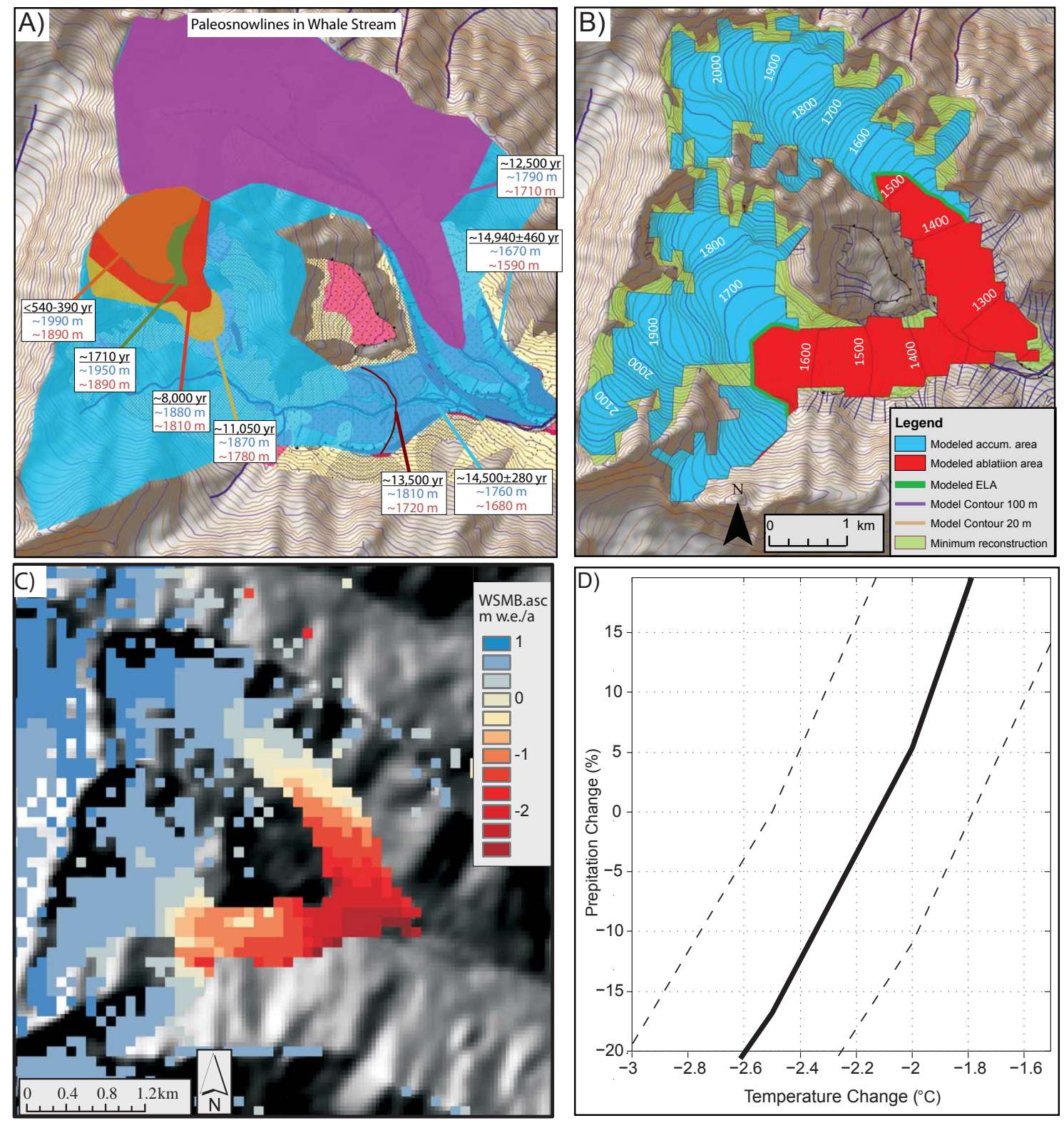

Figure A.2 Modeled ice extent for Whale Stream Glacier. (A) Various glacier outlines and ELAs using the AAR method, (B) modeled glacier extent showing ice surface elevation (20 m contours), accumulation (blue) and ablation (red) areas and ELA overlying the AAR method glacier extent, (C) modeled mass balance gradient ranging from -2 to $+1 \mathrm{~m} \mathrm{a}^{-1}$, and (D) temperature-precipitation change curves with uncertainty for the Whale Stream Late Glacial ice extent. 

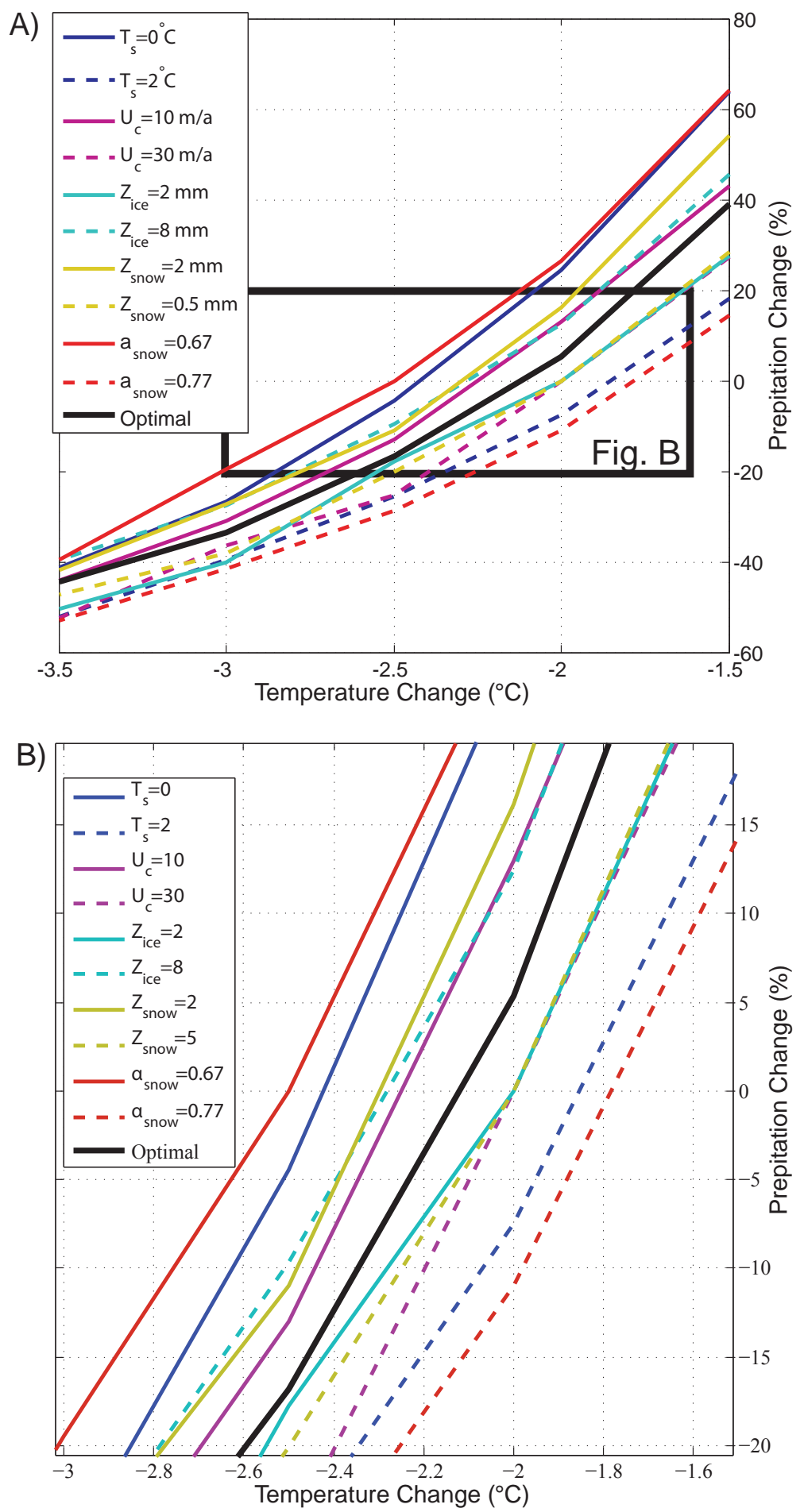

Figure A.3 Parameter testing curves from the temperature-precipitation change combination needed for a Late Glacial Whale Stream ice extent. 


\section{A.3 Subsequent simulations}

Reviewers asked if our palaeoclimate estimates would change if we started from an icefilled valley floor rather than an ice-free valley. The results are identical within error: $\Delta T$ values of $-2.6,-2.1,-1.8^{\circ} \mathrm{C}$ (ice-free) versus $-2.7,-2,-1.8^{\circ} \mathrm{C}$ (ice-filled) for $\Delta P$ set to -20 , 0 , and $+20 \%$ respectively. These results are not included in the manuscript due to space limitations.

The simulations presented in the excerpt above were carried out in 2010 and since then the model has been adapted to improve the mountain glacier simulations. I thought that the palaeoclimate estimates would change if the model used:

1. A finer grid resolution $(25 \mathrm{~m})$ to better refine the gullies and valley slopes.

2. The mass transport and deposition (MTD) model to account for snow avalanche accumulation.

3. A higher characteristic sliding velocity to account for the potential of valley floor sediment to enhance basal sliding.

4. The randomly-generated daily temperature estimates based on monthly means.

The model took significantly longer to run these simulations (days rather than minutes), because of the resolution and subroutines. Only the optimal parameter set (Table A.1) was used to calculate the temperature change, with a precipitation change of $-20,0$, and $20 \%$, needed to simulate ice extent at the Lateglacial moraine. The above adjustments in the model resulted in a temperature change estimate of $-2.4^{\circ} \mathrm{C}$ instead of $-2.1^{\circ} \mathrm{C}$ (Table A.2). These values are both in the range of previously estimated temperature changes for the Lateglacial in central Southern Alps of New Zealand.

Table A.2 Palaeoclimate estimates using two different modelling approaches.

\begin{tabular}{lccccl}
\hline & $\Delta P(\%)$ & -20 & 0 & +20 & Note \\
Old model & $\Delta T\left({ }^{\circ} \mathrm{C}\right)$ & -2.6 & -2.1 & -1.8 & initially ice-free \\
Old model & $\Delta T\left({ }^{\circ} \mathrm{C}\right)$ & -2.7 & -2.0 & -1.8 & initially ice-filled \\
New model & $\Delta T\left({ }^{\circ} \mathrm{C}\right)$ & -2.9 & -2.4 & -2 & initially ice-free
\end{tabular}




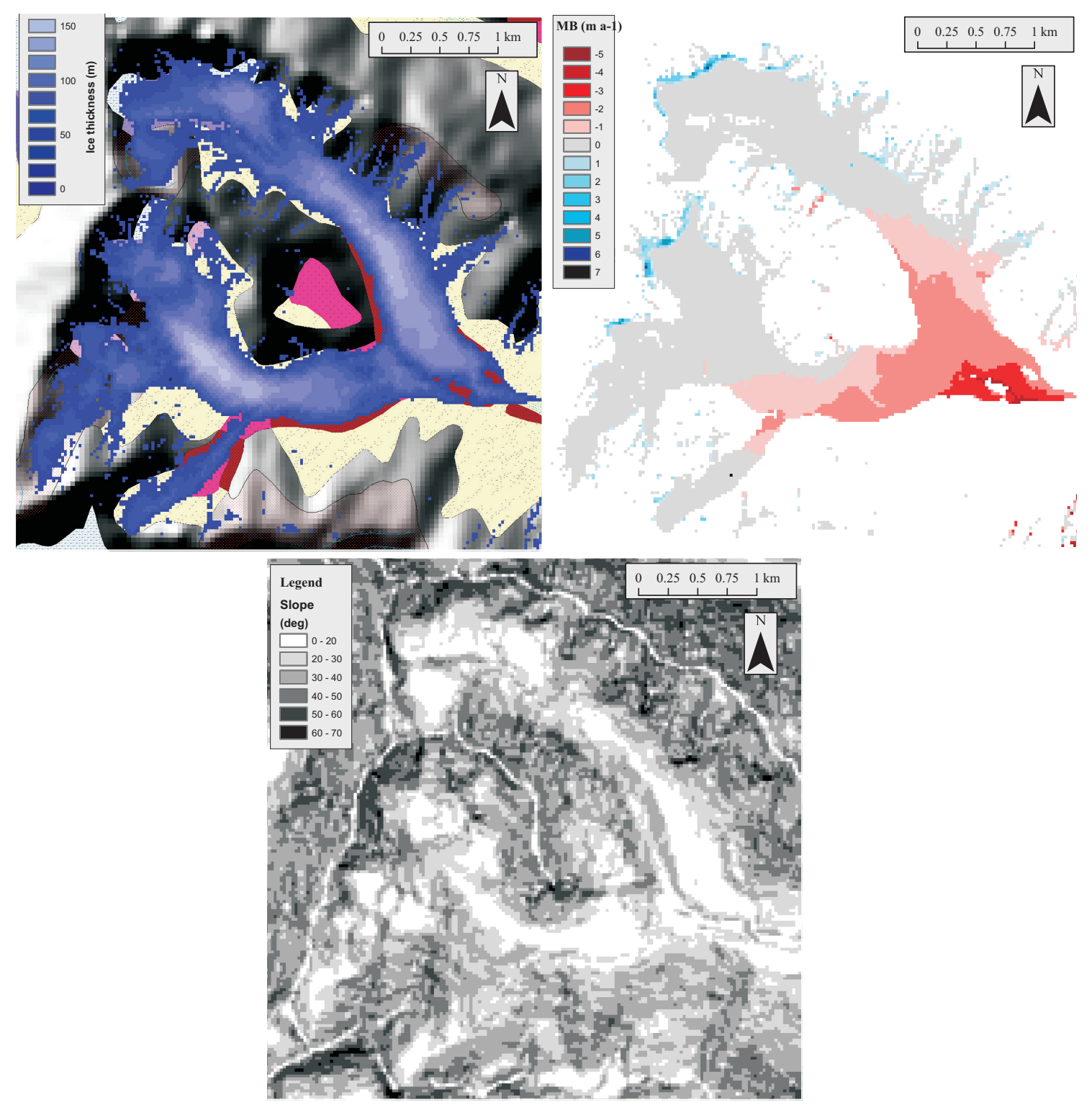

Figure A.4 Whale glacier simulated at $25 \mathrm{~m}$ resolution. The panels show a) ice thickness $(\mathrm{m}), \mathrm{b})$ mass balance $\left(\mathrm{m} \mathrm{a}^{-1}\right)$, c) slope at $25 \mathrm{~m}$ resolution $\left({ }^{\circ}\right)$. 


\title{
Ground penetrating radar profiles from the Cameron
}

\author{
Glacier neve
}

\section{B.1 GPR survey}

I conducted a ground-penetrating radar (GPR) survey on Cameron Glacier on 4-5 December, 2009 with T. Kerr, L. Kees, and A. Mackintosh. A RAMAC system (MALA Geoscience, Malå, Sweden) was used in the GPR survey (Figure B.1). The antennae were dragged over the snow surface by two skiers along cross and long profiles spaced roughly 100 to $200 \mathrm{~m}$ apart (Figure B.2). Profile numbers are linked to their corresponding alias from Chapter 5 in Table B.1. The trace interval was $0.1 \mathrm{~m}$ for both frequencies. These data are stored on the Victoria University of Wellington tuawe network (part of the Antarctic Research Centre modelling network).

\section{B.1.1 Low-frequency data}

Low frequency (25 MHz) data reveal deeper horizons (3 to $100 \mathrm{~m}$ depth) and the goal of this survey was to map the bedrock interface, and thus ice thickness. These data were particularly difficult to interpret because of all the noise in the profiles. Noise can be generated by too many internal reflectors caused by englacial debris, crevasses, and water within the ice. Low frequency data were recorded at a density of 2024 4-bit samples per trace using a time window of $2168 \mathrm{~ns}$. The low frequency profiles are labelled 240-249 and are shown in Figures B.3 to B.5. 


\section{B.1.2 High-frequency data}

High frequency $(500 \mathrm{MHz})$ data were best for detecting shallow snow horizons $(<10 \mathrm{~m}$ depth) and I used these data to map snow depth distribution on the Cameron Glacier. High frequency data were recorded at a density of 440 16-bit samples per trace using a time window of $232 \mathrm{~ns}$. The high frequency profiles are labelled 250-262 and are shown in Figures B.6 to B.17. The figures are shown without interpretation. For examples of profiles with interpretation, see Chapter 5.

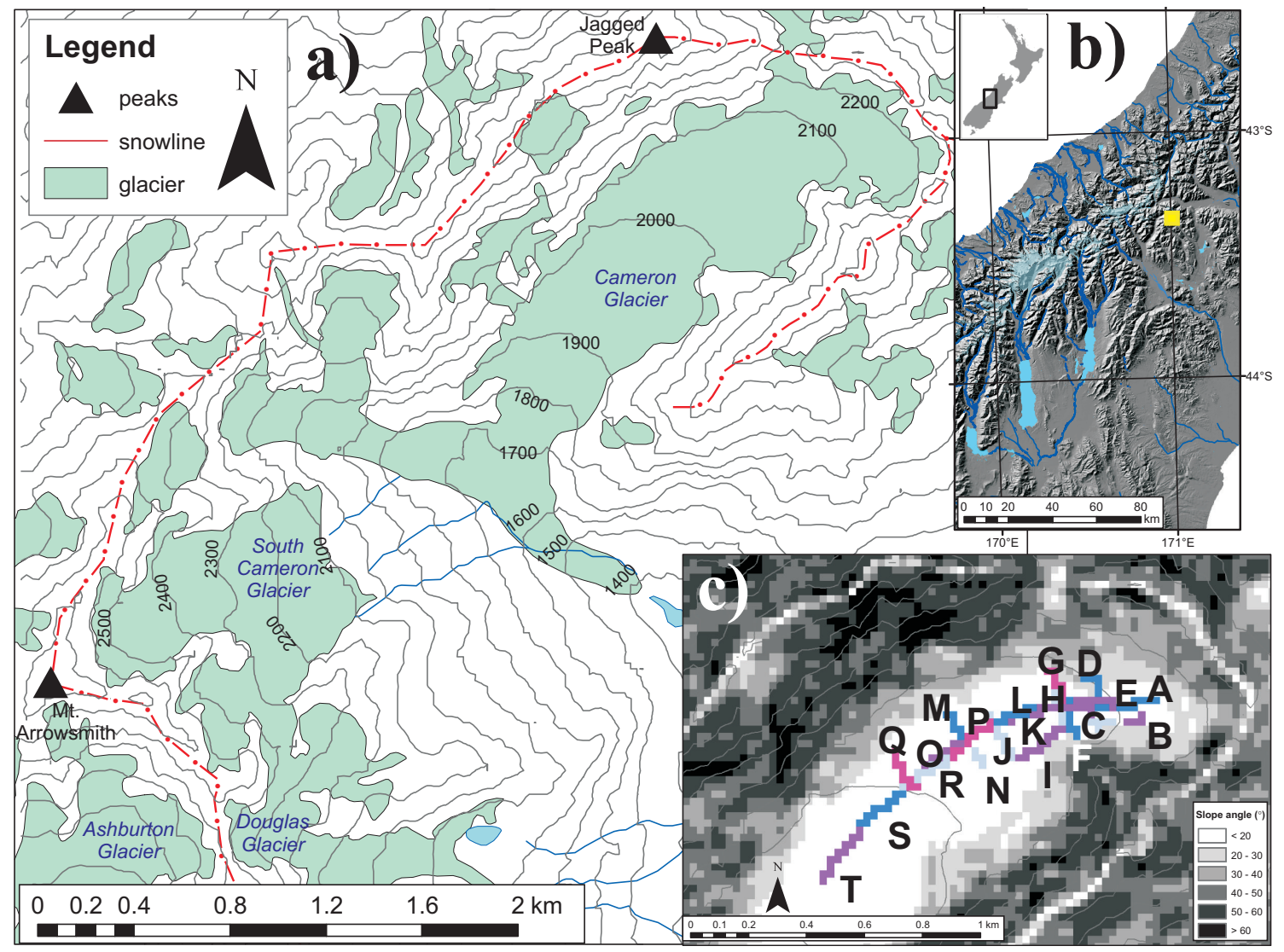

Figure B.1 Map of the Cameron Glacier. a) Topographic map with elevation contours, ridgelines (dotted-dashed red line), glacierised area, and mountain peaks (Mt. Arrowsmith (2781 m asl) toward the southwest, and Jagged Peak (2705 m asl) to the northeast). b) Shaded topography based on the DEM showing the location of study area (yellow square) in South Island, New Zealand. Prominent glaciers, lakes, and rivers are also shown. c) Slope values for a section of the model domain ( $25 \mathrm{~m}$ grid resolution) with labelled GPR profiles on Cameron Glacier. Profile colours are for differentiating lines only. 
Table B.1 Profile information. Direction codes are in reference to the true right or true left sides of the glacier or elevation, left to right (L2R), right to left (R2L), up to down glacier (U2D), down to up glacier (D2U). Profiles used to test the avalanche model are correlated with their alias.

\begin{tabular}{lccl}
\hline $\begin{array}{l}\text { Prof. } \\
(\#)\end{array}$ & $\begin{array}{c}\text { Freq. } \\
(\mathrm{MHz})\end{array}$ & Direction & Alias \\
\hline 241 & 25 & L2R & \\
243 & 25 & L2R & F,G \\
244 & 25 & R2L & \\
245 & 25 & U2D & L,P,O,S,T \\
246 & 25 & L2R & \\
247 & 25 & R2L & \\
248 & 25 & L2R & Q \\
249 & 25 & R2L & \\
250 & 500 & L2R & N,M \\
251 & 500 & R2L & J \\
252 & 500 & D2U & I \\
253 & 500 & L2R & H \\
254 & 500 & D2U & D \\
255 & 500 & R2L & D \\
256 & 500 & D2U & C,B \\
257 & 500 & L2R & \\
258 & 500 & U2D & A,E,K \\
259 & 500 & U2D & R \\
260 & 500 & U2D & \\
261 & 500 & R2L & \\
262 & 500 & D2U & \\
\hline & & & \\
& &
\end{tabular}




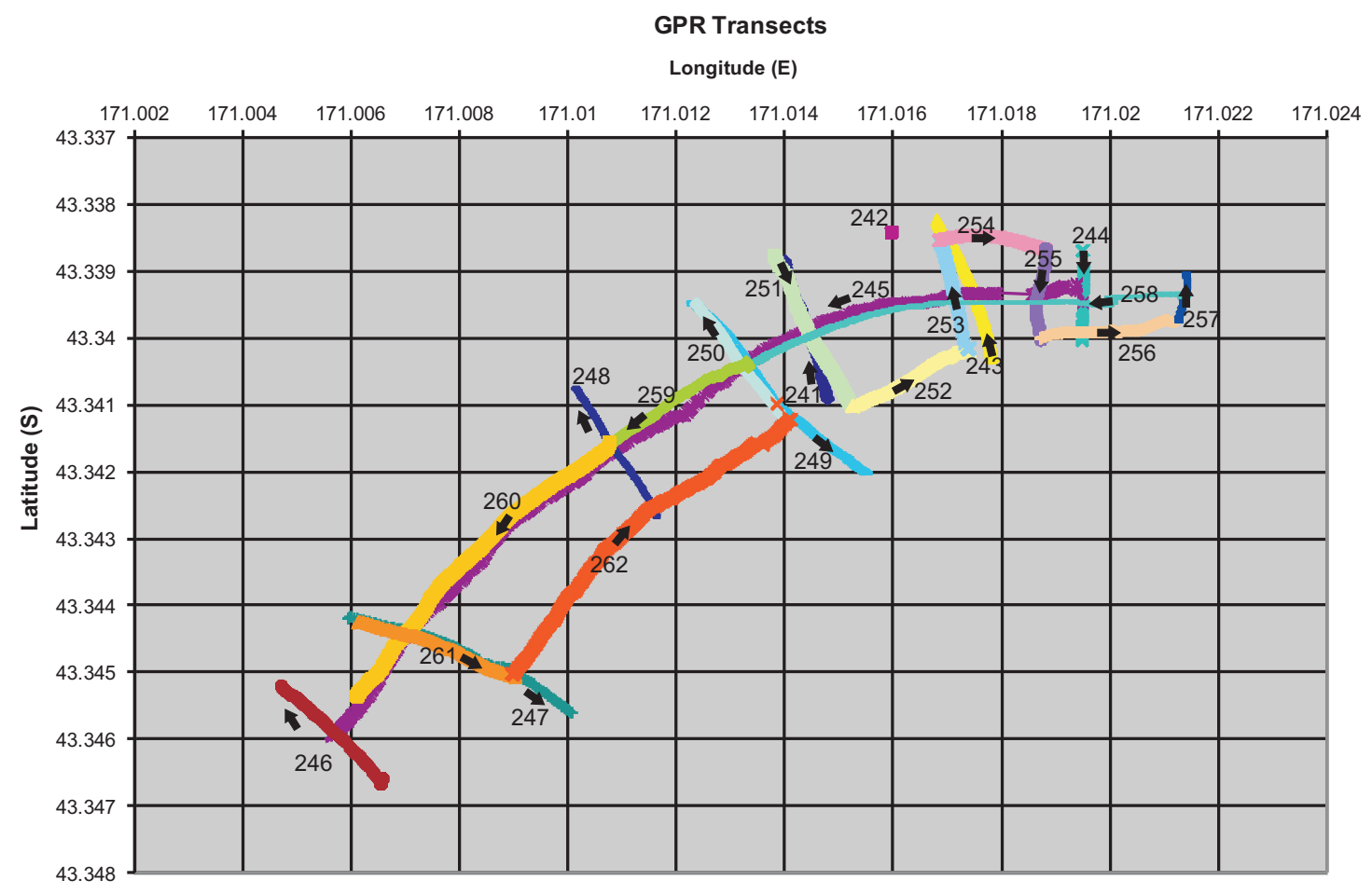

Figure B.2 Plot of the GPS data for each profile. Each profile is labelled with its associated number, an arrow indicating the direction of travel from start to finish, and a colour to differentiate it from the other profiles. 


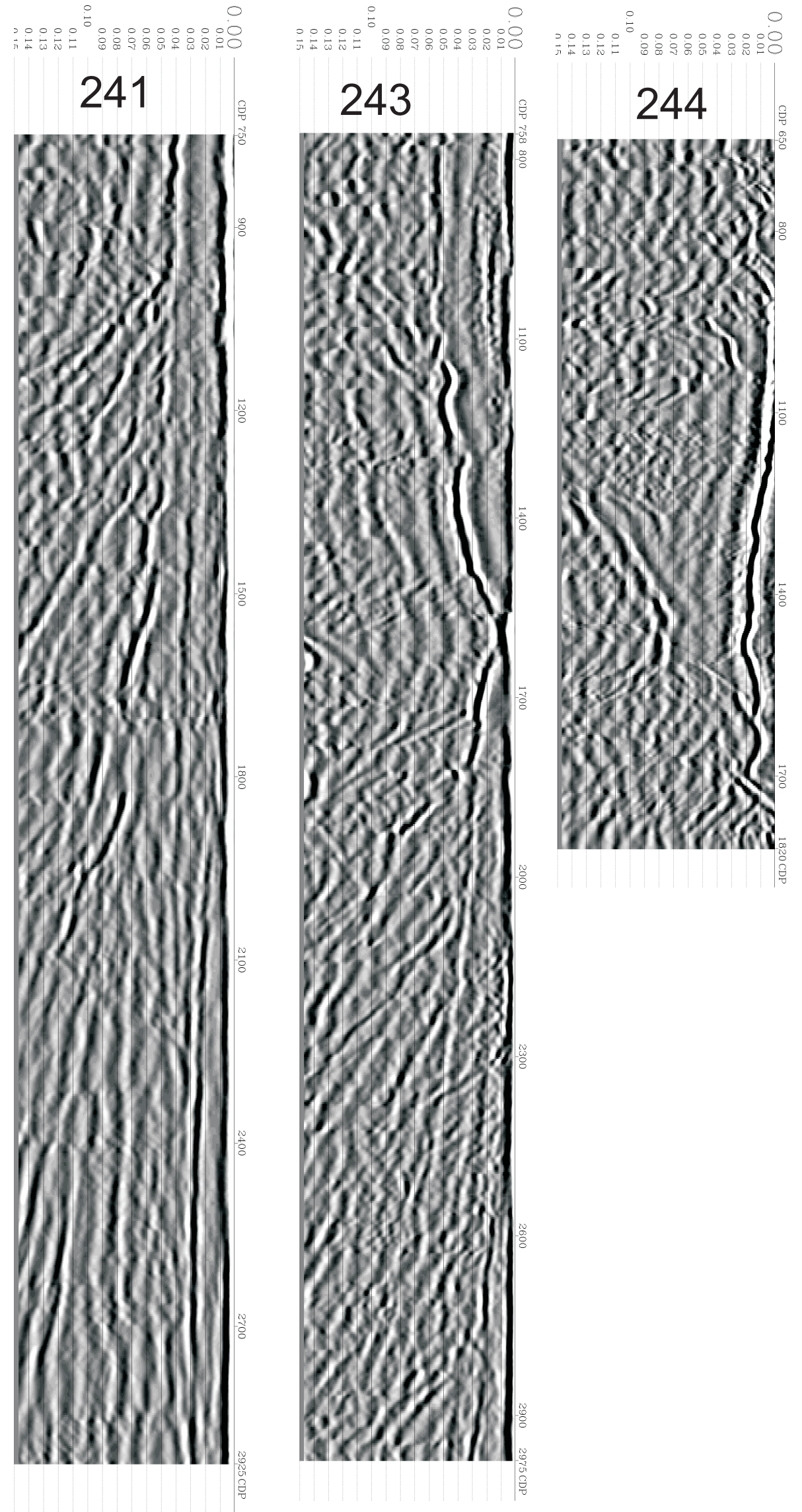

Figure B.3 Profiles 241, 243, and 244. 


\section{5}
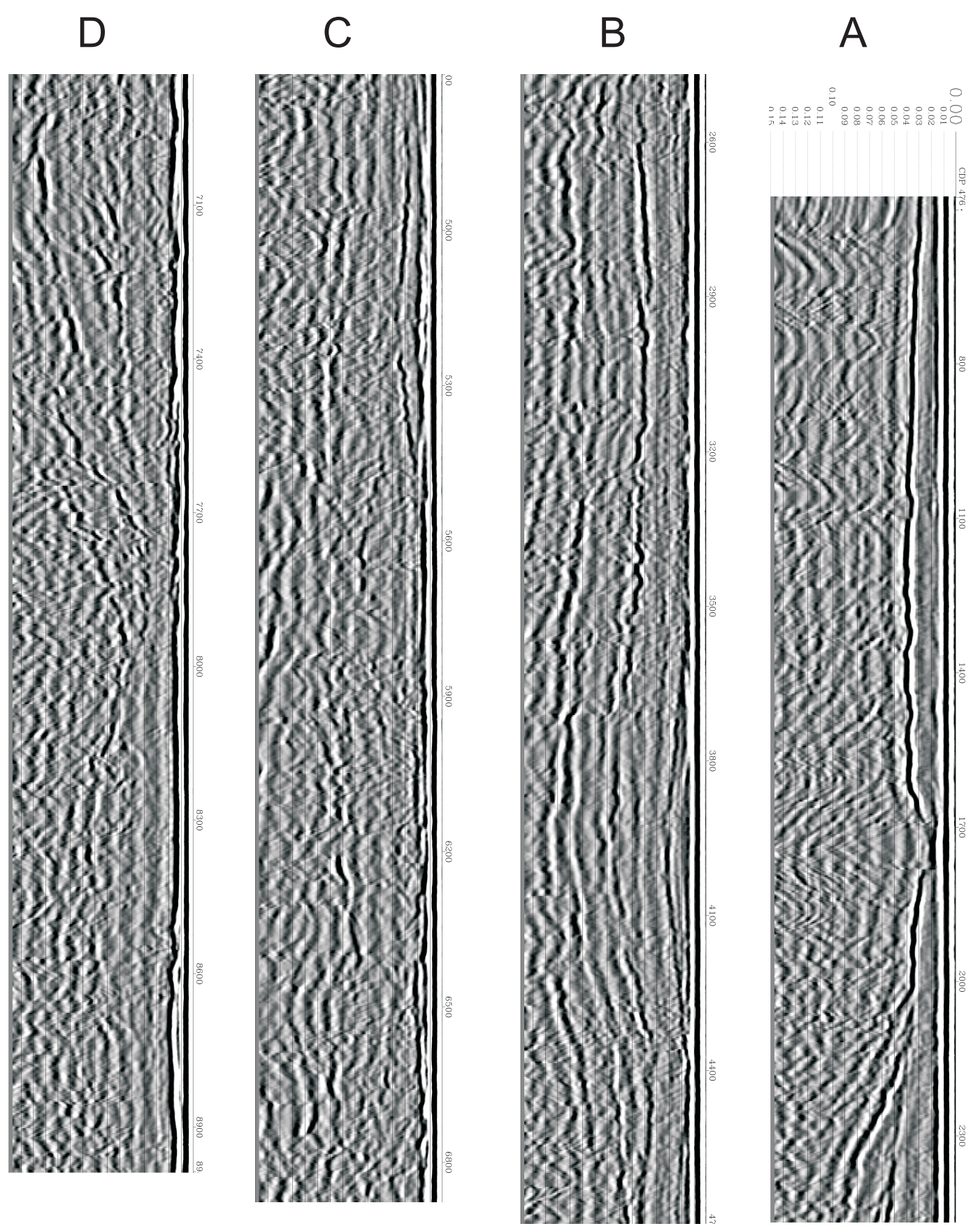

Figure B.4 Profile 245. 

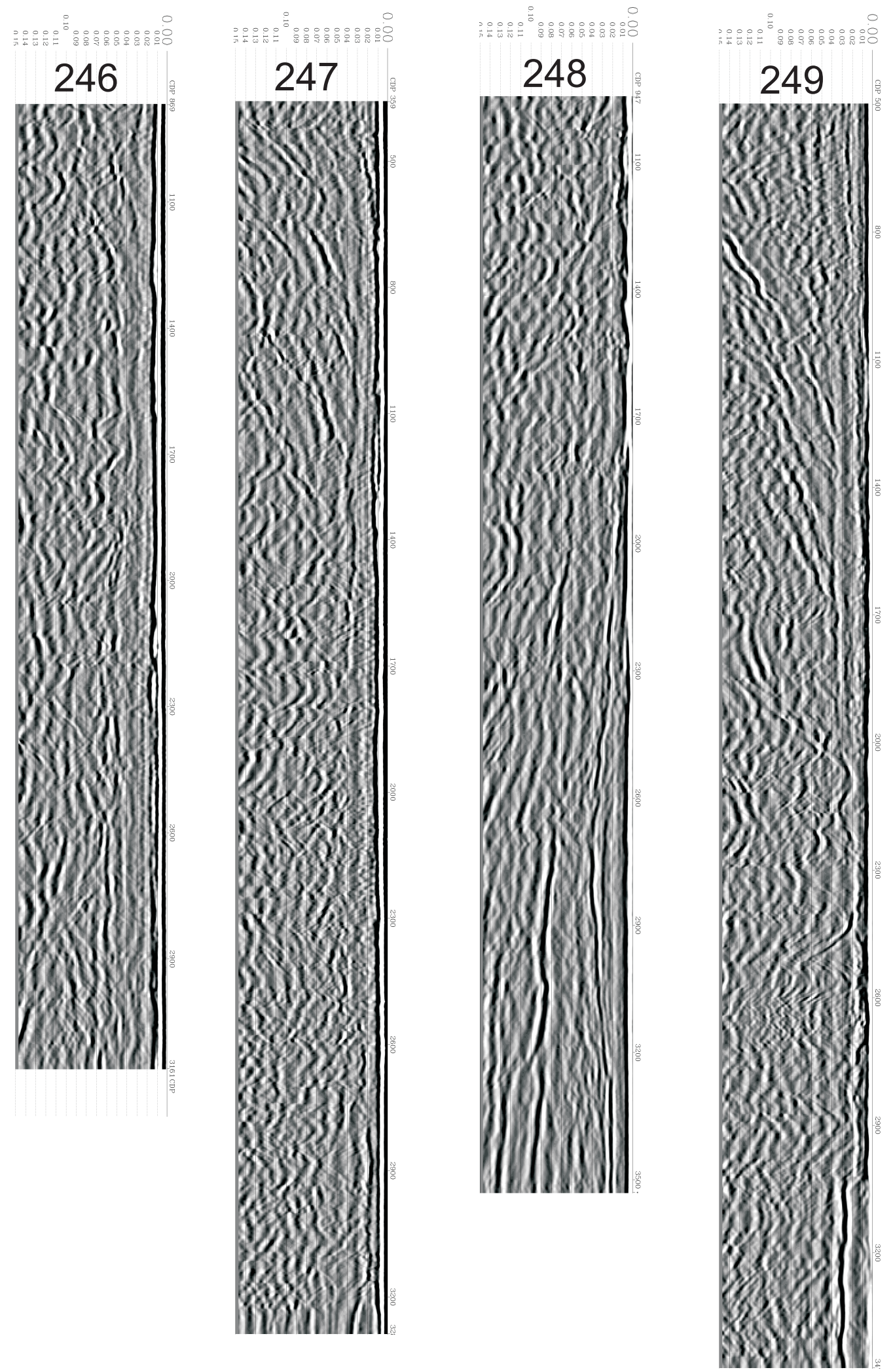

Figure B.5 Profiles 246, 247, 248, and 249. 


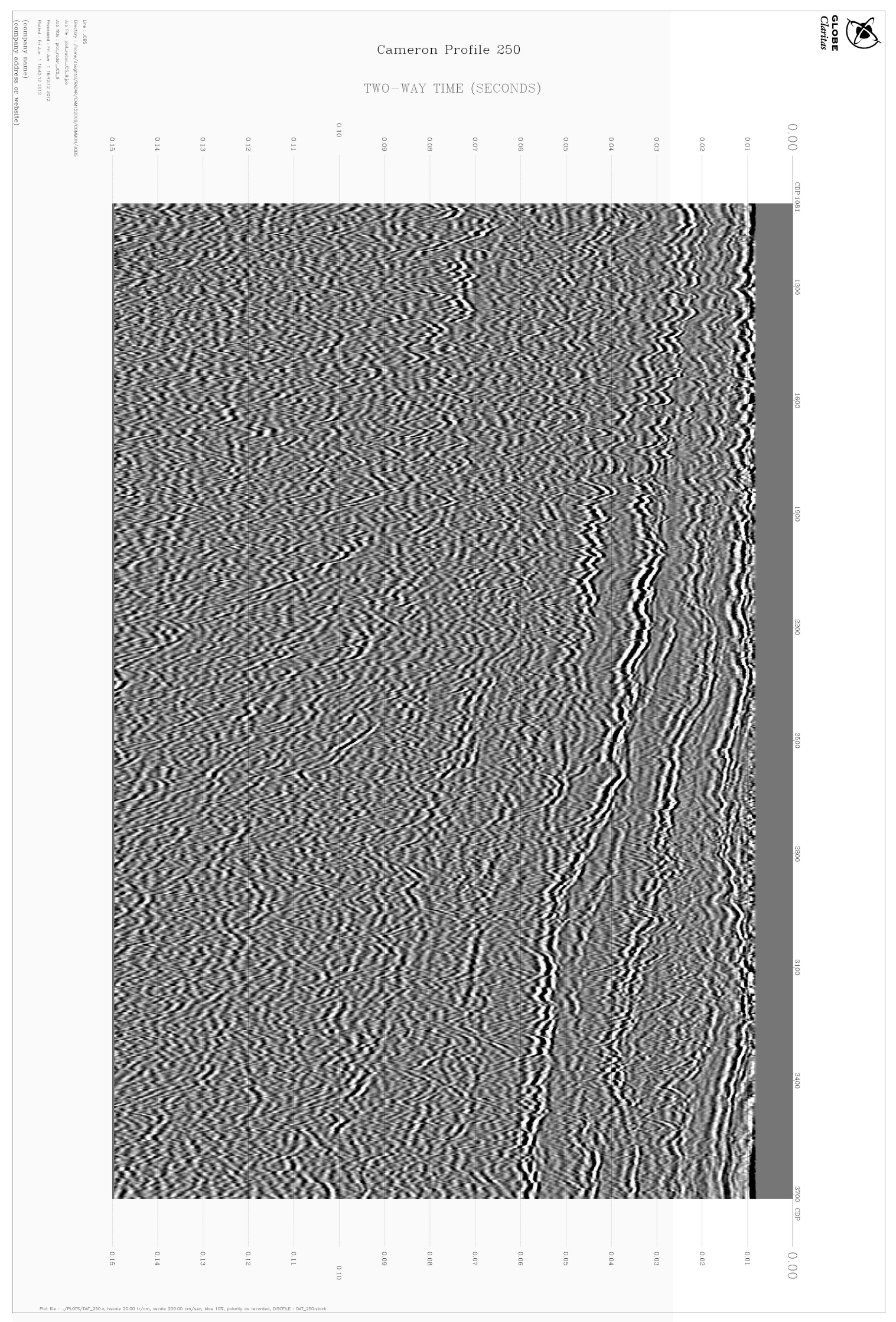

Figure B.6 Profile 250 . 


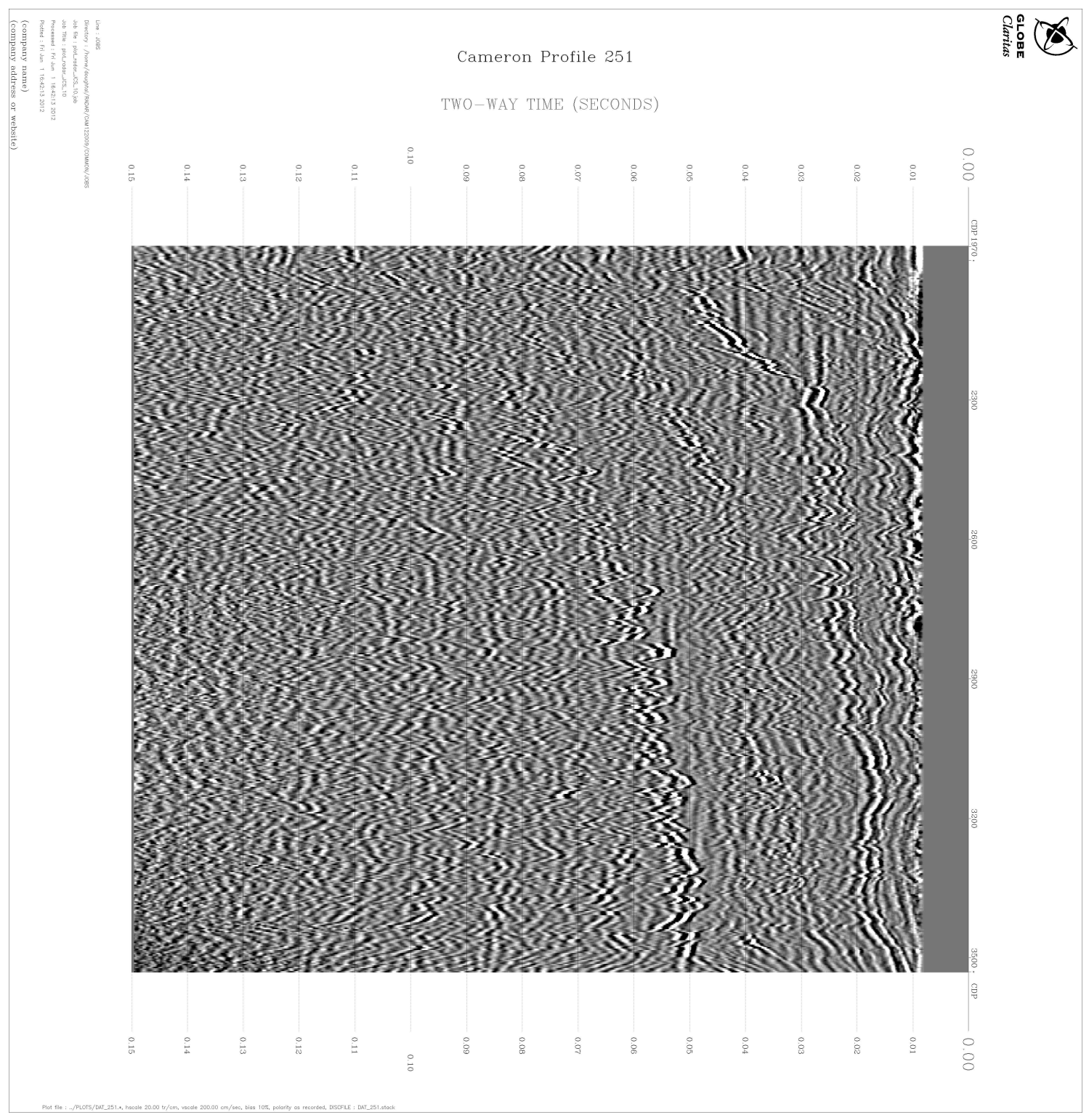

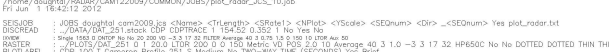

Figure B.7 Profile 251 . 


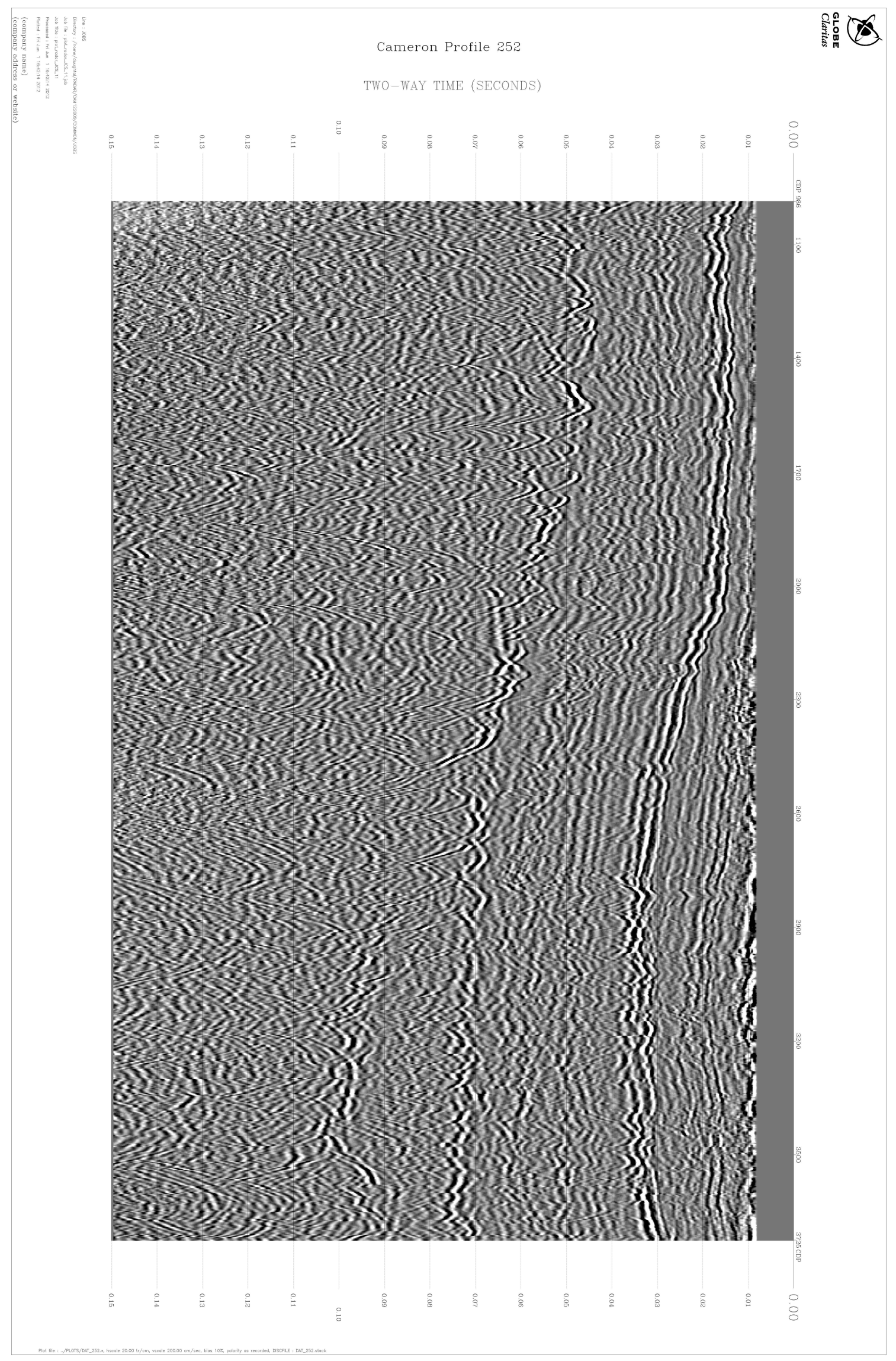

Figure B.8 Profile 252 . 


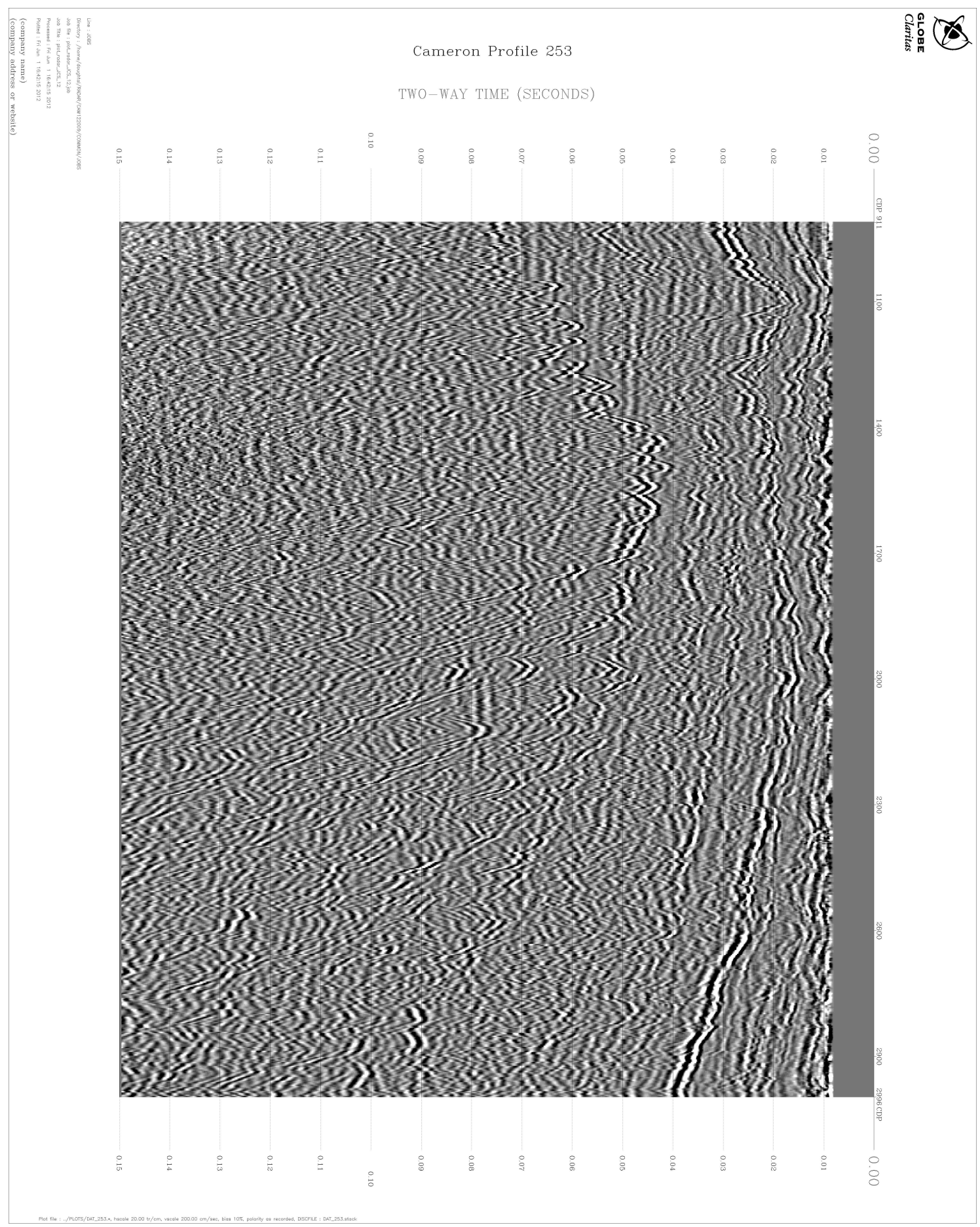

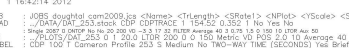

Figure B.9 Profile 253. 


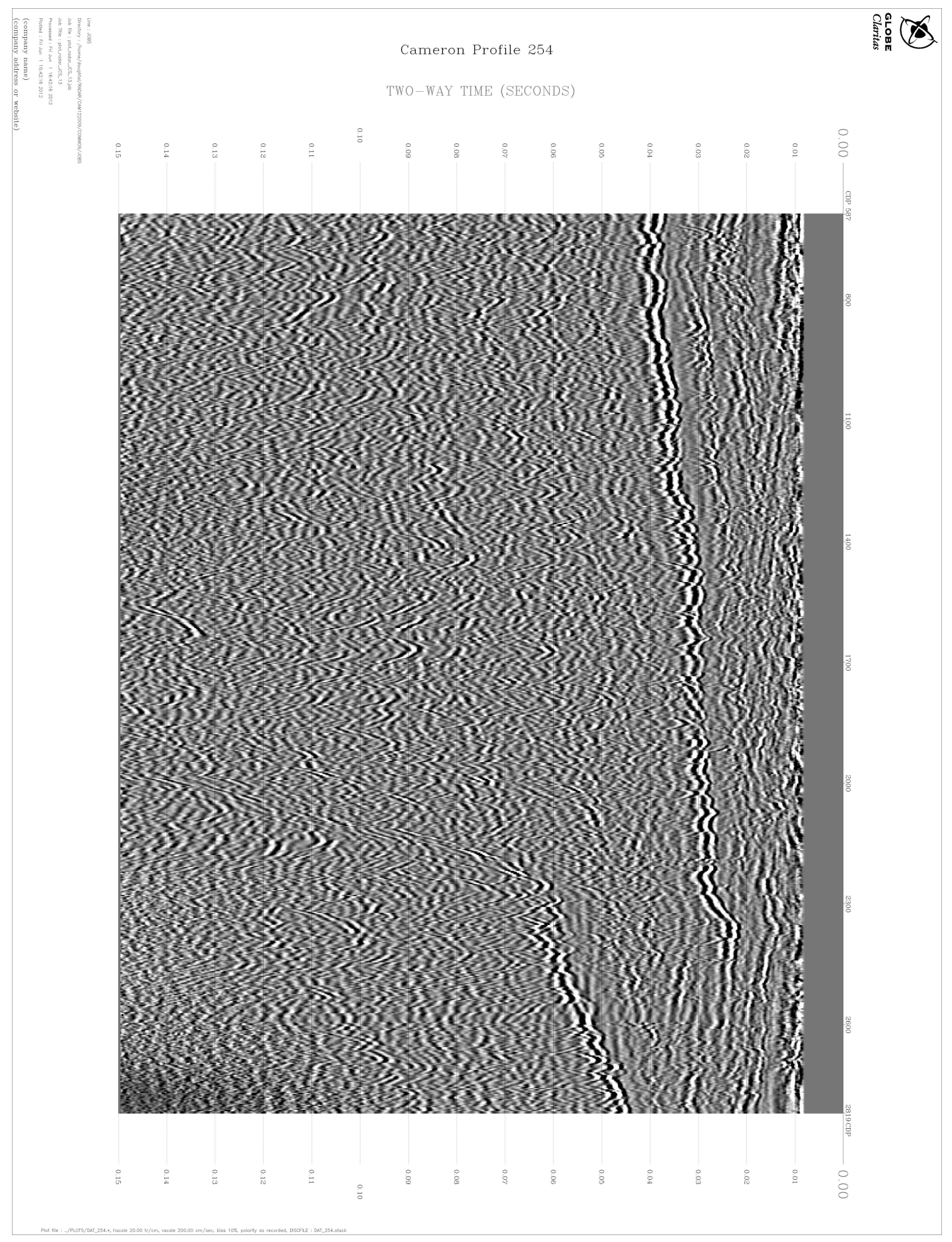

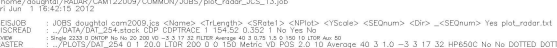

Figure B.10 Profile 254. 


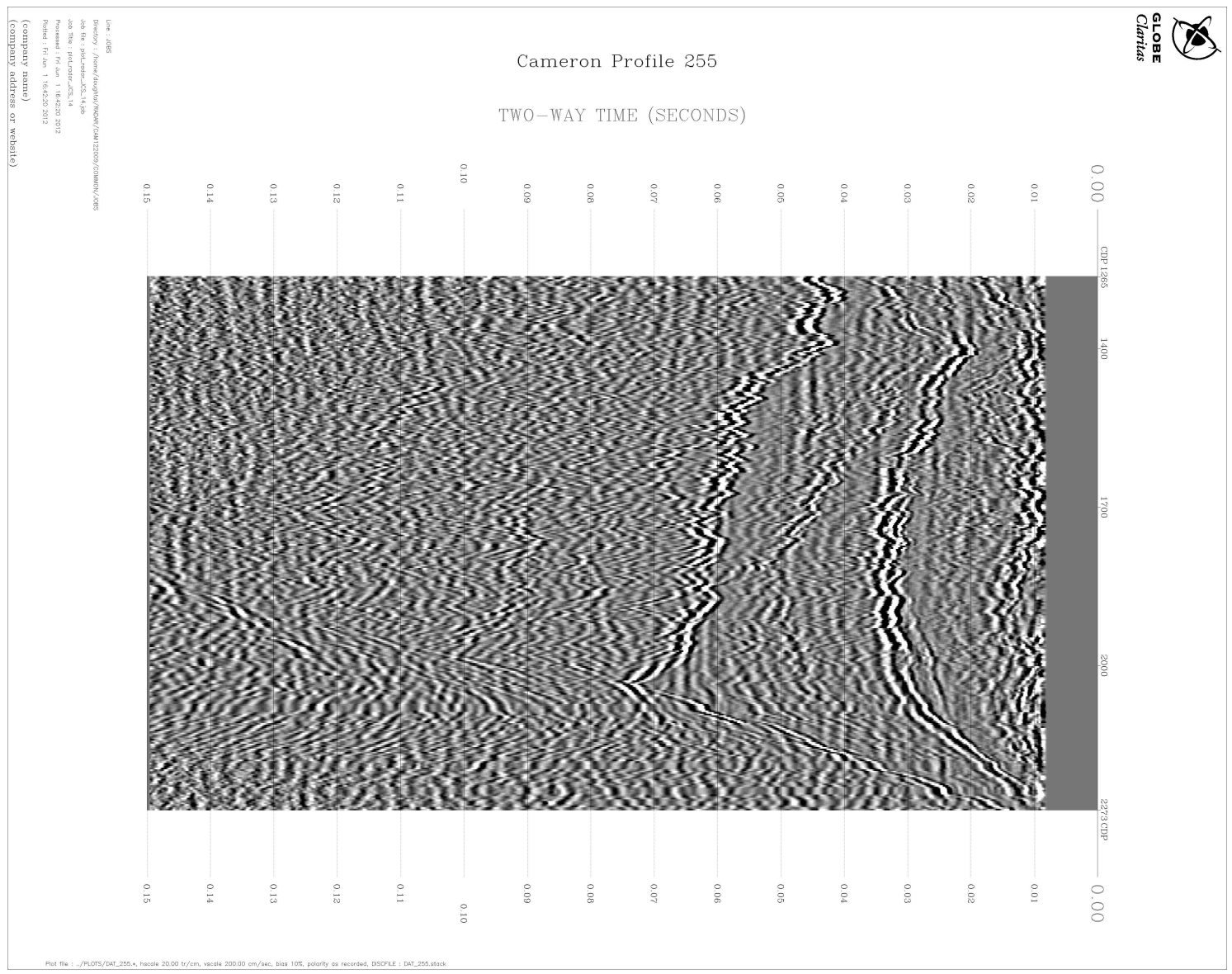

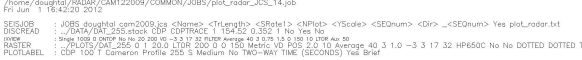

Figure B.11 Profile 255. 


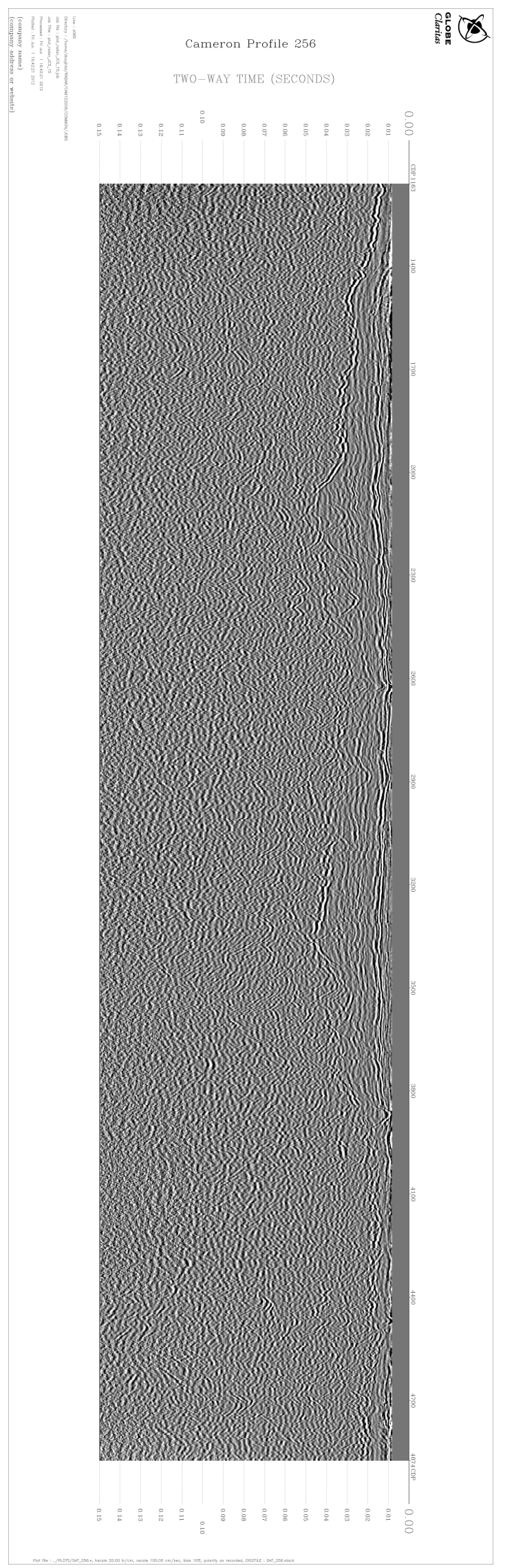

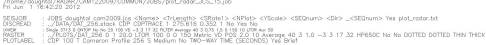

Figure B.12 Profile 256. 


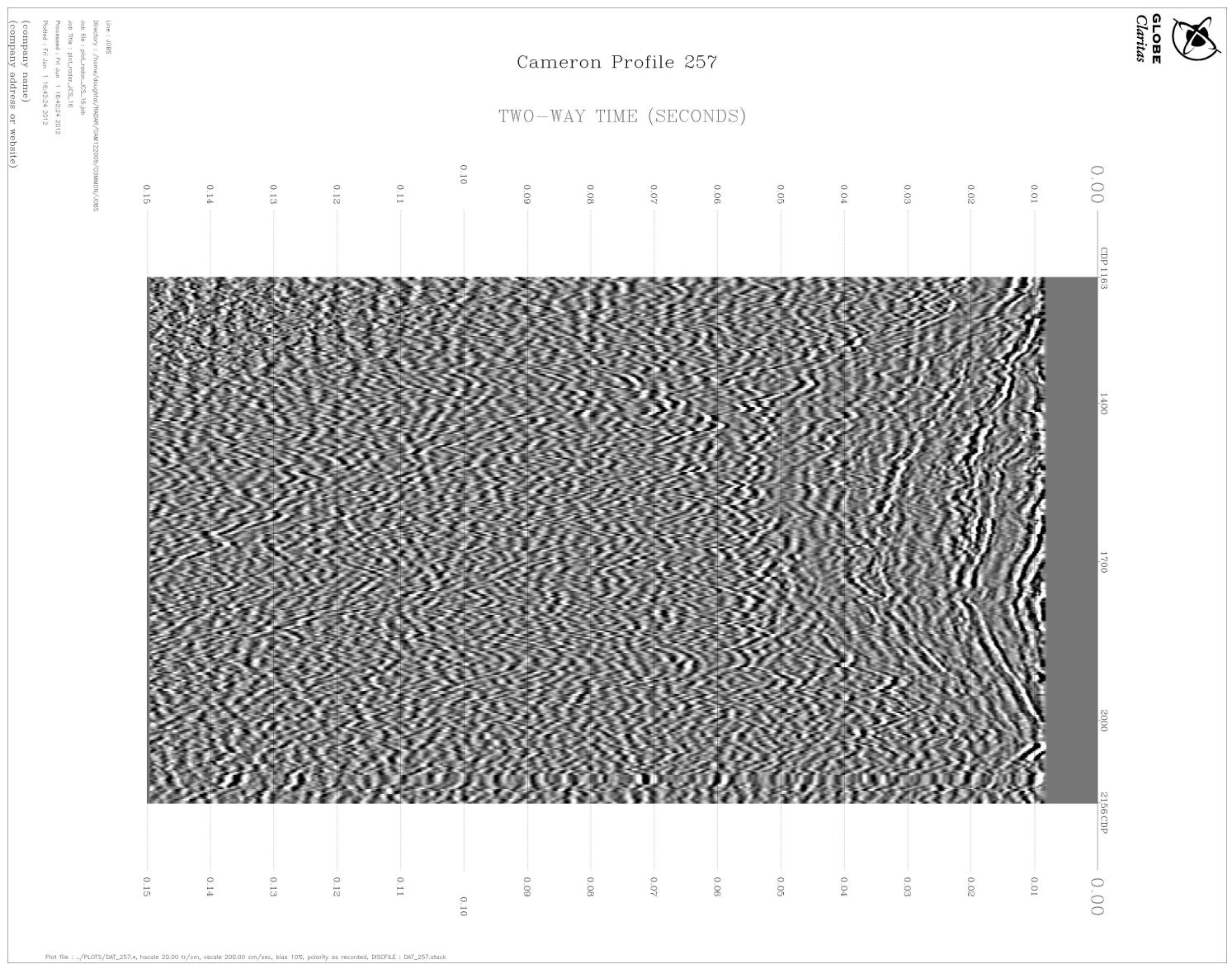

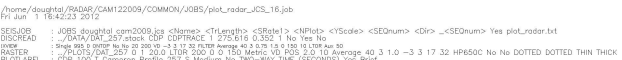

Figure B.13 Profile 257. 


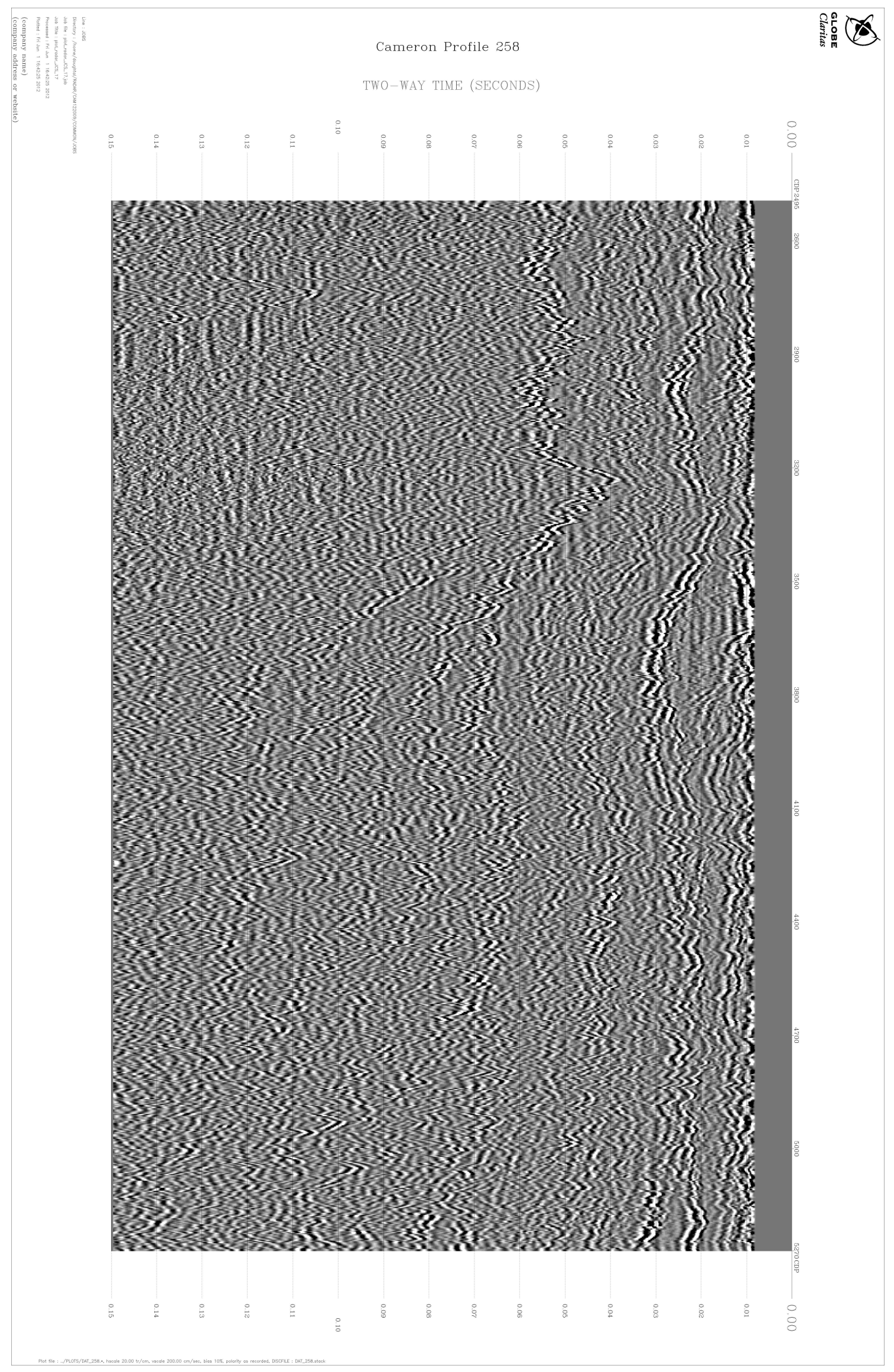

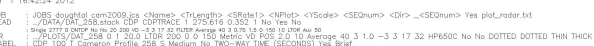

Figure B.14 Profile 258. 


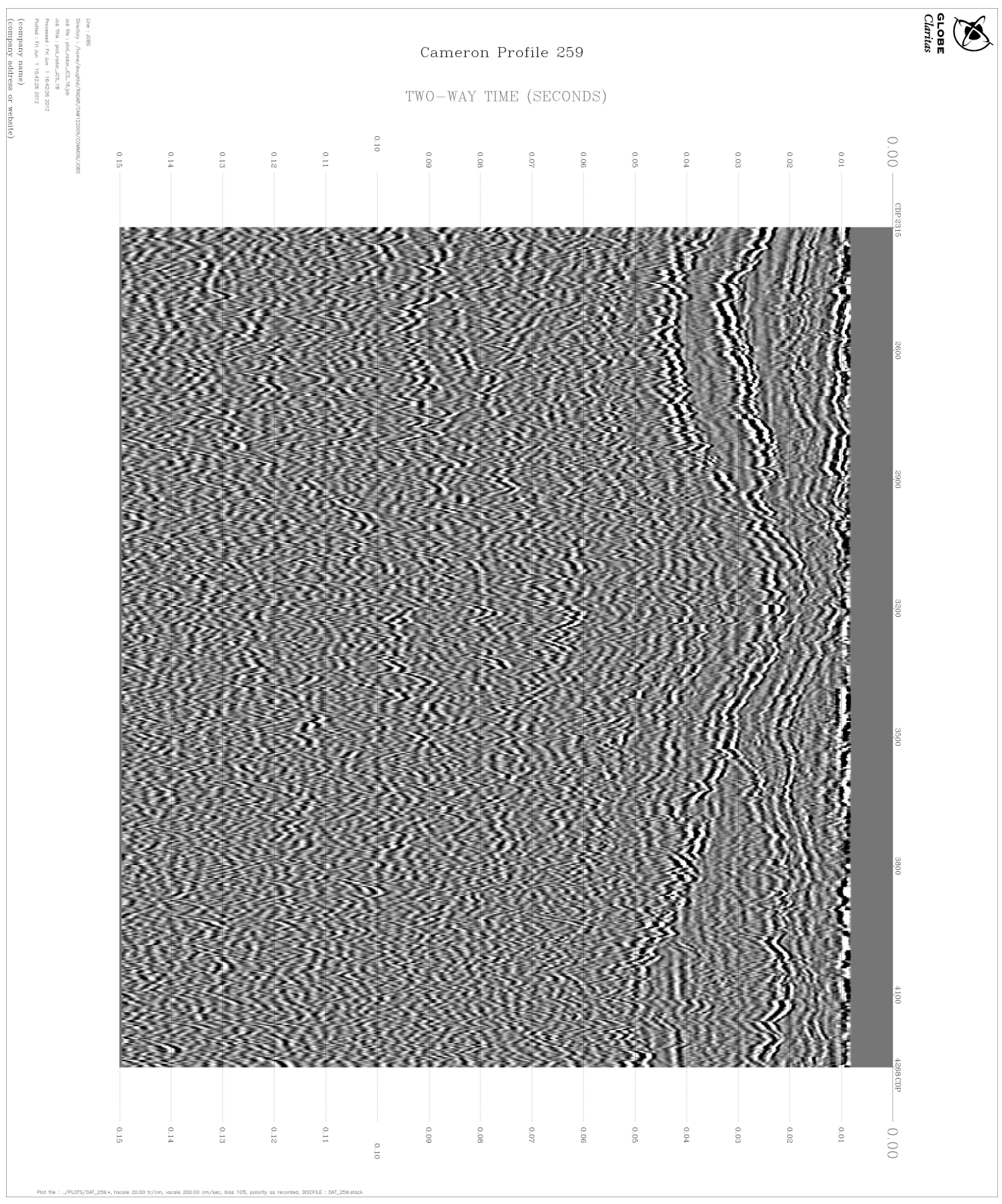

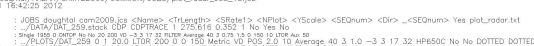

Figure B.15 Profile 259. 


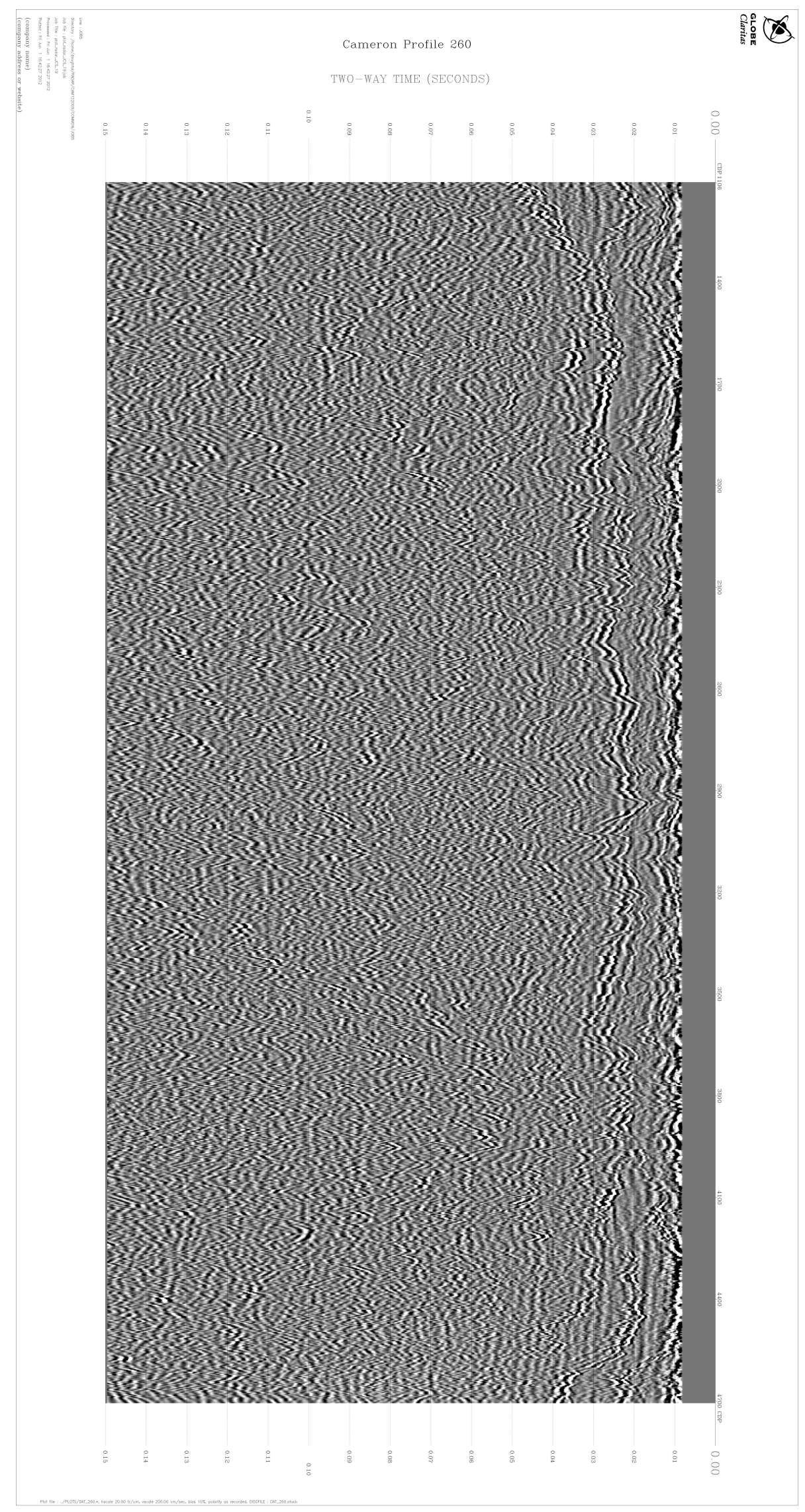

Figure B.16 Profile 260. 


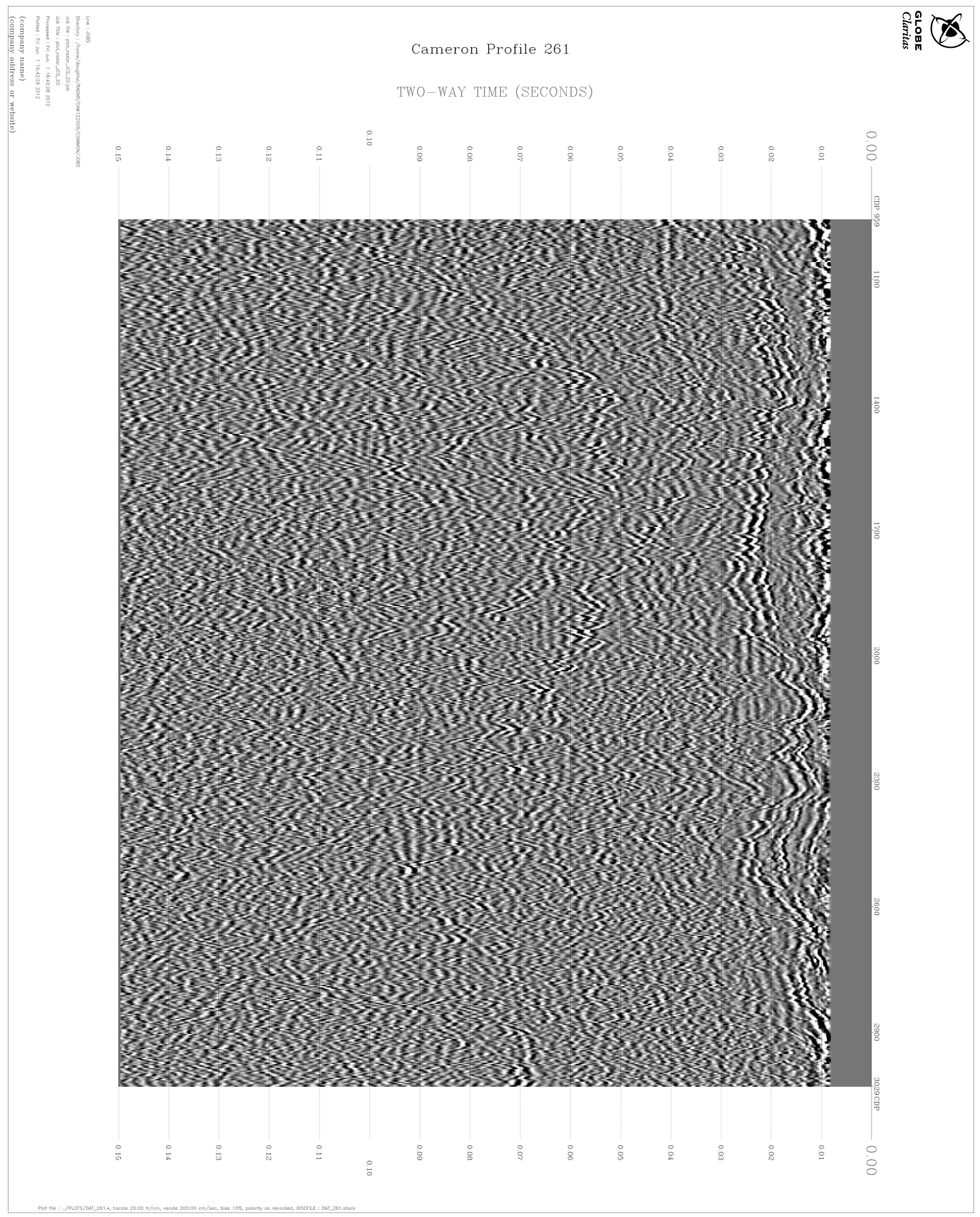

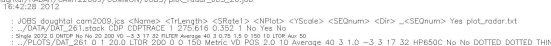

Figure B.17 Profile 261. 


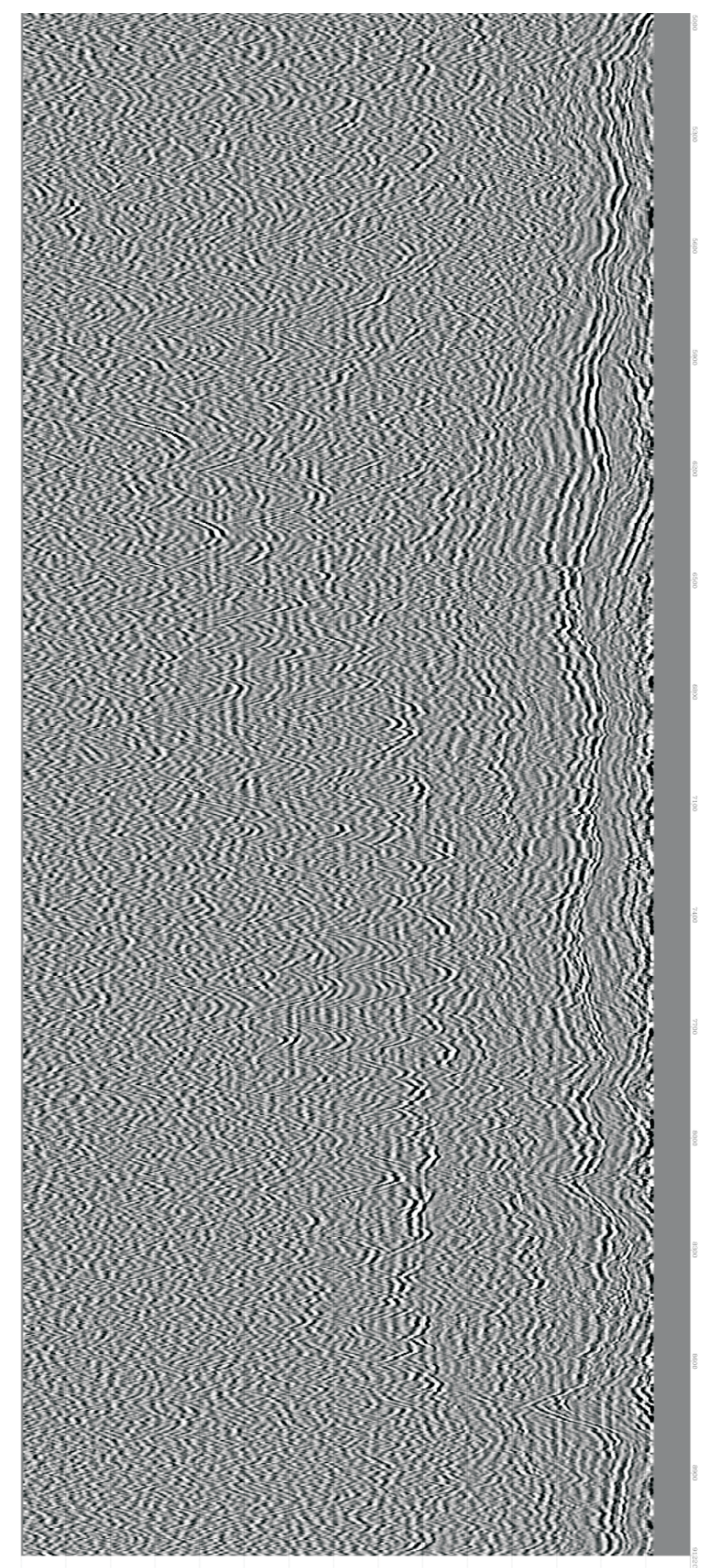

Figure B.18 Profile 262. 


\section{Bibliography}

Ackerley, D., Lorrey, A., Renwick, J.A., Phipps, S.J., Wagner, S., Dean, S., Singarayer, J., Valdes, P., Abe-Ouchi, A., Ohgaito, R., Jones, J.M., 2011. Using synoptic type analysis to understand New Zealand climate during the Mid-Holocene. Climate of the Past Discussions 7, 1301-1337.

Ackert, R., J., Becker, R., Singer, B., Kurz, M., Caffee, M., Mickelson, D., 2008. Patagonian glacier response during the Late Glacial and Holocene transition. Science 321, 392-395.

Alloway, B.V., Lowe, D.J., Barrell, D.J.A., Newnham, R.M., Almond, P.C., Augustinus, P.C., Bertler, N.A.N., Carter, L., Litchfield, N.J., McGlone, M.S., Shulmeister, J., Vandergoes, M.J., Williams, P.W., 2007. Towards a climate event stratigraphy for New Zealand over the past 30000 years (NZ-INTIMATE project). Journal of Quaternary Science 22, 9-35.

Anderson, B., Lawson, W.J., Owens, I.F., Goodsell, B., 2006. Past and future mass balance of Ka Roimata o Hine Hukatere (Franz Josef Glacier). Journal of Glaciology 52, 597-607.

Anderson, B., Lawson, W.J., Owens, I.F., Goodsell, B., 2008. Response of Franz Josef Glacier Ka Roimata o Hine Hukatere to climate change. Global and Planetary Change 63, 23-30.

Anderson, B., Mackintosh, A., 2006. Temperature change is the major driver of lateglacial and Holocene glacier fluctuations in New Zealand. Geology 34, 121-124.

Anderson, B., Mackintosh, A., 2012. Controls on mass balance sensitivity of maritime glaciers in the Southern Alps, New Zealand: The role of debris cover. Journal of Geophysical Research 117, F01003.

Anderson, B., Mackintosh, A., Stumm, D., George, L., Kerr, T., Winter-Billington, A., Fitzsimons, S., 2010. Climate sensitivity of a high-precipitation glacier in New Zealand. Journal of Glaciology 56, 114-128.

Anderton, P.W., Chinn, T.J., 1978. Ivory Glacier, New Zealand, an I.H.D. representative basin study. Journal of Glaciology 20, 67-84.

Arcone, S.A., 2002. Airborne-radar stratigraphy and electrical structure of temperature firn: Bagley Ice Field, Alaska, U.S.A. Journal of Glaciology 48, 317-334.

Balco, G., 2009. The geographic footprint of glacier change. Science 324, 599-600.

Baral, D.R., Hutter, K., Greve, R., 2001. Asymptotic theories of large-scale motion, temperature and moisture distribution in land-based polythermal ice sheets: A critical review and new developments. Applied Mechanics Reviews 54, 215-256.

Barrell, D.J.A., 2011. Quaternary Glaciers of New Zealand, in: Ehlers, J., Gibbard, P.L., Hughes, P.D. (Eds.), Developments in Quaternary Science. Elsevier, Amsterdam. volume 15, pp. 1047-1064.

Barrell, D.J.A., Andersen, B.G., Denton, G.H., 2011. Glacial geomorphology of the central South Island, New Zealand. GNS Science Monograph 27. GNS Science, Lower Hutt, New Zealand. 
Barrows, T.T., Juggins, S., De Deckker, P., Calvo, E., Pelejero, C., 2007a. Long-term sea surface temperature and climate change in the Australian-New Zealand region. Paleoceanography 22, PA2215.

Barrows, T.T., Lehman, S.J., Fifield, L.K., De Deckker, P., 2007b. Absence of cooling in New Zealand and the adjacent ocean during the Younger Dryas chronozone. Science $318,86-89$.

Barry, R.G., 1990. Changes in mountain climate and glacio-hydrological responses. Mountain Research and Development 10, 161-170.

Barry, R.G., 1992. Mountain climatology and past and potential future climatic changes in mountain regions: A review. Mountain Research and Development 12, 71-86.

Benn, D.I., Kirkbride, M.P., Owen, L.A., Brazier, V., 2003. Chapter 15 Glaciated Valley Landsystems, in: Evans, D.J.A. (Ed.), Glacial Landsystems. Hodder Arnold, pp. 372406.

Berger, A., Loutre, M.F., 1991. Insolation values for the climate of the last 10 million years. Quaternary Science Reviews 10, 297-317.

Bernhardt, M., Schulz, K., 2010. SnowSlide: A simple routine for calculating gravitational snow transport. Geophysical Research Letters 37, L11502.

Birkeland, P.W., 1982. Subdivision of Holocene glacial deposits, Ben Ohau Range, New Zealand, using relative-dating methods. Geological Society of America Bulletin 93, 433-449.

Bishop, G., Forsyth, J., 1988. Vanishing ice, an introduction to glaciers based on a study of the Dart Glacier. John McIndoe and New Zealand Geological Survey, DSIR, Dunedin, New Zealand.

Blandford, T.R., Humes, K.S., Harshburger, B.J., Moore, B.C., Walden, V.P., Ye, H., 2008. Seasonal and synoptic variations in near-surface air temperature lapse rates in a mountainous basin. Journal of Applied Meteorology and Climatology 47, 249-261.

Blard, P.H., Wagnon, P., Lave, J., Soruco, A., Sicart, J.E., Francou, B., 2011. Degree-day melt models for paleoclimate reconstructions from tropical glaciers: calibration from mass balance and meteorological data of the Zongo glacier (Bolivia, $16^{\circ} \mathrm{S}$ ). Climate of the Past Discussions 7, 2119-2158.

Blunier, T., Schwander, J., Stauffer, B., Stocker, T., Dällenbach, A., Indermühle, A., Tschumi, J., 1997. Timing of the Antarctic Cold Reversal and the atmospheric $\mathrm{CO}_{2}$ increase with respect to the Younger Dryas event. Geopysical Research Letters 24, 2683-2686.

Bosmans, J.H.C., Drijfhout, S.S., Tuenter, E., Lourens, L.J., Hilgen, F.J., Weber, S.L., 2011. Monsoonal response to mid-Holocene orbital forcing in a high resolution GCM. Climate of the Past Discussions 7, 3609-3652.

Box, G.E.P., Draper, N.R., 1987. Empirical model-building and response surfaces. Wiley, New York.

Bradley, R.S., England, J., 1978. Recent climatic fluctuations of the Canadian High Arctic and their significance for glaciology. Arctic and Alpine Research 10, 715-731. 
Braithwaite, R.J., 1995. Positive degree-day factors for ablation on the Greenland ice sheet studied by energy-balance modelling. Journal of Glaciology 41, 153-160.

Brazier, V., Kirkbride, M.P., Owens, I.F., 1998. The relationship between climate and rock glacier distribution in the Ben Ohau Range, New Zealand. Geografiska Annalers 80, 193-207.

Brock, B.W., Willis, I.C., Sharp, M.J., 2006. Measurement and parameterization of aerodynamic roughness length variations at Haut Glacier d'Arolla, Switzerland. Journal of Glaciology 52, 281-297.

Broecker, W.S., 1998. Paleocean circulation during the last deglaciation: A bipolar seesaw? Paleoceanography 13, 119-121.

Broecker, W.S., Denton, G.H., 1990. What drives glacial cycles? Scientific American 262, 49-56.

Broecker, W.S., Denton, G.H., Edwards, R.L., Cheng, H., Alley, R.B., Putnam, A.E., 2010. Putting the Younger Dryas cold event into context. Quaternary Science Reviews $29,1078-1081$.

Burrows, C.J., 1975. Late Pleistocene and Holocene moraines of the Cameron Valley, Arrowsmith Range, Canterbury, New Zealand. Arctic and Alpine Research 7, 125140 .

Burrows, C.J., 1988. Late Otiran and Early Aranuian radiocarbon dates from South Island localities. New Zealand Natural Sciences 15, 25-36.

Burrows, C.J., 2005. Julius Haast in the Southern Alps. Canterbury University Press, Christchurch, New Zealand.

Burrows, C.J., Russell, J.B., 1990. Aranuian vegetation history of the Arrowsmith Range, Canterbury 1. Pollen diagrams, plant macrofossils, and buried soils from Prospect Hill. New Zealand Journal of Botany 28, 323-345.

Carlson, A.E., 2010. What caused the Younger Dryas cold event. Geology 38, 383-384.

Carter, L., Cortese, G., 2009. Change in the Southern Ocean: Responding to Antarctica. PAGES News 17, 30-32.

Carter, L., Manighetti, B., Ganssen, G., Northcote, L., 2008. Southwest Pacific modulation of abrupt climate change during the Antarctic Cold Reversal - Younger Dryas. Palaeogeography, Palaeoclimatology, Palaeoecology 260, 284-298.

Carter, R.M., Gammon, P.R., Millwood, L., 2004. Glacial-interglacial (MIS 1-10) migrations of the Subtropical Front across ODP Site 1119, Canterbury Bight, Southwest Pacific Ocean. Marine Geology 205, 29-58.

Chinn, T., Fitzharris, B.B., Willsman, A., Salinger, M.J., 2012. Annual ice volume changes 1976-2008 for the New Zealand Southern Alps. Global and Planetary Change 92-93, 105-118.

Chinn, T.J., 1996. New Zealand glacier responses to climate change of the past century. New Zealand Journal of Geology and Geophysics 39, 415-428. 
Chinn, T.J., Heydenrych, C., Salinger, M.J., 2005. Use of the ELA as a practical method of monitoring glacier response to climate in New Zealand's Southern Alps. Journal of Glaciology 51, 85-95.

Chinn, T.J., Whitehouse, I.E., 1980. Glacier snow line variations in the Southern Alps, New Zealand. World Glacier Inventory 126, 219-228.

Chinn, T.J., Willsman, A., Salinger, M.J., 2006. Glacier snowline survey. National Institute of Water \& Atmospheric Research Ltd. Report for Foundation for Research, Science and Technology.

Chinn, T.J.H., 1981. Use of rock weathering-rind thickness for Holocene absolute agedating in New Zealand. Arctic and Alpine Research 13, 33-45.

Chinn, T.J.H., 1995. Glacier fluctuations in the Southern Alps of New Zealand determined from snowline elevations. Arctic and Alpine Research 27, 187-198.

Clare, G.R., Fitzharris, B.B., Chinn, T.J.H., Salinger, M.J., 2002. Interannual variation in end-of-summer snowlines of the Southern Alps of New Zealand, and relationships with Southern Hemisphere atmospheric circulation and sea surface temperature patterns. International Journal of Climatology 22, 107-120.

Clark, P., Dyke, A., Shakun, J., Carlson, A., Clark, J., Wohlfarth, B., Mitrovica, J., Hostetler, S., McCabe, A., 2009. The last glacial maximum. Science 325, 710-714.

Clement, A.C., Seager, R., Cane, M.A., 2000. Suppression of El Niño during the MidHolocene by changes in the Earth's orbit. Paleoceanography 15, 731-737.

Corripio, J., 2003. Vertorial algebra algorithms for calculating terrain parameters from DEMs and solar radiation modelling in mountainous terrain. International Journal of Geographical Information Science 17, 1-23.

Cuffey, K., Paterson, W., 2010. The Physics of Glaciers, fourth edition. ButterworthHeinemann, Oxford, United Kingdom.

Dadic, R., Corripio, J.G., Burlando, P., 2008. Mass-balance estimates for Haut Glacier d'Arolla, Switzerland, from 2000 to 2006 using DEMs and distributed mass-balance modeling. Annals of Glaciology 49, 22-26.

Dadic, R., Mott, R., Lehning, M., Burlando, P., 2010a. Parameterization for wind-induced preferential deposition of snow. Hydrological Processes 24, 1994-2006.

Dadic, R., Mott, R., Lehning, M., Burlando, P., 2010b. Wind influence on snow depth distribution and accumulation over glaciers. Journal of Geophysical Research 115, F01012.

Dadic, R., Mott, R., Lehning, M., Carenzo, M., Anderson, B., Mackintosh, A., in press. Sensitivity of turbulent fluxes to wind speed over snow surfaces in different climatic settings. Advances in Water Resources DOI: 10.1016/j.advwatres.2012.06.010.

Dean, S.M., Stott, P.A., 2009. The effect of local circulation variability on the detection and attribution of New Zealand temperature trends. Journal of Climate 22:23, 62176229.

Denton, G.H., Hendy, C.H., 1994. Younger Dryas age advance of Franz Josef Glacier in the Southern Alps of New Zealand. Science 264, 1434-1437. 
Dieffenbacher-Krall, A.C., Vandergoes, M.J., Denton, G.H., 2007. An inference model for mean summer air temperatures in the Southern Alps, New Zealand, using subfossil chironomids. Quaternary Science Reviews 26, 2487-2504.

Doughty, A.M., Anderson, B.M., Mackintosh, A.N., Kaplan, M.R., Vandergoes, M.J., Barrell, D.J.A., Denton, G.H., Schaefer, J.M., Chinn, T.J.H., Putnam, A.E., in press. Evaluation of Lateglacial temperatures in the Southern Alps of New Zealand based on glacier modelling at Irishman Stream, Ben Ohau Range. Quaternary Science Reviews DOI: $10.1016 /$ j.quascirev.2012.09.013.

Dykes, R.C., Brook, M.S., 2010. Terminus recession, proglacial lake expansion and 21st century calving retreat of Tasman Glacier, New Zealand. New Zealand Geographer 66, 203-217.

Egholm, D.L., Knudsen, M.F., Clark, C.D., Lesemann, J.E., 2011. Modeling the flow of glaciers in steep terrains: The integrated second-order shallow ice approximation (iSOSIA). Journal of Geophysical Research 116, F02012.

Eisenman, I., Huybers, P., 2006. Integrated summer insolation calculations, [online] available from: http://www.gps. caltech.edu/ ian/code/index. html. noaa/ncdc paleoclimatology program data contribution \#2006-079.

Embleton, C., King, C.A.M., 1975. Glacial Geomorphology, Chapter 15. volume 1. Edward Arnold, Great Britain. second edition.

EPICA Community Members, 2006. One-to-one coupling of glacial climate variability in Greenland and Antarctica. Nature 444, 195-198.

Evans, D.J.A., 2003. Chapter 2 Ice-marginal terrestrial landsystems: Active temperate glacier margins, in: Evans, D.J.A. (Ed.), Glacial Landsystems. Hodder Arnold, pp. $12-43$.

Evans, D.J.A., 2008. Geomorphology: Avalanches and moraines. Nature Geoscience 1, 493-494.

Farinotti, D., Huss, M., Bauder, A., Funk, M., Truffer, M., 2009. A method to estimate the ice volume and ice-thickness distribution of alpine glaciers. Journal of Glaciology $55,422-430$.

Fitzharris, B., Lawson, W., Owens, I., 1999. Research on glaciers and snow in New Zealand. Progress in Physical Geography 23, 469-500.

Fitzharris, B.B., Clare, G.R., Renwick, J., 2007. Teleconnections between Andean and New Zealand glaciers. Global and Planetary Change 59, 159-174.

Fitzsimons, S.J., 1997. Late-glacial and early Holocene glacier activity in the Southern Alps, New Zealand. Quaternary International 38/39, 69-76.

Fogwill, C.J., Kubik, P.W., 2005. A glacial stage spanning the Antarctic Cold Reversal in Torres del Paine $\left(51^{\circ} \mathrm{S}\right)$, Chile, based on preliminary cosmogenic exposure ages. Geografiska Annaler: Series A, Physical Geography 87, 403-408.

Fowler, A.M., Boswijk, G., Lorrey, A.M., Gergis, J., Pirie, M., McCloskey, S.P.J., Palmer, J.G., Wunder, J., 2012. Multi-centennial tree-ring record of ENSO-related activity in New Zealand. Nature Climate Change 2, 172-176. 
Furbish, D.J., Andrews, J.T., 1984. The use of hypsometry to indicate long-term stability and response of valley glaciers to changes in mass transfer. Journal of Glaciology 30 , 199-211.

Gage, M., Suggate, R.P., 1958. Glacial chronology of the New Zealand Pleistocene. Geologic Society of America Bulletin 69, 589-598.

Gair, H.S., 1967. Sheet 20, Mt. Cook (1st Ed.) Geol. Map of New Zealand (1:250,000). new zealand geological survey.

Gardelle, J., Berthier, E., Arnaud, Y., 2012. Slight mass gain of Karakoram glaciers in the early twenty-first century. Nature Geoscience 5, 322-325. 10.1038/ngeo1450.

Gellatly, A., 1984. The use of rock weathering-rind thickness to redate moraines in Mount Cook National Park, New Zealand. Arctic and Alpine Research 16, 225-232.

Gellatly, A.F., Chinn, T.J.H., Röthlisberger, F., 1988. Holocene glacier variations in New Zealand: A review. Quaternary Science Reviews 7, 227-242.

Gillett, S., Cullen, N.J., 2011. Atmospheric controls on summer ablation over Brewster Glacier, New Zealand. International Journal of Climatology 31, 2033-2048.

Golledge, N., Hubbard, A., Sugden, D., 2009. Mass balance, flow, and subglacial processes of a modelled Younger Dryas ice cap in Scotland. Journal of Glaciology 55, $32-42$.

Golledge, N.R., Mackintosh, A.N., Anderson, B.M., Buckley, K.M., Doughty, A.M., Barrell, D.J.A., Denton, G.H., Vandergoes, M.J., Andersen, B.G., Schaefer, J.M., 2012. Last Glacial Maximum climate in New Zealand inferred from a modelled Southern Alps icefield. Quaternary Science Reviews 46, 30-45.

Greuell, W., 1992. Hintereisferner, Austria: mass-balance reconstruction and numerical modelling of the historical length variations. Journal of Glaciology 38, 233-244.

Griffiths, G.A., McSaveney, M.J., 1983. Distribution of mean annual precipitation across some steepland regions of New Zealand. New Zealand Journal of Science 26, 197-209.

Gruber, S., 2007. A mass-conserving fast algorithm to parameterize gravitational transport and deposition using digital elevation models. Water Resources Research 43, W06412.

Gruber, S., Peckham, S., 2009. Chapter 7 land-surface parameters and objects in hydrology, in: Hengl, T., Reuter, H.I. (Eds.), Geomorphometry Concepts, Software, Applications. Elsevier. volume 33 of Developments in Soil Science, pp. 171-194.

Hajdas, I., Lowe, D.J., Newnham, R.M., Bonani, G., 2006. Timing of the late-glacial climate reversal in the Southern Hemisphere using high-resolution radiocarbon chronology for Kaipo bog, New Zealand. Quaternary Research 65, 340-345.

Hays, J., Imbrie, J., Shackleton, N., 1976. Variations in the Earth's orbit; pacemaker of the ice ages. Science 194, 1121-1132.

Heilig, A., Schneebeli, M., Eisen, O., 2009. Upward-looking ground-penetrating radar for monitoring snowpack stratigraphy. Cold Regions Science and Technology 59, 152162. 
Henderson, R.D., Thompson, S.M., 1999. Extreme rainfalls in the Southern Alps of New Zealand. Journal of Hydrology (NZ) 38, 309-330.

Herman, F., Braun, J., 2008. Evolution of the glacial landscapes of the Southern Alps of New Zealand: Insights from a glacial erosion model. Journal of Geophysical Research $113, \mathrm{~F} 2$.

Hewitt, K., 2005. The Karakoram Anomaly? Glacier expansion and the 'Elevation Effect', Karakoram Himalaya. Mountain Research and Development 25, 332-340.

Hewitt, K., 2011. Glacier change, concentration, and elevation effects in the Karakoram Himalaya, Upper Indus Basin. Mountain Research and Development 31, 188-200.

Hindmarsh, R.C.A., Le Meur, E., 2001. Dynamical processes involved in the retreat of marine ice sheets. Journal of Glaciology 47, 271-282.

Hock, R., 2005. Glacier melt: A review of processes and their modelling. Progress in Physical Geography 29, 362-391.

Hooker, B.L., Fitzharris, B.B., 1999. The correlation between climatic parameters and the retreat and advance of Franz Josef Glacier, New Zealand. Global and Planetary Change 22, 39-48.

Houlié, N., Stern, T., 2012. A comparison of GPS solutions for strain and SKS fast directions: Implications for modes of shear in the mantle of a plate boundary zone. Earth and Planetary Science Letters 345-348, 117 - 125.

Hubbard, A., 1997. Modelling climate, topography and palaeoglacier fluctuations in the Chilean Andes. Earth Surface Processes and Landforms 22, 79-92.

Hubbard, A., 2000. The verification and significance of three approaches to longitudinal stresses in high-resolution models of glacier flow. Geografiska Annaler: Series A, Physical Geography 82, 471-487.

Hubbard, A., Hein, A.S., Kaplan, M.R., Hulton, N.R., Glasser, N., 2005. A modelling reconstruction of the last glacial maximum ice sheet and its deglaciation in the vicinity of the Northern Patagonian Icefield, South America. Geografiska Annaler: Series A, Physical Geography 87, 375-391.

Huybers, K., Roe, G., 2009. Spatial patterns of glaciers in response to spatial patterns in regional climate. Journal of Climate 22, 4606-4620.

Imbrie, J., Imbrie, K.P., 1986. Ice Ages: Solving the Mystery. Harvard University Press, Cambridge, MA, U.S.A.

Ivy-Ochs, S., Schlüchter, C., Kubik, P.W., Denton, G.H., 1999. Moraine exposure dates imply synchronous Younger Dryas glacier advances in the European Alps and in the Southern Alps of New Zealand. Geografiska Annaler 81, 313-323.

Jiang, N., Griffiths, G., Lorrey, A., 2012. Influence of large-scale climate modes on daily synoptic weather types over New Zealand. International Journal of Climatology .

Kalnay, E., Kanamitsu, M., Kistler, R., Collins, W., Deaven, D., Gandin, L., Iredell, M., Saha, S., White, G., Woollen, J., Zhu, Y., Chelliah, M., Ebisuzaki, W., Higgins, W., Janowiak, J., Mo, K.C., Ropelewski, C., Wang, J., Leetmaa, A., Reynolds, R., Jenne, R., Joseph, D., 1996. The NMC/NCAR 40-Year Reanalysis Project. Bulletin of the American Meteorological Society 77, 437-471. 
Kaplan, M.R., Schaefer, J.M., Denton, G.H., Barrell, D.J.A., Chinn, T.J.H., Putnam, A.E., Andersen, B.G., Finkel, R.C., Schwartz, R., Doughty, A.M., 2010. Glacier retreat in New Zealand during the Younger Dryas stadial. Nature 467, 194-197.

Kaplan, M.R., Schaefer, J.M., Denton, G.H., Doughty, A.M., Barrell, D.J.A., Chinn, T.J.H., Putnam, A.E., Andersen, B.G., Mackintosh, A., Finkel, R.C., Schwartz, R., Anderson, B., submitted. The anatomy of 'long-term' warming since $15 \mathrm{kyr}$ ago in the Southern Alps of New Zealand based on net glacier snowline rise. Geology .

Kaplan, M.R., Strelin, J.A., Schaefer, J.M., Denton, G.H., Finkel, R.C., Schwartz, R., Putnam, A.E., Vandergoes, M.J., Goehring, B.M., Travis, S.G., 2011. In-situ cosmogenic ${ }^{10} \mathrm{Be}$ production rate at Lago Argentino, Patagonia: Implications for late-glacial climate chronology. Earth and Planetary Science Letters 309, 21-32.

Kehrl, L., 2011. Glacier dynamics of the Lower Franz Josef Glacier, New Zealand. Master's thesis. Victoria University of Wellington, New Zealand.

Kessler, M.A., Anderson, R.S., Stock, G.M., 2006. Modeling topographic and climatic control of east-west asymmetry in Sierra Nevada glacier length during the Last Glacial Maximum. Journal of Geophysical Research 111, F02002.

Kidson, J.W., 1994. Relationship of New Zealand daily and monthly weather patterns to synoptic weather types. International Journal of Climatology 14, 723-737.

Kirkbride, M.P., Winkler, S., 2012. Correlation of Late Quaternary moraines: Impact of climate variability, glacier response, and chronological resolution. Quaternary Science Reviews 46, 1-29.

Klok, E.J., Oerlemans, J., 2002. Model study of the spatial distribution of the energy and mass balance of Morteratschgletscher, Switzerland. Journal of Glaciology 48, 505-518.

Knudson, K.P., Hendy, I.L., Neil, H.L., 2011. Re-examining Southern Hemisphere westerly wind behavior: insights from a late Holocene precipitation reconstruction using New Zealand fjord sediments. Quaternary Science Reviews 30, 3124-3138.

Kotlyakov, V.M., 1973. Snow accumulation on mountain glaciers. The role of snow and ice in hydrology. International Association of Scientific Hydrology 1, 394-400.

Laabs, B.J.C., Plummer, M.A., Mickelson, D.M., 2006. Climate during the last glacial maximum in the Wasatch and southern Uinta Mountains inferred from glacier modelling. Geomorphology 75, 300-317.

Lamont, G.N., Chinn, T.J., Fitzharris, B.B., 1999. Slopes of glacier ELAs in the Southern Alps of New Zealand in relation to atmospheric circulation patterns. Global and Planetary Change 22, 209-219.

Le Meur, E., Gagliardini, O., Zwinger, T., Ruokolainen, J., 2004. Glacier flow modelling: a comparison of the Shallow Ice Approximation and the full-Stokes solution. Comptes Rendus Physique 5, 709-722.

Le Meur, E., Vincent, C., 2003. A two-dimensional shallow ice-flow model of Glacier de Saint-Sorlin, France. Journal of Glaciology 49, 527-538.

Leclercq, P.W., Oerlemans, J., 2011. Global and hemispheric temperature reconstruction from glacier length fluctuations. Climate Dynamics 38, 1065-1079. 
Lehning, M., Grünewald, T., Schirmer, M., 2011. Mountain snow distribution governed by an altitudinal gradient and terrain roughness. Geophysical Research Letters 38, L19504.

Lehning, M., Löwe, H., Ryser, M., N., R., 2008. Inhomogeneous precipitation distribution and snow transport in steep terrain. Water Resources Research 44, W07404.

Leysinger Vieli, G.J.M.C., Gudmundsson, G.H., 2004. On estimating length fluctuations of glaciers caused by changes in climatic forcing. Journal of Geophysical Research 109, F01007.

Liston, G.E., Sturm, M., 1998. A snow-transport model for complex terrain. Journal of Glaciology 44, 498-516.

Little, T.A., Cox, S., Vry, J.K., Batt, G., 2005. Variations in exhumation level and uplift rate along the oblique-slip Alpine fault, central Southern Alps, New Zealand. Geological Society of America Bulletin 117, 707-723.

Liu, Z., Kutzbach, J., Wu, L., 2000. Modeling climate shift of El Nino variability in the Holocene. Geophysical Research Letters 27, 2265-2268.

Lorrey, A.M., Vandergoes, M., Almond, P., Renwick, J., Stephens, T., Bostock, H., Mackintosh, A., Newnham, R., Williams, P.W., Ackerley, D., Neil, H., Fowler, A.M., 2012. Palaeocirculation across New Zealand during the last glacial maximum at $\sim 21$ ka. Quaternary Science Reviews 36, 189-213.

Lossev, K.S., 1967. The role of avalanches in mass budget of glaciers. Physics of Snow and Ice: Proceedings 1, 385-388.

Lowell, T., Heusser, C., Andersen, B., Moreno, P., Hauser, A., Heusser, L., Schlüchter, C., Marchant, D., Denton, G., 1995. Interhemispheric correlation of late Pleistocene glacial events. Science 269, 1541-1549.

Machguth, H., Paul, F., Hoelzle, M., Haeberli, W., 2006. Distributed glacier mass-balance modelling as an important component of modern multi-level glacier monitoring. Annals of Glaciology 43, 335-343.

Mackintosh, A.N., Dugmore, A.J., Hubbard, A.L., 2002. Holocene climatic changes in Iceland: Evidence from modelling glacier length fluctuations at Sólheimajökull. Quaternary International 91, 39-52.

Mathieu, R., Chinn, T., Fitzharris, B., 2009. Detecting the equilibrium-line altitudes of New Zealand glaciers using ASTER satellite images. New Zealand Journal of Geology and Geophysics 52, 209-222.

McGlone, M.S., 1995. Lateglacial landscape and vegetation change and the Younger Dryas climate oscillation in New Zealand. Quaternary Science Reviews 14, 867-881.

McGlone, M.S., Turney, C.S.M., Wilmshurst, J.M., 2004. Late-glacial and Holocene vegetation and climatic history of the Cass Basin, central South Island, New Zealand. Quaternary Research 62, 267-279.

McGlone, M.S., Turney, C.S.M., Wilmshurst, J.M., Renwick, J., Pahnke, K., 2010. Divergent trends in land and ocean temperature in the southern ocean over the past 18,000 years. Nature Geoscience 3, 622-626. 
McGregor, V.R., 1967. Holocene moraines and rock glaciers in the central Ben Ohau Range, south Canterbury, New Zealand. Journal of Glaciology 6, 737-748.

McKinnon, K.A., Mackintosh, A.N., Anderson, B.M., Barrell, D.J.A., 2012. The influence of sub-glacial bed evolution on ice extent: a model-based evaluation of the Last Glacial Maximum Pukaki glacier, New Zealand. Quaternary Science Reviews 57, 4657.

Mercer, J.H., 1984. Simultaneous climate change in both hemispheres and similar bipolar interglacial warming: Evidence and implications. Climate Processes and Climate Sensitivity American Geophysical Union Geophysical Monograph 29 5, 307-313.

Milankovitch, M., 1941. Kanon der Erdbestrahlung und seine Andwendung auf das Eiszeiten-problem. Royal Serbian Academy, Belgrade.

Mott, R., Lehning, M., 2010. Meteorological modeling of very high-resolution wind fields and snow deposition for mountains. Journal of Hydrometeorology 11, 934-949.

Moy, C.M., Seltzer, G.O., Rodbell, D.T., Anderson, D.M., 2002. Variability of El Niño/Southern Oscillation activity at millennial timescales during the Holocene epoch. Nature 420, 162-165.

Mullan, A.B., 1995. On the linearity and stability of Southern Oscillation-climate relationships for New Zealand. International Journal of Climatology 15, 1365-1386.

Mullan, A.B., Stuart, S.J., Hadfield, M.G., Smith, M.J., 2010. Report on the review of NIWA's 'Seven-Station' temperature series. NIWA Information Series 78, Website: http://www.niwa.co.nz/our-science/ climate/information-and-resources/nz-temp-record/ seven-station-series-temperature-data.

Neale, S.M., Fitzharris, B.B., 1997. Energy balance and synoptic climatology of a melting snowpack in the Southern Alps, New Zealand. International Journal of Climatology 17, 1595-1609.

Newnham, R., Lowe, D., 2003. Pattern and timing of lateglacial climate change in New Zealand. Geophysical Research Abstracts 5, 05337.

Newnham, R.M., Lowe, D.J., 2000. Fine-resolution pollen record of late-glacial climate reversal from New Zealand. Geology 28, 759-762.

Newnham, R.M., Lowe, D.J., Giles, T., Alloway, B.V., 2007. Vegetation and climate of Auckland, New Zealand, since ca. 32000 cal. yr ago: support for an extended LGM. Journal of Quaternary Science 22, 517-534.

Newnham, R.M., Vandergoes, M.J., Sikes, E., Carter, L., Wilmshurst, J.M., Lowe, D.J., McGlone, M.S., Sandiford, A., 2012. Does the bipolar seesaw extend to the terrestrial southern mid-latitudes? Quaternary Science Reviews 36, 214-222.

NIWA, Retrieved 2009-2011. CliFlo: NIWA's National Climate Database on the Web. Website: http://cliflo.niwa.co.nz/.

Norton, D.A., 1985. A multivariate technique for estimating New Zealand temperature normals. Weather and Climate 5, 64-74.

Oerlemans, J., 1988. Simulation of historic glacier variations with a simple climateglacier model. Journal of Glaciology 34. 
Oerlemans, J., 1989. On the response of valley glaciers to climatic change, in: Oerlemans, J. (Ed.), Glacier Fluctuations and Climatic Change. Proceedings of the Symposium on Glacier Fluctuations and Climatic Change, held in Amsterdam. Kluwer Academic Publishers, pp. 353-371.

Oerlemans, J., 1992. Climate sensitivity of glaciers in southern Norway: Application of an energy-balance model to Nigardsbreen, Hellstugubreen, and Alfotbreen. Journal of Glaciology 38, 223-232.

Oerlemans, J., 2000. Holocene glacier fluctuations: Is the current rate of retreat exceptional? Annals of Glaciology 31, 39-44.

Oerlemans, J., 2001. Glaciers and Climate Change. A.A. Balkema Publishers, Amsterdam.

Oerlemans, J., 2005. Extracting a climate signal from 169 glacier records. Science 308, 675-677.

Oerlemans, J., Grisogono, W., 2002. Glacier winds and parameterisation of the related surface heat fluxes. Tellus 54A, 440-452.

Oerlemans, J., Knap, W.H., 1998. A 1 year record of global radiation and albedo in the ablation zone of Morteratschgletcher, Switzerland. Journal of Glaciology 44, 231-238.

Ohmura, A., 2001. Physical basis for the temperature-based melt-index method. Journal of Applied Meteorology 40, 753-761.

Oke, T., 1987. Boundary layer climates. Routledge Press, London.

Oreskes, N., Shrader-Frechette, K., Belitz, K., 1994. Verification, validation, and confirmation of numerical models in the Earth sciences. Science 263, 641-646.

Pahnke, K., Zahn, R., Elderfield, H., Schulz, M., 2003. 340,000-year centennial-scale marine record of Southern Hemisphere climatic oscillation. Science 301, 948-952.

Paterson, W.S.B., 1994. The Physics of Glaciers, 3rd Edition. Pergamon, Oxford.

Plummer, M., Porinchu, D., 2003. Simulating the dynamic behavior of a Sierra Nevada glacier in response to the forcing implied by a new high-resolution record of Younger Dryas temperature variations, paper no. 49-6, XVI INQUA Congress, Reno, Nevada.

Plummer, M.A., Phillips, F.M., 2003. A 2-D numerical model of snow/ice energy and ice flow for paleo climatic interpretation of glacial geomorphic features. Quaternary Science Reviews 22, 1389-1406.

Porter, S.C., 1975a. Equilibrium-line altitudes of late Quaternary glaciers in the Southern Alps, New Zealand. Quaternary Research 5, 27-47.

Porter, S.C., 1975b. Glaciation limit in New Zealand's Southern Alps. Arctic and Alpine Research 7, 33-37.

Purdie, H., Anderson, B., Lawson, W., Mackintosh, A., 2011a. Controls on spatial variability in snow accumulation on glaciers in the Southern Alps, New Zealand; as revealed by crevasse stratigraphy. Hydrological Processes 25, 54-63. 
Purdie, H., Mackintosh, A., Lawson, W., Anderson, B., 2011b. Synoptic influences on snow accumulation on glaciers east and west of a topographic divide: Southern Alps, New Zealand. Arctic, Antarctic, and Alpine Research 43, 82-94.

Purdie, H., Mackintosh, A., Lawson, W., Anderson, B., Morgenstern, U., Chinn, T., Mayewski, P., 2011c. Interannual variability in net accumulation on Tasman Glacier and its relationship with climate. Global and Planetary Change 77, 142-152.

Putnam, A.E., Denton, G.H., Schaefer, J.M., Barrell, D.J.A., Andersen, B.G., Finkel, R.C., Schwartz, R., Doughty, A.M., Kaplan, M.R., Schlüchter, C., 2010a. Glacier advance in southern middle-latitudes during the Antarctic Cold Reversal. Nature Geoscience 3, 700-704.

Putnam, A.E., Schaefer, J.M., Barrell, D.J.A., Vandergoes, M., Denton, G.H., Kaplan, M.R., Finkel, R.C., Schwartz, R., Goehring, B.M., Kelley, S.E., 2010b. In situ cosmogenic ${ }^{10} \mathrm{Be}$ production-rate calibration from the Southern Alps, New Zealand. Quaternary Geochronology 5, 392-409.

Putnam, A.E., Schaefer, J.M., Denton, G.H., Barrell, D.J.A., Birkel, S.D., Andersen, B.G., Kaplan, M.R., Finkel, R.C., Schwartz, R., Doughty, A.M., 2013. The Last Glacial Maximum at $44^{\circ} \mathrm{S}$ documented by a ${ }^{10} \mathrm{Be}$ moraine chronology at Lake Ohau, Southern Alps of New Zealand. Quaternary Science Reviews 62, 114-141.

Putnam, A.E., Schaefer, J.M., Denton, G.H., Barrell, D.J.A., Finkel, R.C., Andersen, B.G., Schwartz, R., Chinn, T.J.H., Doughty, A.M., 2012. Regional climate control of glaciers in New Zealand and Europe during the pre-industrial Holocene. Nature Geoscience 5, 627-630.

Ravens, J.M., 1995. Globe Claritas: Seismic processing software manual. volume 95/43. Institute of Geological \& Nuclear Sciences.

Reichert, B., Bengtsson, L., Oerlemans, J., 2002. Recent glacier retreat exceeds internal variability. Journal of Climate 15, 3069-3081.

Reznichenko, N., Davies, T., Shulmeister, J., McSaveney, M., 2010. Effects of debris on ice-surface melting rates: An experimental study. Journal of Glaciology 56, 384-394.

Roe, G., 2011. What do glaciers tell us about climate variability and climate change? Journal of Glaciology 57, 567-578.

Roe, G., O’Neal, M., 2009. The response of glaciers to intrinsic climate variability: Observations and models of late Holocene variations in the Pacific Northwest. Journal of Glaciology 55, 839-854.

Rojas, M., Moreno, P., 2010. Atmospheric circulation changes and neoglacial conditions in the Southern Hemisphere mid-latitudes: Insights from PMIP 2 simulations at $6 \mathrm{kyr}$. Climate Dynamics DOI 10.1007/s00382-010-0866-3.

Rowan, A., Plummer, M., Brocklehurst, S., Jones, M., Schultz, D., in press. Drainage capture and discharge variations driven by glaciation in the Southern Alps, New Zealand. Geology .

Salinger, M., Mullan, A., 1999. New Zealand climate: Temperature and precipitation variations and their links with atmospheric circulation 1930-1994. International Journal of Climatology 19, 1049-1071. 
Salinger, M.J., Renwick, J.A., Mullan, A.B., 2001. Interdecadal Pacific oscillation and south Pacific climate. International Journal of Climatology 21, 1705-1721.

Schaefer, J.M., Denton, G.H., Kaplan, M., Putnam, A., Finkel, R.C., Barrell, D.J.A., Andersen, B.G., Schwartz, R., Mackintosh, A., Chinn, T., Schlüchter, C., 2009. Highfrequency Holocene glacier fluctuations in New Zealand differ from the northern signature. Science 324, 622-625.

Shulmeister, J., Fink, D., Hyatt, O.M., Thackray, G.D., Rother, H., 2010a. Cosmogenic ${ }^{10} \mathrm{Be}$ and ${ }^{26} \mathrm{Al}$ exposure ages of moraines in the Rakaia Valley, New Zealand and the nature of the last termination in New Zealand glacial systems. Earth and Planetary Science Letters 297, 558-566.

Shulmeister, J., McKay, R., Singer, C., McLea, W., 2001. Glacial geology of the Cobb Valley, Northwest Nelson. New Zealand Journal of Geology and Geophysics 44, 4754.

Shulmeister, J., Thackray, G.D., Rieser, U., Hyatt, O.M., Rother, H., Smart, C.C., Evans, D.J.A., 2010b. The stratigraphy, timing and climatic implications of glaciolacustrine deposits in the middle Rakaia Valley, South Island, New Zealand. Quaternary Science Reviews 29, 2362-2381.

Sikes, E.L., Howard, W.R., Samson, C.R., Mahan, T.S., Robertson, L.G., Volkman, J.K., 2009. Southern Ocean seasonal temperature and Subtropical Front movement on the South Tasman Rise in the late Quaternary. Paleoceanography 24, PA2201.

Singer, C., Shulmeister, J., McLea, B., 1998. Evidence against a significant Younger Dryas cooling event in New Zealand. Science 281, 812-814.

Solomon, S., Qin, D., Manning, M., Chen, Z., Marquis, M., Averyt, K.B., Tignor, M., Miller, H.L. (Eds.), 2007. Climate Change 2007: The Physical Science Basis. Contribution of Working Group I to the Fourth Assessment Report of the Intergovernmental Panel on Climate Change. Cambridge University Press, Cambridge, United Kingdom and New York, NY, U.S.A.

Soons, J.M., Gullentops, F.W., 1973. Glacial advances in the Rakaia Valley, New Zealand. New Zealand Journal of Geology and Geophysics 16, 425-438.

Stokes, C.R., Popovnin, V., Aleynikov, A., Gurney, S.D., Shahgedanova, M., 2007. Recent glacier retreat in the Caucasus Mountains, Russia and associated increase in supraglacial debris cover and supra-/proglacial lake development. Annals of Glaciology 46, 195-203.

Strelin, J.A., Denton, G.H., Vandergoes, M.J., Ninnemann, U.S., Putnam, A.E., 2011. Radiocarbon chronology of the late-glacial Puerto Bandera moraines, Southern Patagonian Icefield, Argentina. Quaternary Science Reviews 30, 2551-2569.

Stuart, S., 2011. Observations and modelling of precipitation in the Southern Alps of New Zealand. Master's thesis. Victoria University of Wellington. Wellington, New Zealand.

Stumm, D., 2011. The mass balance of selected glaciers of the Southern Alps in New Zealand. Ph.D. thesis. University of Otago. University of Otago, Dunedin, New Zealand.

Sturman, A.P., Tapper, N.J., 1996. The weather and climate of Australia and New Zealand. Oxford University Press, Melbourne, Australia. 
Suggate, R.P., 1961. The upper boundary of the Hawera Series. Transactions of the Royal Society of New Zealand 1, 11-16.

Suggate, R.P., 1965. Late Pleistocene geology of the northern part of the South Island, New Zealand. New Zealand Geological Survey Bulletin 77.

Suggate, R.P., 1990. Late Pliocene and Quaternary glaciations of New Zealand. Quaternary Science Reviews 9, 175-197.

Suggate, R.P., Almond, P.C., 2005. The Last Glacial Maximum (LGM) in western South Island, New Zealand: Implications for the global LGM and MIS 2. Quaternary Science Reviews 24, 1923-1940.

Tait, A., Zheng, X., 2007. Analysis of the spatial interpolation error associated with maps of median annual climate variables. National Institute of Water \& Atmospheric Research Ltd., Website: http://www.niwa.co.nz/sites/default/files/ import/attachments/Climate_Maps_Error_Analysis.pdf.

Tovar, D.S., Shulmeister, J., Davies, T.R., 2008. Evidence for a landslide origin of New Zealand's Waiho Loop moraine. Nature Geoscience 1, 524-526.

Trenberth, K.E., Jones, P.D., Ambenje, P., Bojariu, R., Easterling, D., Tank, A.K., Parker, D., Rahimzadeh, F., Renwick, J.A., Rusticucci, M., Soden, B., Zhai, P., 2007. Observations: Surface and Atmospheric Climate Change, in: Solomon, S., Qin, D., Manning, M., Chen, Z., Marquis, M., Averyt, K.B., Tignor, M., Miller, H.L. (Eds.), Climate Change 2007: The Physical Science Basis. Contribution of Working Group I to the Fourth Assessment Report of the Intergovernmental Panel on Climate Change. Cambridge University Press, Cambridge, United Kingdom and New York, NY, USA, pp. 235-336.

Turney, C.S.M., McGlone, M.S., Wilmshurst, J.M., 2003. Asynchronous climate change between New Zealand and the North Atlantic during the last deglaciation. Geology 31, 223-226.

Turney, C.S.M., Roberts, R.G., de Jonge, N., Prior, C., Wilmshurst, J.M., McGlone, M.S., Cooper, J., 2007. Redating the advance of the New Zealand Franz Josef Glacier during the last termination: Evidence for asynchronous climate change. Quaternary Science Reviews 26, 3037-3042.

Vacco, D.A., Alley, R.B., Pollard, D., 2010. Glacial advance and stagnation caused by rock avalanches. Earth and Planetary Science Letters 294, 123-130.

Vandergoes, M.J., Dieffenbacher-Krall, A.C., Newnham, R.M., Denton, G.H., Blaauw, M., 2008. Cooling and changing seasonality in the Southern Alps, New Zealand during the Antarctic Cold Reversal. Quaternary Science Reviews 27, 589-601.

Vandergoes, M.J., Fitzsimons, S.J., 2003. The last glacial-interglacial transition (LGIT) in south Westland, New Zealand: Paleoecological insight into mid-latitude Southern Hemisphere climate change. Quaternary Science Reviews 22, 1461-1476.

Vandergoes, M.J., Newnham, R.M., Preusser, F., Hendy, C.H., Lowell, T.V., Fitzsimons, S.J., Hogg, A.G., Uwe Kasper, H., Schlüchter, C., 2005. Regional insolation forcing of late Quaternary climate change in the Southern Hemisphere. Nature 436, 242-245.

van der Veen, C.J., 1999. Evaluating the performance of cryospheric models. Polar Geography 23, 83-96. 
Warren, C.R., Kirkbride, M.P., 2003. Tasman Glacier, New Zelaand: 20th-century thinning and predicted calving retreat. Annals of Glaciology 36, 173-178.

WGMS, 2011. Glacier mass balance bulletin no. 11 (2008-2009). World Glacier Monitoring Service Website: http://www.geo.uzh.ch/microsite/wgms/pub_ wgms.html.

Williams, P., King, D., Zhao, J.X., Collerson, K., 2005. Late Pleistocene to Holocene composite speleothem ${ }^{18} \mathrm{O}$ and ${ }^{13} \mathrm{C}$ chronologies from South Island, New Zealand-did a global Younger Dryas really exist? Earth and Planetary Science Letters 230, 301-317.

Williams, P.W., Neil, H.L., Zhao, J.X., 2010. Age frequency distribution and revised stable isotope curves for New Zealand speleothems: Palaeoclimatic implications. International Journal of Speleology 39, 99-112.

Willsman, A.P., Chinn, T., Hendrikx, J., Lorrey, A., 2010. New Zealand Glacier Monitoring: End of Summer Snowline Survey 2010. National Institute of Water \& Atmospheric Research Ltd. NIWA Client Report: CHC2010-113.

Willsman, A.P., Chinn, T., Lorrey, A., 2012. New Zealand Glacier Monitoring: End of Summer Snowline Survey 2011. National Institute of Water \& Atmospheric Research Ltd. NIWA Client Report: CHC2012-052.

Winkler, S., 2005. The Schmidt hammer as a relative age dating technique: Potential and limitations of its application on Holocene moraines in Mt Cook National Park, Southern Alps, New Zealand. New Zealand Journal of Geology and Geophysics 48, $105-116$.

Winkler, S., Chinn, T., Gärtner-Roer, I., Nussbaumer, S.U., Zemp, M., Zumbühl, H.J., 2010. An introduction to mountain glaciers as climate indicators with spatial and temporal diversity. Erdkunde 64, 97-118.

Woo, M., Fitzharris, B.B., 1992. Reconstruction of mass balance variations for Franz Josef Glacier, New Zealand, 1913 to 1989. Arctic and Alpine Research 24, 281-290. 


\begin{abstract}
Glacier length fluctuations reflect changes in climate, most notably temperature and precipitation. By this reasoning, moraines, which represent former glacier extent, can be used to estimate past climate. However, estimating palaeoclimate from moraines is not a straight-forward process and involves several assumptions. For example, recent studies have suggested that interannual stochastic variability in temperature in a steady-state climate can cause a glacier to experience kilometre-scale fluctuations. Such studies cast doubt on the usefulness of moraines as climate proxy indicators.
\end{abstract}

Detailed glacial geomorphological maps and moraine chronologies have improved our understanding of the spatial and temporal extent of past glacial events in New Zealand. Palaeoclimate estimates associated with these moraines have thus-far come from simple methods, such as the accumulation area ratio, with unquantifiable uncertainties. I used a numerical modelling approach to approximate the present-day glacier mass balance pattern, which includes the effects of snow avalanching on glacier mass balance. I then used the models to reconstruct palaeoclimate for Lateglacial and Holocene glacial events in New Zealand, and to better understand moraine-glacier-climate relationships. The climate reconstructions come from simulating past glacier expansions to specific terminal moraines, but I also simulated glacier fluctuations in response to a previously derived temperature reconstruction, and to interannual stochastic variability in temperature. The purpose behind each simulation was to identify the drivers of significant glacier fluctuations.

The modelling results support the hypothesis that New Zealand moraine records reflect past climate, especially changes in temperature. Lateglacial climate was reconstructed to be $2-3^{\circ} \mathrm{C}$ lower than the present day. This temperature range agrees well with previous estimates from moraines and other climate proxy records in New Zealand. Modelled temperature estimates for the Holocene moraines are slightly colder than those derived from simpler methods, due to a non-linear relationship found between snowline lowering and glacier length. This relationship results from the specific valley shape and glacier geometry, and is likely to occur in other, similarly-shaped glacier valleys. The simulations forced 
by interannual stochastic variability in temperature do not show significant ( $>300 \mathrm{~m}$ ) fluctuations in the glacier terminus. Such fluctuations can not explain the Holocene moraine sequence that I examined, which extends $>2 \mathrm{~km}$ beyond the present-day glacier terminus. Stochastic temperature change could, however, in part, cause fluctuations in glacier extent during an overall glacier recession. Modelling shows that it is also unlikely that glaciers advanced to Holocene and Lateglacial moraine positions as a result of precipitation changes alone. For these reasons, temperature changes are a necessary part of explaining past glacier extents, especially during the Lateglacial, and the moraines examined here likely reflect changes in mean climate in New Zealand.

The glacier modelling studies indicate that simpler methods, such as the accumulation area ratio, can be used to appropriately reconstruct past climate from glacial evidence, as long as the glacier catchment has a straight forward geometry, shallow bed slope and no tributary glaciers. Non-linear relationships between climate change and glacier length develop when valley shape is more complex, and glaciers within these systems are probably better simulated using a modelling approach. Using a numerical modelling approach, it is also possible to gain a greater understanding of glacier response time, length sensitivities, and estimates of ice extent in valleys within the model domain where geomorphic evidence is not available. In this manner, numerical models can be used as a tool for understanding past climate and glacier sensitivity, thus improving the confidence in the palaeoclimate interpretations. 